\title{
THE MULTI-DIMENSIONAL ANALYSIS OF SOCIAL EXCLUSION
}

\author{
BY \\ Ruth Levitas, Christina Pantazis, Eldin Fahmy, David Gordon, \\ Eva Lloyd and Demi Patsios
}

Department of Sociology and School for Social Policy Townsend Centre for the International Study of Poverty and

Bristol Institute for Public Affairs

University of Bristol

\section{January 2007}

Views expressed in this report are not necessarily those of the Social Exclusion Task Force or any other government department.

This report was funded by the Department for Communities and Local Government (DCLG) when the Social Exclusion Unit (the predecessor of the current Social Exclusion Task Force based at the Cabinet Office) was based at DCLG. 


\section{CONTENTS}

List of tables and figures $\quad 4$

List of abbreviations $\quad 5$

$\begin{array}{lr}\text { Acknowledgements } & 8\end{array}$

$\begin{array}{ll}\text { Executive Summary } & 9\end{array}$

$\begin{array}{lll}\text { Chapter One } & \text { Background and Introduction }\end{array}$

Chapter Two Concepts and Definitions of Social Exclusion $\quad 18$ conceptualising social exclusion 18 deep exclusion 25

Chapter Three From Concepts to Indicators 32

single indicator sets $\quad 32$

children 38

young people $\quad 43$

working age adults $\quad 47$

later life 49

additional indicator sets $\quad 51$

Chapter Four Survey Analyses of Social Exclusion 55

Millennium Survey of Poverty and

Social Exclusion $\quad 55$

British Household Panel Survey $\quad 68$

Families and Children Study $\quad 78$

English Longitudinal Study of Ageing $\quad 80$

Chapter Five Devising and Applying the Bristol Social 86

Exclusion Matrix (B-SEM)

the matrix $\quad 86$

applying the B-SEM to survey data sets $\quad 96$

administrative sources $\quad 105$

$\begin{array}{lll}\text { Chapter Six } & \text { Conclusions and Recommendations } & 117\end{array}$

further research $\quad 118$

survey data $\quad 120$

administrative data $\quad 125$

specialist research on non-household and $\quad 126$ under-represented population groups 
Appendix $1 \quad$ Opportunity For All Indicators 2005

Appendix $2 \quad$ Monitoring Poverty and Social Exclusion Indicators

Appendix 3 Index of Multiple Deprivation

Appendix $4 \quad$ Audit Commission Quality of Life Indicators

Appendix 5 Proportion of the population perceiving items or activity as necessary

Appendix $6 \quad$ A Survey of Surveys

Appendix $7 \quad$ Applying the B-SEM

Appendix 8 Statistical analyses of social exclusion indicators

Bibliography 


\section{List of tables and figures}

\section{Tables}

2.1 Definitions of social exclusion or inclusion

3.1 Harmonised indicators of social exclusion adopted by the EU in 2001

3.2 Proposed European indicators of social exclusion (Atkinson indicators)

4.1 Association between social exclusion and other dimensions of exclusion

4.2 Percentage of young people excluded using the PSE approach, on a selected number of indicators

4.3 Percentage of pensioner households excluded using the PSE approach

5.1 Major cross-sectional surveys used in the application of B-SEM

5.2 Major panel/cohort surveys used in the application of B-SEM

\section{Figures}

4.1 Number of indicators of social exclusion and poverty reported by PSE respondents, out of a possible eight

6.1 Causal relationships between the 10 domains 


\section{List of abbreviations}

ACORN A Classification of Residential Neighbourhood

ALSPAC Avon Longitudinal Study of Parents and Children

ADMID administrative data sets for measuring impact on disadvantage

APS Annual Population Survey

ASBO Anti-Social Behaviour Order

ASHE Association for the Study of Higher Education

BCS70 British Cohort Study 1970

BHPS British Household Panel Survey

BMA British Medical Association

B-SEM Bristol Social Exclusion Matrix

CAB Citizens Advice Bureau

CAPI computer-assisted personal interviewing

CASI computer-assisted self-interviewing

CDRP Crime and Disorder Reduction Partnership

CJS Criminal Justice System

CMPO Centre for Market and Public Organisation

CRSP Centre for Research in Social Policy

CSV Community Service Volunteers

DCLG Department for Communities and Local Government

DCMS Department of Culture, Media and Sport

DfES Department for Education and Skills

DfT Department for Transport

DH Department of Health

DTI Department of Trade and Industry

DWP Department for Work and Pensions

ECHP European Community Household Panel

EFS Expenditure and Food Survey

ELSA English Longitudinal Study of Ageing

ESRC Economic and Social Research Council

FACS Families and Children Study

FRS Family Resources Survey

GHQ General Health Questionnaire

GHS General Household Survey

GLM General Linear Model

GSS Government Statistical Service

GWR geographical weighted regression

HBAI Households Below Average Income

HEFCE Higher Education Funding Council for England

HESA Higher Education Statistics Agency

HMRC Her Majesty's Revenue and Customs

HOCS Home Office Citizenship Survey

HSE Health and Safety Executive

IMD Index of Multiple Deprivation 
ISEW Index of Sustainable Economic Welfare

JCSHR Joint Centre for Scottish Housing Research

JRF Joseph Rowntree Foundation

JUVOS Joint Unemployment and Vacancies Operating System

LFS Labour Force Survey

LLFS Local Labour Force Survey

LSE-CASE Centre for the Analysis of Social Exclusion at the London School of Economics and Political Science

LSYPE Longitudinal Study of Young People

MAR missing at random

MAUP modifiable areal unit problem

MDP Measure of Domestic Progress

MUD moral underclass discourse

NAPincl national action plan on social inclusion

NatCen National Centre for Social Research

NCDS National Child Development Study

NDS National Data Strategy

NEF New Economics Foundation

NES New Earnings Survey

NeSS Neighbourhood Statistics Service

NFER National Foundation for Educational Research

NINOs National Insurance numbers

NPD National Pupil Dataset

NPI New Policy Institute

NS-SEC National Statistics socioeconomic class

NS-SEG National Statistics socioeconomic group

OCJS Offending, Crime and Justice Survey

ODPM Office of the Deputy Prime Minister

OLS ordinary least squares

ONS Office for National Statistics

PLASC Pupil Level Annual School Census

PLUG PLASC/NPD User Group

PSA Public Service Agreement

PSE Survey Millennium Survey of Poverty and Social Exclusion

RED redistributive

SARs Samples of Anonymised Records

SEH Survey of English Housing

SEU Social Exclusion Unit

SID social integrationist approach

SLFS Scottish Labour Force Survey

SPLS Supporting People Local System

SPSS Statistical Package for the Social Sciences

SQOL OA Survey of Quality of Life in Old Age

SSSI site of special scientific interest 
UCAS Universities and Colleges Admissions Service

WLFS Welsh Labour Force Survey

WLPS Work and Pensions Longitudinal Study 


\section{Acknowledgements}

We would like to acknowledge the help and cooperation, often to very tight deadlines, of academic colleagues and researchers in government departments during this project. Especial thanks are due to Matt Barnes, Chris Cuthbert and Anita Krishnamurthy, initially based in the Social Exclusion Unit at the Office of the Deputy Prime Minister (ODPM), for their help in setting up the project and for supportive liaison during major institutional re-organisation. We would also like to thank Mohib Rahman, Tim Crozier, Peter Stubbs and Penny Allen from the Department for Communities and Local Government (DCLG); Bill Sheppard and Fraser Macleod from the Department for Work and Pensions (DWP); Richard Bartholomew and Isabella Craig from the Department for Education and Skills (DfES); Pete Watson and Rachel Peto from the Citizens Advice Bureau (CAB). We are grateful to Peter Elias from the UK National Data Strategy (NDS) for access to the draft report on administrative data. At the University of Bristol, we would like to thank Alan Crowther, Elaine Escott and Rachel Ireson, as well as George Davey-Smith, Andy Ness and Lynn Molloy, as well as give particular thanks to David Herrick for extensive advice on ALSPAC (Avon Longitudinal Study of Parents and Children). Dawn Rushen undertook the copy-editing of a long and complex report at very short notice, and we are grateful for her expertise, professionalism and patience. 


\section{Executive summary}

The purpose of this project was to review existing sources on multi-dimensional disadvantage or severe forms of social exclusion characterised as 'deep exclusion'; to recommend possibilities for secondary analysis of existing data sets to explore the dynamics of 'deep exclusion'; to identify any relevant gaps in the knowledge base; and to recommend research strategies for filling such gaps.

The first task was to define social exclusion and deep exclusion and to identify the appropriate 'dimensions' contributing to multi-dimensional disadvantage. A working definition of social exclusion was adopted after exploration of the wide range available in the literature:

Social exclusion is a complex and multi-dimensional process. It involves the lack or denial of resources, rights, goods and services, and the inability to participate in the normal relationships and activities, available to the majority of people in a society, whether in economic, social, cultural or political arenas. It affects both the quality of life of individuals and the equity and cohesion of society as a whole.

'Social exclusion' itself is universally regarded in the academic and policy literature as involving multi-dimensional disadvantage. 'Deep exclusion' cannot therefore be clearly differentiated from social inclusion on this basis. However, there are degrees of severity of social exclusion. Severe or deep exclusion was therefore defined as follows:

Deep exclusion refers to exclusion across more than one domain or dimension of disadvantage, resulting in severe negative consequences for quality of life, well-being and future life chances.

Although there are several indices relating to social exclusion and related matters, many of these are principally descriptive and do not allow for analysis of interacting variables. The multivariate analysis that has been done on social exclusion is of variable quality and is inconsistent in the definitions of social exclusion and the domains and indicators used.

It is not clear that 'deep exclusion' is separable from social exclusion more generally, or produced by different 'drivers'. The demonstration of causality in social science is extremely difficult. However, there is overwhelming evidence that poverty is a major risk factor in almost all domains of exclusion that have been explored. Bradshaw et al (2004) stress the importance of distinguishing between macro-drivers that increase the overall levels of social exclusion, or particular aspects of it such as homelessness, and the causes or correlates of individual vulnerability. It is also useful to distinguish between risk factors which signal the 
greater vulnerability of a category of individuals, and triggers which have a direct causal impact.

A matrix of appropriate domains and topic areas was constructed looking across four stages of the life course: childhood, youth, working-age adulthood and later life. This matrix, the Bristol Social Exclusion Matrix, or B-SEM, contains 10 dimensions or domains of potential importance in social exclusion:

\begin{tabular}{ll} 
Resources: & \multicolumn{1}{c}{ Material/economic resources } \\
& Access to public and private services \\
& Social resources \\
Participation: & Economic participation \\
& Social participation \\
& Culture, education and skills \\
& Political and civic participation \\
Quality of life & $\begin{array}{l}\text { Health and well-being } \\
\text { Living environment } \\
\end{array}$ \\
& Crime, harm and criminalisation
\end{tabular}

The interactive nature of social exclusion means that these domains and topics are often both outcomes and risk factors. The substantive coverage and the methodological adequacy of a range of data sets was then assessed. While there is a great deal of data collected on aspects of disadvantage in existing surveys and administrative data sets, very few cover the range of aspects of multiple disadvantage or social exclusion included in the B-SEM.

Some people most at risk of social exclusion are omitted entirely from household surveys. They include all of the population living in institutions, such as some children in local authority care or in young offenders' institutions; disabled children in residential care; disabled adults; those hospitalised or in prison; older people in residential care; and some asylum seekers, notably those in holding institutions. Homeless people are also missed by household surveys. Other groups are under-represented in household surveys, including some of those most vulnerable to social exclusion, such as some minority ethnic groups, those on low incomes and residentially mobile populations including travellers.

There are also sections of the population who, although technically eligible for inclusion, are under-represented in social surveys. Again, these are often groups who may be particularly vulnerable to social exclusion, such as those on low incomes. Even where representation is proportionate, the numbers in vulnerable groups may be too small for further analysis unless original sample sizes are very large. This applies, for example, to the numbers of minority ethnic respondents in many surveys. Different research strategies need to be put in place to 
investigate the dynamics of social exclusion in vulnerable groups excluded from or underrepresented in household surveys.

The best existing surveys for secondary analysis of multi-dimensional disadvantage were identified as: Families and Children Study (FACS); British Household Panel Survey (BHPS); English Longitudinal Study of Ageing (ELSA); General Household Survey (GHS); Millennium Survey of Poverty and Social Exclusion (PSE Survey); Avon Longitudinal Study of Parents and Children (ALSPAC). For young people, the best sources are the cohort studies initiated in 1958, 1970 and 2000. The Longitudinal Study of Young People (LSYPE) is likely to become an important addition although meaningful results for this group will not become available for some years. Pooled data from the GHS is also a useful source for looking at social exclusion among young people.

A new household survey, the UK Longitudinal Household Survey (UKLHS), is under construction that will have a sample size of 40,000 and is expected to generate data from 2008. Steps should be taken to ensure there are appropriate questions on social exclusion.

Administrative data sources may be considered as an alternative to survey data. Two major reports, Pleace and Bretherton (2006) reporting for the DWP and Jones and Elias (2006), reporting for the NDS, have recently been published. Both note the potential advantages of linking administrative data sources, or linking them to survey data, but both raise issues of data quality as well as ethical and legal issues in the use of such data, and questions of public trust.

\section{Recommendations}

1. We recommend secondary analysis using B-SEM to identify appropriate domains and indicators of the surveys listed above.

2. The PSE Survey has the most extensive coverage of social exclusion. We recommend repeating an improved version of the PSE Survey with a larger sample size and an ethnic booster. If possible we would recommend re-contacting the households in the original survey to provide a longitudinal element.

3. We recommend the generation of a 'Social Exclusion Module' based on the B-SEM for inclusion in the future UKLHS (or in the BHPS or GHS).

4. We recommend that qualitative research work using in-depth interviews and life history techniques be undertaken with those groups at particular risk of social 
exclusion, especially those who are excluded from or under-represented in household surveys. Such qualitative work should use biographical methods to explore the experience of social exclusion and the nature and sequence of precipitating events and events and interventions that reduce or prevent exclusion.

5. We recommend that the findings from this qualitative work be used where possible to inform specialised surveys of social exclusion among the non-household population.

There are also changes that could be made to existing data collection practices that would improve the adequacy of existing data in relation to measuring social exclusion:

6. We recommend that more consideration is given to the use of ethnic and other boosters in existing survey research to improve the overall usefulness of these sources.

7. We recommend that a religious variable be routinely included in surveys, and that administrative data such as IMD (Index of Multiple Deprivation) scores are also added to existing surveys.

8. We recommend that the UKLHS builds on BHPS best practice and includes a children's cohort. In general, we recommend that more survey research collects data directly from children, with the age of respondents taken as far down as possible, certainly from about seven years of age.

9. In view of the inconsistent use of age categories in relation to young people, we recommend the more consistent application of the United Nations 16-24 age boundaries.

10. We recommend that in future sweeps of ELSA a sample for Wales be included.

11. We recommend further consideration of the use of administrative data. However, in line with recent reports from the DWP and National Data Strategy, we recommend that the interrelated questions of ethics, public trust and data quality are kept to the forefront when considering the use of administrative records for purposes other than those for which they were originally generated. 


\section{Chapter one}

\section{Background and introduction}

The incoming Labour government made social exclusion a key policy issue in 1997. The Social Exclusion Unit (SEU) was set up to provide a cross-departmental approach to the complex problems of specific groups, initially focusing on rough sleepers, truancy and school exclusion, teenage pregnancy and young people not in education, employment or training. The SEU defined social exclusion as:

... a shorthand term for what can happen when people or areas suffer from a combination of linked problems such as unemployment, poor skills, low incomes, poor housing, high crime environments, bad health and family breakdown.

This definition, albeit impressionistic, captures the multi-dimensional character of the problem the government sought to address. But the effectiveness of government policy in this crucial area cannot be assessed without appropriate data, raising the issue of relevant indicators of social exclusion. Debate in 1998-99 in academic, policy and think-tank circles resulted in the production of two sets of indicators from existing statistics, the New Policy Institute's (NPI) Poverty and Social Exclusion in Britain and the government's own Opportunity for All series. The government also made a commitment to abolish child poverty, with specific interim targets.

The European Union also put poverty and social exclusion at the heart of its social policy at the Lisbon Summit in 2000, with specific criteria set out at Nice in 2001, together with a requirement that each member state produce a biennial national action plan on social inclusion (NAPincl). The Nice criteria include a specific reference to addressing vulnerable groups at particular risk of exclusion. The EU has also produced a package of 'primary' and 'secondary' indicators of exclusion, while suggesting that appropriate 'tertiary' indicators be developed at national level. The UK had already done much of this work, and was able to draw extensively on the Opportunity for All reports in the 2001 NAPincl, and subsequently to build on these.

All these forms of measurement rely on batteries of single indicators. These have multiple problems and do not distinguish between risk factors and outcomes. They cannot prioritise one indicator, or potential field of intervention, over another. They say nothing about the interaction of different factors. They can gloss over the methodological problems in the 
production of individual indicators - although both the NPI and Opportunity for All report the origins and robustness of each indicator. Two main quantitative studies in the UK have tried to overcome these problems, and to (a) move from the definition of social exclusion to measurement and (b) examine the interaction of different dimensions of social exclusion. They are the secondary analysis of the British Household Panel Survey (BHPS) undertaken by Burchardt and colleagues (Burchardt, 2000; Burchardt et al, 2002) at the Centre for the Analysis of Social Exclusion at the London School of Economics and Political Science (LSECASE), and the Rowntree-funded Millennium Survey of Poverty and Social Exclusion in Britain (PSE Survey), carried out in 1999 (Gordon et al, 2000; Pantazis et al, 2006).

Miliband (2006) recommends thinking about social exclusion in three ways: wide, deep and concentrated exclusion. Wide exclusion refers to the large number of people excluded on a single or small number of indicator(s). Concentrated exclusion refers to the geographic concentration of problems and to area exclusion. Deep exclusion refers to those excluded on multiple and overlapping dimensions. The purpose of this piece of research is to examine the scope for looking at the interaction of factors in social exclusion, and specifically in 'deep exclusion' or multiple disadvantage, using existing databases.

To make sure current information bases are fully exploited we need to explore the potential for additional secondary analysis of existing data sets. Assessment of the specialised data sets that have already been used to explore social exclusion is crucial. A range of general and specialised surveys, both cross-sectional and longitudinal, could potentially add to our knowledge in this field, as could some administrative data. The first task is to look at the range of quantitative data available, primarily in England and Wales, and to establish what could be used to measure the interaction of multiple factors in deep exclusion. The second task is to set out a range of options for future research, which might include adaptation or secondary analysis of existing data sets and/or the use of new specialised surveys or qualitative research to help define appropriate policy intervention in relation to 'deep exclusion'. The stages of the research were therefore set out as follows:

\section{Identify the different conceptual frameworks and their implications for} measurement in the theoretical and policy literature. This would include concepts embedded in current government policy and sets of indicators such as the Opportunity for All reports, the NPI series on Monitoring Poverty and Social Exclusion and the work of the SEU; a brief treatment of those underpinning EU policy on social exclusion, the Nice criteria and 
the development of European indicators; those informing quantitative research such as the PSE Survey and LSE-CASE; and those current in the wider academic literature.

\section{Clarify the possible meaning of deep exclusion in relation to these frameworks.}

\section{Construct an indicative social exclusion matrix identifying the principal domains} and dimensions of social exclusion, and topic areas within these. The UK government typically commissions about 20 social surveys each year. Many of these surveys contain key information pertinent to the study of social exclusion. It would be possible ultimately to develop a searchable meta-database on social exclusion that documents relevant survey data sources, question items and associated information (for example, sampling methods, coverage etc). The Office for National Statistics (ONS) has successfully applied this approach in the development of the ONS social capital survey matrix. The topics in a comparable social exclusion matrix should be sensitive to the possible different character of social exclusion at different stages of the life course, childhood, youth, working age and later life.

4. Identify the data sets to be addressed, including a range of repeat cross-sectional surveys, longitudinal surveys and one-off surveys, and both general surveys across the household population (such as the General Household Survey or GHS), and those targeted at particular groups (such as the Families and Children Study or FACS). Key sources are the BHPS and PSE, since these are the primary sources that have been used to analyse 'social exclusion’ across the population as a whole. Administrative data sets might also be useful.

\section{Identify a specific set of questions to be addressed in relation to each data set.}

What data is collected relating to the different domains and dimensions of social exclusion? What are the main strengths and weaknesses of each data set in terms of the character of the achieved sample, the definitions used and the mode of data collection? Here it was necessary to consider how far the target population of the survey itself excludes those experiencing 'deep exclusion', such as the non-household population. We also looked at differential response rates (in cross-sectional and longitudinal surveys) and attrition rates (in longitudinal surveys). The processes of weighting that are normally used to compensate for these may have different implications for looking at the most vulnerable groups than for assessing the population as a whole. In relation to each data set, we also considered how previous analyses of this data addressed the 'multi-dimensional' character of social exclusion, and whether the data lends itself to further multivariate analysis that would address the dynamics of deep exclusion. 
6. Consolidate the results of this detailed investigation and consider which research strategies and which studies best estimate and/or track multi-dimensional exclusion, and what scope there is for further secondary analysis of existing data using multivariate techniques.

\section{Identify gaps in the knowledge base, and make recommendations for further research.}

The organisation of this report follows the same logic as the original research framework. Chapters Two to Four explore the main definitions of and approaches to social exclusion, and the indicators hitherto used in its measurement. This review is used to derive operational definitions of 'social exclusion' and 'deep exclusion' at the individual or household level. An operational definition is one that is theoretically and practically amenable to measurement either directly or by use of a proxy indicator. The relevant domains of disadvantage are derived from existing literature and indicator sets, as are a range of individual topics within each domain. Both domains and indicators are considered in relation to four life course stages: childhood, youth, working-age adulthood and later life.

From this background, a matrix of domains and topic areas, the Bristol Social Exclusion Matrix (B-SEM), is outlined in Chapter Five. This was then used to assess the coverage of a range of key cross-sectional and longitudinal social surveys and the potential of administrative data. For this part of the research, the team accessed the Economic and Social Research Council (ESRC) data archive and other relevant data banks, and systematically cross-matched each questionnaire to the derived matrix. The technical report on each survey was used to identify the size and composition of the sample, and especially the representation, under-representation and omission of sub-groups, particularly those likely to be vulnerable to social exclusion. Each data set was subsequently considered by the team's statistical experts for its potential for analysing social exclusion, and notes incorporated into the supporting summary for each survey. Chapter Five summarises the overall findings from this exercise, Appendix 6 contains a detailed account of the characteristics of each survey considered. Appendix 7 provides a tabular version of the B-SEM for each survey, showing the extent of the data coverage in relation to social exclusion.

The Government Statistical Service (GSS) and the ESRC also undertake methodological work. There is a great deal of work going on in different government departments on the 
methodological possibilities and difficulties associated with the use of survey and administrative data, addressing both general issues and their impact on specific surveys. In addition, a National Data Strategy (NDS) was launched in 2005. The component parts of this include a UK Data Forum, and the national Longitudinal Strategy Committee (see Buck 2002) that will report annually in February to the UK Data Forum and the ESRC Research Resources Board (NDS, 2005a, 2005b). As part of this, the ESRC commissioned a report on existing panel and cohort studies (Martin et al, 2006), as well as an audit of administrative data resources (Jones and Elias, 2006).

In relation to administrative data, the huge range of data held by different government departments and the small scale of this study necessitated a highly selective approach. The research team contacted key individuals in the Department for Education and Skills (DfES), Department for Work and Pensions (DWP) and the Citizens Advice Bureau (CAB), and also consulted relevant GSS methodology papers with particular attention to non-response errors (GSS 1998, 1999, 1999a, 1999c, 2000, 2001). The feedback from this exercise made a very useful contribution to a preliminary general assessment of possibilities here, as well as identifying other work on merging data sets due to report shortly. It is evident that there is a great deal of duplication of effort in this area, and steps should be taken to minimise this, at least by ensuring that relevant researchers in government departments are aware of the work of the independent NDS.

Chapter Six of this report assesses the potential of existing data and the extent of current knowledge gaps and makes some recommendations about future research strategies. It makes recommendations about the best data sets for further analysis of the dynamics of multidimensional disadvantage. It also draws on the B-SEM and the appraisal of data sets to identify knowledge gaps. These are of three kinds: first, substantive areas that are not covered by existing surveys, but where additional data could be collected in future by the use of supplementary questions; second, groups of the population who are inadequately covered by existing surveys, where specialised work might be appropriate. Cross cutting these two forms of knowledge gap is the issue of whether certain kinds of information might more appropriately be sought by qualitative research methods rather than through large-scale social surveys, even of a specialist kind. 


\section{Chapter two}

\section{Concepts and definitions of social exclusion}

\section{Conceptualising social exclusion}

The main purpose of this project, as outlined in Chapter One, is to explore the scope for the analysis of 'deep exclusion' or multiple disadvantage across a range of existing data sets, and to identify gaps in the knowledge base and potential strategies for filling those gaps.

The first task is to establish what is meant by social exclusion in general and deep exclusion in particular, and thus in broad terms what the relevant dimensions of 'disadvantage' might be. In 1997, the SEU defined social exclusion as:

... a shorthand term for what can happen when people or areas suffer from a combination of linked problems such as unemployment, poor skills, low incomes, poor housing, high crime environments, bad health and family breakdown.

This definition encapsulates multiple disadvantage, but is also quite vague in that it does not specify 'what can happen'.

Within two years, the UK government had established an annual audit of 'poverty and social exclusion', the Opportunity for All reports, beginning in 1999, although this also does not offer a very specific definition. It adds to the SEU formulation that:

Social exclusion occurs where different factors combine to trap individuals and areas in a spiral of disadvantage. (DSS, 1999, p 23)

Poverty is seen as multi-dimensional:

Lack of income, access to good-quality health, education and housing, and the quality of the local environment all affect people's well-being. Our view of poverty covers all these aspects. (DSS, 1999, p 23) 
Poverty ... [exists] when people are denied opportunities to work, to learn, to live healthy and secure lives, and to live out their retirement years in security. (DSS, 1999, p 23)

Alongside the Opportunity for All reports, the NPI, in conjunction with the Joseph Rowntree Foundation (JRF), from 1998 produced its own annual series Monitoring Poverty and Social Exclusion. The NPI has developed an extensive website (www.npi.org.uk) that goes substantially beyond the report issued annually as hard copy, and is an invaluable resource (the indicators are discussed below). There is, however, very little definitional discussion in either virtual or hard copy versions. The 2005 report includes no definition (Palmer et al, 2005). The website, drawing on the definition in the first report (Howarth et al, 1998) says:

While the number of people on low income, measured in various different ways, are naturally treated as an important aspect of poverty and social exclusion, this report stretches well beyond that. The notion of poverty that has guided the development of this report is where people lack many of the opportunities that are available to the average citizen. Low income and limited expenditure, especially on essentials, will be indicative of this, but the report also includes many indicators of things that researchers have been found to be disproportionately associated with low income, for example, certain forms of ill-health and restricted access to services. This broad concept of poverty coincides with the emerging concept of social exclusion. Its great practical value is that it widens the focus to include factors that may be thought to cause severe and chronic disadvantage. In the context of this report, this means that indicators connected with long term lack of paid work, or poor educational qualifications, can be included alongside more readily understood aspects of poverty. (NPI, 2006)

In 1989, the European Commission was asked by the Council of Ministers to examine policies to combat social exclusion. In 2000, the Lisbon Summit put poverty and social exclusion at the heart of EU social policy. Specific criteria were set out at Nice in 2001, together with a requirement that each member state produce a biennial national action plan on social inclusion (NAPincl). The Nice objectives, which include a specific reference to addressing vulnerable groups at particular risk of exclusion, are as follows:

- Facilitating participation in employment and access by all to resources, rights, goods and services 
- Preventing the risks of exclusion

- Helping the most vulnerable

- Mobilising all relevant bodies in overcoming exclusion.

'Helping the most vulnerable' might be seen as an early pre-occupation of the SEU: its early reports focused on particular groups - rough sleepers, those truanting from or excluded from school, pregnant teenagers, young people not in education, or training. A large part of its work subsequently focused on neighbourhood disadvantage. In 2004, alongside continuing work on specific groups such as looked-after children, prisoners and those suffering poor mental health, the emphasis shifted to a programme of work on Breaking the Cycle and preventing social exclusion, including a substantial amount of commissioned work on The drivers of social exclusion (Bradshaw et al, 2004). In May 2006 the issue of social exclusion was given Cabinet-level priority with the appointment of a Minister for Social Exclusion. This, however, was followed with the announcement in June 2006 of the closure of the SEU itself, with its work being transferred to a smaller task force in the Cabinet Office responsible for trying to persuade Whitehall departments to focus on the most severely excluded. The Social Exclusion Task Force (SETF) avoids the terminology of the Treasury, whose Children and Young People's Policy Review (launched in conjunction with the Department for Education and Skills and informing the 2007 Comprehensive Spending Review) includes 'the stock of families already regarded as high cost, high harm' and those 'at high risk of moving into this situation' (HM Treasury 2006; see also Feinstein and Sabates 2006). For SETF, references to ‘disadvantage and harm’ (SETF 2006:5) are accompanied by prioritisation of 'specific hard-to-reach groups, including children in care, people with mental health problems and teenagers at risk of pregnancy’ (SETF, 2006, p. 95), and an emphasis on early intervention. However, there are also references to 'problem families' (Cabinet Office 2006), and a strong emphasis in the report on the responsibility of the excluded themselves: Thus 'In this Action Plan we have focused on some of the most excluded groups, such as children in care or adults leading chaotic lives - groups that have generally failed to fulfil their potential and accept the responsibilities that most of us take for granted' (SETF 2006:10).

It is notable that all the approaches outlined above tend to use 'poverty and social exclusion' as an inseparable dyad. However, there are definitions in the UK, European and global literature that address social exclusion as distinct from poverty, as shown in Table 2.1. 
Table 2.1: Definitions of social exclusion or inclusion

\begin{tabular}{|c|c|}
\hline 1 & $\begin{array}{l}\ldots \text { a shorthand term for what can happen when people or areas suffer from a combination of } \\
\text { linked problems such as unemployment, poor skills, low incomes, poor housing, high crime } \\
\text { environments, bad health and family breakdown. (SEU, 1997) }\end{array}$ \\
\hline 2 & $\begin{array}{l}\text { Social exclusion occurs where different factors combine to trap individuals and areas in a } \\
\text { spiral of disadvantage. (DSS, 1999, p 23) }\end{array}$ \\
\hline 3 & $\begin{array}{l}\text { Social exclusion is a process, which causes individuals or groups, who are geographically } \\
\text { resident in a society, not to participate in the normal activities of citizens in that society. } \\
\text { (Scottish Executive, nd) }\end{array}$ \\
\hline 4 & $\begin{array}{l}\text { The notion of poverty that has guided the development of this report is where people lack } \\
\text { many of the opportunities that are available to the average citizen.... This broad concept of } \\
\text { poverty coincides with the emerging concept of social exclusion. (NPI, Howarth et al, 1998) }\end{array}$ \\
\hline 5 & $\begin{array}{l}\text { The processes by which individuals and their communities become polarised, socially } \\
\text { differentiated and unequal. (ESRC, 2004) }\end{array}$ \\
\hline 6 & $\begin{array}{l}\text { The dynamic process of being shut out from any of the social, economic, political and } \\
\text { cultural systems which determine the social integration of a person in society. (Walker and } \\
\text { Walker, 1997, p 8) }\end{array}$ \\
\hline 7 & $\begin{array}{l}\text { A lack or denial of access to the kinds of social relations, social customs and activities in } \\
\text { which the great majority of people in British society engage. In current usage, social } \\
\text { exclusion is often regarded as a 'process' rather than a 'state' and this helps in being } \\
\text { constructively precise in deciding its relationship to poverty. (Gordon et al, 2000, p 73) }\end{array}$ \\
\hline 8 & $\begin{array}{l}\text { An individual is socially excluded if (a) he or she is geographically resident in a society but } \\
\text { (b) for reasons beyond his or her control, he or she cannot participate in the normal activities } \\
\text { of citizens in that society, and (c) he or she would like to so participate. (Burchardt et al, } \\
2002 \text {, pp 30, 32) }\end{array}$ \\
\hline 9 & l participation, lack of social integration and lack of power. (Room, 1995 ) \\
\hline 10 & $\begin{array}{l}\text { Social exclusion is a broader concept than poverty, encompassing not only low material } \\
\text { means but the inability to participate effectively in economic, social, political and cultural } \\
\text { life and in some characterisations alienation and distance from mainstream society. (Duffy, } \\
\text { 1995) }\end{array}$ \\
\hline 11 & $\begin{array}{l}\text { (Social Inclusion) The development of capacity and opportunity to play a full role, not only } \\
\text { in economic terms, but also in social, psychological and political terms. (EU Employment } \\
\text { and Social Affairs Directorate) }\end{array}$ \\
\hline 12 & $\begin{array}{l}\text { An accumulation of confluent processes with successive ruptures arising from the heart of } \\
\text { the economy, politics and society, which gradually distances and places persons, groups, } \\
\text { communities and territories in a position of inferiority in relation to centres of power, } \\
\text { resources and prevailing values. (Estivill, 2003, p 19) }\end{array}$ \\
\hline
\end{tabular}

Several points about these definitions have a bearing on the present project.

First, they are pitched at two different levels. They refer to structures, processes and characteristics of the society as a whole, as well as to the experience of individuals situated within these. This is particularly true of the ESRC reference to 'polarisation' (definition 5) and Estivill's reference to ruptures arising from the heart of economy, politics and society (definition 12). These, as well as references to power (definitions 9, 12) and inequality (definition 5), point to the structural causes and contexts of the individual experience of exclusion. The structural character of social exclusion, relating it to wider economic processes and inequalities, has been a feature of much academic writing (Brown and Crompton, 1994; Byrne, 1999, 2005; Levitas, 1998, 2005). Some writers have not only noted the contribution 
of polarisation and inequality to the growth of social exclusion (see Rowntree, 1995), but have drawn attention to what Barry calls an 'upper threshold' of social exclusion, permitting self-exclusion by the rich (Hutton, 1996; Barry, 2002). Such forms of closure may be of particular importance in the context of rising inequality and falling social mobility (Aldridge, 2001, 2004).

Second, although the definitions may be clear and precise, their level of abstraction means they are not empirically precise. While they help to conceptualise social exclusion, this is not the same as providing an operational definition that is amenable to measurement. Operational definitions are always a compromise between conceptual precision and clarity and what is theoretically and practically measurable. Consequently, many reports on aspects of social exclusion open by grappling with the variation in definitions, and the difficulty of operationalising these. For example, several refer to disconnection from economic processes, but do not specify what this means in practice. This is often taken to mean non-participation in, or exclusion from, the labour market, perhaps partly because of macro-economic policies that involve increasing labour force participation rates. Other sources include participation in unpaid or caring work. Some contemporary literature regards consumption, which can also be construed as an economic process, as crucial to identity formation and self-respect (Bauman, 1998; Bowring, 2000).

Third, several of the definitions refer to exclusion from activities that are 'normal' or available to the 'average citizen', or to the majority of citizens. While this appears to be an empirical question, it is also a normative one. The selection of which activities 'matter' involves a judgement, and one that may change over time, as expectations and opportunities change.

Fourth, the definitions raise questions of both choice and capability. They refer to being 'shut out' (definition 6) or 'denied access' (definition 7). Less strongly, some refer to an inability to participate when the individual would like to do so (definition 5). The question is whether those who 'choose' not to participate can be treated as socially excluded. The question of choice is discussed further below in relation to the PSE Survey. But among other things, it raises the question of capability. Definition 11 (for social inclusion) refers to the development of the capacity to participate. The issues here are similar to the distinction in political theory between positive and negative freedom. Negative freedom means there is no external force preventing an individual from acting in a given way (such as, for example, voting). Positive 
freedom includes also the capacity and resources required to exercise that freedom including resources such as education, information and transport, as well as material resources such as income.

Fifth, the Nice criteria specifically distinguish risks from access to goods, resources, services and employment (implicitly therefore constitutive of exclusion). Labour market inactivity may be seen as constitutive of social exclusion (at least for working-age adults). Alternatively, it may be seen as a risk factor, increasing the probability of poverty and social exclusion. It may, of course, be both. In exploring or constructing indicators, the distinction between outcome measures and risk factors is important (see Barnes, 2005). An analysis that usefully deploys this distinction in analysing social exclusion among older people is Barnes et al (2006). However, it is characteristic of the process of social exclusion that many outcomes also constitute risk factors, so the distinction is not absolute.

A useful report from the Department for Transport (DfT) points to a range of factors that can be summarised as risks, relations and resources, but also endorses the emphasis in the literature on some different aspects of social exclusion from those outlined above - questions of status, recognition and self-esteem, as well as expectations and power:

Oppenheim (1998) suggests that it is necessary to focus on social exclusion rather than poverty for a number of reasons. Social exclusion is multi-causal, relational, and it includes less tangible aspects than poverty such as the loss of status, power, self-esteem and expectations.... We might also add here that another important aspect of exclusion is political exclusion and the inability to influence decision making, which can be affected by a lack of resources, including time, telephones, transport and articulacy. (DfT, nd, p 10)

The reference to recognition and self-esteem here is particularly interesting. 'Respect' has become part of the vocabulary of New Labour in relation to efforts to tackle anti-social behaviour: it is generally oriented to cultivating greater respect for others and for social norms from those perceived as problem groups. The academic literature in the social sciences has also been increasingly concerned with respect and recognition, but from a rather different perspective: the failure to respect those who are socially excluded by virtue of poverty or stigmatised statuses such as ethnicity (Honneth and Anderson, 1996; Sennett, 1998, 2004; Fraser et al, 2003). Questions of respect and recognition have been argued to be central to poverty (Lister, 2004) and to relations of social class more generally (Sayer, 2005). This can 
be related to the EU definition (definition 11) that refers to playing a full part in society in psychological terms, and the NPI (definition 4) reference to access to opportunities, which can be interpreted as including the opportunity for social confirmation of personal worth. In this context, some of the language of recent government reports on those experiencing social exclusion is significant: there are several potentially stigmatising references to people with 'chaotic lives’ (Social Exclusion Task Force, 2006).

Other work has also addressed the question of social exclusion in terms of the quality of life of older people (Barnes et al, 2006). This is conceptually helpful, since quality of life is the background concern of much of the work on social exclusion. Exclusion on one or more dimensions has a severe negative impact on quality of life. The centrality of this has been somewhat obscured by an over-emphasis on paid work, so that in 1998 the NPI identified "a lack of clarity about what social exclusion might mean" for older people "because neither inclusion within education and training nor inclusion within paid work will be central to overcoming any problem” (Howarth et al, 1998, p 14).

Some theorists contend that persistence over time is an integral aspect of social exclusion (Room, 1995; Barnes, 2005). It is probably true that the persistence of poverty, deprivation and multiple disadvantage exacerbates their negative impact, especially on future life chances. However, the question of what is taken to be 'persistence' is problematic. The relationships between the dimensions and domains of social exclusion are complex. The very interactional processes recognised in the project of multivariate analysis imply that many, if not all, these dimensions are simultaneously exclusionary outcomes and causal factors for other dimensions of exclusion, although the strength and direction of causality will vary. The consequences of different forms of disadvantage, for different lengths of time, at different points in the life cycle, are likely to vary considerably. For example, five years in poverty between the ages of seven and twelve may have more significant consequences than the same period between 27 and 32. Housing deprivation in early life has been shown to have an impact on health (Marsh et al, 1999). In the present state of knowledge, judgements about the importance of persistence can only be arbitrary. For example, Barnes' (2005) secondary analysis of the BHPS defined persistent long-term disadvantage as disadvantage in at least seven out of nine years, but there is not theoretical or empirical justification for this choice of threshold. Empirical investigation of the effects of persistent exclusion on different dimensions is important, and further research is needed here, but building arbitrary measures of persistence into a definition of social exclusion inhibits rather than facilitates such investigation. 
A composite working definition of social exclusion that encapsulates many of the factors reflected in the literature is:

Social exclusion is a complex and multi-dimensional process. It involves the lack or denial of resources, rights, goods and services, and the inability to participate in the normal relationships and activities, available to the majority of people in a society, whether in economic, social, cultural or political arenas. It affects both the quality of life of individuals and the equity and cohesion of society as a whole.

This definition does not address the structural issues of inequality, polarisation, social mobility and social closure noted above. A definition is a purposive construction, and this is designed to facilitate the exploration of the experience or effects of exclusion at the individual and/or household level. In the context of the present study, structural characteristics are best seen as drivers of social exclusion, rather than constitutive of it. A review of the literature on the drivers of social exclusion conducted for the SEU in 2004 identified three areas of macrodrivers. "Poverty, inequality and social exclusion”, it argues, "are driven upwards and downwards by three major contextual factors: demographic, labour market and social policy" (Bradshaw et al, 2004, p 9). The demographic factors operating in the past to increase levels of social exclusion have been "large youth cohorts, ageing and increased dependency ratios, and family change, particularly the increase in lone parent families”. The impact of these is currently less, but there are additional trends of inward migration, single living and cohabitation that may possibly lead to increased levels of social exclusion. Labour market factors have included unemployment, 'flexibility' and greater insecurity in the labour market, the dispersion of earnings and the concentration of work. Social policy changes in the 1980s and 1990s also, they argue, led to increased levels of social exclusion: uprating benefits in line with prices rather than earnings; abolition and cuts to some benefits; a shift from direct to indirect taxation and a consequently more regressive system; cuts in service expenditure, especially on housing, or increases that were insufficient to meet increased need. However, they point out that if social policy can be a macro-driver of social exclusion, it is also capable of reducing it (Bradshaw et al, 2004, pp 13, 100).

\section{Deep exclusion}

Multi-dimensionality is key to the idea of 'deep exclusion'. This term was introduced into the conceptual field by David Miliband, who argued in March 2005 that "social exclusion exists 
in wide, deep and concentrated forms, and it is important not to confuse them” (Miliband, 2006, p 3). 'Wide exclusion' refers to those deprived on a single indicator. 'Deep exclusion' refers to those who are excluded on multiple counts, while 'concentrated exclusion' refers to the concentration of problems in particular geographical areas. "Here we get closer to a more recognisable definition of social exclusion reflecting the most disadvantaged in society" (Miliband, 2006, p 7). Miliband suggested that the SEU and other government departments need to set minimum standards across different stages of the life course - for children, working-age adults and older people. A large minority would be below one or more of the basic minimum standards. (Indeed, it is even possible that a majority of the population could be considered socially excluded on at least one count.)

In the same speech Miliband emphasised the multi-dimensionality of social exclusion in general: "the focus on social exclusion signalled that there was more than one dimension to inequality” - assets, skills, social networks and housing, as well as income (Miliband, 2006, p 4). He identified four distinctive features of government thinking in terms of social exclusion:

- it is relative and relational

- it is multi-dimensional

- the extension of state help must be accompanied by an extension of personal responsibility

- it is embedded in power relations that constrain and define the capabilities and choices of individuals.

If the third of these points is a political claim, the first, second and fourth evidently reflect both the original SEU definition and aspects of the alternative definitions outlined above.

Many of the attempts to define social exclusion distinguish it from poverty precisely on the basis of its multi-dimensional, relational and dynamic character. Poverty, by contrast, is portrayed as a distributive concept, concerned with resources, or in some cases, simply low income. There may be some confusion generated by the habitual use of low income as a simple indicator of poverty, which does not necessarily imply a conceptual identity. The distinction between poverty and social exclusion is less easy to sustain in the context of some of the literature on poverty. The Copenhagen World Summit for Social Development, to which the UK is signatory, defines poverty in ways that incorporate social exclusion: 
Lack of income and productive resources to ensure sustainable livelihoods; hunger and malnutrition; ill-health; limited or lack of access to services; increased morbidity from illness; homelessness and inadequate housing; unsafe environments and social discrimination and exclusion. It is also characterised by lack of participation in decisionmaking and in civil, social and cultural life. (UN, 1995)

The most recent literature on poverty emphasises the relational questions of recognition and respect (Lister, 2004). There is a growing body of work on the development of capacities and capabilities, building on the work of Amartya Sen (Nussbaum and Sen, 1993; Sen, 1995, 2001).

To some extent these differences are semantic, since all are concerned with multiple disadvantage. However, in some cases definitions of and policy approaches to poverty and social exclusion embed questions of causality. Levitas $(1998,2005)$ identifies three different orientations to social exclusion in British public policy, implying different models of causality and different policy interventions. In the redistributive (RED) model, lack of material resources is presumed to be the root cause:

Individuals, families and groups can be said to be in poverty when they lack the resources to obtain the types of diet, participate in the activities and have the living conditions and amenities which are customary, or at least are widely encouraged and approved, in the societies to which they belong. Their resources are so seriously below those commanded by the average individual or family that they are, in effect, excluded from ordinary living patterns, customs and activities. (Townsend, 1979, p 32)

The dominant model both in the EU and in the UK has been a social integrationist approach (SID), in which employment is central. Notably, access to employment precedes access to resources in the first Nice criterion. In this model, paid work is seen as important not just as the most effective route out of material poverty but as an integrating factor in its own right. Bhalla and Lapeyre (1997) suggest that there are three main categories of the social aspects of social exclusion: access to social services (such as health and education); access to the labour market (precariousness of employment, as distinct from low pay); and the opportunity for social participation. But they stress the importance of the precariousness of the labour market and unemployment in relation to economic and social respects. The third model identified by Levitas is a moral underclass discourse (MUD) that focuses on the behavioural and attitudinal 
characteristics of the excluded and their imputed deficiencies. Silver (1994) also argues that there are three dominant approaches to social exclusion, linked to different models of the welfare state. The importance of these arguments is both that different people may understand quite different things by the term 'social exclusion', and impute quite different causal processes, and causal relationships between factors need to be established empirically, not embedded in definitions.

The question of whether 'deep exclusion' is a distinct phenomenon from social exclusion more generally, or produced by different 'drivers' is, in the light of the existing definitions of social exclusion, very unclear. This applies to the macro-drivers identified by Bradshaw and colleagues. Bradshaw et al (2004) make two further points that are crucial to the scope of the current project. One is the importance of distinguishing between macro-drivers that increase the overall levels of social exclusion, or particular aspects of it such as homelessness, and the causes or correlates of individual vulnerability to social exclusion. Where individuals are concerned, it is also useful to distinguish between risk factors and triggers. Risk factors signal increased vulnerability of a category of individuals, while triggers have a direct causal impact. Triggers are in fact only specifically identified by Bradshaw et al in relation to homelessness, where leaving local authority care or prison are critical.

Bradshaw et al also make the point that establishing causation in social sciences research is particularly difficult:

The aim is to establish drivers. We understand drivers to mean the factors that cause or generate social exclusion. In social science, it is extremely difficult to establish cause. An association, relationship or correlation is often the best that can be demonstrated. Even then there are problems in demonstrating the direction of relationship between the driver and social exclusion, or whether it is the driver itself or a factor associated with the driver that produces the exclusion. (Bradshaw et al, 2004, p 6)

The drivers of social exclusion concentrated on "serious degrees of deprivation" (Bradshaw et al, 2004, p 9). It argued that social exclusion could either be approached through its impact on particular vulnerable groups, or through the lens of different domains. Following the latter strategy, it took as its main domains those set out in the SEU tender document for that project. The domains are thus not theoretically generated or justified, but follow conventional divisions that partially coincide with policy areas. The domains explored were income, 
employment, education, health, housing, neighbourhoods (including transport, social capital and neighbourhood deprivation) and crime.

Because of the multi-faceted and interactive process of social exclusion, the drivers of social exclusion that are identified by Bradshaw et al partly coincide with the domains themselves: low income, unemployment, education, ill-health (including substance misuse, child accidental death and mental health problems), housing (especially homelessness), transport problems, crime and fear of crime. Although our current project is primarily concerned with 'deep' exclusion, it is notable that in relation to 'concentrated' exclusion, Bradshaw et al concluded from the literature that neighbourhood effects were often overstated, and that "neighbourhood factors were less important than individual characteristics” (Bradshaw et al, 2004, p 107). Poverty was identified as a key factor in most other dimensions of exclusion.

The work on The drivers of social exclusion, together with an investigation of the concept itself, calls into question the existence of a distinctive phenomenon of deep exclusion. If social exclusion itself is about multiple disadvantage, deep exclusion is simply the most severe manifestation of an already severe process. Rather than treating deep exclusion as a qualitatively distinct phenomenon, it is perhaps more accurate to recognise that just as there are very marked difference of access to goods, services resources, power, recognition and so on among the socially included, so the socially excluded vary in the severity of their condition: deep exclusion is a matter of degree.

A working definition of deep exclusion might therefore be:

\section{Deep exclusion refers to exclusion across more than one domain or dimension of disadvantage, resulting in severe negative consequences for quality of life, well-being and future life chances.}

Deep exclusion thus emphasises the issue of multiple and severe disadvantage. Miliband's (2006) examples of multiple deprivation are:

- struggling with basic skills and long-term unemployed

- a child in poverty, in poor housing, with a parent suffering mental illness

- homeless, on drugs, without skills, and without family. 
These, and especially the last example, echo the concerns encapsulated in the SEU's original description of social exclusion, as well as being wholly consistent with the United Nations (UN) definition of overall poverty.

The dimensions Miliband referred to included:

- 10.1 million working-age adults without an NVQ (National Vocational Qualification) Level 2 qualification

- 3.8 million working-age people in workless households

- $\quad 3.2$ million children who live in non-decent housing

- 2.2 million older people living in relative low-income households

- 464,000 19-year-olds with no Level 2 qualifications

- 194,000 16- to 18-year-olds not in education, employment or training

- 2.2 million children in absolute poverty

- 3.5 children in relative poverty

- 5.2 million people struggling with basic literacy and numeracy

- homeless people

- housebound elderly.

One widely cited social policy expert cites seven dimensions to social exclusion itself (PercySmith, 2000:9):

- economic (for example, long-term unemployment, workless households, income poverty)

- $\quad$ social (for example, homelessness, crime, disaffected youth)

- political (for example, disempowerment, lack of political rights, alienation from/lack of confidence in political processes)

- neighbourhood (for example, decaying housing stock, environmental degradation)

- individual (for example, mental and physical ill-health, educational underachievement)

- $\quad$ spatial (for example, concentration/marginalisation of vulnerable groups).

- group (concentration of the above characteristics in particular groups: elderly, disabled, ethnic minorities). 
Thus although the distinction between wide and deep exclusion makes intuitive sense at a descriptive level, it does depend very much on how many dimensions are identified, and what they are. For example, low income and material deprivation may be treated as separate dimensions, or used to generate a compound indicator of poverty as in the PSE Survey (see Chapter Four). One partial solution to this is to think in terms of a hierarchy of domains, topics and indicators, rather than 'dimensions', and accept that there may be a variety of appropriate or possible indicators within a given domain or for a specified topic. This is particularly important when contemplating the use of existing data sets, where the task is to assess whether there is data that could be used as a proxy indicator for the topics under scrutiny.

We are still faced with the question of what these domains might be, and which topics might be identified as most important within each of these domains. The next chapter, therefore, considers the indicator sets that have so far been used to measure or monitor social exclusion, in order to assess their adequacy, before returning to the identification of topics within individual domains.

What is socially regarded as 'appropriate' participation, and the obstacles to it, varies across the life course. The domains may differ in the weight of their significance for different life stages. For example, while economic participation is not irrelevant to children (who may be in part-time paid work or acting as unpaid carers), it is clearly not (in the UK) of the same significance as it is for adults. Indeed, substantial economic participation by a child might be seen as a mark of social exclusion rather than inclusion. The importance of economic participation in relation to older people is more open to empirical investigation and public debate, especially in the context of proposals to increase the state pension age. Many, of course, participate in the sense of having substantial caring responsibilities, which again can be exclusionary rather than inclusionary. Even given the relevance of the domains and even the topics across the life course, the appropriate indicators will vary for different stages of the life course. 


\section{Chapter three}

\section{From concepts to indicators}

\section{Single indicator sets}

From the outset it was recognised that effective government policy to combat poverty and social exclusion requires appropriate data, raising the issue of relevant indicators of social exclusion. Debate in 1998-99 in academic, policy and think-tank circles in the UK resulted in the production of two sets of indicators from existing statistics. Subsequently, in 2001 the EU adopted its own set of measures to provide comparative data across member states - an indicator set somewhat narrower than either of the UK versions, and notably narrower than those proposed in a major report to the Social Protection Committee (Atkinson et al, 2002). The most important sets of single indicators currently produced or proposed are therefore:

- the Laeken indicators, the agreed battery of indicators for measuring progress in tackling poverty and social exclusion across the EU;

- the wider set proposed to the Social Protection Committee, the Atkinson indicators;

- the indicators included in NAPincl. These go beyond the Laeken indicators, and essentially coincide with those forming the basis of the UK annual audit of poverty and social exclusion, initiated in 1999 as Opportunity for All;

- the separate but overlapping series developed by the NPI and JRF, Monitoring Poverty and Social Exclusion.

Levitas (2006) argues that batteries of single indicators have both merits and problems. On the positive side, they are relatively cheap to compile. Moreover, being usually based on existing data sets, time series data can be produced. The drawbacks include the danger of defining social exclusion in terms of available indicators, so that we measure what we can rather than what we want; the difficulties of setting priorities between different indicators; and a possible lack of attention to the quality of the individual indicators and the data on which they are based. Notwithstanding these drawbacks, it is useful to examine these sets of indicators, since although the derivation of single indicator sets from multiple sources means direct multivariate analysis is not possible, they do point to the areas regarded by government and by independent experts as crucial aspects of poverty and social exclusion. This helps identify the topics for which we need to search for relevant data and/or identify gaps and lacunae in the body of existing data. For the individual stages of the life course, we have also 
drawn on the relevant specialist literatures to look at gaps in the conceptualisation and coverage of social exclusion.

The Laeken indicators (Table 3.1) are relatively narrow in scope. They mainly address questions of distributive poverty, inequality and labour market access, including some measures of low educational attainment and qualification. Otherwise, there are just two indicators of well-being: life expectancy and self-defined health status.

The Laeken primary and secondary indicators are constrained by the data that can be produced in comparable form across the EU. The Open Method of Coordination is also predicated on the practices of monitoring and sharing best practice. It is accepted that other 'tertiary' indicators are needed that are sensitive to the particular conditions in individual member states. However, it is notable that the priority here is given to economic, rather than social, political or cultural dislocations - either because this is deemed more important, or because the economic sphere is assumed to be causal.

Table 3.1: Harmonised indicators of social exclusion adopted by the EU in 2001

\begin{tabular}{|l|l|}
\hline & Indicator \\
\hline & Primary indicators \\
\hline $\mathbf{1}$ & $\begin{array}{l}\text { Low income rate after transfers with low-income threshold set at 60\% median income, with } \\
\text { breakdowns by gender, age, activity status, household type and housing tenure }\end{array}$ \\
\hline $\mathbf{2}$ & Distribution of income, using income quintile ratio \\
\hline $\mathbf{3}$ & Persistence of low income \\
\hline $\mathbf{4}$ & Median low income gap \\
\hline $\mathbf{5}$ & Regional cohesion (measured by variation of employment rates) \\
\hline $\mathbf{6}$ & Long-term unemployment rate \\
\hline $\mathbf{7}$ & People living in jobless households \\
\hline $\mathbf{8}$ & Early school leavers not in education or training \\
\hline $\mathbf{9}$ & Life expectancy at birth \\
\hline $\mathbf{1 0}$ & Self-defined health status by income level \\
\hline & Secondary indicators \\
\hline $\mathbf{1 1}$ & $\begin{array}{l}\text { Dispersion around the low-income threshold using } 40 \%, 50 \% \text { and } 70 \% \text { median national } \\
\text { income }\end{array}$ \\
\hline $\mathbf{1 2}$ & Low income rate anchored at a fixed point in time \\
\hline $\mathbf{1 3}$ & Low income rate before transfers \\
\hline $\mathbf{1 4}$ & Gini coefficient \\
\hline $\mathbf{1 5}$ & Persistent low income (below 50\% median income) \\
\hline $\mathbf{1 6}$ & Long-term (over 12 months) unemployment share \\
\hline $\mathbf{1 7}$ & Very long-term (over 24 months) unemployment share \\
\hline $\mathbf{1 8}$ & People with low educational attainment \\
\hline
\end{tabular}

Source: Social Protection Committee (2001)

The Laeken indicators are a subset of those proposed to the Social Protection Committee, the Atkinson indicators (Table 3.2). One striking feature of these is the priority given to housing 
adequacy, different aspects of which are included as a level one, or primary, indicator; as a level two indicator; and as three of the eight proposed new areas of measurement. However, most of the level one and level two indicators are again concerned with the risk of income poverty and labour market vulnerability. Most other features of social exclusion are areas where appropriate indicators need to be developed, but they identify the relevant additional areas of social exclusion as:

- health

- deprivation

- $\quad$ access to education

- housing

- basic skills (literacy and numeracy)

- access to public and private services

- social participation, including internet access. 
Table 3.2: Proposed European indicators of social exclusion (Atkinson indicators)

\begin{tabular}{|c|c|}
\hline & Indicator \\
\hline & Level one \\
\hline 1 & The risk of financial poverty as measured by $50 \%$ and $60 \%$ of national median income \\
\hline 2 & $\begin{array}{l}\text { Income inequality as measured by the quintile share ratio, that is, the ratio of the share of } \\
\text { national income received by the top } 20 \% \text { of households relative to the bottom } 20 \% \text { of } \\
\text { households }\end{array}$ \\
\hline 3 & $\begin{array}{l}\text { The proportion of those aged 18-24 with only lower secondary education (and not in } \\
\text { education or training) }\end{array}$ \\
\hline 4 & $\begin{array}{l}\text { Overall and long-term unemployment rates measured on an International Labour } \\
\text { Organization basis }\end{array}$ \\
\hline 5 & Proportion of population living in jobless households \\
\hline 6 & $\begin{array}{l}\text { Proportion of population dying before the age of } 65 \text {, or the ratio of those in bottom and top } \\
\text { quintile groups who classify their health as bad or very bad on the World Health } \\
\text { Organization definition }\end{array}$ \\
\hline 7 & $\begin{array}{l}\text { Proportion of people living in households lacking specified amenities or with specified } \\
\text { housing faults }\end{array}$ \\
\hline & Level two \\
\hline 8 & $\begin{array}{l}\text { Proportion of people in households below } 40 \% \text { and below } 70 \% \text { of median income, and } \\
\text { proportion below } 60 \% \text { of the median fixed in real terms }\end{array}$ \\
\hline 9 & Value of $60 \%$ of median threshold in purchasing power for two- and four-person households \\
\hline 10 & Proportion of the population living in households permanently at risk of financial poverty \\
\hline 11 & $\begin{array}{l}\text { Mean and median equivalised poverty gap for a poverty line set at } 60 \% \text { median income. } \\
\text { (This measures depth of the poverty by calculating the extent to which those in poverty fall } \\
\text { below the poverty line) }\end{array}$ \\
\hline 12 & Income inequality as measured by the decile ration and the Gini coefficient \\
\hline 13 & Proportion of the population aged 18-59 (64) with only lower secondary education or less \\
\hline 14 & $\begin{array}{l}\text { Proportion of discouraged workers, proportion non-employed and proportion in involuntary } \\
\text { part-time work, as a percentage of total 18-64 population excluding those in full-time } \\
\text { education }\end{array}$ \\
\hline 15 & Proportion of people living in jobless households with current income below 60\% median \\
\hline 16 & Proportion of employees living in households at risk of poverty (60\% median) \\
\hline 17 & Proportion of people who are low paid \\
\hline 18 & $\begin{array}{l}\text { Proportion of people unable to obtain medical treatment for financial reasons or because of } \\
\text { waiting lists }\end{array}$ \\
\hline 19 & Proportion of the population living in overcrowded housing \\
\hline 20 & Proportion of people who have been in arrears on rent or mortgage payments \\
\hline \multirow[t]{2}{*}{21} & Proportion of people living in households unable in an emergency to raise a specified sum \\
\hline & Indicators to be developed \\
\hline 22 & Non-monetary indicators of deprivation \\
\hline 23 & Differential access to education \\
\hline 24 & Housing of poor environmental quality \\
\hline 25 & Housing cost \\
\hline 26 & Homelessness and precarious housing \\
\hline 27 & Literacy and numeracy \\
\hline 28 & Access to public and essential private services \\
\hline 29 & Social participation and access to internet \\
\hline
\end{tabular}

\section{Opportunity for All and Monitoring Poverty and Social Exclusion}

The indicators developed for the UK's own poverty and social exclusion audit, Opportunity for All, are shown in Appendix 1. These are organised in different sections corresponding to different stage of the life course: 
- children and young people

- working-age people

- $\quad$ people aged 50+ and retired people

- communities (all ages).

This reflects a general acceptance that the precise meaning of social exclusion and its appropriate indicators vary between age groups.

In all, there are 60 Opportunity for All indicators in the 2005 report (see Appendix 1), 25 of which apply to children and young people, 18 to people of working age, 10 to those aged over 50, and 7 to communities. The balance of these reflects two things: the emphasis, in policy terms, on early intervention (consistent with the second Nice criterion, 'preventing the risks of exclusion'); and the relative underdevelopment of indicators for older people, for whom labour market activity is not required and is a less central concern in terms of social inclusion. This in turn underlines the fact that labour market activity is, at the UK level as well as in Europe, perceived as a central element of social inclusion.

There are overlaps between the groups. A 'child' is defined for the purposes of the low income indicators as "an individual aged under 16, or an unmarried 16 to 18-year-old on a course up to and including A level standard (or up to and including Highers in Scotland)” (DWP 2006, p 155). There is no equivalent definition for a 'young person'. Those of working age include all those who are not children and are below state pension age (less than 65 for men, less than 60 for women). The inclusion of those over 50 in the headline description of this group is somewhat misleading (see below).

The NPI’s Monitoring Poverty and Social Exclusion series has been in existence since 1998, and has developed as new indicators have been added. The current set is in part informed by Responsibility for All: A national strategy for social inclusion, produced by the NPI in conjunction with The Fabian Society around the time of the production of the first UK NAPincl (Howarth et al, 2001). Its purpose, consistent with the fourth Nice criterion, was to consider a national strategy involving non-governmental agencies alongside government. It suggested specifying the minimum living standards citizens might expect, including minimum income standards and minimum service standards from both public and private providers. 
The organisation of the NPI indicators shown in Appendix 2 is slightly different from the Opportunity for All set, in that the low-income figures are treated en bloc. These include an indicator of material deprivation drawn from the BHPS, although it is of limited usefulness, giving figures for the number of households lacking two out of three consumer durables, video, freezer and washing machine (the NPI note that this is 'driven by data availability and somewhat arbitrary'). Thereafter the life course sequence is followed as in the Opportunity for All except that the sections for children and young people are separated, and the working adults section applies mainly to those over the age of 25. However, since both take a life course approach, it makes sense to discuss the indicators together under the age-related headings used by Opportunity for All.

In addition to the life course indicators, both Opportunity for All and the NPI have indicators at community level. Those in the Opportunity for All series cover employment rates in deprived areas, crime rates in high-crime areas, housing that falls below the set standard of decency, households in fuel poverty, life expectancy at birth, the attainment gap at Key Stage 2 and casualties in deprived areas.

In the NPI set, the 'community' or 'social cohesion' indicators include non-participation in a range of organisations: trades unions, professional associations, environmental groups, parents'school associations, pensioner groups, community groups, tenant/resident groups, women's groups, religious groups, sports clubs, social groups and political parties, with the data drawn from the BHPS. Notwithstanding the criticisms of an over-focus on paid work in government approaches, and the consequent incorporation of indicators on the quality of work, the justifications for the inclusion of this indicator portray voluntary activity as a means to, or a substitute for, paid work rather than a valued activity in its own right:

Social networks are a means of finding paid employment and other forms of occupation. A lack of contacts has been shown to prolong unemployment. The long term unemployed often have low levels of social engagement beyond their immediate families. Policies aimed at reducing poverty and social exclusion through paid work depend partly on fostering networks between the employed and unemployed. (NPI, 2006)

For people for whom paid work is difficult to find, or inappropriate as in the case of pensioners, other means of participation can help to fulfil the basic human needs for a sense of competence, worth and socialisation. These range from political parties, trade 
unions and tenants groups to social groups and sports clubs. People's local communities can provide numerous opportunities both for help and for the chance to help. (NPI, 2006)

Access to services constitutes a separate sub-section in the 'community' section of the NPI report, which is comprised of transport, not having a bank account, and not having home insurance (indicators 45, 46, 47). This section also contains a series of indicators on the quality, cost and precariousness of housing. Although there are more indicators on these topics included in the NPI report, they are in many cases assessed by the report's authors as of only medium or limited robustness.

\section{Children}

In 2004, of 59.8 million residents in the UK, 11.6 million, or nearly 20\%, were under the age of 16. The Opportunity for All section on children, as for all groups, includes several indicators of income poverty. Although the measurement of child poverty is changing to include a combination of low income and material deprivation, as yet no indicators of the latter are incorporated into the Opportunity for All series. Attempts have been made to construct a time series using proxy measures from FACS and the new section of the Family Resources Survey (FRS) (Willitts, 2006). The health indicators mainly apply to younger age groups: infant mortality, child protection registrations, obesity in the under 10 age group, smoking in the under-15s. The serious unintentional injury indicator similarly only applies to those under the age of 16. There is a range of indicators of development (for Sure Start areas only), access to education and educational attainment. Households in temporary accommodation and those in non-decent housing are counted. However, there are no servicerelated or participation indicators included. Specific attention is given to the outcomes for looked-after children and for teenage parents.

Monitoring Poverty and Social Exclusion has a smaller number of indicators for children than the Opportunity for All set, grouped under the headings of economic circumstances, health and well-being, and education. It addresses some of the most serious exclusions, including not only permanent inclusion from school but incarceration in young offenders’ institutions.

A further relevant set of indicators is the Every Child Matters framework, which similarly identifies a range of domains, topics and ultimately, indicators. Originally designed to provide indicators and targets related to the development and well-being of children, the domains and topics are data and target driven rather than theoretically derived. Cross-cutting inequalities of 
ethnicity, neighbourhood deprivation, gender, disability and family background (including occupation, family type and income) are treated as risk factors. Groups at acute risk of exclusion are also identified. Five domains are used. The framework is formulated to be 'positive' rather than a deficit model, as indicated by the language used in the original documents (shown here in brackets). Although the merits of this are clear, there are also risks: it can be read as exhortatory, placing too much responsibility upon children for effecting their own inclusion.

- Being healthy (Be healthy)

- Safety and security (Stay safe)

- Enjoying and achieving (Enjoy and achieve)

- Social and civic participation (Make a positive contribution)

- Economic well-being (Achieve economic well-being).

However, if we consider the domains in the ECM framework across the life-course and compare them with the Opportunity for All and NPI indicators, we can see that the latter offer almost no indicators on social and civic participation. There are no indicators of 'enjoying and achieving' for older people, and only the lack of NVQ Level 2 qualifications for those of working age. Indeed, there are very few indicators for older people at all.

The Every Child Matters framework does draw attention to a range of issues and indicators that are important in discussing the inclusion and well-being of children (and potentially of other age groups). Compared to other and earlier strategies, the Every Child Matters framework aims to be much more comprehensive in its perspective on what are children and young people's needs and how to meet them. Consequently its avowed aim is 'whole systems change' (DfES, 2006a), both in respect of strategy and governance and of delivering children's services. The outcomes framework for its five domains (DfES, 2006b) contains 26 Public Service Agreements (PSAs) and 13 other key indicators, including some from the National Service Framework for Children, Young People and Maternity Services. Described as focusing primarily on early intervention and effective prevention, these range across health, social care, education, family and youth justice systems and environmental factors such as housing, road traffic and children's involvement in community regeneration. While necessarily brief and broad, arguably these targets and indicators reflect a contested interpretation of the key pathways towards achieving priority national targets and other indicators, in particular for children in poverty. 
For instance, the aims and targets associated with Enjoy and achieve are biased towards achieving, such as in achieving 'stretching national educational standards' at primary and secondary level, rather than enjoying. More interesting from a poverty and social exclusion perspective, is the aim included under Make a positive contribution that 'Children and young people develop enterprising behaviour'. This is related to the Department of Trade and Industry (DTI) national target of the percentage of 18- to 24-year-olds who are self-employed, manage own business or have thought seriously about starting their own business. Yet any judgements relating directly to children and young people's enterprising behaviours are lacking from the related inspection section of the outcomes framework, as they are from those provided for the domain Achieve economic well-being.

The framework thereby ignores the "overwhelming evidence" (Hobbs et al, 1996, p 16) for children and young people's extensive participation in paid employment. This issue is not only strongly linked to poverty (Middleton and Loumidis, 2001) and risks to children's health and educational attainment, but the area is also covered by more than 200 laws and by-laws currently in force (Better Regulation Task Force, 2004). This illustrates the Every Child Matters framework's lack of scope regarding important aspects of child well-being and social inclusion.

The scope of child indicators in poverty and social exclusion surveys is rather broader than this. For example, The 1999 PSE Survey children's indicators (see Chapter Four) are more extensive than either the 2005 Monitoring Poverty and Social Exclusion indicators (Appendix 1), or the 2005 Opportunity for All indicators (Appendix 2). These additional indicators, such as age-related participation in social activities, experience of bullying, temporary exclusion and additional indicators of material deprivation should be included among child indicators in future. A recent report by the Loughborough team for Save the Children (Adelman et al, 2003) contains the most extensive description of the nature of children's poverty and social exclusion in Britain employing PSE Survey indicators and data. Another report for Save the Children on child poverty (Magadi and Middleton, 2005) is based on the most recent BHPS data 1994-2002 and thus covers England, Scotland and Wales.

While respondents aged over 16 were included from BHPS wave 1 onwards, from wave 4 (1994/95) onwards a youth survey of children and young people aged 11-16 has been undertaken in tandem with the adult survey. Currently this is the only representative youth 
survey that covers issues related to poverty and social inclusion. This invaluable source of data on children's direct experience of social exclusion has been analysed by Magadi and Middleton (2005, p 6) in terms of (a) relationships with friends and family; (b) pocket money and part-time work; (c) school experience and career aspirations; and (d) emotional wellbeing. All make excellent indicators of social exclusion.

Some other general surveys include indicators that appear to be relevant to the multidimensional measurement of children's social exclusion. The 2004 FACS (Lyon et al. 2006), employs additional indicators such as the 'number of food and meal items family were unable to afford' from section 10 on material deprivation, children's access to 'technology' and 'happiness' from section 14 on children's activities and leisure time and items from section 15 on child maintenance.

There are some significant gaps and omissions in pertinent indicators of the well-being of children. In its recent report, the Fabian Commission on Life Chances and Child Poverty draws attention (The Fabian Society, 2006, p 97) to the ONS (1999a) survey of child mental health, which established clear links between family income, housing quality and child mental health. Findings indicated that children in families on an income of less than $£ 100$ a week were three times more likely to suffer from a mental disorder than children in families living on $£ 500$ a week or more. Similarly, children in social housing were three times more likely to suffer from a mental disorder than those in privately owned housing. Such disorders and emotional and behavioural problems are linked to aspects of social exclusion such as stigma and discrimination, disrupted schooling and social isolation. Data from a three-year follow-up survey have recently been published, confirming these trends.

PSE Survey data demonstrate that social exclusion is more prevalent among families with younger children, yet the ONS data are confined to children aged 5-15. This suggests that the extent of such problems among children may be underrepresented. The British Medical Association's (BMA) report on Child and adolescent mental health: A guide for healthcare professionals (BMA, 2006) reported that 1 in 10 children between the ages of 1 and 15 has a mental health disorder, rising to $45 \%$ of those in local authority care. The report further argued that poverty and deprivation constitute major risk factors. In contrast the FACS child health data do not include mental health indicators and their creation would seem a valuable addition to those collected by the BHPS youth survey. 
Virtually all information about children in social surveys is collected from adults, and thus from proxy informants. There are considerable difficulties associated with the reliability of proxy informants (GSS, 1999a). This makes the BHPS youth cohort data even more valuable, but with the limitation of the lower age limit of the cohort being 11 years. Few qualitative studies have measured the impact of social exclusion on British children in childhood itself from a child's perspective: Middleton et al (1994), Davis and Ridge (1997), Roker (1998), Shropshire and Middleton (1999), who used data from 1995, and Ridge (2002). Some of these studies included children younger than 11 among the respondents. Shropshire and Middleton (1999) explored understanding of the economic world, immediate expectations and future aspirations among a sample of 435 poor children aged between 5 and 16 . They found that among the children in lone-parent and Income Support families, significant numbers worried about their families lacking money to live on, were reconciled to not getting the birthday presents they wanted, and, crucially, anticipated that they would take unskilled and low-paid jobs.

Such findings suggest not only that these children were 'learning to be poor', but also that they experience a considerable amount of worry and disappointment. Children articulated the impact of poverty and social exclusion with great clarity in Ridge's (2002) study. Young teenagers talked to her about feelings associated with experiences such as not being able to afford the 'right' clothes like their peers and being unable to participate in school trips. These themes were previously explored by Ashworth et al (19944a, 1994b) with focus groups of 130 children aged 8-16.

A study of life as a disabled child conducted among 300 children and young people aged 1219 by Davis and his colleagues (Davis et al, 2003) as part of the ESRC Children 5-16 research programme in the late 1990s highlighted the social exclusion and isolating attitudes children may experience, notably in education, whether mainstream or special. According to 'Irene', a girl in secondary school with a visual impairment interviewed for this study:

It's like they don't make you feel independent. Like they want to do stuff for you. It's like you want help, but you don’t want like charity.... (Davis et al, 2003, p 206)

It is now more generally recognised that the voices of children themselves should inform policy making if it is to be relevant and effective, as the pertinent sections of the 1989 UN 
Convention of the Rights of the Child and of the 1989 Children Act have become more embedded in policy and practice.

\section{Young people}

For young adults, there are in fact very few specific Opportunity for All indicators, despite that fact that the 15-24 age group includes 7.5 million people and makes up $13 \%$ of the UK population. Indicator 10 addresses 16- to 18-year-olds (not) in education or training. In terms of health, there is only the potentially health-related indicator of teenage conception in the children's section. However, the indicators for illicit drug use, listed under working-age adults, in fact apply to the 16-24 age group.

The NPI indicators for young adults are grouped into 'transitions to adulthood' and 'economic circumstances'. The 'transition to adulthood' indicators are, like those in the Opportunity for All report, chiefly concerned with education, employment and training, although Monitoring Poverty and Social Exclusion also provides figures on the numbers of young people with criminal records. Low pay (indicator 21) is also included in the section on young adults, perhaps a particular problem for those excluded from the minimum wage legislation. The NPI website also gives figures for the treatment of problem drug use and suicides. The inclusion of suicide is justified not, as one might expect, as a health outcome, or as the most extreme form of self-exclusion, but because "what makes suicide a particularly important issue in terms of poverty and social exclusion is the connection between suicide and socio-economic conditions” (www.poverty.org.uk/22/why/htm).

The NPI works on a wide range of projects. Their report on young adults' access to services, Sidelined, argues that "the needs of young adults are much wider than simply employment, education and training” (Howarth and Street, 2000, p 5). They cite housing, counselling, health services, personal support services, advice and information services. Moreover, while the new Connexions service is directed at 13- to 19-year-olds, Sidelined argues that specific service provision is appropriate and necessary up to the age of 25. This concern with services for young people is reflected in the SEU report Transitions: Young adults with complex needs, which says that "the transition to adulthood is more difficult if you also have to deal with one or more of the following issues: poor housing; homelessness; substance misuse; mental health issues; poor health; poor education or long-term unemployment” (SEU, 2005, p 8). The importance of appropriate services, considered not just in relation to age, but to language and cultural differences, is stressed in the BMA's report on Child and adolescent mental health: A 
guide for healthcare professionals (BMA, 2006). The BMA report also noted that mental health services are not tailored to the needs of young people, and this is a key barrier to their use. Young people are more likely to use local services that are open after school hours.

Recent years have witnessed an increasing recognition among policy makers and practitioners of the problems of youth social exclusion, deprivation and poverty as linked problems that require concerted and coordinated interventions if they are to be tackled effectively. This policy agenda was first laid out in the SEU's Bridging the gap report (SEU, 1999a) and in the subsequent Policy Action Team report on young people (SEU, 2000), and is reflected in the development of the New Deal programme for young people, the introduction of the Connexions service, and especially in more recent and far-reaching changes in youth policy and service provision as envisaged within the Treasury review of financial support for young people (HM Treasury, 2004), and in the youth Green Paper, Youth Matters (DfES, 2005a, 2005b).

As a result, and in addition to reforms of mainstream youth provision, the past decade has also witnessed the introduction of many targeted initiatives designed to address social exclusion among specific groups of vulnerable young people, including young people not in education, employment or training, teenage parents, children in care and runaways (SEU, 1999a, 1999b, 2002a, 2003a, 2005).

The main focus of policy interventions in recent years has therefore been on tackling the most extreme forms of youth marginalisation rather than addressing more widespread problems of low income and deprivation among young people (Fahmy, 2006a, 2006b). While the trends identified above reflect a shift towards a more holistic, 'joined-up' approach, the relationship between these targeted interventions and mainstream provision therefore needs to be reexamined to ensure that youth policy and provision is effective in preventing youth poverty and exclusion as well as in tackling its consequences (Bynner et al, 2004).

Recent policy, as embodied in the Every Child Matters agenda (for example, HM Treasury, 2003) and the subsequent Youth Matters Green Paper (DfES, 2005) has emphasised the importance not only of reactive measures to tackle youth exclusion and marginalisation, but also of preventative work to combat youth poverty and disadvantage. However, developing a more preventative approach also requires a better understanding of risk and protective factors 
- and effective approaches to prevention - based on a theoretically consistent taxonomy of social disadvantage and extensive interrogation of appropriate available data sources.

In their 1999 review of the evidence base on youth disadvantage Morris et al (1999, p 1) argued that:

There is a dearth of reliable evidence on the scope of disadvantage. Definitions of 'disadvantage' are diverse, the variables used to characterise young people are not uniform and individuals do not have unique identifiers that would enable them to be tracked as they move between different state systems. The extent, nature and development of multiple disadvantage across the primary and teenage years is thus hard to gauge, and tailoring programmes to tackle different facets of the problem is difficult.

There has undoubtedly been much progress in the measurement and analysis of youth poverty and social exclusion since Morris et al's study. This is especially so with respect to our understanding of the extent and dynamics of youth poverty and deprivation. Several recent studies have drawn on cohort and panel data to investigate the persistence of poverty across generations (Blanden and Gibbons, 2006), and the factors that predict poverty entry and exit among young people in the UK (Bynner, 2003; Blanden, 2006), and in comparison with other EU member states (Barnes et al, 2002; Apospori and Millar, 2003; Aassve et al, 2005). Nevertheless, many of Morris et al's observations remain pertinent in assessing the appropriateness of existing social exclusion indicators for young people. For this study, it is important to note several conceptual and methodological problems in the definition, measurement and analysis of youth disadvantage:

- varying definitions of 'disadvantage', each based on different theoretical constructs;

- confusion over causality and inference, specifically with respect to what constitutes a symptom, cause and consequence of disadvantage;

- different methods of scaling and quantifying those experiencing different aspects of disadvantage;

- the absence of individual identifiers making it impossible to establish the extent of multiple disadvantage across multiple data sources;

- the consequences of limitations in survey sampling methods in capturing the extent and nature of youth disadvantage; 
- the limitations of cross-sectional data in capturing the dynamic process of youth transitions.

These cast doubt on the conceptual and methodological adequacy of existing approaches to the measurement of multiple disadvantage among young people based on the social indicators included in the four sets above: the Laeken indicators, the Atkinson indicators, the Opportunity for All framework and the NPI/JRF Monitoring Poverty and Social Exclusion series. Each of these approaches is based on a suite of measures that typically include both causes of multiple deprivation (for example, low educational attainment), symptoms of material and social deprivation (for example, material and social deprivation), and outcomes of deprivation (for example, poor health). It is vital to distinguish theoretically between symptoms of material and social deprivation and its correlates (low income, poor health outcomes, low educational achievement). The relationship between multiple deprivation and its correlates is rarely unidirectional, and causal inferences derived from empirical analysis are rarely unequivocal. Nonetheless, it is important to distinguish young people's material and social well-being on the one hand, and predictors or 'risk markers' of youth deprivation and exclusion on the other (for example, educational/employment status, health status, etc).

Additional conceptual issues that need to be addressed in assessing the appropriateness of existing indicators of deprivation and social exclusion among young people include:

- differing understandings of disadvantage

- absence of youth-centred approaches to conceptualising 'exclusion'

- focus on indirect, income measures of poverty

- an overemphasis on indicators of labour market insertion (at the expense of the quality of social support networks and domestic transitions)

- overemphasis on 'risk markers'(rather than direct measures of exclusion).

These observations are reflected in the focus of the Every Child Matters framework especially with regard to the emphasis on indicators of labour market insertion and 'risk markers' (for example, teenage pregnancy) at the expense of developing a more holistic understanding of youth transitions. Greater emphasis is needed on indicators of the quality of young people's social relationships and transitions (for example, personal and familial relationships, social isolation and support, social participation, subjective well-being). Equally, the normative 
assumptions of existing indicators need to be explicitly acknowledged given the increasing diversification and de-traditionalisation of youth transitions.

A number of wider methodological issues are especially pertinent to the investigation of youth disadvantage. These include the inadequate sample sizes for detailed sub-group analysis, and the inappropriateness of household surveys as a sampling frame for investigating severe disadvantage. In addition, the limitations of existing categorising variables (especially of household type) in representing the diversity of youth transitions need to be acknowledged. As a result, it is extremely difficult to represent the fluidity and complexity of young people's transitions within conventional multi-purpose surveys.

\section{Working-age adults}

Most of the Opportunity for All indicators for working-age adults concern income and employment. The additional, health-related, indicators for this group as a whole are suicide rates and smoking, and rough sleeping (which is related to poor physical and mental health and premature death). The additional dimensions identified by the Atkinson indicators are largely absent. It is notable that although housing decency is an indicator of exclusion for children and young people, and for older people, it is absent from the list for those of working-age adults. Access to education or training is not covered, and nor is service provision or participation.

Responsibility for All: A national strategy for social inclusion (Howarth et al, 2001) was critical of the emphasis on work in the policy and assessment of social exclusion. Although the NPI, like the UK government, regards exclusion from or disadvantage in the labour market as a key aspect and cause of social exclusion, it nevertheless argued that supplementary indicators and policies are necessary:

The existing programme focuses heavily on getting people into paid work, but a more critical view of the jobs that are available is now needed. The quality of jobs and experience of work for many people is still very poor, undermining the effectiveness of what is being attempted. (Howarth et al, 2001, p 2)

People who face disadvantage entering the labour market often continue to do so when actually in work. (Howarth et al, 2001, p 7) 
One aspect of this is low pay. However:

Besides pay itself ... it will be necessary to look at other aspects of work: working conditions; access to training and opportunities for career development; democratic representation at work; pension provision; sickness and other benefits; freedom from discrimination; and time off for family commitments. (Howarth et al, 2001, p 8)

The second key area stressed in the report is service provision:

Access to high quality and affordable essential private services is critical to the quality of life. Two groups of essential services are distinguished in this report: basic services, including the utilities but also food; and enabling or infrastructure services including telephone, basic financial services, transport, and - increasingly - the internet. (Howarth et al, 2001, p 5)

In summary, it identified three areas (besides community and non-governmental organisation participation) where sustained attention was needed:

- The quality and experience of work at the lower end of the labour market

- The suitability, affordability and accessibility of essential private services

- The level and standard of mainstream public services enjoyed by lower income households, irrespective of where they live. (Howarth, et al, 2001, p 9)

Although the report does not focus on measurement, the corollary is that appropriate indicators would be needed in these areas. Some indicators have subsequently been incorporated into Monitoring Poverty and Social Exclusion.

For working-age adults over 25, there is a block of NPI indicators on low pay by gender, ethnicity, disability and economic sector. There are also indicators (see indicator 30) assessing insecurity at work: the proportion of those on Jobseeker's Allowance last claiming less than six months ago; those on temporary/part-time contracts wanting permanent/full-time work; and unionisation. Support at work (indicator 31) is indicated by access to job-related training. Health is represented by limiting long-standing illness, premature death, obesity and mental illness - none of which figure in the specific indicators for young people. Indicator 31a, adults without qualifications, includes those lacking basic literacy and numeracy skills. 
Bradshaw et al note that "both the policy and research literature on education and social exclusion focus almost exclusively on one dimension of exclusion - involvement in production via employment and/or training, which is seen as creating opportunities for consumption and the building of wealth” (Bradshaw et al, 2004, p 32). It has "virtually nothing to say about how education differentially affects participation in the political and social life of the community” ( p 33). The only exception to this is Parsons and Bynner’s 2002 study on behalf of the Basic Skills Agency. Bradshaw et al observe that although there is relatively little research in this field, “Access to adult and continuing, lifelong education has the potential to reduce social exclusion, as do a wide range of community-based projects aimed at both school-leavers and adults” (Bradshaw et al, 2004, p 32). Indeed, one could argue that such participation constitutes a form of inclusion, as conceptualised in Barnes et al's (2006) secondary analysis of the English Longitudinal Study of Ageing (ELSA) (see Chapter Four).

What is striking is the absence of non-work-related indicators for working-age adults, other than in the PSE Survey (discussed in Chapter Four). Questions of quality of life, addressed to a greater (although still limited) extent for other age groups need to be addressed across the population as a whole.

\section{Later Life}

The proportion of the UK population over state pension age in 2004 was nearly 19\%, or over 11 million people. Over a third of the population (34\% or 20 million people) were aged over 50. Despite the large and increasing size of this group, the Opportunity for All indicators for older people are sparse. Moreover, although these ostensibly apply to those over 50 rather than just those over state pension age, the three measures of low income apply to pensioners only. The indicators on non-state pension contributions apply to people of working age (and would more usefully be categorised in that earlier section, as a risk factor for later exclusion). For health, there is only 'healthy life expectancy at 65', and no assessment of the prevalence, for example, of limiting long-standing illness in this age group. There are two indicators of intensive home care and community-based services to those over 65, which might best be understood as access to specialised services. Whether enabling people to live at home necessarily reduces their social exclusion is a difficult question. There is one indicator of housing decency for those over 60, and one of fear of crime, also for those over 60. 
In the NPI set, for pensioners there is an indicator based on those without private income rather than working-age contributions to non-state pensions (thus an outcome rather than a risk indicator). Deprivation and health are included in the form of excess winter deaths and limiting long-standing illness. Additionally, this section addresses rural access to a range of services - GP surgeries, local shops, bus and taxi services - and those lacking a telephone (indicators 41a and 41b). These are bracketed under a sub-heading of 'isolation and support'. No indicators of these are used for younger age groups. Indeed, the problem of social isolation arising (in part) from living alone is generally seen as a problem for older people: Miliband (2006, p 9) argues that "Living alone in itself is not a marker of exclusion, but in conjunction with poverty, worklessness or health problems, living alone can reinforce an individual's exclusion from society. We have a duty to ensure the ageing generation does not become a lonely generation”.

Barnes et al (2006) use ELSA to look at the social exclusion of older people (again defined as those aged over 50). This constructs seven dimensions of social exclusion from ELSA. A number of key characteristics associated with multiple exclusion are not treated as aspects of exclusion in themselves, but as risk factors (see Chapter Four). This highlights the difficulty in distinguishing between risk factors and outcomes - both physical and mental health, for example, are outcomes as well as risk factors, as are mobility and income. Social support and access to age-specific services are not in the headlined dimensions.

The SEU report A Sure Start to later life (SEU, 2006), which draws substantially on the analysis of ELSA, covers a variety of themes. Like the ELSA report, social relationships are given a high priority:

... independence alone is not enough if we want to improve the quality of life of older people and tackle exclusion. Everyone, including older people, has the right to participate and continue throughout their lives having meaningful relationships and roles. (SEU, 2006, p 8; emphasis in original)

It also raises the issue of age discrimination. Moreover, the executive summary stresses the centrality of social relations and of participation in leisure, learning and volunteering - factors that might be deemed relevant to social inclusion in all age groups. Consultation with older people stressed "the importance of good relationships with family and friends, of having a role, feeling useful, and being treated with respect” (SEU, 2006, p 18). 
What is striking is the tendency to treat quality of life issues as constitutive of social exclusion once non-participation in the labour market is socially regarded as legitimate. The indicators used for older people thus point to issues that might be explored across a wider age range.

\section{Additional indicator sets}

Given the limitations of the main indicator sets on social exclusion, we also looked at some additional batteries of indicators. These included the Index of Multiple Deprivation (IMD), the Audit Commission's local quality of life indicators (2005) for use by local authorities, and the sustainable development indicators. It is notable that these indicator sets, like many others, are divided into different domains. However, the delineation of domains shows little consistency even between indices that touch on similar themes of deprivation and exclusion. The ascription of topics to domains is also inconsistent. We also looked at some new, exploratory research into the development of quality of life and well-being indicators that could be operationalised at an individual rather than an aggregate level.

\section{Index of Multiple Deprivation}

The IMD uses 33 indicators to measure deprivation in each of the 8,415 wards in England. These indicators are categorised into the seven domains of:

- income deprivation

- employment deprivation

- health deprivation and disability

- education, skills and training deprivation

- barriers to housing and services

- crime

- living environment deprivation.

\section{Audit Commission local quality of life indicators}

The Audit Commission have also developed quality of life indicators for use at the level of local government. Like the sustainable development indicators, these are often at area rather than individual level. Ten domains are identified:

- people and place

- community cohesion and involvement 
- community safety

- culture and leisure

- economic well-being

- education and lifelong learning

- environment

- health and social well-being

- housing

- $\quad$ transport and access

- other indicators.

The economic well-being indicators are again very focused on paid work. The percentage in low-income households appears as an indicator only for children and the over-60s, not for young people and adults of working age. The domain of education and lifelong learning focuses simply on education and training. There is, in fact, no indicator at all relating to lifelong learning. As with the sustainable development indicators, the environmental indicators are mainly area-focused, such as levels of key air pollutants. However, some perceived pollution and litter - could be used as indicators of area satisfaction. Health and social well-being includes limiting long-term illness and teenage pregnancy under the age of 18 , but actually no indicators of social well-being at all.

\section{Sustainable development indicators}

One of the least developed areas of indicators is that of quality of life and well-being, although these concepts recur in the social exclusion literature and in a plethora of government reports on social exclusion and related issues. The UK sustainable development strategy framework indicators address some relevant issues. There are 147 indicators overall, and 15 headline indicators (raising the problems noted above about priorities etc). They are mainly defined at aggregate rather than individual level. Besides environmental indicators such as greenhouse gas emissions and river quality, they include levels of employment, workless households, childhood poverty, pensioner poverty, education, health inequalities and mobility (walking/cycling). The topics also include social justice, environmental equality and well-being, although there are as yet no agreed indicators for these.

However, there is a growing body of work not yet incorporated into official indicators that looks at questions of quality of life and well-being, and indeed happiness (Nussbaum and Sen, 1993; Layard, 2005; Seligman , 2003; Donovan et al 2002; Kahneman et al, 2004). In the UK, 
the New Economics Foundation (NEF) has pioneered work in this area since 2001, with a dedicated centre set up in 2006 for the promotion of wellbeing and the development of appropriate measurement.

There have been many attempts to incorporate questions of sustainability and quality of life into macro-economic indicators, and consequently to demonstrate that collective well-being and quality of life had risen far less than Gross Domestic Product (GDP) in recent decades. The MDP (Measure of Domestic Progress) and older ISEW (Index of Sustainable Economic Welfare) are conceived mainly as alternative or complementary to GDP. The main areas of adjustment are deductions for environmental costs and social costs, and additions for the value of domestic labour. "Key differences between MDP and the ISEW are the inclusion in MDP of the costs of crime and family breakdown, and some adjustments to the methodologies used to account for climate change and resource depletion” (NEF, 2004, p 6). Income inequality has a negative effect on both ISEW and the MDP. It is included as a social cost as it reduces life satisfaction for members of society. (It also, as Wilkinson [1996, 2006] shows, reduces average life expectancy). Most of this work is at an aggregate, national level, rather than providing individual or household-level indicators. The emphasis in this report is on UK measures, but there are many similar attempts at re-calculating composite indicators of living standards elsewhere, at both national and international level.

NEF have also pioneered attempts to measure well-being at an individual level, although they themselves argue that more work needs to be carried out on the development of appropriate indicators. They argue that above a certain level of affluence, aggregate levels of well-being are not affected by economic growth - comparing 2002 to 1973, GDP had increased by 60\% and life satisfaction remained constant. Both rich people and those moderately well off are significantly happier than the 'seriously impoverished', but the differences between the first two groups are small. They cite ONS statistics suggesting that $10 \%$ of the population suffers from depression at any one time; and report claims that the percentage of the population thinking that "other people can generally be trusted" has dropped from $60 \%$ in the 1950 s to 30\% in 2000 (Shah and Marks, 2004, p 6).

The measure of well-being that they use is more sophisticated than a simple 'life satisfaction' question. It includes three aspects:

- life satisfaction, looking at satisfaction, pleasure, enjoyment; 
- personal development, for which there is as yet no standard psychological indicator.

Conceptually, this includes engagement in life, curiosity, 'flow', personal development and growth, autonomy, purpose, feeling life has meaning. Although the authors do not make this link, it could be related to Sen's notion of capability;

- social well-being - belonging to communities, positive attitude to others, pro-social behaviour etc. In spite of the reference to trust, social well-being is not the same as social capital: it is entirely based on individual perceptions and attitudes. (NEF, 2004, p 6)

The factors argued to be central to well-being are marriage or long-term cohabitation and intimate friend and family networks; exercise; education, which has little effect on life satisfaction, but does affect the other two variables; and living next to open green space. Work is treated broadly, to include voluntary and unpaid caring work: it is argued that voluntary work has a greater positive effect on well-being; that unemployment has large negative effects for both employed and unemployed people; and that inequality has a negative effect on well-being.

Since the 2000 Local Government Act, local authorities are empowered to take action that improves economic, social or environmental well-being in their area. NEF were involved in the development of the Audit Commission's quality of life indicators (Appendix 4) (Higginson et al, 2003). They have also piloted work on the tripartite measure of well-being in conjunction with Nottingham City Council, looking at the well-being of young people aged 7-19. 'Curiosity' was used as a proxy for personal development. The findings suggest that the three aspects are not reducible to each other, although self-esteem is key to all of them. They reveal substantial levels of unhappiness and depression, especially in secondary school pupils; a marked decline in curiosity during the secondary school years, especially for girls; and that the primary school with the best academic results was also the one with the highest levels of unhappiness. The data was not robust enough to examine the impact of poverty, but parental unemployment had a negative effect. The implications of the findings from this research are unclear, and it is in any case not nationally representative. It does, however, indicate new possibilities for developing measures of well-being, as well as suggest the kinds of indicators we might look for in existing research - perhaps especially proxies for self-esteem. NEF themselves recommend testing multivariate models on a larger scale, over a longer period of time, across all age groups and in specific settings (Marks et al, 2004). 


\section{Chapter four}

\section{Survey analyses of social exclusion}

We also looked at the major survey analyses that address the question of social exclusion. The principal sources are the PSE Survey, which was specifically designed to measure social exclusion, and secondary analyses of other data sets, such as the BHPS, FACS and ELSA. These studies are important both for conceptualisation of social exclusion and the resultant indicators, and for their substantive findings.

\section{Millennium Survey of Poverty and Social Exclusion}

Unlike all the other survey data sets reviewed for this study, the PSE Survey was specifically designed to measure poverty and social exclusion. It was, and still is, the only survey undertaken to measure social exclusion in Britain. Carried out in 1999, it built on the 1983 and 1990 Breadline Britain Surveys (Mack and Lansley, 1985; Gordon and Pantazis, 1997). In developing the PSE Survey, other surveys were referred to (for example, the European Community Household Panel (ECHP) Survey, and Small fortunes: The National Survey of the Lifestyles and Living Standards of Children). Focus group research also fed into the questionnaire's development, principally in terms of negotiating the list of items and activities that adults and children should have, and should not have to go without.

The survey exists in two parts. The ONS Omnibus Survey carried out in June 1999 included questions on the necessities of life for adults and children. The second part involved a followup survey of a sub-sample of respondents from the 1998-99 GHS, and was uniquely designed to give greater probability that people on lower income groups would be selected. The followup survey forms the main part of the PSE Survey; the survey asked respondents whether they (and their children) went without items and social activities through choice or lack of money. Additionally, respondents were asked an extensive range of questions relating to other aspects of social exclusion including questions on paid work, unpaid caring responsibilities, contact with friends and family, social support, participation in civil and political activities, access to public and private services, debt and exclusion from financial services, crime and harm, health, and disability. As a result, the PSE Survey provides the most complete coverage of domains and topics relating to social exclusion as identified in the B-SEM.

Gordon et al (2000) detailed the main findings from the PSE Survey; however, the most comprehensive secondary analysis of the PSE Survey appears in an edited collection by Pantazis et al (2006). The collection includes general chapters on the measurement of poverty 
and social exclusion; chapters on the processes that relate to poverty and social exclusion including paid work, debt, local services and crime; and other chapters on the risks of poverty and social exclusion for particular social groups such as children, young people and older groups. Beyond this edited collection there has been some secondary analysis of the PSE Survey focusing on specific issues such as preference (McKay, 2004); the housing needs of disabled children (Beresford and Oldman, 2002); poverty and social exclusion among children (Adelman et al, 2003); and also home ownership and poverty (Burrows, 2003). Due to the focus of our brief, this section will review the secondary analysis of the PSE Survey from Pantazis et al (2006) and Adelman et al (2003).

\section{Social exclusion: definition, dimensions and evidence}

In the original report by Gordon et al (2000, p 73) social exclusion was defined as:

A lack or denial of access to the kinds of social relations, social customs and activities in which the great majority of people in British society engage. In current usage, social exclusion is often regarded as a 'process' rather than a 'state' and this helps in being constructively precise in deciding its relationship to poverty.

Unlike other approaches to social exclusion that focus almost exclusively on poverty, lack of work, or area exclusion, the PSE approach extended the investigation of social exclusion to encapsulate social relationships by drawing inspiration from Townsend's (1979) work. As Levitas (2006, p 136) explained:

The PSE approach is more explicitly concerned with people's quality of life and the place of social relations in this - and the impact of poverty and (lack of) paid work on these social relationships.

Consequently, the PSE approach distinguished between four dimensions of social exclusion:

- impoverishment (exclusion from adequate income or resources)

- labour market exclusion (exclusion from paid work)

- $\quad$ service exclusion (exclusion from public and private services)

- exclusion from social relations (exclusion from social, civil, political participation, social support, social contact, confinement). 


\section{Impoverishment}

The PSE Survey employed a variety of measures of poverty including:

- income (OECD [Organisation for Economic Co-operation and Development] equivalised, PSE equivalised, Households Below Average Income [HBAI]);

- subjective poverty (respondents were asked: whether they considered themselves poor or whether they had lived in poverty for most of their lives, and whether they considered their household income to be below that necessary to keep a household like theirs out of overall and absolute poverty);

- lack of socially perceived necessities.

The main poverty measure used in the PSE Survey was the lack of socially perceived necessities. This measure, which is also known as the consensual poverty method, involved three steps (Gordon, 2006, p 43): first, establishing which items and activities were perceived by the public as necessities of life ${ }^{1}$ (see Appendix 5); second, identifying those who had an enforced lack of socially perceived necessities, that is, were going without because of money; and third, determining what levels of household income people ran a greater risk of not being able to afford the socially perceived necessities. (Further details of the statistical techniques used in the construction of this method can be found in Gordon et al. 2000, Appendix 2.) On this basis, 25\% of the population were found to be living in poverty in 1999, representing 14 million people in Britain. A further $2 \%$ were identified as rising out poverty and $13 \%$ were potentially vulnerable to poverty. Because the PSE Survey built on the previous Breadline Britain Surveys it was able to provide trends in poverty, demonstrating that poverty had risen from $14 \%$ of households in 1983 to $21 \%$ by 1990 but by the new millennium that proportion had risen still further to encompass almost one in four of all households.

\section{Labour market exclusion}

The PSE Survey found high levels of non-participation in the labour market. For example, $43 \%$ of adults ( $50 \%$ of women and $36 \%$ of men) were without work, and $34 \%$ (38\% of women and 30\%) lived in jobless households, leading Levitas (2006, p 137) to argue that "with such high levels of non-participation in paid work, treating this as constitutive of social exclusion becomes problematic" (emphasis in original). Nevertheless there is an expectation that paid work results in people being better off both financially and socially than those who are either unemployed or economically inactive. In this context, Bailey's re-analysis of the 
PSE Survey confirmed that "individuals in work have lower poverty rates than those not in work, and full-time workers have lower poverty rates than part-time workers” (Bailey, 2006, pp 170-1), although the benefits of work varied for men and women depending on which poverty measure was used. On the other hand the impact of work on sociability and social support was less clear: those in part-time work were less likely to have low levels of contact compared to those working full time or with no work while part-time workers (whether female or male) displayed the highest levels of support.

\section{Service exclusion}

One of the major strengths of the PSE Survey was its inclusion of questions on local services; respondents were asked how essential they considered a wide range of general and, agespecific, services normally either provided or subsidised by the council or private businesses:

- libraries

- public sports facilities, museums and galleries

- evening classes

- public/community/village hall

- hospital with an Accident \& Emergency (A\&E) department

- doctor

- dentist

- optician

- post office

- places of worship

- bus services

- train/tube station

- petrol stations

- chemists

- corner shop

- access to medium to large supermarkets

- $\quad$ access to banks and building societies

- pub

- cinema or theatre

- facilities for children to play safely nearby

- school meals 
- youth clubs

- after-school clubs

- public transport to school

- $\quad$ nurseries, playgroups, mother and toddler groups

- availability of home help

- availability of Meals on Wheels

- special transport for those with mobility problems.

Respondents were then asked whether they used these services and, if not, whether this was due to inadequacy, unavailability or unaffordability.

Fisher and Bramley's (2006) analysis demonstrated that general public services declined in usage over the 1990s (comparisons were made with the 1990 Breadline Britain Survey), and "this is associated with a decline in the proportion of people regarding these services as essential” (p 241). Some services such as doctors, post offices, supermarkets and chemists remained almost universal (and also essential) in 1999. Further "a pro-rich bias remained consistent for usage of demand-led leisure and information services over the 1990s, and in many cases this bias increased somewhat. Bus services remain pro-poor in their distribution of usage. Children's services display a mixed picture, with some shift in favour of higher incomes in the case of child care. Services for elderly people show a generally pro-poor pattern...” (p 242). The main obstacle to usage (particularly in relation to play facilities, school meals, youth clubs and public transport for children) was confirmed as unavailability and unsuitability rather than affordability but poor households "face poorer-quality services and that poverty reinforces constraints on service usage” (p 242).

Analysis of whether people excluded from local services were also excluded on other dimensions of social exclusion confirmed a mixed pattern. While service exclusion was only very slightly related to social participation, stronger relationships were found in relation to joblessness and poverty: 
Table 4.1: Association between service exclusion and other dimensions of exclusion

\begin{tabular}{l|c}
\hline Exclusion category & $\begin{array}{c}\text { Excluded from 3+ } \\
\text { service (\%) }^{\mathbf{a}}\end{array}$ \\
\hline Poor household (lacking 2+ social necessities) & 25 \\
Lowest quintile equivalent income & 23 \\
Jobless household (working age) & 22 \\
\hline Lack of social participation (4+ activities $^{\mathbf{b}}$ ) & 16 \\
Retired household & 16 \\
Not lacking social participation & 15 \\
With workers in household & 12 \\
Not lowest quintile & 12 \\
Not poor & 11 \\
& $\mathbf{1 5}$ \\
\hline
\end{tabular}

Notes: ${ }^{a}$ Exclusion from three or more services because not available or unaffordable. ${ }^{\mathrm{b}}$ From seven activities: evening out each fortnight; meal out each month; family meal each fortnight; visits to family each fortnight; go to pub each fortnight; attend church; guest at wedding, funeral etc.

Source: Fisher and Bramley (2006, p 217)

\section{Exclusion from social relations}

A pioneering feature of the PSE approach was its direct measurement of exclusion from social relations. It employed five themes ${ }^{2}$ :

- non-participation in common social activities;

- the extent of people's social networks and the extent to which they are socially isolated;

- the support available to individuals on a routine basis and in times of crisis;

- disengagement from political and civic activity;

- confinement, resulting from fear of crime, disability or other factors.

Analysis of the data relating to common social activities confirmed that with few exceptions, higher proportions of people claimed they were not participating because they did not want to rather than because they could not afford to. Nevertheless some social groups were worse affected by non-participation - young adults (aged 16-34), those aged over 65, women, single people with children, those without paid work, and those living in poverty. Poverty was established as a clear risk factor for reduced social participation, with those below $60 \%$ of the median household income being three times more likely to be non-participating in seven or more activities than those with higher incomes. 
The significance of lack of money was confirmed in the analysis of the follow-up question that probed for a wider range of responses to why people do not participate. This revealed that lack of money was the most cited response to why people did not participate in common social activities and that time constraints (of both paid and unpaid work) were also significant in reducing participation rates. Further examination of the relationship between equivalised income and lack of participation demonstrated declining participation with falls in income: "Below about £260 equivalised OECD income, social participation is increasingly curtailed" (Levitas, 2006, p 150). She added:

What this suggests is that whatever people say about not wanting too participate in, or not being interested in, particular activities, low income restricts participation, and does so progressively. Of course, no correlation can itself establish a causal link, but in the absence on any other plausible account of causation at work here, it seems reasonable to conclude that poverty has a direct impact on the levels of social participation. (p 151)

In relation to social networks and social isolation, the PSE Survey found that $18 \%$ of the population lives alone, affecting more women than men especially in the later years. Other findings on the degree of contact with friends and family revealed that:

- $41 \%$ of the sample does not have a relative outside the household whom they see or speak to on a daily basis;

- $9 \%$ of the population have no family member outside the household whom they see or speak to at least weekly;

- $1 \%$ has no effective family contact outside the household (that is, no family member they see or speak to at least once a year);

- $\quad 7 \%$ have no friend they see or speak to at least weekly;

- $3 \%$ have no friend they see or speak to at least yearly;

- just over $1 \%$ of respondents (all men) have neither a family member nor a friend with whom they are in contact at least weekly. (Levitas, 2006, p 142)

There were few differences between people living in poverty and those better off with regards to social networks, although contacts were biased towards the family for the poor and friends for the non-poor (Levitas, 2006, p 143). 
When asked what factors prevented them from meeting up more often with family and friends, the most cited factor was pressure of time; $27 \%$ reported lack of time due to paid work, $9 \%$ said lack of time due to childcare responsibilities, and $4 \%$ claimed lack of time due to caring responsibilities. Levitas (2006, p 148) wrote that "for more than one in four of the adult population as a whole (and thus a significantly higher proportion of those in paid work), employment is a brake on social contact and integration”.

As well as the degree of social contact, the PSE Survey tapped into the level of support respondents felt they would have in range of different situations:

- needing help around the home if in bed with flu/illness

- needing help with heavy household or gardening jobs

- needing someone to look after their home or possessions while away

- needing someone to look after children or an adult dependent

- needing advice about an important life change

- being upset because of problems with spouse/partner

- feeling depressed and wanting someone to talk to.

The analysis demonstrated that poor people had weaker support than others, across both practical and emotional indicators ${ }^{3}$. Poorer levels of support were felt by working-age jobless households, pensioner households, but the lowest levels of support were reported by those living alone. On the other hand, lone parents had relatively good levels of support. Indeed they reported the highest levels of emotional support in the sample. In assessing the impact of paid work on social support, Levitas found that people not in work but not living in a poor household had both the best practical support and by far the best emotional support. However, the small size of this group meant that caution had to be expressed in interpreting whether non-participation in paid work, when not accompanied by poverty, leads to social exclusion (the problem of small sample size is discussed further below).

\section{Degrees of exclusion}

No headline figure for the numbers of socially excluded was given by Levitas (2006), justified on the basis that the dimensions of social exclusion are not so closely related. The analysis did however attempt to look at the degree of exclusion by considering exclusion across eight dimensions: poverty, lack of paid work, living in a jobless households, service exclusion, non-participation in social activities, social isolation, poor social support, and civil 
and political disengagement. The analysis, which did not weight the specific indicators in order of importance, highlighted that the majority of the population was socially excluded on at least one indicator. Just under one quarter of the population (22\%) were excluded on four or more dimensions, that is, half of the eight dimensions considered. (see Figure 4.1).

Figure 4.1: Number of indicators of social exclusion and poverty ${ }^{\mathrm{a}}$ reported by PSE respondents, out of a possible eight

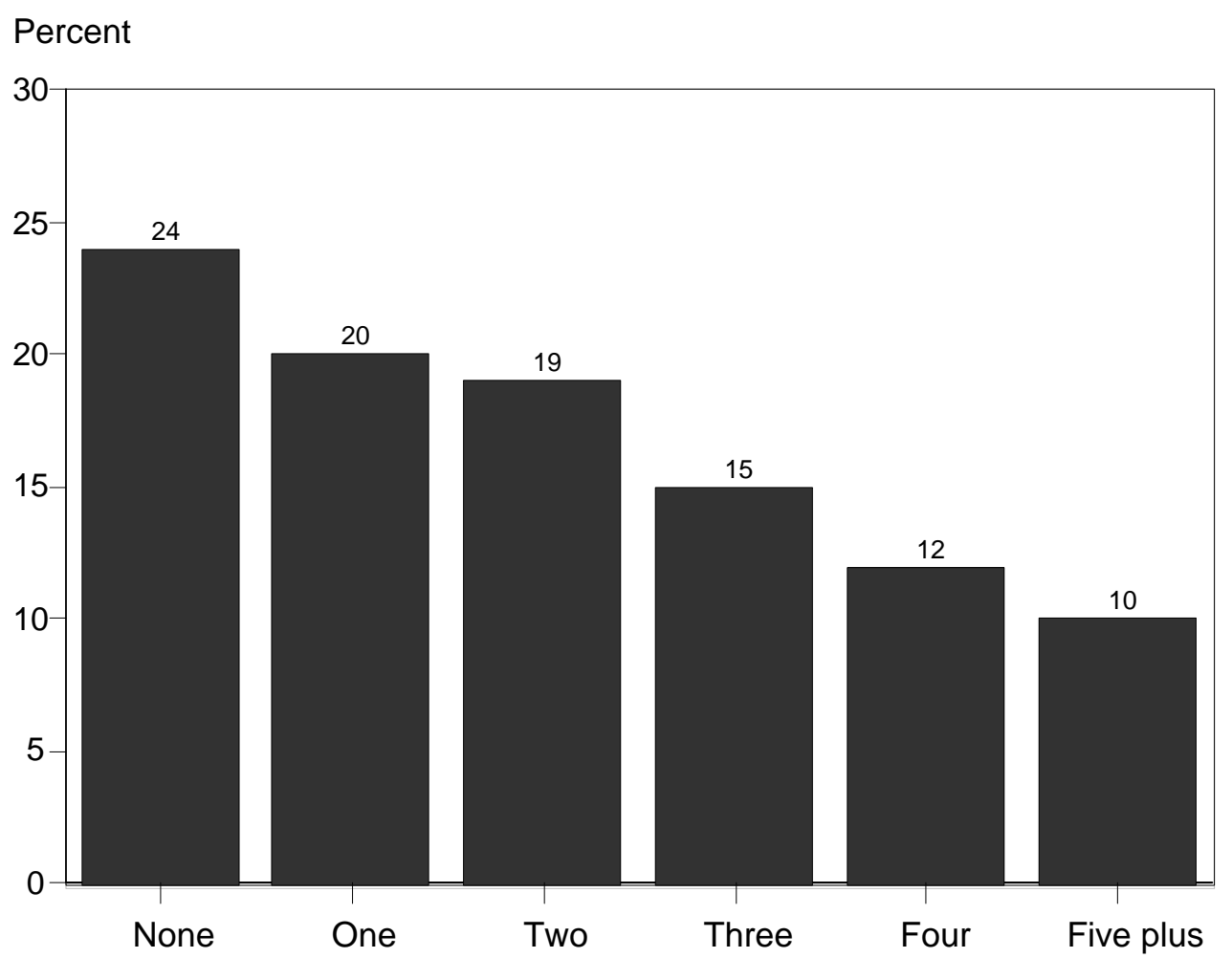

\begin{abstract}
*Note: Dimension included: (i) not in paid work; (ii) lives in a jobless household; (iii) is excluded from three plus services because unaffordable or unavailable/unsuitable; (iv) does not participate in five plus social activities for any reason; (v) has no daily contact with either friend or family; (vi) has poor support on four plus indicators; (vii) is not currently or involved in the past three years in civil and political activities (including voting); (viii) is poor (defined in terms of living in objective poverty, subjective poor or income poverty).

Source: Levitas (2006, p 154)
\end{abstract}

\title{
Children
}

Building on the previous Breadline Britain Surveys and the Small Fortunes study (Middleton et al, 1997), the PSE Survey contained direct measures of children's social and material deprivation. It also went further than its forerunners by adding a new dimension to children's experience of poverty and social exclusion by examining how resources are shared within households. 
Up to one third of children went without essential items activities, including three meals a day, toys, out-of-school activities or adequate clothing according the 1999 PSE Survey (Lloyd, 2006). Eighteen per cent of children went without two or more activities defined as necessities by the British population. The risk of poverty was higher for some children than it was for others. For example, while $42 \%$ of children in jobless households were going without two or more necessities, poverty rates were still high for those children living with earners; $37 \%$ of children in households with one full-time worker and $32 \%$ of children in households with full-time workers were deprived of at least one item. Poverty risks were higher for children in lone-parent households, children in larger families, children in minority ethnic households and those living in social housing. Nevertheless, analysis of the intra-household distribution of resources revealed that with the five items and activities considered, over $80 \%$ of children did not go without even if their parents did - suggesting that parents will attempt to protect their children from poverty (Lloyd, 2006: 331).

\section{Young people}

Fahmy's (2006a) analysis of young people (aged 16-24 and 25-34) provided evidence that youth transitions in Britain are becoming more "protracted, complex, and often more hazardous”. A greater proportion of young people reported below average incomes than among the sample as a whole. Furthermore young people were more likely to be necessities poor. The results were strongly gendered such that $43 \%$ of young women experienced poverty compared to 28\% of young men (Fahmy, 2006a, p 354).

Fahmy (2006a) considered other dimensions of social exclusion. Age differences were found in relation to local service usage but these tended to be related to usage. Young people were more likely to report dissatisfaction with local services compared to others, particularly in relation to community services such as GPs, opticians, buses and trains, for example. However, compared to all adults, young people were less socially isolated with fewer than 1 in 10 saying that their contact with family members is less than once a week. Nevertheless, Nevertheless, analyses of GHS data suggest that young people are less able to draw on their friendship networks in a 'crisis' than other working-age adults so that the impact of social isolation may be greater for young people than for older respondents (Fahmy, 2006b).

Exclusion from civic engagement and community participation were also investigated by Fahmy in some detail, confirming that "overall young people are somewhat less likely to 
participate in a range of social, community and political organisations than older age groups” (Fahmy, 2006a, p 363). Cronbach's alpha was used to assess the reliability of the indicators in the civic engagement index. Analysis demonstrated that young people were considerably less likely to be involved in the formal political process, but Fahmy states that the types of involvement considered in the PSE Survey captures the formal process of politics and underplays participation in the types of unstructured and informal political activity that are favoured by more marginalised groups. Thus, there should be scope in broadening the types of organisations and activities that would come under the umbrella of civic and political participation. The main findings relating to social exclusion for young people are illustrated in Table 4.2.

Table 4.2: Percentage of young people excluded using PSE approach, on a selected number of indicators

\begin{tabular}{|l|c|c|}
\hline Dimension & $\begin{array}{l}\text { Young } \\
\text { people, } \\
\text { aged 16-24 } \\
\text { (\%) }\end{array}$ & $\begin{array}{l}\text { Young } \\
\text { people, } \\
\text { aged 25-34 } \\
\text { (\%) }\end{array}$ \\
\hline Poverty & 20 & 11 \\
Below 60\% median OECD & 24 & 15 \\
Below 50\% median HBAI & 26 & 15 \\
Below 50\% mean PSE & 17 & 12 \\
Below Minimum Income Guarantee threshold & 11 & - \\
\hline Service exclusion & 30 & - \\
Dissatisfaction with social amenities & & - \\
Dissatisfaction with community services & & - \\
\hline Social relations & 7 & - \\
Social networks & 1 & - \\
Contact with family members: less than weekly & & - \\
Contact with friends/neighbours: less than weekly & 68 & \\
Civic engagement & 22 & \\
None & 10 & \\
One & & \\
Two or more & & \\
\hline
\end{tabular}

Source: Adapted from Fahmy (2006a)

\section{Older people}

A complex picture of the nature of pensioner poverty and social exclusion has been furnished by the PSE Survey data. For example, Patsios (2006) found not only that many pensioners clearly suffer from poverty and are excluded from participating in the mainstream life of society but also that poverty, deprivation and social exclusion are inextricably linked. His analysis confirmed that there are many ways in which pensioners can become cut off from 
society and impoverished. However, there was also evidence that not all pensioners suffered equally in terms of poverty and social exclusion.

The picture which emerges is of two very distinct groups of pensioners, each varying in the degree to which they experience poverty and social exclusion. A 'better-off' group, made up mostly of younger pensioners living in pensioner couple households, who experience low levels of poverty and social exclusion, and a 'worse-off' group, who are often female pensioners living alone, experiencing much higher levels of poverty and social exclusion. (p 453)

Moreover, the analysis revealed that older pensioners were more likely to report that they cannot afford to pay for elderly services (home helps etc) and they also have lower levels of participation in civic activities. Patsios concluded that poverty and exclusion are highest among single women pensioners, particularly younger single women pensioners, who are the poorest and most excluded group of all pensioners. Table 4.3 summarises the main findings of the pensioners analysis in relation to the main dimensions of the PSE approach.

Table 4.3: Percentage of pensioner households excluded using PSE approach

\begin{tabular}{|l|c|}
\hline Dimension & Percentage \\
\hline Labour market exclusion & 93 \\
Labour market inactive & 60 \\
Living in a workless household & \\
\hline Service exclusion & \\
Utilities & 7 \\
Utility disconnection & 2 \\
Restricted use of utilities & 2 \\
Borrowed money to pay for day-to-day needs & 8 \\
Use of public and private services & 16 \\
Public services unaffordable/unavailable (2+) & 28 \\
Private services unaffordable/unavailable (2+) & 7 \\
Public/private services unaffordable/unavailable (2+) & \\
Elderly/disabled services unaffordable/unavailable (1+) & 19 \\
\hline Social relations & 20 \\
Non-participation in common social activities- “can't afford” & 14 \\
Socially isolated - “no daily contact with family/friends” & 44 \\
Lack of informal support - “poor practical/emotional support” & 15 \\
Socially disengaged - “no current civic/political engagement” & \\
Socially confined - “affordability reason for not participating” & \\
\hline
\end{tabular}


Summary of strengths and limitations of the Millennium Survey of Poverty and Social Exclusion

The PSE Survey offers a number of potential advantages to social policy analysts in relation to the study of exclusion, including:

- It provides a close overlap with the domains identified in B-SEM. In particular, it has extensive coverage of social exclusion using four dimensions: (a) impoverishment; (b) labour market exclusion; (c) service exclusion; and (d) exclusion from social relations. The PSE Survey pioneered the direct measurement of social relations as part of social exclusion and includes extensive questions on the usage of local services - often a neglected dimension by other surveys.

- It contains direct measures of poverty for both adults and children covering a range of domains (for example, housing, health, food, clothing items and social activities). The FRS has now included questions relating to material and social deprivation, but this represents only a small sub-set of PSE Survey questions.

- It has reliable income measures and subjective measures of poverty based on UN agreed definitions.

- There are questions on choice which allows for an analysis of the extent to which individuals are going without certain items and activities through choice rather than due to a lack of money.

- It allows for the exploration of intra-household poverty and exclusion in relation to women and children.

- As the PSE Survey repeated some of the questions in the 1990 and 1983 Breadline Britain Surveys (for example, questions relating to the perception of necessities, material and social deprivation, subjective poverty, local services), there is the possibility of undertaking trend analysis.

- There is the potential for multivariate analyses (for example, general linear models, etc) across a range of themes relating to multiple exclusion (for example, health and wellbeing, crime and social harm, economic participation and social and economic resources).

- It over-sampled households in low-income groups.

- There is a self-reported element for sensitive topics e.g. sexual assaults.

The disadvantages of the PSE Survey in relation to the study of multi-dimensional exclusion include the following: 
- The sample size is relatively small and this limits the analysis of social exclusion for vulnerable sub-groups, for example, minority ethnic respondents and lone mothers.

- The response rate is lower than most surveys. This was most probably the result of the length of the questionnaire (Gordon et al, 2000).

- The 1999 PSE Survey is now relatively dated and there are no plans to repeat the survey.

- As with the majority of surveys, information was not collected directly from children in 1999.

- There is no longitudinal component to the survey, which is a disadvantage for certain kinds of statistical analysis, although such a component could be built into any repeat of the survey.

\section{British Household Panel Survey}

Unlike the PSE Survey, the BHPS was not designed to measure social exclusion. The indicators that have been used are therefore, like those in the batteries of single indicators, driven by a compromise between understandings of social exclusion and the availability of data.

There have been a number of secondary analyses of the BHPS that bear on social exclusion or on multiple disadvantage. The most important of these are Burchardt's 'Social exclusion: concepts and evidence' (2000); Taylor et al's Low income and multiple disadvantage 19912001 (2004), commissioned by the SEU, together with Taylor (2005), which provides an update for 1997-2003; and Barnes' (2005) Social exclusion in Great Britain. These three general analyses are considered in turn. In addition Save the Children UK has undertaken secondary analysis of the BHPS relating to child poverty.

\section{Social exclusion: concepts and evidence}

Burchardt proffers a working definition of social exclusion as follows:

An individual is socially excluded if he or she does not participate to a reasonable degree over time in certain key activities of his or her society, and (a) this is for reasons beyond his or her control, and (b) he or she would like to participate. (Burchardt, 2000, p 388)

This study draws on data from the first five waves of the BHPS, from 1991 to 1995. The response and attrition problems with the BHPS are clearly noted, as is the fact that, as a household survey, it excludes institutional and homeless populations. The results are adjusted 
with cross-sectional weights to 'correct' for non-response in individual years: the initial sample achieved a 74\% response rate. There are also longitudinal weights to adjust for the effects of attrition: $73 \%$ of those interviewed in the first wave gave an interview at the fifth wave. It is also noted that "the 'socially excluded"” may "have characteristics not controlled for in the weighting procedures that make them more likely to drop out of the panel”, although it is claimed that "the effect on results in not likely to be large" (Burchardt 2000, p 401).

The analysis identifies four dimensions on which participation is thought important: consumption, production, political engagement and social interaction. Corresponding indicators are drawn from the BHPS: low income; lack of engagement in a socially valued activity; not voting, and not taking part in any campaigning activity; and lacking emotional support. A single cut-off point was identified on each dimension. Partly because the BHPS does not collect data that would directly address the question of choice, these cut-offs were set at a low level: the assumption is that anyone who could participate more fully and wanted to would do so. The cut-off points are:

Consumption/ low income: less than 50\% mean equivalised household income

Production/socially valued activity: those 'socially included' are in paid work, education or training, caring for family, or over state retirement age

Political engagement: respondents count as included if either voted in 1992 election or are a member of a trades union, political party, parents' association or tenants'/residents' group

Social interaction: exclusion is lacking support on any one of five dimensions on which data is collected in the BHPS.

The data was subjected to both cross-sectional and longitudinal analysis. In 1991, less than two thirds of the population (61.6\%) were not excluded on any dimension. A total of $9.8 \%$ were excluded on two or more dimensions, and a tiny minority $(0.3 \%)$ on all four. This pattern held across the first five waves. The association between low income and the other dimensions is higher than between the other three. The production dimension carried the highest risk of multiple exclusion.

The longitudinal analysis showed that many more people suffered exclusion over time than in any single year. However, there is a continuum on each dimension between those 
experiencing exclusion in a single year and those excluded for two, three, four or five years. Burchardt concludes that "dividing the population into two groups, one who experience short-term and another who experience long-term or even permanent exclusion, would be misleading” (Burchardt, 2000, p 397). Long-term exclusion on a single dimension was associated with greater risk of multiple exclusion. In particular "those with low income at each of the first four waves were three and a half times more likely to be excluded on more than one dimension by wave 5 than those who had never experienced low income”. However, “[a]nalysis of the BHPS provides no evidence of a group of households cut off from the principal activities of mainstream society over an extended period of time” (Burchardt, 2000, p 400).

This limited study shows some of the possibilities of secondary analysis of the BHPS. The approach was extended in Burchardt et al (2002) to 1998, with similar results. However, the final negative finding can be understood in two ways. One is that the concept of deep exclusion is problematic, as exclusion is, generally, more widespread. Or, those who are at greatest risk of deep exclusion are not to be found in the household population.

Moreover, the number of dimensions in this exploratory analysis is small - very much narrower than the range of domains identified in other sources. The operationalisation is not differentiated by stage of the life course except in the treatment of those over state pension age. Here, bizarrely, everyone is treated as 'included' on the production dimension even if they are not participating in any of the specified ways. As Taylor et al (2004) comment, the additive approach is methodologically problematic. The 'index' is also limited in not including any indicators of housing, health or skill disadvantage.

\section{Low income and multiple disadvantage 1991-2001}

Taylor et al (2004) do not specifically formulate their analysis in terms of social exclusion, but similarly address the extent, and relationships between, disadvantage across a series of dimensions. Indeed, they regard social exclusion as conceptually unclear, and reiterate that the work does not constitute an index of social exclusion. The basis of their analysis is the first 11 waves of the BHPS, from 1991 to 2001. As in Burchardt (2000), the data is analysed as a series of repeat cross-sectional analyses over time, and as a longitudinal data set. The longitudinal data set is divided into two five-year periods, 1991-96 and 1996-2001. It is also analysed separately for those of working age and those over the state retirement age. One of the peculiarities of this analysis is that being on a low income is defined not by reference to 
the usual $60 \%$ median equivalised household income (or, for earlier studies $50 \%$ of the mean), but in terms of falling in the lowest quintile of the income distribution. This may have affected the correlations between income and other aspects of disadvantage. However, since the proportion of national income calculated after housing costs accruing to the bottom quintile was constant at $6 \%$ across the period in question, and that accruing to the bottom $50 \%$ of the income distribution remained constant at $25 \%$, any effects are likely to have been small.

The analysis uses a wider set of dimensions of disadvantage than Burchardt (2000). Nevertheless, the data is limited to that collected in the BHPS, and the authors note that there are areas of exclusion not covered, notably 'access to health and transport services, homelessness, participation in crime, drug abuse, and journey time to the nearest shop or post office'. The domains covered, and the indicators in each domain, are shown below:

\section{Low income}

In bottom quintile of income distribution

\section{Employment disadvantage}

Unemployed - currently not working and having to search for work in the previous four weeks

Workless household - living in a household in which no members are currently in work

\section{Education disadvantage}

Has no qualifications

\section{Accommodation disadvantage}

Lives in social housing

The number of persons per room

Accommodation suffers from lack of space

Accommodation suffers from lack of light

Accommodation suffers from inadequate heating

Accommodation suffers from condensation

Accommodation suffers from a leaking roof

Accommodation suffers from damp

Accommodation suffers from rot

\section{Health disadvantage}

Health limits the ability to climb stairs

Health limits the ability to walk for at least 10 minutes 
Health limits the amount of housework possible

Health limits the type or amount of work possible

Smoker - whether the individual currently smokes

Mental health score - General Health Questionnaire (GHQ) measure of mental distress

\section{Social isolation disadvantage}

Has no one who will listen

Has no one to help them in a crisis

Lives alone

The number of organisations in which active

\section{Material disadvantage and financial hardship}

Does not have access to a car

Does not have access to a colour TV

Does not have access to a VCR

Does not have access to a washing machine

Does not have access to a dishwasher

Does not have access to a microwave oven

Does not have access to a home PC

Does not have access to a CD player

Has problems meeting housing costs

Has been more than two months in arrears with their rent/mortgage

Cannot afford to keep their home warm

Cannot afford an annual holiday away from home

Cannot afford to replace worn furniture

Cannot afford to buy new clothes

Cannot afford to eat meat on alternate days

Cannot afford to feed visitors at least once a month

\section{Local environment indicators}

Accommodation suffers from problems relating to noisy neighbours

Accommodation suffers from problems relating to a noisy street

Accommodation suffers from problems relating to pollution

Accommodation suffers from problems relating to vandalism or crime.

There are substantial overlaps with our theoretically derived matrix B-SEM set out in Chapter Five, but also substantial gaps as a result of the data available in the survey. Moreover, 'living alone' is treated as an indicator, rather than a risk factor, for social isolation, as is living in 
social housing. The internal consistency of the indicators in each domain were assessed using Cronbach's alpha (with varying results) and the relationships between domains of disadvantage using Pearson's chi-squared, a non-parametric test for trend and Spearman's rank correlation coefficient. The analysis was partly concerned to address the question of whether disadvantage had become more entrenched over the time periods 1991-96 and 19962001. The conclusions for working-age adults and for pensioners are rather different, although a larger proportion of both groups experienced persistent low income in the 1996-2001 period compared to 1991-96.

For working-age adults, individuals generally became better off in each time period: the fraction experiencing disadvantage fell, the proportion with zero disadvantages rose, and the mean number of disadvantages fell. However, there was a rise in disadvantage in both periods for those entering low income. Like Burchardt, Taylor et al conclude that there is no evidence that disadvantage became more acute during this time period for working-age adults. Despite a general improvement in terms of the number of disadvantages for this age group, there was less evidence of improvement in terms of poor health and social isolation. Indeed, the health position of the bottom income quintile declined both absolutely and relatively over the time period. There are clear associations between low income, especially persistent low income, and the other domains. Although the position on non-income indicators improved both relatively and absolutely, this improvement slowed after 1996.

For pensioners, the analysis shows less encouraging results. Looking at the same people over time, their position deteriorated, although this is partly attributed to the ageing process. The average number of disadvantages experienced by pensioners increased. The deterioration was greater in the 1996-2001 period than in 1991-96. There was also an increase in the persistence of poor mental health for both working-age adults and pensioners. The relationship between different domains of disadvantage (including income) is more complex than for working-age individuals. Taylor et al (2004, p 148) suggest that the measures of disadvantage in the BHPS are not good indicators of social exclusion for pensioners.

The analysis also considers the interaction between dimensions of disadvantage, and especially their relationship to low income. For working-age adults, living in social housing, overcrowding, ownership of consumer durables, and lifestyle hardship were most highly correlated with income; mental health, subjective social isolation and living alone were least associated with income (Taylor et al, 2004, p 79). For pensioners, income was most closely 
correlated with living in social housing, ownership of consumer durables, lifestyle hardship, living alone, the number of organisations in which the individual was active and having no qualifications. Health indicators, housing quality, subjective local area quality, housing payment problems and the summary social isolation measure had only weak correlations with income (Taylor et al, 2004, p 94). An assessment of the relationship between a range of measures of disadvantage showed surprisingly low levels of correlation between different dimensions, apart from income, living in a workless household and living in social housing. There is evidence that the association between variables, including income, is not constant over time. In addition, Taylor et al and Burchardt comment at several points that the assessments of the level of disadvantage, and the associations between different dimensions, are highly sensitive to the precise definitions and thresholds used.

Taylor (2005) provides an updated analysis of the BHPS for the 1997-2003 period. This analysis looks at 10 indicators of disadvantage: unemployment; living in a workless household; lacking qualifications; living in social housing; overcrowding; poor mental health; poor health; living alone; lacking consumer durables; and financial stress. Unlike Taylor et al 2004), but like Burchardt (2000) and Burchardt et al (2002), the dimensions of disadvantage are treated additively. This analysis appears to be the basis of the results cited in Miliband (2006) claiming that social exclusion has diminished over this period. However, the author yet again stresses that the non-household population is excluded, and that the BHPS is not designed to measure social exclusion. (Martin et al, 2006, also comment on the absence from the study of any immigrant population since the launch of the panel in 1991). The analysis shows that the proportions of working-age adults and of pensioners experiencing multiple disadvantage declined over this period. However, it should be noted that this is measured against an absolute standard rather than against changing - rising - average living standards, and thus such a fall would be expected. Changes in the demographic profile between 1997 and 2003 of working-age adults experiencing multiple disadvantage appear to show an increasing concentration of disadvantage in the 35-55 age group, and a marked rise in the proportion of single men. This may be related to a policy focus on addressing child and pensioner poverty. However, the weighted numbers for those experiencing five or more disadvantages are low. Since the actual numbers in the sample will be yet lower, these results should be treated with caution. The problem of low numbers in vulnerable sub-groups is part of the reason for the recommendation in Martin et al's (2006) Strategic review of panel and cohort studies that the BPHS panel size be increased to 40,000. 


\section{Social exclusion in Britain}

Barnes’ 2005 study uses the BHPS data both for an analysis of social exclusion in Britain and a comparison with European data using the ECHP (European Community Household Panel) dataset. Following Room (1995, 1998, 2000) it approaches social exclusion both in terms of multiple disadvantage and persistence, thus using both cross-sectional and longitudinal analyses. Adapting Walker and Walker's (1997, p 8) definition, it defines social exclusion thus:

Social exclusion refers to the multidimensional and dynamic process of being shut out, fully or partially, from the economic, social and cultural systems that determine the social integration of a person in society.

It focuses on working-age adults, noting that there is a lack of information on children in the BHPS, and that the social exclusion of those over retirement age raises different questions. The cross-sectional and longitudinal weights are not used because they are designed for the full sample rather than this subset. It was argued in 1995 that not using the weights had no effect on the attrition rates for income poverty. This study assumes that the same can therefore be said of social exclusion, an assumption that may not be correct. The analysis covers nine BHPS waves from 1991-99. The study uses multivariate analysis based on logistic regression.

Seven dimensions of social exclusion are identified:

- financial situation

- ownership of durable goods

- quality of housing

- neighbourhood perception

- personal social relationships

- physical health

- psychological well-being.

Notably, labour market position is treated as a risk factor for social exclusion rather than a component of it. Thresholds are developed using both relative data drawn from the Poverty and Social Exclusion Survey (PSE) (see Gordon et al, 2000; Pantazis et al, 2006) and absolute levels. Again, an additive method is then used. In 1996, more than half the working-age 
population were disadvantaged on at least one indicator, but only $22 \%$ on two or more and $8 \%$ on three or more. Income poverty was again shown to have high correlations with other dimensions of disadvantage, but the links between other dimensions were again complex. Factor analysis suggested three groups: household economic deprivation; personal civic exclusion; and personal health exclusion. Numbers were insufficient to undertake further analysis of those disadvantaged in all three areas. However, 3\% of working-age individuals experiencing disadvantage fell in this category. Repeat cross-sectional analysis showed that the extent of disadvantage on the economic indicators declined in the 1990s (although the financial situation is measured against a fixed standard, so this is to be expected). Levels of physical health disadvantage rose during this period.

The sample for longitudinal analysis consists of those working-age adults who completed a full questionnaire at each of the nine waves of the survey, reducing the effective sample from the 7,041 in the first wave to 3,106. Although the proportions in each demographic category are not dissimilar to the original sample, the reduced sample size limits analysis. General and differential attrition means, for example, that the actual number of lone parents with dependent children dropped from 422 to 124 over the waves of the survey. Attempts are made to look at the duration of disadvantage in terms of occasional, recurrent, short-term and longterm persistence. The study looks at longitudinal multi-dimensional disadvantage. While 52\% of individuals were never disadvantaged on more than one indicator - that is, did not experience multiple disadvantage - 48\% were so disadvantaged. Twenty-one per cent suffered persistent long-term disadvantage, meaning disadvantage in at least seven out of nine years. Sixty per cent suffered persistent disadvantage, meaning disadvantage in more than two waves of the survey with a break of no more than one wave. Analysis by demographic groups was hampered by small sample sizes, notably "the low numbers of economically deprived individuals in the BHPS data set” (Barnes, 2005, p 124). Notably, labour market activity was associated with increased chances of experiencing persistent personal civic exclusion, especially in comparison with those caring for the home or family members. Only a very small minority, less than $2 \%$ of the working-age population, experienced persistent disadvantage across all three fields - a multiple exclusion that might map on to the notion of deep exclusion. Although further analysis of the characteristics of this group was attempted, given the total numbers in the overall sample this is based on 30-60 individuals.

Barnes (2005, pp 178-9) points out that the range of information collected in the BHPS is less comprehensive than in the PSE Survey. Other problems identified with the BHPS are 
“comprehensiveness, consistency, time-span, geographical detail, survey coverage, attrition and sample size” (Barnes, 2005, p 185).

\section{Britain's poorest children revisited: evidence from the BHPS (1994-2002)}

Magadi and Middleton (2005) used BHPS data and net household income variables. Their study used three waves of the BHPS that have become available since 1999. It provides an update on earlier work on Britain's poorest children (Adelman et al, 2003), which used two data sets: the 1999 PSE Survey and the first nine waves (1991-99) of the BHPS. Compared to the earlier study Britain's poorest children revisited provides supplementary data in respect of four areas that had been found to be particularly policy relevant after the initial study was published. These are:

- the proportion of children in severe and persistent poverty;

- characteristics of children in severe and persistent poverty;

- persistent and severe childhood poverty and household exclusion; and

- persistent and severe childhood poverty and young people’s social exclusion.

"The analysis is based on experience of poverty, over a five-year period, among children and young people aged below 20 years” (Magadi and Middleton, 2005, p xii). The definitions used were the same as for the 2003 study. Children in households with income below $27 \%$ of the median income were classified as living in severe poverty, whereas non-severe poverty was considered to be affecting children living in households with an income below between $27 \%$ and $59 \%$ of the median. Children living in severe and persistent poverty were classified as those living for three or more years in poverty and at least one year in severe poverty.

The general advantages of the BHPS in relation to the study of multi-dimensional exclusion as it affects Britain's children include:

- that young people aged 16 and over have always been included in the BHPS;

- the sample of BHPS child cohorts between 1994 and 2002 was constructed in such a way that each child was observed for five years, from different starting ages. Starting with children below one year, this eventually spanned cohorts from a starting age of 5 , 10 and 15 years; 
- from wave $4(1994 / 2005)$ onwards proxy informants are no longer the only ones used for data on children and young people aged 11-16, but a sub-sample of this age group is also included for interviewing;

- the 2005 Centre for Research in Social Policy (CRSP) report provides an analysis of social exclusion of children and young people aged 11-16 that is based on data from this youth component of the BHPS. Two-generational data on the nature and experience of social exclusion as it affects children and young people aged 11-16 are therefore available and strengthen reliability of the data and therefore the authoritativeness of the analysis;

- the areas covered by the BHPS are quite comprehensive in terms of families' poverty status and access to employment, savings, benefits, housing, as well as local area data and data on family composition and any changes in such factors; all these factors are pertinent to children; and

- the BHPS analyses include data on part-time work, schooling and pocket money, as well as children's subjective experiences such as relationships with family, with friends and with teachers.

The general disadvantages of the BHPS in relation to the study of multi-dimensional exclusion as it affects Britain's children include the following:

- the BHPS data do not cover material deprivation in depth;

- it should be possible to collect data directly from children below the age of 11 , certainly from children aged 7 upwards. The BHPS has yet to do this; and

- despite its longitudinal aspect, the BHPS does not supply data by which children's educational and economic achievements can be assessed. This would allow an analysis of the impact of social exclusion.

\section{Families and Children Study}

There have been a large number of secondary analyses of FACS data. They include the following types of reports:

- Four studies with 'findings' from waves 3, 4, 5 and 6 of the FACS have been published by the National Centre for Social Research (NatCen) since 1999. These also count as DWP research reports. The latest of these is by Lyon et al (2006) on the 2004 FACS data set. 
- Twenty-two research reports using FACS data, other than the 'findings' reports, have been published by the DWP since 2001 in their Research Report series.

- Six 'in-house' reports using FACS data have been published by the DWP since 2001.

- Nine DWP working papers have been published by the DWP since 2002 using FACS data.

- Four refereed journal articles have been published in the UK.

- There are also five technical reports on waves 3, 4, 5 and 6 of the FACS that have been published by NatCen since 1999, and all wave guides, questionnaires and other associated technical details are available from the UK Data Archive.

- The HM Revenue and Customs Analysis Team have also made use of FACS data in recent reports on take-up of Tax Credits.

- Several recent studies emanating from the Institute of Fiscal Studies have made use of FACS data. These include: Goodman and Myck (2005).

- Another recent secondary study making of the FACS data for the analysis of child poverty is Bradshaw et al (2006).

Despite the extensive use of this data set, most of the associated reports deal with material deprivation rather than social exclusion as related to poverty. A partial exception is the DWP Working Paper No 10 by Michele Calandrino (2003) which explores the 'consistent poverty' approach to poverty measurement with the help of FACS data. She argues that 'consistent poverty' resonates well with the common perception of poverty as exclusion from ordinary living patterns due to lack of resources. Deprivation indicators, defined as the enforced lack of material goods or social activities, aim at measuring living standards in a direct way. Given the wide range of data collected by FACS (see Appendices 6 and 7) it is perhaps surprising that it does not appear to have been specifically analysed in terms of social exclusion. There is clearly scope for such analysis.

The advantages of FACS are:

- The broad topic coverage includes material and social necessities, as well as housing and access to services;

- It has a relatively high cross-sectional response rate for a survey of this kind;

- It includes a longitudinal element; 
- It includes data on some critical life events, including change in personal relationship status, births and changes in employment status, as well as less common risk factors such as divorce and relationship breakdown;

- Some data is collected directly from children. FACS is one of the very few large-scale surveys to elicit information from children themselves specifically in relation to neighbourhood and access to services, social participation, and health and well-being; and

- The emphasis on children's services and policy interventions encourages evaluation of policy effectiveness and outcomes.

The disadvantages are:

- It has high attrition rates, especially for minority ethnic families, those receiving state benefits, non-working and non-home-owning families, who are all groups likely to be at increased risk of exclusion, which limits the reliability of longitudinal analysis; and

- There is quite a high use of proxy informants.

\section{English Longitudinal Study of Ageing}

Given the infancy of ELSA, secondary analysis in terms of social exclusion and multiple disadvantage is limited to Barnes et al's (2006) study. Their analysis measured the patterns of different forms of social exclusion among older people and examined the key risk factors, or indicators, of social exclusion among older people (50 years of age and older). This study draws on data from wave 1 of ELSA.

\section{According to Barnes et al:}

One of the great strengths of ELSA is that it covers a very wide range of topics including individual and household characteristics; physical, cognitive, mental and psychological health; housing, work, pensions, income and assets; expectations for the future; social participation and social support. This diversity is invaluable here, as examining the relationship between social exclusion and a wide range of other factors is key to the investigations in this study. (2006, p 14) 
One of the key aims of their study was to examine the multiple dimensions of social exclusion, in terms of the SEU's explanation of what social exclusion is, and how it might be measured. Barnes et al adopt the SEU's definition of social exclusion: "what can happen when people or areas suffer from a combination of linked problems such as unemployment, poor skills, low incomes, poor housing, high crime environments, bad health and family breakdown” (Barnes et al, 2006, p 12). They go on to state that, "since there is no universally agreed way to measure social exclusion, the choice of dimensions used in this study has been guided by the theoretical literature on social exclusion of older people and by current policy interests. These dimensions have been amended and built on as appropriate, taking the opportunities and constraints of the ELSA survey into account” (Barnes et al, 2006, p 16).

Using available data in ELSA, they constructed seven dimensions of social exclusion. Furthermore, each of the dimensions has a 'scoring mechanism' and a 'cut-off threshold' at which the authors suggest exclusion occurs. The dimensions and the percentage of older people excluded are as follows:

- social relationships ('frequency’ of contact and 'density’ of relationship with children, family and friends): $12 \%$ excluded;

- cultural and leisure activities (for example, going to a cinema or theatre): $11 \%$ excluded;

- civic activities (for example, membership of a local interest group, voluntary work, voting): $12 \%$ excluded;

- basic services (for example, health services, shops): 9\% excluded;

- neighbourhood (for example, safety and friendliness of local people): 13\% excluded;

- financial products (for example, bank account, pension): $10 \%$ excluded;

- material goods (for example, consumer durables, central heating): $11 \%$ excluded.

Comparing these findings to other studies of social exclusion such as the PSE Survey (Gordon et al, 2000; Pantazis et al, 2006) and SQOL OA (Survey of Quality of Life in Old Age) (Scharf et al, 2002) is problematic because the scoring mechanisms and cut-off thresholds employed in each study are different. Barnes et al's study relies primarily on differential scoring mechanisms depending on the particular dimension of exclusion under review, whereas the PSE Survey and SQOL OA relied more on binary scoring and resisted transforming raw answer categories into 'scaled scores'. For example, contact with a family member or friend was divided into two general categories: daily contact and weekly contact. Each respondent 
was given a score of 1 if they had contact with a family member or friend daily and 0 if they did not have contact. In ELSA scores could range from 1 (saw 'three or more times a week) to 0 (saw 'less than once a year or never'). The implications of the different scoring mechanisms, the creation of summative indices, as well 'cut-off' thresholds points at which someone is excluded means that the findings of ELSA need to be qualified, particularly if they are to be used to compare results with the findings of other studies of social exclusion and multiple disadvantage.

In order to examine the 'risk' factors for exclusion, Barnes et al carried out separate logistic regression analyses (using the same risk factors) on each dimension of exclusion. The following risk factors were closely related to a single dimension of exclusion:

- social relationships: living alone, having no partner, children or siblings or being unemployed;

- cultural activities: having poor health or feeling depressed;

- civic activities: having no private transport, feeling depressed or being unemployed;

- basic services: being older, having poor health, lacking access to transport (whether private or public), living alone or feeling depressed;

- neighbourhood exclusion: having poor health or living in a deprived area;

- financial products: having a low income, being non-white or renting accommodation;

- material goods: living alone, being older, not having access to a car or van or not owning their accommodation (Barnes et al, 2006, p 37).

Furthermore, results show that the risk factors were not the same for each of the dimensions. The factors with the widest influence over the dimensions were:

- depression (six dimensions, not material goods);

- $\quad$ poor health (related to five dimensions: not civic activities and financial products);

- living alone (related to four dimensions: basic services, material goods, social relationships and civic activities);

- membership of a non-white ethnic group (related to four dimensions: cultural activities, civic activities, financial products and material goods);

- renting accommodation (related to four dimensions: civic activities, neighbourhood, financial products and material goods); 
- not having access to a private car or van (related to four dimensions: social relationships, cultural activities, basic services and material goods);

- low income (related to three dimensions: financial products, material goods and cultural activities);

- being female (related to three dimensions: cultural activities, civic activities and financial products). (Barnes et al, 2006, pp 8-9)

The authors also examined 'multiple exclusion', which they defined as applying to 'those excluded on three or more dimensions'. Findings revealed that around half of older people are not excluded on any of the dimensions but:

- $\quad 29 \%$ are excluded on one dimension

- $13 \%$ are excluded on two dimensions

- $\quad 7 \%$ are excluded on three or more dimensions.

Their secondary analysis then carried out another a second stage of logistic regression analyses in order to determine the main 'risk' factors for 'multiple exclusion' among older people (on three or more dimensions only). Their findings revealed seven key characteristics that are most strongly related to an older person experiencing multiple exclusion:

- $\quad$ age (being 80 and over)

- family type (living alone, having no living children)

- health (poor mental or physical health)

- mobility (no access to private car and never uses public transport)

- housing tenure (rented accommodation)

- income (low income, benefits as the main source of income)

- telephone (those without access to a telephone). (Barnes et al, 2006, p 8)

In addition, their study showed that different forms (or dimensions) of exclusion were inextricably linked but that there appeared to be "no simple domino effect where exclusion in one area appears to link to exclusion in another and so on” (Barnes et al, 2006, p 9).

When compared with the B-SEM developed for this review (see Chapter Five), we find some key and interesting differences with respect to what were considered 'risk factors' of 
exclusion in Barnes et al's study. The following variables were considered as 'risk' factors, not 'sub-themes' as is found in the theoretical matrix:

- education

- main activity status

- health (self-rated)

- psycho-social well-being

- depression

- provide unpaid care

- household income

- use of public transport

- $\quad$ physical activity (exercise).

Furthermore, there was parity on the following 'risk' factors:

- gender

- age

- ethnicity

- tenure

- household type (family type).

The following variables did not appear as 'risk' factors in Barnes et al:

- social class

- religious affiliation

- $\quad$ some critical life events such as deaths, marriages and divorce.

Barnes et al also examined the impact of social exclusion on quality of life. Not surprisingly, they found that "there appears to be a connection between multiple exclusion and the quality of life/well-being of older people” (Barnes et al, 2006, p 10). Overall quality of life falls as the number of dimensions older people are excluded on increases. The aspects of quality of life defined in terms of self-realisation (optimism, life satisfaction, disposition, energy) appear to be most related to 'multiple exclusion'. Multiply excluded older people are also likely to report a lack of control over their lives (Barnes et al, 2006). 
In terms of the B-SEM, ELSA contains 'full' information for 21 sub-themes and 'partial' information for 13 sub-themes respectively. As the ELSA social exclusion data matrix shows, the data are strong as regards material/economic resources and weak as regards crime, harm and criminalisation and political and civic participation domains. A major gap in the data is the lack of any measurements of subjective poverty. This has been rectified and appeared in wave 2 of the data collection. Also, there is limited information on possession of necessities (only 11 household durables), participation in common social activities (only five social activities), and use of public/private services (11 basic services). There is also no follow-up on the reasons why these items are not owned, or why the respondents do not participate in common activities and/or use basic services.

Barnes et al were the first researchers to examine the social exclusion and multiple disadvantage of older people using ELSA data. However, they only used the first wave of data. As data from the second and subsequent waves of ELSA become available, other researchers will be able to build on this work. Subsequent analyses of ELSA data incorporating more than one wave will certainly allow for more in-depth analysis and better understanding of how social exclusion develops and whether it is short-lived or long lasting.

\section{Notes}

${ }^{1}$ Thirty-five out of the 53 adult items and activities were regarded as necessities by the population.

${ }^{2}$ Disengagement from political and civic activity and confinement were examined in the first report of the main findings of the PSE Survey (see Gordon et al, 2000).

${ }^{3}$ The first four items listed relate to practical support, the following three to emotional support. 


\section{Chapter five}

\section{Devising and Applying the Bristol Social Exclusion Matrix (B- SEM)}

\section{The Matrix}

We defined social exclusion and deep exclusion above in the following terms:

Social exclusion is a complex process operating across several dimensions or domains. It involves both the lack or denial of resources, rights, goods and services, and the inability to participate in the normal relationships and activities, available to the majority of people in a society, whether in economic, social, cultural or political arenas. It affects both the quality of life of individuals and the equity and cohesion of society as a whole.

Deep exclusion refers to exclusion across more than one domain or dimension of disadvantage, resulting in severe negative consequences for quality of life, well-being and future life chances.

These definitions have the advantage of not narrowly limiting the causal processes at work in social exclusion, or the factors that affect life chances. These are open to empirical investigation. The operational issue is then the identification of domains and dimensions. The direct measurement of quality of life and well-being is essential.

The three main areas in which the domains fall are those of resources, participation and quality of life. Of course there is a sense in which all the domains reflect aspects of quality of life. However, in line with the expressed interest of the SEU in direct measures of this, the existence of other government indicator sets (specifically, the Audit Commission's local quality of life indicators and the headline sustainable development indicators), and an expanding literature on themes of well-being and happiness, we have incorporated some topics relating directly to this theme.

\section{Resources}

The first Nice criterion refers to 'access by all to resources, rights, goods and services'. This is incorporated into our composite definition of social exclusion. There is an established understanding in the policy literature that 'resources' means far more than income 
(Townsend, 1979). It is reflected in traditional attempts to estimate the value of the 'social wage' (Sefton, 2002), but also in the bracketing together of resources goods and services. In line with the increasing recognition that family members and social networks are also a resource in both practical and emotional terms, we have divided 'resources' into three domains: material/economic resources; access to public and private services; and social resources.

\section{Domain 1: Material/economic resources}

The most obvious indicator of material and economic resources is of course income. The misconception that poverty is generally understood simply as a matter of low income arises from the apparent simplicity of using this as an indicator. In fact, the assessment of what constitutes 'income', and the collection of reliable data, are far from straightforward. There is, for example, an increasing literature on the importance of assets including, but not confined to, home ownership, which underpinned the establishing of child trust funds (for example, Kelly and Lissauer, 2000; White, 2001; White et al, 2006). Pension contributions may be treated either as assets or simply as an indicator of lowered risk of future poverty, and thus frequently appear as an indicator of social inclusion/exclusion (for example, NPI, Opportunity for All, Burchardt, 2000; Burchardt et al, 2002). Debt may be seen as the opposite of financial assets, and debt, problem debt and financial exclusion are also the subjects of an extensive literature (for example, Kempson and Whyley, 1999; SEU, 2004; Kempson et al, 2004; McKay and Collard, 2006). The lack of basic material necessities has also had an increasing profile in the assessment of poverty and social exclusion, most notably in the Breadline Britain Surveys (Mack and Lansley, 1985; Gordon and Pantazis, 1997; Gordon et al, 2000; Pantazis et al, 2006) but also in the measures used in government surveys such as FACS. Subjective poverty captures the sense of exclusion from 'normal' standards of living. The topic areas identified are listed below.

- Income. The drivers of social exclusion notes that "households with relatively low incomes were more likely than others to be socially excluded on all dimensions except isolation and lack of support” (Bradshaw et al, 2004, p 14). We have divided this into estimated income and components of income since it may be significant what kind of income data is provided in particular surveys.

- Possession of necessities (necessities differ for children). This is a direct measure of material deprivation, used extensively in the PSE Survey and now incorporated into the official measurement of child poverty, and into survey measures such as FACS. 
- Home ownership.

- Other assets and savings. This would include child trust funds for children, private pension contributions for working-age adults, receipt of private pensions for older peoples and other assets. There is an increasing interest in asset-based welfare, and the contributions to or receipt of private pensions is a recurrent theme in social exclusion measurement.

- Debt. The UK has very high levels of personal indebtedness. It is a particular problem for those on low income (see, for example, SEU, 2004).

- Subjective poverty. People's perception of whether they live or have lived in poverty, or whether their income is below the standard needed to keep their family/home out of absolute or overall poverty is an indicator in the PSE Survey.

\section{Domain 2: Access to public and private services}

Resources, as argued above, does not refer simply to cash incomes, nor indeed to privately owned and deployable assets. The importance of access to services, whether private or public, including utilities in the home, is recognised throughout the social policy literature. It is also specifically linked to the question of social exclusion in a number of key reports and surveys (for example, Howarth et al, 2001; PSE Survey; Monitoring Poverty and Social Exclusion). The IMD includes a section on barriers to housing and services, including the distance to specific services. Some services (such as transport; see SEU, 2003b) are relevant to all age groups. Others, such as childcare, youth services and home care services for older people may be age specific. In applying the matrix to individual data sets, it is important to be sensitive to the range of services on which information is available for different stage of the life course:

- Public services

- Utilities

- Transport

- $\quad$ Private services

- Access to financial services (includes access to a bank account).

\section{Domain 3: Social resources}

The Opportunity for All and NPI series between them raise issues about children who are institutionalised or otherwise placed in local authority care, while earlier SEU reports have focused on young runaways, 'looked-after' children and adult offenders (SEU, 2002a, 2002b, 2003a). We have amalgamated this concern into a single category of those separated from 
family and those who are institutionalised. While this does not necessarily betoken a lack of family support, it does mean that that support is not available on a day-to-day basis. There is an increasing awareness of the importance of social networks to individual well-being, including, but not confined to, the provision of social support. Questions on social support are now routinely incorporated into some surveys at national and European level. There is also a large literature on social capital, far too extensive to address here (but see Putnam, 2001). We have preferred the term 'social resources' to that of 'social capital', since the latter looks from the perspective of communities rather than individuals. Nevertheless, there are overlaps between the two. The extent and quality of social networks has also been argued to facilitate labour market participation (Demos, 1997).

- Institutionalisation/separation from family (includes looked-after children and all those in residential care, young offenders' institutions or prison. This will not generally be captured in household surveys);

- Social support (affective and instrumental);

- Frequency and quality of contact with family members/friends/co-workers.

\section{Participation}

Participation in economic, social, cultural and political life - or its absence - is a key feature of many definitions of social exclusion, as demonstrated earlier in Chapter Two.

\section{Domain 4: Economic participation}

As we have seen, access to employment is part of the first Nice criterion, 'Facilitating participation in employment and access by all to resources, rights, goods and services'. Employment is important as a route to access to material resources (domain 1) but there is not an absolute fit. Some in employment are poorly paid; some not in employment may have decent or even substantial incomes. It is often argued that paid work is inclusionary in its own right. But whether work is a positive, inclusionary experience depends partly on the financial rewards it brings, and partly on the nature and quality of working life. Consequently the NPI's Monitoring Poverty and Social Exclusion includes data on low pay and on working conditions.

Treating those outside the labour market as thereby socially excluded should be treated with caution: in 1999 about $43 \%$ of all adults were not in a paid job, and over a third lived in a 
jobless household. It is widely accepted that caring activities and unpaid work are also forms of economic participation.

This domain is relevant to all age groups. Children may be in paid work, or may be providing unpaid care, as may older people (DH, 1999). The effects of paid work and caring are not necessarily inclusionary. They may be exclusionary, as in the case of child carers who are unable to participate in the normal activities of their age group, or they may be ambiguous. These relationships can be tested empirically:

- $\quad$ Paid work - employed, self-employed, unemployed, non-employed

- Providing unpaid care

- Undertaking unpaid work

- Nature of working life (includes type of occupation and full-time/part-time status)

- Quality of working life (includes anti-social hours of work, nature of contract, leave entitlement, flexible working arrangements, benefits, workplace injuries).

\section{Domain 5: Social participation}

Several of the definitions in Chapter Two (definitions 6, 9, 10, 11) refer to social participation. Others refer to participation in normal activities (definitions 3, 7, 8). The Atkinson indicators include ‘social participation' as an area where indicators need to be developed. The dividing line between social participation and economic or cultural or political participation is of course difficult: work, politics and culture may or may not involve high-quality social interaction. We have here differentiated social participation, as the PSE Survey does, in terms of participation in common social activities. The ground covered here is similar to that of ELSA and Sure Start in later life, but extended from older people across the whole age range: Sure Start in later life emphasises the importance of meaningful relationships and roles, while Townsend (1979) argued that lack of resources might prevent people from carrying out normatively defined roles as parents, grandparents, children and so on:

- Participation in common social activities

- Social roles. 


\section{Domain 6: Culture, education and skills}

Two issues need to be considered here: cultural capital and cultural participation. Cultural capital is a concept that has its origins in the work of the French sociologist Pierre Bourdieu, where it is intimately linked to processes of social exclusion. These, however, are not principally about the exclusion of a disadvantaged minority from the mainstream, but about the maintenance of class domination by an elite. Cultural capital is of three kinds. Institutionalised cultural capital refers to such things as educational qualifications, and the topic areas identified here are principally of this kind. Objectified cultural capital refers to objects such as works of art, books, music and so on. Embodied cultural capital, however, refers to non-accredited, possibly tacit knowledge, and a range of tastes, dispositions, behaviours and demeanours acquired through participation in a privileged social environment. This latter form of cultural capital is likely to affect the extent to which institutionalised cultural capital can be 'converted' into economic capital by access to particular occupations or promotion within them (Bourdieu, 1984, 1997). Most empirical work on cultural capital has been in the field of education, and addresses the acquisition of formal qualifications. The topic areas that we have identified as associated with this are basic skills (which affect not just employability but have a much wider impact on social participation); educational attainment; and access to education. The conceptual relationship between cultural capital and social exclusion is addressed in Levitas (2004).

The question of cultural participation is slightly different. Of course what constitutes cultural participation is a complex area, especially in a multicultural society. But the development of an inclusionary strategy has been a major preoccupation of the Department of Culture, Media and Sport (DCMS) in recent years (for example, DCMS, 2001, 2003a, 2003b), as well as the Arts Council (Arts Council of England, 1999; Jermyn, 2001). In addition, the ESRC has recently funded a survey specifically addressing cultural capital and social exclusion that is theoretically rooted in Bourdieu's work, and looks both at cultural leisure activities (included here as a topic area) and at cultural tastes (see Cultural Trends, 2004, 2006).

We have also included internet access as a separate topic in the domain of cultural participation, as it involves access to knowledge, and acknowledges the potential significance of the 'digital divide':

- Basic skills (literacy, numeracy, competence in English)

- Educational attainment 
- Access to education (includes school exclusion, but also includes access to lifelong learning for working-age adults and older people)

- Cultural leisure activities

- Internet access.

\section{Domain 7: Political and civic participation}

Opportunity for All, Monitoring Poverty and Social Exclusion and the IMD include no indicators on political participation, and nor are such indicators proposed in the Atkinson series (see Chapter One). The Audit Commission's local quality of life indicators include the election turn-out at local level as an indicator of community involvement. Nevertheless, the definitional emphasis on exclusion from the political domain makes it important to seek indicators of political and social participation. Moreover, for older people, where the emphasis on paid work is diminished, civic activities form one of the seven dimensions derived by Barnes et al (2006) from ELSA. Secondary analysis of the BHPS also includes this dimension, as does the PSE Survey.

In general, where such information is collected, it is usually confined to asking the general population about participation in voluntary activity, group memberships and voting behaviour. We have included these topics here. However, given the focus on social exclusion, we have also included citizenship status and enfranchisement that would potentially identify more specific exclusions from the political process. Indicators of 'civic efficacy', of people's feeling of being able to influence decisions, would also provide some sense of subjective exclusion or its absence; a similar indicator is included in the Audit Commission's local quality of life indicators:

- Citizenship status

- Enfranchisement (voter registration and entitlement, as well as whether people voted)

- Political participation

- Civic efficacy (for example, feeling able to affect decisions)

- Civic participation, voluntary activity/membership (note that this will include active membership of faith groups).

\section{Quality of life}

All of the domains can be seen as aspects of quality of life. Consequently, many of the issues covered above are themselves incorporated into the Audit Commission's local quality of life 
indicators. However, there are some additional aspects of quality of life that are not captured by the resources/participation dimensions. And, as we have seen, quality of life looms large in the indicators of social exclusion generated by ELSA, once paid work is given a lower priority.

\section{Domain 8: Health and well-being}

The IMD includes a domain for health deprivation and disability at aggregate level. The quality of life indicators similarly include a domain of health and well-being, again at aggregate level. Monitoring Poverty and Social Exclusion includes a range of aggregate indicators for children (low birth weight babies, infant mortality, dental health, accidental deaths and teenage conceptions); for young adults (drug users treated and suicides); for working-age adults (premature death, limiting long-standing illness, mental health and obesity); and for older people (excess winter deaths). Health is treated as a risk factor for social exclusion in Barnes et al's (2006) analysis of ELSA. 'Being healthy' and 'Enjoying and achieving' (which maps on to aspects of well-being) are two of the five dimensions in the Every Child Matters framework. There is thus no dispute about the significance of this domain. Many of the topics above, however, are amenable to use only at the aggregate level, not at the level of the individual or household, and are thus not appropriate for a matrix evaluating survey data. The topics selected below are all ones where data might meaningfully be sought from individuals. In addition to the more conventional indicators of physical and mental health and disability, as well as self-harm that is particularly significant for young people, we have added some potential indicators of well-being based on the literature discussed in Chapter Three. Thus the inclusion of life satisfaction, personal development, self-esteem in this domain draws on the sustainable development indicators and the work by the NEF discussed above.

- Physical health and exercise

- Mental health

- Disability

- Life satisfaction

- Personal development (including for children, but not only for them)

- Self-esteem/ personal efficacy

- Vulnerability to stigma (for example, long-term receipt of means-tested benefits)

- Self-harm and substance misuse. 


\section{Domain 9: Living environment}

Homelessness and housing quality are included in most sets of indicators, and homelessness is identified as a domain in The drivers of social exclusion. Both the IMD and the Audit Commission's local quality of life indicators cover environmental issues and housing, as do the sustainable development indicators. Housing quality appears as an indicator to be developed in the Atkinson indicators. Housing that falls below the set standard of decency has recently been incorporated into the Opportunity for All series for children, young people and the over-50s, although it is mysteriously absent for adults. Monitoring Poverty and Social Exclusion includes several aggregate statistics on homelessness and housing quality. In addition most of these indicator sets identify neighbourhood quality, safety and/or satisfaction as an issue in disadvantage, as does Barnes et al (2006) and the PSE Survey. We have added access to open space to the more conventional indicators as it is associated with well-being.

- Housing quality

- Homelessness

- Neighbourhood safety (including traffic, atmospheric pollution, noise pollution)

- Neighbourhood satisfaction

- Access to open space (demonstrated as important to well-being).

\section{Domain 10: Crime, harm and criminalisation}

Crime occurs as a domain in the IMD, although simply as the aggregate incidence of four major groups of crime (burglary, theft, criminal damage and violence). It appears as 'community safety' in the quality of life indicators, here encompassing road traffic accidents that we have included above as an environmental consideration. The quality of life indicators also include, under 'community cohesion', an indicator of how far local residents think attacks on the basis of colour, ethnicity or religion is a problem in the area. Monitoring Poverty and Social Exclusion looks at victimisation rates, while Opportunity for All looks at crime rates in high-crime areas. Opportunity for All also includes figures on child protection registrations, while the Every Child Matters framework prioritises safety. However, it is not just children who may be subject to physical abuse within the home, but women and dependent older people. We have tried to capture the appropriate topics at an individual level in terms of exposure to harm as objective/subjective safety, exposure to bullying or harassment and discrimination. 
If these topics reflect the potentially exclusionary nature of being the object of harm, there is also precedent in the literature and in the indicator sets for regarding the perpetrators of harm as potentially excluded, stigmatised or criminalised. For example, Monitoring Poverty and Social Exclusion includes figures for the numbers in young offenders' institutions, and the numbers of 18- to 20-year-olds with criminal records. Again, moving from the aggregate to the individual level, and extending this across all age groups, we have included as potential indicators of social exclusion having a criminal record, or an Anti-Social Behaviour Order (ASBO), or being imprisoned.

- Objective safety/victimisation (this includes actual and risk of abuse within the home, for children and adults)

- Subjective safety, for example, perceptions and fear of crime (home and neighbourhood)

- Exposure to bullying and harassment

- Discrimination

- Criminal record

- ASBO

- Imprisonment.

\section{Risk factors}

It is in the nature of the interactive process of social exclusion that many of these dimensions constitute risk factors as well as outcomes. There are additional factors that are not in themselves dimensions of social inclusion/exclusion, but which may constitute risk factors. In using the B-SEM to assess the scope of individual surveys, we also need to check whether they collect data on the following risk factors:

- gender

- ethnicity

- social class

- housing tenure

- household composition

- religious affiliation

- critical life events 
Most, but not all, of these will be routinely collected in most household surveys. Religious affiliation is less routinely recorded, although may be very important in terms of forms of participation, especially as it intersects with gender, and in terms of discrimination. We have also included 'critical life events' as a risk factor. Especially in longitudinal surveys, information about these could potentially be important. Critical life events include bereavement, divorce or relationship breakdown (or divorce of parents), retirement and institutionalisation. They also include more potentially positive life events such as the formation of relationships (known to be important in lone parents leaving poverty), the birth of children or young people leaving home.

\section{Applying the B-SEM to survey data sets}

The matrix devised above is a tool for exploring the range of data on social exclusion available in existing data sets and administrative sources. Accordingly, we looked at 27 crosssectional, and longitudinal data sets (Tables 5.1 and 5.2) to locate usable indicators of social exclusion. In each case, besides addressing whether there is data on each of the topics identified, we needed to address the coverage of the survey with particular reference to potentially excluded groups.

Table 5.1: Major cross-sectional surveys used in the application of B-SEM

Title of survey

Annual Population Survey

British Crime Survey

Expenditure and Food Survey

Family Resources Survey

General Household Survey

General Household Survey (Elderly Individuals in Private

Households Supplement)

Health Survey for England

Home Office Citizenship Survey

Labour Force Survey

ONS Omnibus Survey

OPCS/ONS Survey of Psychiatric Morbidity

Poverty and Social Exclusion Survey

Survey of English Housing

Survey of Quality of Life in Older Age
Type

Repeat

Repeat

Repeat

Repeat

Repeat

Repeat

Repeat

Repeat

Repeat

Repeat

Repeat

One-off

Repeat

One-off 
Table 5.2: Major panel/cohort surveys used in the application of B-SEM

Title of survey

Avon Longitudinal Study of Parents and Children

British Cohort Study

British Household Panel Survey

English Longitudinal Study of Ageing

European Communities Household Panel Survey

European Statistics on Income and Living Conditions (EU-SILC)

Families and Children Study

Longitudinal Study of Young People in England

Millennium Cohort Study

National Child Development Study (NCDS)

Offending, Crime and Justice Survey

ONS Longitudinal Study - England and Wales

Youth Cohort Study
Type

Cohort

Cohort

Panel

Panel

Panel

Refreshed panel

Refreshed panel

Cohort

Cohort

Cohort

Refreshed panel

Panel

Cohort

The data matrix can be found in Appendix 7 and contains a key indicating whether the topic is covered by the survey, for each of our five population groups:

- Children

- Young People (16 to 24)

- Working Age Adults

- Older people 1 (50 to 60/65)

- Older people 2 (60/65 plus)

For each topic and population group we examined the extent of coverage (whether there was full or partial coverage of the topic), the source of the information (whether information relating to children was provided by children themselves or by adults on behalf children), and also whether the adult interviewee's information related only to themselves or their household.

\section{A survey of surveys}

Our brief also involved identifying the strengths and weaknesses of each survey data set in terms of the character of the achieved sample, the definitions used and the mode of data collection. Detailed descriptions of each of the 27 surveys reviewed can be found in Appendix 6. Our analysis and application of B-SEM revealed a number of possibilities for researchers interested in undertaking secondary analysis of these data sets, as well as various concerns. The main themes arising from our analyses are discussed below.

\section{Coverage of social exclusion topics}

The social exclusion domains and themes identified in the B-SEM are rarely all included in the major surveys reviewed by this study. All the surveys cover some aspects of social 
exclusion but, in general, often by the very nature of their remit, they tend to focus on specific areas or topics and consequently exclude others. For example, the Family Resources Survey (FRS) provides very detailed and reliable information on income and has since 2005 introduced a small sub-set of questions on adult and children's material and social deprivation, but it does not include questions on social relations. The Labour Force Survey (LFS) and the larger Annual Population Survey (APS) provide extensive coverage of issues related to the labour market, and also education and training but do not include questions on material and social deprivation or other aspects of social relations. The British Crime Survey has very reliable data on victimisation experiences but has relatively few questions on other aspects of social exclusion. The Home Office Citizenship Survey (HOCS) is an excellent resource for examining issues relating to social, civic and community participation, as well as for neighbourhood satisfaction and access to services. However, the limited range of classificatory variables within this survey - and in the case of income and benefits data shortcomings in the quality of the data itself - somewhat undermine its usefulness as a resource in investigating multi-dimensional exclusion within the B-SEM framework.

There are, however, some exceptions. The PSE Survey, undertaken in 1999 with the specific aim of measuring poverty and social exclusion, represents the survey closest to the B-SEM. All themes in the B-SEM are incorporated in the survey including crime, harm and criminalisation, which many other surveys fail to include. Crucially, the PSE Survey contains detailed coverage of material and social deprivation for both adults and children and has uniquely identified social relations as one of the key dimensions for understanding social exclusion and consequently includes extensive questions on social support, social contact and social participation.

With the exception of the 1999 PSE Survey, the BHPS provides probably the best overall coverage of the those themes relating to the B-SEM model including material and economic resources, access to services, social resources, economic, social, cultural and civic/political participation, health and well-being and the living environment. Only with respect to crime, harm and criminalisation are there significant gaps, although in addition the deprivation items are rather restrictive, and as discussed elsewhere the adequacy of the BHPS in relation to the B-SEM framework is somewhat undermined by relatively small sample sizes.

The next best general survey in terms of topic coverage is the GHS. The survey has reliable information on income, ownership of consumer durables, economic and social participation 
and support, civil and political participation, health and well-being, and also some limited data on the quality of the living environment. It does, however, contain some large omissions including an absence of questions on public and private services and also crime, harm and criminalisation. In terms of deprivation, only material goods and not social activities are covered in the GHS. Furthermore, GHS questions on consumer durables fail to differentiate between those answers where respondents lack items through choice and those going without because of affordability.

Beyond general surveys and, in relation to surveys specific to the different stages of the life course there are a few surveys containing relatively good data coverage. The Avon Longitudinal Survey of Parents and Children (ALSPAC), the Families and Children Survey (FACS) and the Longitudinal Survey of Young People in England (LSYPE) are all characterised by fairly comprehensive topic coverage. In particular, the FACS data provide relatively good coverage of material and social deprivation, housing and the built environment and access to services. Similarly, the LSYPE provides excellent coverage of young people's educational profiles and, as the cohort matures, of the economic and social position and social attitudes of young respondents. ALSPAC also provides good coverage of the sub-domains, although is relatively weak on income and material and social deprivation. The English Longitudinal Survey of Ageing (ELSA) also overlaps well with the B-SEM. The survey contains questions on all the themes included in the B-SEM, although it is has stronger coverage in some areas than in others. For example, it provides relatively good coverage of material and economic resources, social, economic and political participation, and also health and well-being, but has poorer coverage of issues relating to the quality of the living environment and crime, harm and criminalisation.

In reviewing data coverage of surveys, we additionally considered the inclusion of risk factors associated with social exclusion and also critical life events that may act as important triggers for social exclusion. While all surveys universally included coverage of risk factors such as gender, age, housing tenure, social class and so on, very few surveys included religious denomination. Similarly, with the exception of some surveys such as the PSE Survey and the GHS, few routinely collected information on critical life events such as bereavement, separation and divorce or pregnancy. Furthermore, very few surveys included additional local area data such as the IMD (Index of Multiple Deprivation) or ACORN (A Classification of Residential Neighbourhood). 


\section{Coverage of the institutional and homeless populations}

The most vulnerable of the socially excluded population in the UK resides in institutions or is homeless and, therefore, is not captured by any of the household surveys under review. The majority of the surveys carried out in the UK include only individuals in private households which means that a number of socially diverse, but exceptionally vulnerable, groups are missed by these surveys. These groups include all those in:

- hospitals (for example, the infirm, those with mental difficulties)

- secure accommodation such as young offenders' institutions, local authority homes for young offenders, secure hospitals, detention centres (for the young, asylum seekers), and adult prisons

- residential/institutional accommodation (for example, disabled children, older people)

- children’s care homes

- people living rough on the streets.

These groups experience multiple forms of exclusion or what could be termed 'deep exclusion'. For instance, the SEU (1998) report on rough sleepers showed that many rough sleepers were on the streets because they were forced to leave home, many came from local authority backgrounds or had been in prison, and that they faced serious physical and mental health problems including alcohol and drug addictions. Similarly, the SEU (2002b) report, Reducing re-offending by ex-prisoners, acknowledged that many prisoners have experienced a lifetime of social exclusion. It reported that compared with the general population, "prisoners are thirteen times as likely to have been in care as a child, thirteen times as likely to be unemployed, ten times as likely to have been a regular truant, two and a half times as likely to have had a family member convicted of a criminal offence, six times as likely to have been a young father, and fifteen times as likely to be HIV positive ... 80 per cent have the writing skills, 65 per cent the numeracy skills and 50 per cent the reading skills at or below the level of an 11-year old child. 60 to 70 per cent of prisoners were using drugs before imprisonment. Over 70 per cent suffer from at least two mental disorders” (SEU, 2002b, p 6).

There have been some specialist surveys on a few of these population groups, but these have tended to be one-off surveys and are now dated. For example, the last government-funded surveys of disability, covering adults in private households, children in private households, adults in communal establishments and children in communal establishments, were carried out between 1984 and 1988 (ONS, 1989). Similarly, the last national survey of prisoners was 
in 1991 (ONS), while the most recent survey of psychiatric morbidity among homeless people was in 1994 (OPCS, 1994). In 2000, the Health and Safety Executive (HSE) focused on the health and social exclusion of older people and included a sample of care home residents, but the sample did not appear to be representative of all care homes in England.

On the other hand, there are no national or large-scale surveys on some of these other vulnerable groups, for example, in relation to asylum seekers or refugee communities. Smallscale surveys have been carried out but these are unrepresentative of the total population groups (see, for example, Migration Resource Centre, 2006). Furthermore, trafficked people (including children traded as domestic servants, and women sold for prostitution), whose very existence is clandestine, are by definition impossible to survey. A separate, but related problem, is that even taking into account these omissions, household surveys may still not be representative of all groups and this will include other hidden population groups such as those without a legal right to reside in the UK (see also the section below on non-response).

\section{Information derived from proxy informants}

Many surveys we reviewed make use of proxy informants but there are often data quality issues from answers given by proxy informants. Interviews by proxy tend to fall into two categories: (a) where a carer or an adult relative living in the same household answers questions because the respondent is unavailable for interview; and (b) where an adult (usually the parent) answers questions on the circumstances relating to their children. In some surveys (for example, the LFS) up to one third of respondents will be proxy informants. This poses questions of data reliability. One study (Dawe and Knight, 1997), examining the quality of the information provided by proxy informants in the LFS, found that although there was close agreement on many questions between the answers given by proxy informants and those answers given by the subjects themselves, some questions - particularly those on income and number of hours worked - which require very detailed numerical information showed a poor overlap.

The majority of surveys containing proxy informants will involve proxies because the respondent is unavailable to take part; fewer surveys involve parents acting as proxy informants. Among those surveys requiring direct information on children and using parents as proxy informants, are the PSE Survey (parents completed questions on material and social deprivation experienced by their children); the GHS (parents answered questions related to the health and well-being of their children); and the FACS (main respondent answered 
questions related to the health, well-being and education of their children; main respondent provided partner data where the partner was not available for interview).

However, a growing number of data sets now include children. Sometimes this is in the form of booster samples but more often it is because only children or young people are included in the survey's population coverage. Examples include the Expenditure and Food Survey (EFS) where children aged 7-15 keep a simplified expenditure diary; the HOCS, which has included children's and young people's booster samples; the LSYPE, which involved young people aged 13-14 in its first wave; and the Offending, Crime and Justice Survey (OCJS), which involves children as young as 10 . While questions still abound in relation to the reliability of information provided by children (for example, self-reported offending studies have traditionally been seen as unreliable because children are thought to exaggerate their offences; see Coleman and Moynihan, 1996), computer-assisted interview methods (such as CAPI [computer-assisted personal interviewing] and CASI [computer-assisted self-interviewing]) may help improve the reliability of survey data involving children.

\section{Design effects and non-response}

If social survey data are to generate a balanced sample on which reliable inferences can be drawn about the wider population of interest, it is vital that respondents have an equal probability of selection and that all selected respondents agree to be interviewed. Only rarely, however, are surveys based on equal selection probabilities, either because researchers wish to deliberately over-sample specific population sub-groups to boost sample sizes (see above) or due to inadequacies in the sampling frame. For example, the postal address file, which is routinely used as a sampling frame in many large-scale UK surveys, does not indicate the number of people living at each address so it is impossible to ensure equal selection probabilities. As a result weighting is usually applied to correct for non-equal selection probabilities and differential response rates across the sample.

Nevertheless, although survey weighting is widely applied the topic remains relatively poorly understood in the social science community for a variety of reasons. First, commonly used software continue to provide biased parameter estimates and spurious levels of significance potentially with serious policy consequences (Crockett, 2006; Dale, 2006) ${ }^{1}$. Second, and perhaps of more fundamental significance, weighting strategies differ significantly across surveys depending on the sampling strategy adopted and the precision of parameter estimates will also vary within surveys depending on the focus of investigation. For example, where 
clustering effects are present stratified samples better reflect the underlying population than a simple random sample.

However, it is only possible to obtain unbiased estimates if the data includes primary sampling units and strata that often is not the case in the datasets reviewed here. Moreover, the effect of stratification in increasing the precision of estimates depends on the relationship between the characteristic of interest and stratification criteria. Survey weighting for nonresponse is usually undertaken on the basis of characteristics (such as household type, tenure, social class), which are strongly associated with various dimensions of exclusion. Plewis' (2004a) analyses suggest that this may increase rather than reduce the non-response bias of parameter estimates. Clearly the problem of sample non-response is especially important in relation to the B-SEM approach since it is well known that non-response bias is associated with these characteristics.

The nature of non-response bias in relation to panel and cohort studies is further complicated by sample attrition over time. It is also well established that in the UK differential sample attrition is associated with many of those factors either associated with multi-dimensional exclusion or themselves constituting dimensions of the B-SEM approach. For example, differential attrition rates in the 1970 British Cohort Study are associated with parental social class, employment status and educational achievement, household benefit receipt, parents' country of origin and housing tenure (Bynner, 1996). Similarly, attrition rates in the ECHP Survey vary by tenure, economic status, educational achievement, socioeconomic group (SEG), and income status, and multivariate analysis suggests that the odds of sample attrition among income-poor households in Northern Europe are around 30\% higher than for non-poor households (Behr et al, 2002; Watson, 2003). However, although it is possible to weight data to account for differential attrition in panel and cohort studies, the estimation of longitudinal errors remains a contentious one.

\section{Item non-response}

Item non-response refers to missing data for respondents on individual survey variables and is a major problem because non-response is rarely missing at random (MAR). A range of advanced solutions have been proposed including 'hot deck' imputation and regression imputation (see, for example, Carpenter and Kenward, 2006). However, their application in substantive social science disciplines remains limited, and this is a particular problem in 
relation to those categorical variables covered by the B-SEM approach, where straightforward imputation methods are not readily available (Dale, 2006).

Nonetheless, there is considerable evidence that simply ignoring missing data will substantially bias both parameter estimates and their statistical significance. This is a particular problem in cohort and panel studies where complete data may only be present for a relatively small subset of respondents or cases. As a result, parameter estimates may be substantially biased and sample sizes will frequently be too small to support statistically generalisable analyses. Fortunately panel and cohort data allow for robust imputation on the basis of comparison with other waves or sweeps of the dataset. Clearly, this is not so for the cross-sectional studies reviewed here.

\section{Sample sizes}

However, arguably the most important practical issue with regard to data quality in the analysis of multi-dimensional exclusion is that of sample size. As has been noted elsewhere in this report sample sizes in many of the 'large-scale' social surveys are rarely sufficient to facilitate detailed analysis of those population sub-groups most vulnerable to multidimensional exclusion as operationalised within the B-SEM context.

There is at present a clear trade-off between topic coverage and sample size in this respect. Many of the largest surveys covered by this review such as the APS, the LFS, the ONS Longitudinal Study (as well as the census Samples of Anonymised Records, or SARs) often contain sufficient samples of population sub-groups to allow for robust generalisation beyond the study sample to the wider population of interest. However, as the B-SEM data matrix illustrates, their topic coverage is often very limited since, partly as a consequence of their size, they are key multi-purpose surveys. Conversely, the most comprehensive topic coverage is associated with the national poverty surveys (for example, the 1999 PSE Survey and its predecessors) where sample sizes are usually too small to allow for robust estimation in relation to those population sub-groups most vulnerable to exclusion. Similar observations are pertinent in relation to opportunities for the spatial analysis of data relating to multidimensional exclusion within the B-SEM framework (which is beyond the scope of this review).

A number of strategies are available to at least partially compensate for these shortcomings in sample sizes. First, for those surveys based on a repeated cross-sectional design it is usually 
possible to pool samples across waves to increase sample sizes. This is of course dependent on the extent to which variable definitions are consistent across waves, which is in itself a major issue. The need for greater harmonisation in concepts, definitions, design and processing practices is now widely recognised (for example, ONS, 2004a). However, in addition to harmonisation across surveys, harmonisation across time is clearly critical. For example, until recently household-level data in most surveys were based on the concept of 'head of household', a concept that has now been superceded by that of 'household reference person', which no longer gives priority to male partners. In practice, such definitional changes can have important effects on the distribution of key classificatory variables, such as social class, which are used in the analysis of multi-dimensional or 'deep exclusion'.

Second, booster samples are increasingly used as means of facilitating analysis of relatively small population sub-groups. Several of the surveys covered by this review have benefited from inclusion of booster samples of this type - or from the over-sampling of groups vulnerable to poverty and exclusion as part of the overall survey design as in the 1999 PSE Survey. Surveys incorporating additional boosters for relatively small or 'hard-to-reach' population groups include: British Crime Survey, 2004-05 (minority ethnic group, young people); BHPS (Scotland, Wales); HOCS, 2003 (minority ethnic group, young people); OCJS, 2003 (minority ethnic group); 2000-01 SQOL OA (minority ethnic group). Nevertheless, there remains considerable scope for extending this approach to investigate the social circumstances of other population groups especially at risk of exclusion including, for example, lone parents, large families, unemployed people, people with disabilities, and so on.

\section{Administrative sources}

In addition to the survey data discussed in detail above, in this report there is a vast range of administrative information held by different government departments. There has been a great deal of interest in linking different data sets, both as a research resource and for policy purposes such as fraud detection. Several publications by the GSS address the potential use of administrative data (e.g.GSS 1999a, 2000). White et al suggested that longitudinal data would be improved by linking information from administrative sources to survey data, inasmuch as this is compatible with legal and ethical requirements. They argued that much greater use is made of administrative data in other countries, notably the US, Denmark and Sweden, and suggest "a review of methodological issues connected with this type of administrative data" (GSS, 2000, p 7). Such a review was undertaken by NDS in its first year of operation, 
reporting as Jones and Elias (2006). The justification and scope of the review were set out as follows:

\section{The development of administrative data resources}

Much important information about individuals and organisations is retained nowadays through the use of information technology. The capture and storage of the details of transactions between organisations and individuals has created resources with the potential to inform social scientific research directly or, via data linkage techniques, to enhance existing resources. Such data cover a wide variety of fields in both the public sector and private sectors, including demographics, consumer behaviour, education, social care and community support, crime, transport, health, taxation, social security, housing and migration. Via personal or organisational identifiers, data from different sources can be linked to generate rich resources for research purposes. However, the scope for data linkage may be restricted by ethical considerations surrounding the sensitive nature of the linked data, by legal requirements and by the resource costs of undertaking linkage.

There is a need to establish the scope, quality and potential that public and private administrative data can offer as research resources. Given the wide variety of administrative data, work in this area needs to be focussed on some important examples. Particular areas where attention could be directed include the registration and record system within the National Health Service, the Department for Work and Pensions Longitudinal Study of Benefit and Pension records and the Department for Education and Skills Pupil Level Annual Schools Census.

To progress work in this area, the following action is proposed:

An audit of the major administrative databases held by government departments and agencies will be prepared. This audit will report on the potential such data have to inform research on a range of issues (with particular emphasis on data quality and coverage), the accessibility of such data for different research purposes (data anonymisation, the need for 'safe-settings', etc), the feasibility of linking between different administrative data sources and with census and survey records. The audit will exemplify best practice linking already achieved or recently undertaken. This audit will be augmented by a study of public attitudes to data linking and the use of administrative data for research purposes. Work in this area will be undertaken as a close collaboration between the Economic and Social 
Research Council, relevant government departments/agencies and the Office for National Statistics (NDS, 2006, p 10).

This section draws substantially on the results of that review. A similar review specifically focusing on social exclusion would be a major undertaking. However, many of the same points would hold, and some of the difficulties of administrative data are particularly acute in relation to social exclusion. White et al (GSS, 2000) point out that administrative data sources generally cover a narrow range of information compared to survey data. This would be a particular drawback in the analysis of social exclusion, which, as indicated above, requires a wide range of types of information.

In addition to the UK NDS report, the disadvantaged groups team at the DWP has examined the potential of linking data sets more directly focused on disadvantage (Sheppard, 2006; Pleace and Bretherton 2006).

The methodological issues about administrative data overlap with those of applying to survey data, notably questions of coverage and data quality. In addition, there are legal and ethical issues concerning the use of data for purposes other than those for which it was compiled. These are particularly acute in relation to the potential merging of data sets. Such merging also poses technical challenges. Moreover, these areas of concern are not independent: the ethical and legal difficulties may also bear on the quality of data. These issues are discussed in general terms below. We then comment on some specific data sets that may be of particular interest in relation to social exclusion.

\section{Coverage}

Coverage is an issue for administrative data sets as well as for social surveys. Jones and Elias (2006, pp 66-7) argue that administrative data is perceived as providing $100 \%$ coverage of the target population. The data sets are consequently much larger: the DWP Longitudinal Study will contain 100 times the number of cases as the LFS. Problems of attrition are sometimes argued to be minimal, although Jones and Elias (2006, p 73) point out that matching errors can lead to potentially large losses of data.

Although one might assume that because they are not based on samples, such records are in some sense more 'complete'; this is not necessarily the case. The target population of administrative data sets does not always coincide with the population in which researchers are 
interested, and relevant groups may be omitted. For example, the Jobseeker's Allowance count omits those seeking work but not claiming benefits, and is thus a poor measure of unemployment compared to the LFS (which has difficulties of its own). The National Pupil Dataset (NPD) discussed below does not include pupils in the independent sector.

\section{Data quality}

The ESRC-commissioned review of longitudinal data sources endorses the principle of using administrative data sets, but again advises caution in relation to data quality:

The addition of administrative data to the datasets is seen by many of our respondents as hugely beneficial - a view which we endorse. Such identifiers as National Insurance numbers (NINOs) if added to longitudinal datasets would hugely enhance their research potential because of the wide range of DWP employment, income and benefits data that could be linked via them. However we are also conscious of the need for caution in seeing such data as some kind of panacea for augmenting longitudinal datasets and filling gaps in the longitudinal record. Apart from issues of data access, concerns about quality arise with quite a lot of the administrative information that is collected. Dialogue with data producers is needed as to how far the data can best serve the interests of a particular piece of research. We are aware that the issue of access to administrative data is under discussion by the UK Data Forum; we would encourage its members to take account of data quality issues as well as access and confidentiality (Martin et al, 2006, p 60).

Jones and Elias (2006) suggest that administrative data is perceived as more accurate than survey data, and especially less susceptible to respondents' recall errors or misreporting. However, they urge caution on this point:

The problem, potentially with administrative data is that they may be collected to varying standards and that coding standards and/or methods of transcribing data may vary across departments.... [D]ata entries may be subject to spelling mistakes, anomalous ordering or mis-recording. More generally administrative data might be of variable quality across departments and subject to missing observation, discontinuities, changing in systems of coding, and so on. (Jones and Elias, 2006, p 73) 
White et al also draw attention to the particular problems of data quality that may affect administrative sources, "such as incomplete recording or documentation which is not designed for external use” (GSS, 2000, p 39).

A more comprehensive account of problems that may affect administrative data sets to an even greater extent than surveys is provided by Ruddock's Measuring and improving data quality (GSS, 1999a), the final report of a GSS task force on non-sampling error. These include not only coverage errors, discussed above, but non-sampling errors can take a variety of forms, identified by Ruddock as coverage errors, non-response errors resulting from refusals to participate or answer particular questions, the accuracy of data, the impact of the context and mode of data collection, and the nature and role of the interviewer. Forms of error described by Ruddock as respondent and questionnaire errors, mode errors, and interview error (GSS, 1999a, p 33), raise basic methodological questions about the quality of data for research purposes: what was asked, of whom, in what setting and for what purpose? How was the data recorded? To what extent does it depend on observation by a third party, or proxy informants? While these issues affect all survey research, they are an even greater issue in administrative encounters, where the initial purpose of the encounter and the power relationship may be quite different, such as in applications for benefit. Scott (1990) points out that administrative records can never be treated by social scientists or researchers as neutral reporting of events. They are always shaped by political contexts and more general cultural and ideological assumptions, as well as the particular institutional contexts in which data is produced. There are also forms of error that occur in the editing and analysis of data, described as systems errors or errors in the systems for processing different kinds of data; and data handling errors described by Ruddock as errors in "data capture, editing and coding of open-ended textual responses” (GSS, 1999a, p 7) that may lead to bias and increase in variance.

\section{Technical, ethical and legal issues}

Gill (GSS, 2001) discusses the difficulties of record linking in relation to the generation of statistical information. Much of the report concerns technical procedures and difficulties. It alerts potential users to the problems of matching cases and the possibility of errors (such as where more than one individual has the same name). The merging of data sets in ways that would track individuals also poses technical difficulties and dangers of errors. However, even if these can be overcome, the legal and ethical obstacles are formidable. 
Gill (GSS, 2001) also draws attention to the ethical and legal constraints concerning the protection of individual identity and the use of data for purposes other than those for which it is collected. These matters are covered both by primary legislation such as the Data Protection Act (1998) and the National Statistics Code of Practice. Gill makes the further point that where individual identity cannot be deduced from any single source, data combination may reduce this protection or increase 'disclosivity'. Similar issues are also noted by the UK NDS:

An important part of the research process is the nature of the arrangements which exist to regulate access to confidential or potentially disclosive data. High quality research requires facilities for good data access. This may involve linking between various data sources (eg linking administrative data to survey information held on individuals). Such procedures raise ethical issues relating to the confidentiality of data and the nature of consent required for linking data. Restrictions on access may also exist for legal reasons or because of the nature of undertakings to data providers given or implied during data collection. The National Data Strategy must provide guidance and common solutions to the procedures required to facilitate high quality research whilst ensuring data are used in accordance with any necessary restrictions on use. (NDS, 2005 b, p 5)

The launch report of the new Social Exclusion Task Force acknowledges the existence of statutory obstacles to data sharing, and includes an action point to overcome this: "The Government will explore how to extend data sharing in relation to the most excluded or atrisk groups, including any additional powers that may be necessary” (Social Exclusion Task Force, 2006, p 35).

Such plans are controversial. The Ministerial Committee on Data Sharing, MISC 31, set up to develop the government's strategy on data-sharing across the public sector, has already attracted criticism for announcing that information will normally be shared in the public sector, provided it is in the public interest. This is a change in the default position that a justification should be provided in terms of pupose for each instance of data sharing. Privacy campaigners and other critics have seen this as a potential threat to civil liberties and a potential breach of the European Convention on Human Rights (Ballard, 2006; Cross, 2006; Cross and Travis, 2006; Kablenet, 2006). Concern is not confined to pressure groups, but is widespread across the population: 
Research by MORI has found that 60 per cent of the population are fairly or very concerned about public services sharing their personal information. Awareness of the level of information held on them by public services was also low among the general population, with 64 per cent saying they did not feel 'well informed' about the data being kept about them (MORI 2003). A more general distrust of central government, regardless of the party in power, has also been reported by successive surveys of the UK population (MORI 2002). (Pleace and Bretherton, 2006, p. 77)

The Information sharing vision statement (DCA, 2006) sets out to allay fears on this issue, while ethical considerations have been at the centre of discussions about developing the Work and Pensions Longitudinal Study (WLPS) (Walker, 2003; DWP, 2005a, 2005c). The political controversy is outside the remit of this report, but is relevant in terms of public trust and the potential impact on data quality. The Data Protection Register is broadly in support of data sharing but warns that the government risks losing public trust if 'reasonable expectations of privacy are not met' (Cross, 2006). Such trust rests on the perception, rather than the reality, of confidentiality. Its reduction may affect the quality of administrative data, but also runs the risk of a significant and damaging effect on the response rates and data quality in social surveys where participation is voluntary.

Jones and Elias (2006, p 78) recommend the setting up of an Administrative Data Resources Service that would address problems of access, issues of data linkage and "undertaking quality reviews of administration data resources to establish their strengths and weaknesses as research resources”. We would endorse this recommendation, as there is no point in undertaking elaborate statistical analyses of temptingly large data sets without a quality assessment of all the contributing data sources.

\section{Work and Pensions Longitudinal Study}

The major data set held by the DWP that bears on social exclusion is the WPLS. The WPLS links benefit and programme records with employment records from the former Inland Revenue, now Her Majesty’s Revenue and Customs (HMRC). Thus Tax, National Insurance, benefit and employment programme records are being linked, together with Pension Credit data, Housing Benefit and Council Tax benefit data. It also includes data on Welfare to Work programme participation, including age of youngest child for those on the New Deal for Lone Parents, disability, ethnicity and destination on leaving the programme. Linkage is through NINOs. Information has also been added about ISA (Individual Savings Account), PEP 
(Personal Equity Plan), TESSA (Tax-Exempt Special Savings Account), private pension pots or savings accounts information from HMRC. Links to DfES data sets require the resolution of technical and legal issues in the sharing of data between government departments.

The purpose of the WPLS is to evaluate the success of existing government intitiatives and to provide the evidence base for the better targeting of resources. It has existed in its present form since October 2005. A comprehensive list of possible uses is provided by the DWP (DWP, 2005b). According to Jones and Elias (2006, p 17):

The 100 per cent coverage means that WPLS is unmatched in the UK as a longitudinal data resource. As well as providing a very much enhanced facility for welfare-to-work and pension planning related policy analysis within the department, it also provides an important resource for future research work on individual labour market experiences and transitions.

In spite of the very wide range of data collated in the WPLS, there are large areas of information missing in terms of social exclusion. Notable absences (because they are not included in administrative returns) are information about health, education, material deprivation, social networks and social participation. The WPLS can provide a unique resource for looking at patterns of labour market participation, employment, benefit use and so on; but is much more limited in relation to social participation and well-being in a broader sense.

\section{The ADMID report}

The disadvantaged groups team at the DWP has considered the possibilities of linking national records with data from service providers working at local authority level to provide better information about adults facing multiple barriers to employment. The ADMID (Administrative Datasets for Measuring Impacts of Disadvantage) study was designed "to explore the possible advantages of linking project level, local authority level and city-level datasets with DWP datasets as a meams to improve the range and extent of data available on 'hard to help' groups who are able to work” (Pleace and Bretherton, 2006). It addressed the views of "local service providers, service commissioners and service users" on the desirability, practicality and legality of data sharing. 
This work is driven by two concerns. First, the well-being of those who face multiple barriers to employment (including people released from prison, early leavers from the Armed Forces, homeless people, ex-offenders and refugees, and those dependent on drugs or alcohol) and are at risk of sustained social exclusion. Second, the "high 'lifetime' costs to the Exchequer because benefits are claimed for sustained periods and people tend to make high use of publicly-funded services” (Pleace and Bretherton, 2006, p.1). This double imperative may be part of the reason for the report's finding that the issue of trust is again an obstacle, both for service users and service providers.

The potential advantages of data sharing are clear:

A detailed longitudinal dataset would allow specific individuals and localities to be more accurately targeted with services. Services and programmes could also be evaluated longitudinally. The life courses of people in the target group could be better understood and services tailored accordingly. (Pleace and Bretherton, 2006, p.1)

The disadvantages concern data quality, potential stigma and, above all, issues of trust. Service providers raised questions about inaccuray and oversimplification, for example the use of categories such as drug user. Not only does this cover a range of people with different needs, but there were concerns about the label continuing to be attached to an individual in an enduring way, even when it had ceased to be applicable. Among service providers,

While many respondents saw advantages in the capacity to track individuals longitudinally, they found it difficult to reconcile this with some concerns about the implications for service users centred around the use of data to monitor individuals. (Pleace and Bretherton, 2006, p. 4)

Service users often "regarded themselves as being in a situation of surveillance by an overarching 'state' which processed their personal data in an arbitrary way" (p. 6) . Even free and informed consent appeared an insufficient answer because of levels of distrust. Service providers were concerned that people would refuse to engage with services if asked to sign consent forms for data sharing, and there were also concerns about resource implications for service providers. 
Pleace and Bretherton concluded that 'a combination of better education about the DPA and clear rules that provide reassurance about the uses to which shared data can be put could facilitate data sharing between people facing multiple barriers to work, local service providers and DWP' (p. 7), and that further research is necessary. Although this final recommendation might go some way to addressing the issue of trust, it does not address the issues raised in the report about data quality.

\section{Department for Education and Skills}

The DfES has a central 'data warehouse' that contains a range of data on individual school pupils, schools and records from the Learning and Skills Council. There are plans to integrate information on higher education from the Higher Education Statistics Agency (HESA) and the Universities and Colleges Admissions Service (UCAS), which can be linked to individual pupils, and also to incorporate social care statistics from the Department of Health (DH). There is a new NPD on all children in the state school system: some eight million individual records are added each year. The individual pupil records are based on PLASC, the Pupil Level Annual School Census. Returns are compulsory for schools in the state sector, and optional for maintained nursery schools. It should be underlined, however, that this is not a complete national data base, as it excludes all those educated in the independent sector. The records are linked by unique pupil identifiers, so tracking of individuals and longitudinal analysis are possible. The data on individual pupils includes gender, ethnicity, age, receipt of free school meals, educational attainment, information on special educational needs, postcode and school attended. The data can be accessed through the PLASC/NPD User Group (PLUG), funded by the DfES and ESRC and managed at the Centre for Market and Public Organisation (CMPO) at the University of Bristol (Jones and Elias, 2006).

\section{Client Records}

Some of the data included in the WPLS is based on Client Records. Client Records are kept by a variety of different governemt and other agencies. For example, there are two separate datasets relating to clients receiving services from local authorities. One, the Supporting People Client Record, is concerned with the characteristics of the clients themselves, and is compiled from individual Client Record sheets. These sheets are generated by completion of an interview form with preset categories. The form is completed by the service provider, not the client, and in some cases comes at yet another remove through a proxy informant for the client. Such a process is inevitably subject to interviewer error, in that the interviwer is 
requird to categorise the client on the basis of information given, into the precoded groups (which are not mutually exclusive). It is also prone to respondent error, in that the client or their representative may consciously or unconsciously give partial or inaccurate information. A related set of administrative data is the Supporting People Local System (SPLS), which records data on service provision to this client group, although it has, as described below, suffered both technical and data quality problems. The data collected, as indicated below, is (as is the case with many administrative data sets) rather narrow for any useful multivariate analysis of social exclusion.

The Supporting People programme was launched in April 2003. It aims to provide highquality services to vulnerable people living in the community. It does this by providing housing-related support, in order to improve the quality of life of service users and adopt interventions that prevent people requiring institutional care. The programme is administered by the top-tier authorities (150 administering authorities) who run the programme at a local authority level. The data collection, processing and preliminary statistical analysis is carried out by the Client Record Office at the Joint Centre for Scottish Housing Research (JCSHR). The 150 administering authorities and the Department for Communities and Local Government (DCLG) are also provided with reports of summary information from the Client Record Forms every quarter (produced by the JCSHR). These reports are also published on their website (www.spclientrecord.org.uk). DCLG use this information to monitor fair access to Supporting People services for those who are eligible, and to examine whether the range of support needs in their local area is being met. It can also be used by administering authorities working together to coordinate services regionally. DCLG receive the data in an SPSS format, to enable in-house analysis and answer ad hoc queries. DCLG also provide data analysis on drug-related client groups to the Home Office for the Drugs Intervention Programme on a quarterly basis. SPLS is a quarterly dataset from 150 administering authorities in England. It collects data on services to vulnerable people living in the community. SPLS is a data return from the service perspective, consisting of 29 CSV files containing data on supply, costs of services, accreditation data, quality assessment framework data, performance data and service reviews.

A copy of the Client Record Form can be found at http://ggsrv-cold.standrews.ac.uk/spclientrecord/ClientRecord/2006_7/Client_Record_Form\%202006_7.pdf.

The Client Record Form was developed to record standard information about clients starting to receive services through the Supporting People programme in England. The Client Record 
collects information on a client's characteristics (for example, their age, sex, their economic status and their ethnic origin the informant's relationship to the client,), the provider type, service type, the client's primary and secondary client groups, the accommodation previously occupied and the referral type. Information is collected on all new clients accessing a Supporting People service. Information, however, is not measured if the client stops receiving the support or service. There are 21 client groups, including Young People at Risk, Young People Leaving Care and Teenage Parents.

Client Records are also held by voluntary sector agencies such as the CAB. These too are of limited value. While reasonably complete data is collected by CAB on the nature of clients' problems, only limited information is collected on clients' characteristics, and most of this is on a voluntary basis and thus not representative of the caseload as a whole. For example, employment status, the provision of unpaid care and participation in unpaid work are all optional fields. Self-reported income is similarly optional with a low level of completion, while computed income is calculated only for a small number of money advice cases. Housing tenure is also an optional field. Information about disability has recently become a compulsory item of information. Information about homelessness or discrimination is collected only where this bears on the problem for which advice is sought. No information is collected on educational levels, social and political participation, health or well-being. In terms of the quantitative analysis of social exclusion, then, the CAB database is of limited usefulness. However, there may be greater scope for qualitative analysis of these records in terms of presenting problems, surrounding difficulties and what is known of client characteristics.

All the Client Records suggest that the coverage and quality of data is a fundamental consideration in the prospects for secondary analysis. 


\section{Chapter six \\ Conclusions and recommendations}

There is a range of existing definitions of multiple disadvantage or social exclusion. Some of these refer to structural characteristics of the social system, or to aggregate indicators. Because this project was designed to consider the possibility of sub-system analysis of survey data at the household or individual level, an appropriate definition was derived from the literature as:

Social exclusion is a complex and multi-dimensional process. It involves the lack or denial of resources, rights, goods and services, and the inability to participate in the normal relationships and activities, available to the majority of people in a society, whether in economic, social, cultural or political arenas. It affects both the quality of life of individuals and the equity and cohesion of society as a whole.

The brief asked for the exploration of ‘deep exclusion’ or multiple disadvantage. Exploration showed that the concept of 'deep exclusion' as a qualitatively different phenomenon from 'social exclusion' does not exist in the academic or policy literature. This is because 'social exclusion' itself is universally regarded as involving multi-dimensional disadvantage. It is, however, recognised that there are degrees of severity of social exclusion, just as there are degrees of inclusion. Severe or deep exclusion could, therefore, potentially be defined as follows:

Deep exclusion refers to exclusion across more than one domain or dimension of disadvantage, resulting in severe negative consequences for quality of life, well-being and future life chances.

It is possible to derive from these definitions and from the surrounding literature a series of domains and sub-domains of potential exclusion that should be considered.

Those domains and sub-domains are:

\section{Resources}

Material/economic resources

Access to public and private services 
Social resources

\section{Participation}

\section{Economic participation}

Social participation

Culture, education and skills

Political and civic participation

\section{Quality of life}

\section{Health and well-being}

\section{Living environment}

\section{Crime, harm and criminalisation}

Within each sub-domain, individual topics have been identified, where the availability of indicators in existing data sets can be explored. Together with the individual topics, which differ for different life course stages, this array of domains constitutes the B-SEM.

It should be noted that there is a wide variation in the array of domains identified in the literature and used in analysis. The B-SEM differs from most approaches in being theorydriven rather than data-driven, and in therefore asking what information we need, rather than simply what information we have. It therefore acts as a benchmark for systematically assessing the current availability of data.

\section{Further research}

As is usual in addressing complex topics, further research needs to employ a range of strategies, including secondary analysis of existing data sets, the generation of new survey modules, the use of qualitative methods, and the use of specialised surveys preferably informed by qualitative research. There is no single answer to the question of which research strategies best estimate and/or track multidimensional exclusion, or how we should best use analysis to measure multi-dimensional exclusion. A proper understanding of social exclusion requires a combination of all these approaches. Nevertheless, the B-SEM provides a heuristic device for assessing the coverage of existing data, and shows that there is a shortage of adequate data for the understanding of exclusionary processes and the drivers, risk factors and triggers of social exclusion. While the B-SEM identifies the appropriate domains of investigation, estimating or tracking social exclusion depends on the prior understanding of the causal relationship between domains. 
Fig. 6.1 below gives a graphical illustration of the potential complexity of the interaction between domains.

\section{Causal relationships between the 10 domains}

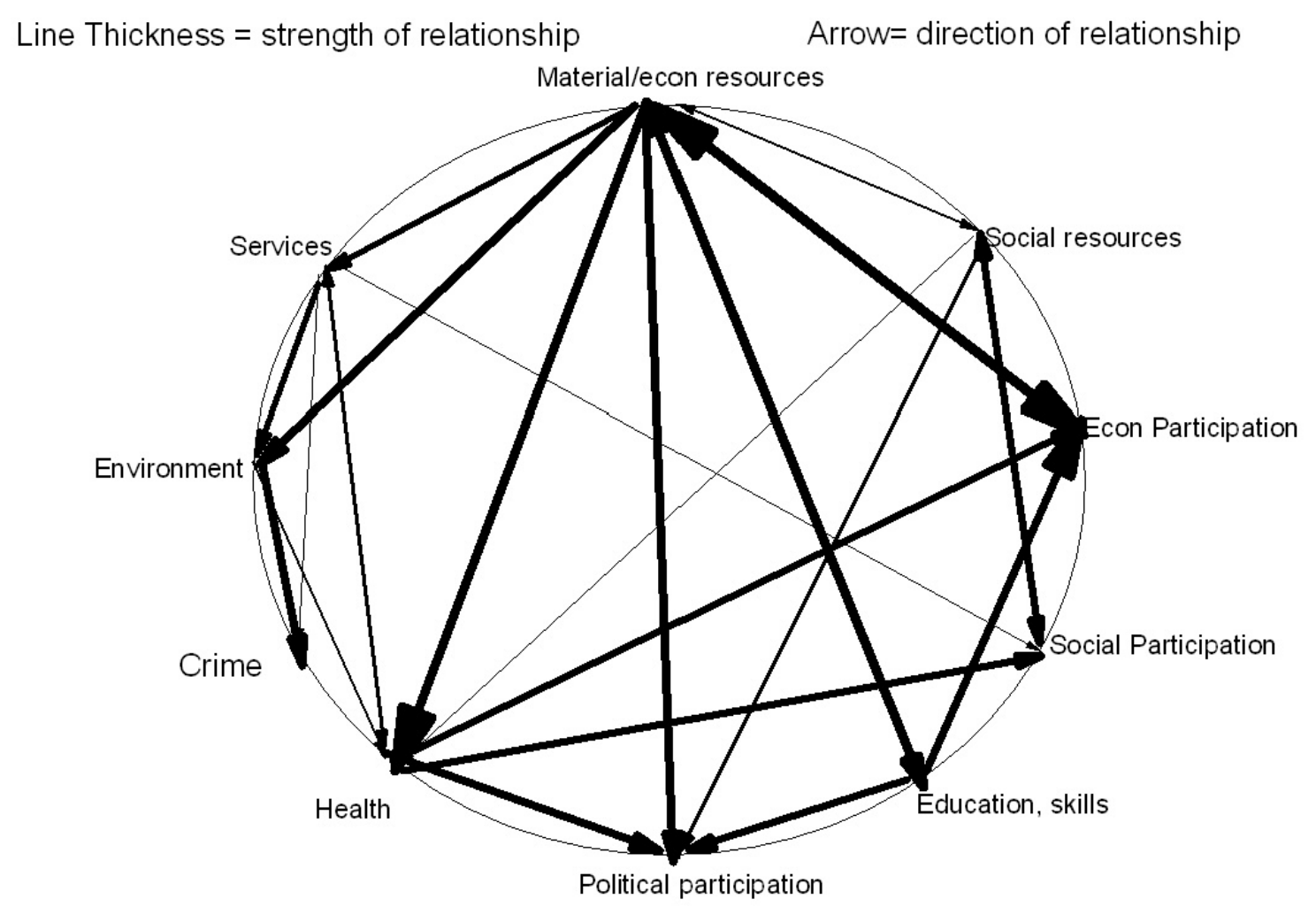

Even a purpose-designed longitudinal survey constructed to cover all ten domains of the BSEM would be limited by the exclusion of the non-household population, including many of the most vulnerable people in our society. There is scope for secondary analysis of some of the better surveys (in terms of their usefulness in relation to social exclusion), as indicated below. However, the strength of the B_SEM is that it draws attention to the limits of coverage of each data set, and the absence of coverage of particular domains needs to be noted in each instance. It is tempting to simply ignore the domains where data is thin or absent, but this will simply reproduce the existing weaknesses in our understanding of exclusionary processes.

It is likely that future research will reveal, as suggested in Fig 6.1, that some domains are more important as risk factors for other, and some are effectively outcomes with lesser causal effects. The present state of knowledge is such that it would be risky to make assumptions here and to regard some domains as having lesser importance. Notwithstanding the need to maintain as broad a coverage as possible across the domains of the B-SEM, we do (for example) know that income poverty and material deprivation constitute a driver for most 
other domains of exclusion. This has implications for policy interventions both at the individual and household levels and at the level of social structure.

Although we identify below possible data sets for further secondary analysis, it is beyond the scope of this project to specify particular analyses. Some detailed issues relating to statistical inference are set out in Appendix 8. The key point is that there are a wide range of different questions that can be asked, or hypotheses that can be tested, in relation to the interaction of variables in social exclusion, and the appropriate techniques must be selected in relation to these and the specific nature of the data in individual surveys. It is also important in terms of the reliability of findings that causal models are cross-tested on different datasets rather than derived from and tested on the same data.

As discussed above, some presentations of data on social exclusion involve adding up the number of dimensions on which people are excluded. This is simply a descriptive, not an analytic, device, which tells us nothing about the interaction of the domains of exclusion, which is the primary objective of multidimensional analysis. Even from a descriptive point of view, the additive approach is problematic, since it implicitly assigns equal weight to each dimension, and this is unlikely to be empirically correct. Moreover, additive presentations depend on the identification of thresholds and binary divisions on individual dimensions, such that individuals can be identified as included/excluded rather than more or less excluded. In the present state of knowledge, such thresholds are almost always wholly arbitrary. They need to be established empirically as for example in Levitas (2006) where it was demonstrable from the PSE data that social participation dropped more sharply below a threshold income, or Townsend (1979) which showed a similar income threshold for deepening material deprivation. Composite 'numbers' of those multiply excluded are highly sensitive to the chosen thresholds and the particular indicators used for different dimensions, and add little to our understanding of exclusionary processes and appropriate policy interventions.

\section{Survey data}

A key question addressed by this project is the scope for secondary analysis of existing survey data in ways that will shed light on the states and processes of social exclusion. There is a great deal of data collected on aspects of disadvantage in existing surveys and administrative data sets. However, very few cover the range of aspects of multiple disadvantage or social 
exclusion included in the B-SEM. The question of data coverage must be looked at in conjunction with population coverage. Here, there are a number of crucial issues:

- Household-based surveys by their very nature exclude vulnerable sections of the population, especially those living in institutions such as residential homes (for children, disabled people, older people), nursing homes, prisons and so on. Travellers and asylum seekers are also likely to be excluded, as are those who are homeless.

- There are sections of the population who although technically eligible for inclusion are under-represented in social surveys. Again, these are often groups who may be particularly vulnerable to social exclusion, such as those on low incomes or in temporary accommodation, or young residentially mobile people.

- Even where representation is proportionate, the numbers in vulnerable groups may be too small for further analysis unless original sample sizes are very large. This applies, for example, to the numbers of minority ethnic respondents in many surveys, as well as to lone parents and to younger and older pensioners.

- The geographical coverage of some surveys is limited. Not all cover the whole of the UK, and Northern Ireland (in particular) is often un- or under-represented. It is important in developing further research or new data sources to consider how far similar data is or should be available for all four countries of the UK.

- Data quality and sample estimates are affected where proxy informants are used and in some surveys large sections of data are derived from proxy informants. This a particular issue in relation to children, where proxy informants are the norm, although there is an increasing acceptance of the possibility and merits of direct data collection. In further research it is important that children's cohorts be included and that the age of respondents is taken as far down as possible, certainly to about seven years of age.

- The majority of surveys include the common risk factors associated with social exclusion such as gender, age, housing tenure, SEG and ethnicity. However, only a limited number include critical life events that may act as triggers for social exclusion, such as a death in the family, divorce or separation or pregnancy. Very few surveys include information on religious affiliation.

- Few surveys include additional administrative data such as IMD scores or ACORN neighbourhood.

With these cautionary points in mind, it would, however, be possible to undertake useful secondary analysis on some existing data sets using the B-SEM. Consistent with the life 
course approach taken throughout this project, we have assessed the following data sets as likely to generate additional useful understanding.

\section{Children}

FACS collects a wide range of data (and there is scope for additional questions to be added in the future). Quite a lot of analysis has been undertaken of this rich data set, but most of it focuses on child poverty and material deprivation. We recommend further analysis of FACS using B-SEM to explore other aspects of social exclusion, thus building on Willitts (2006) and McKay and Collard (2004).

ALSPAC, although not a nationally representative sample, has exceptionally rich data that could be used for the analysis of social exclusion.

\section{Young people}

At present there is no ideal single data set for looking at young people and further work needs to draw on a number of sources. Indeed, there is no consistency in current survey approaches in the definition of a young person. We would recommend the more consistent application of the UN 16-24 definition, while bearing in mind that the most important issue is that of youth transitions. Notwithstanding its limited geographical coverage, the most promising data for this age group is likely to be the LSYPE, although the relevant data that will allow meaningful comparison of cohorts will not become available for some years.

Existing research and policy in this area have increasingly tended to focus upon exploring the situation and needs of 'socially excluded' youth specifically with reference to discrete though connected instances of marginalisation (e.g. NEET, teenage pregnancy, substance misuse, homelessness, etc.). Nevertheless, experiences of poverty and exclusion are not confined to a small minority but are a common experience for young people at various points in their transitions to adulthood. Addressing youth poverty is thus an important policy objective in its own right, as well as a lever in reducing the hazard of more extreme forms of exclusion and marginalisation.

At the same time there is some evidence that changes in the nature of youth transitions may be increasing both the relative risk of poverty and exclusion for young people relative to other life phases, and the persistence of poverty in later life. Future research informed by a longitudinal perspective is therefore needed to investigate the extent of inter-generational 
change in the relative risks of multidimensional exclusion for young people. This research agenda is important both in developing the evidence base for future youth policy and in influencing the wider welfare reform agenda.

Recent research within this framework has drawn heavily upon the 1958 and 1970 birth cohorts in order to explore the changing dynamics of disadvantage across generations (e.g. Blanden \& Gibbons, 2006; Bynner et al., 2003). However, whilst scope exists for further analysis of these data they also have several significant shortcomings related to:

- The effects of differential attrition (and unit non-response) amongst relatively 'disadvantaged' young respondents

- The limited range and adequacy of indicators measuring poverty, deprivation and disadvantage in the birth cohort studies

- The absence of a cohort study investigating the transitions of young people in the 1990s

For the above reasons it is useful to augment such analyses with those informed by a quasicohort approach based upon analysis of pooled cross-sectional data. Amongst existing largescale official surveys the General Household Survey (GHS) offers unique opportunities for investigating the changing profile of income poverty, deprivation, and wider forms of disadvantage amongst Britain's young people. The advantages of this approach include:

- Minimising problems of non-response bias, specifically those relating to differential sample attrition in panel studies

- Wider range of items relating to material deprivation and more adequate measurement of income compared with the 1958/70 cohort studies

- Broad time coverage of the GHS (since 1970) allows for investigation of the ways in which the predictors of youth exclusion based upon the B-SEM approach have changed over the past 35 years

- Relatively large sample sizes based upon pooling at (for example) 5-year intervals allows for further dis-aggregation of the youth sample (aged 16-24)

We therefore recommend use of existing cohort data (that is, the 1958/1970 cohort studies) in order to make longitudinal comparisons of youth transitions using the B-SEM approach. Some work has been undertaken in this area but there remains considerable scope for further analysis. Allied to this - and since the data series extends back to 1970 - we would also 
recommend using pooled cross-sections of the GHS to develop a quasi-cohort approach.

This is especially important in relation to specific dimensions of the B-SEM model such as income poverty and deprivation.

\section{Working-age adults}

The best existing longitudinal survey from the point of view of social exclusion is the BHPS. Secondary analysis of this would be more useful than some earlier analyses if it were undertaken using the wider categories of the B-SEM. However, there are, as discussed above and indicated in the survey commentary, some serious problems about the BHPS. These include its small sample size, differential attrition and non-inclusion of the post-1990 immigrant population.

Recent recommendations to extend the sample size of the BHPS to 40,000 are currently being taken forward in discussions for a new longitudinal survey, the UKLHS. The first sweep of data is likely to be in 2008. Consultations about content are ongoing. We strongly recommend that there is input into these consultations to ensure the generation of adequate and appropriate data on social exclusion. We also recommend that the survey builds on BHPS best practice and includes a children's cohort.

The best repeat cross-sectional survey is the GHS. It would be possible to develop a social exclusion module (as was done for the social capital module), which could be used in future surveys on a longitudinal basis. While the GHS is one possible home for such a module, it could be used elsewhere, as in the BHPS and later the UKLHS. We recommend the development of a social exclusion module based on the B-SEM.

The APS is another possibility, especially for exploring the geography of social exclusion (a question outside our brief). The sample size is very large at almost 0.5 million and it includes Northern Ireland. However, its topic coverage is focused mainly on labour market exclusion.

\section{Later Life}

By far the best source of data on older people is the ELSA. It follows up the same individuals frequently, and has a refreshed panel. The sample is large and the range of topics wide. It includes critical life events, and allows for hazards and event analysis. For example, is would be possible to look at the impact of retirement on younger (50-60/65) respondents. It makes 
possible the analysis of the process of social exclusion at the latter stages of the life course. We recommend the analysis of ELSA using the B-SEM tool. We also recommend that in future sweeps, a sample be included for Wales.

\section{All age groups}

The survey that covers the widest range of information across the domains of social exclusion and across the life course is the PSE Survey. This has the disadvantage of being crosssectional and of having been carried out only once, so that neither longitudinal nor repeat cross-sectional analysis is possible. The sample size is also too small for the detailed analysis of some vulnerable groups, especially minority ethnic groups. We would recommend repeating an improved version of the PSE Survey with a larger sample size and a minority ethnic booster. If possible we would recommend re-contacting the households in the original survey to provide a longitudinal element.

We also recommend that more consideration is given to the use of minority ethnic and other boosters in existing survey research to improve the overall usefulness of these sources.

\section{Administrative data}

We recommend a further consideration of the use of administrative data following the publication of the ADMID report and UK NDS report on this issue. There are clearly possibilities here both for tracking of individual cases and for linked anonymised records as a research resource. However, in addition to technical issues, there are two areas of concern. First, there is the question of data quality. Although administrative data may not be subject to the same kinds of sampling error as survey data, it is particularly vulnerable to a range of nonsampling errors. Unlike survey data, its quality is not routinely assessed in these terms, so there is no independent assessment of its quality. Second, there are debates about ethics, confidentiality, informed consent and public trust in relation to data sharing across government. Social researchers are governed by ethical codes that place a high value on confidentiality and informed consent. These considerations would remain even if legal obstacles were removed. The loss of public trust might also have a general impact on data quality, in relation to both administrative and survey data. Third, there are currently legislative differences among the four countries of the UK that may have an effect on the feasibility of cross-programme linking of data for the whole of the UK. For example, there is interim legislation, which sets aside doctors' duties of confidentiality and allows the 
disclosure of patient information without consent for (among other things): linking data from multiple sources, validating its quality and completeness and avoiding incorrect linkage or duplication; and audit, monitoring, and analysing of health service provision of care and treatment. However, the legislation applies only in England and Wales. The Confidentiality and Security Advisory Group for Scotland has proposed a solution that does not require legislation, but relies on government guidance which sets out situations in which a 'legal defence’ can justify overriding consent requirements (see English et al, 2002).

We recommend that these considerations are kept to the forefront when considering the use of administrative records for purposes other than those for which they were originally generated.

\section{Specialist research on non-household and under-represented population groups}

A key issue in the analysis of social exclusion using existing data is the absence of vulnerable groups of the population from the social survey base because they are not included in the household population. There are two possible strategies for approaching this problem, which should be seen as complementary rather than as alternatives.

One is the use of specialist surveys directed at, for example, children in care, homeless people, refugees, prisoners and institutional populations in different forms of residential care for adults. Only the decennial census provides information on the non-household population and there have been very few specialist surveys. Such survey information on disabled children in institutions dates back to 1985; the last national survey of the prison population took place in 1991. The numbers concerned are not necessarily small. For example, some 500,000 older people are in care homes - that is about 1 in 20 of all older people. Over a fifth of those aged over 85 are in institutional care (Royal Commission on Long Term Care, 1999).

The second strategy is detailed qualitative research using life history and biographical techniques to identify exclusionary processes and experiences. This would be a useful way of identifying critical life events both leading to and preventing exclusion. Biographical techniques have already been used in relation to social exclusion in a comparative crossEuropean project (Chamberlayne et al, 2002). In general, qualitative research is superior to survey research for exploring individual experiences, and can offer far greater insights into complex interactions of factors. Qualitative research has enormous merits in its own right, but 
can also provide the basis of better questions for specialist surveys. B-SEM could be used to develop a topic guide for use in qualitative research, although in its present form it is designed for survey assessment.

We recommend qualitative work with selected groups at particular risk of social exclusion, especially those who are excluded from or under-represented in household surveys. Such groups include: children in care, homeless people, people with disabilities, asylum seekers, prisoners and ex-prisoners, and all age groups living in institutions. Such qualitative work should use biographical methods to explore the experience of social exclusion and the nature and sequence of precipitating events.

We recommend that the findings from this qualitative work be used where possible to inform specialised surveys of social exclusion among the non-household population. 
Appendix 1: Opportunity for All 2005 indicators

\begin{tabular}{|c|c|c|c|}
\hline \multicolumn{2}{|c|}{ Children and young people } & \multirow[b]{2}{*}{ Coverage } & \multirow[b]{2}{*}{ Source } \\
\hline Indi & ator & & \\
\hline 1 & Children in workless households & GB & LFS \\
\hline 2 & Low income & & \\
\hline $2 \mathbf{2 a}$ & Relative low income & GB & HBAI/FRS \\
\hline $2 \mathbf{b}$ & Absolute low income & GB & HBAI/FRS \\
\hline 2c & Persistent low income & GB & HBAI/FRS/BHPS \\
\hline 3 & Teenage pregnancy & & \\
\hline $3 \mathbf{a}$ & Teenage conceptions & England & ONS \\
\hline 3b & $\begin{array}{l}\text { Teenage parents in education, } \\
\text { employment or training }\end{array}$ & England & ONS/LFS \\
\hline 4 & $\begin{array}{l}\text { Children with appropriate levels of } \\
\text { development in Sure Start areas: }\end{array}$ & & \\
\hline $4 \mathbf{a}$ & Communication, language and literacy & England & DfES \\
\hline $4 \mathbf{b}$ & $\begin{array}{l}\text { Personal, social and emotional } \\
\text { development }\end{array}$ & England & DfES \\
\hline 5 & Key Stage 2 (11-year-olds) attainment & England & DfES \\
\hline 6 & Attainment & & \\
\hline $6 \mathbf{a}$ & 16-year-olds achievement & England & GCSE results etc \\
\hline 6b & Schools below floor target & England & GCSE results etc \\
\hline 7 & $\begin{array}{l}\text { 19-year-olds with at least a Level } 2 \\
\text { qualification }\end{array}$ & England & LFS \\
\hline 8 & School attendance & England & DfES \\
\hline 9 & $\begin{array}{l}\text { Improvement in outcomes for looked- } \\
\text { after children }\end{array}$ & & \\
\hline $9 a$ & Education gap & England & Returns to DfES \\
\hline 9b & $\begin{array}{l}\text { Not in education, employment or } \\
\text { training }\end{array}$ & England & Returns to DfES \\
\hline 9c & $\begin{array}{l}\text { Stability in the lives of looked-after } \\
\text { children }\end{array}$ & England & Returns to DfES \\
\hline 10 & 16- to 18 -year-olds in learning & England & $\begin{array}{l}\text { Education returns } \\
\text { and LFS }\end{array}$ \\
\hline 11 & Infant mortality & $\begin{array}{l}\text { England + } \\
\text { Wales }\end{array}$ & ONS \\
\hline 12 & Serious unintentional injury & England & DH/ONS \\
\hline 13 & Smoking prevalence for: & & \\
\hline 13a & Pregnant women & England & $\begin{array}{l}\text { Infant Feeding } \\
\text { Survey (5yearly) }\end{array}$ \\
\hline 13b & Children aged 11-15 & England & NCSR/NFER \\
\hline 14 & Obesity for children 2-10 & England & $\begin{array}{l}\text { Health Survey for } \\
\text { England }\end{array}$ \\
\hline 15 & $\begin{array}{l}\text { Re-registrations on Child Protection } \\
\text { Register }\end{array}$ & England & $\begin{array}{l}\text { Personal Social } \\
\text { Services } \\
\text { Performance } \\
\text { Assessment } \\
\text { Framework } \\
\text { Indicators }\end{array}$ \\
\hline 16 & $\begin{array}{l}\text { Housing that falls below the set } \\
\text { standard of decency }\end{array}$ & England & $\begin{array}{l}\text { English House } \\
\text { Condition Survey } \\
\text { (continuous) }\end{array}$ \\
\hline 17 & Families in temporary accommodation & England & $\begin{array}{l}\text { P1(E) quarterly } \\
\text { returns, ODPM }\end{array}$ \\
\hline
\end{tabular}




\begin{tabular}{|c|c|c|c|}
\hline \multicolumn{2}{|c|}{ People of working age } & \multirow{3}{*}{$\begin{array}{l}\text { Coverage } \\
\text { GB }\end{array}$} & \multirow{3}{*}{$\begin{array}{l}\text { Source } \\
\text { LFS }\end{array}$} \\
\hline Indic & ator & & \\
\hline 18 & Employment rate & & \\
\hline 19 & Employment of disadvantaged groups & & \\
\hline 19a & Disabled people & GB & LFS \\
\hline 19b & Lone parents & GB & LFS \\
\hline 19c & Minority ethnic people & GB & LFS \\
\hline 19d & People aged 50 and over & GB & LFS \\
\hline 19e & Lowest qualified & GB & LFS \\
\hline 20 & $\begin{array}{l}\text { Working-age people in workless } \\
\text { households }\end{array}$ & GB & LFS \\
\hline 21 & $\begin{array}{l}\text { Working-age people without a Level } 2 \\
\text { GNVQ qualification or higher }\end{array}$ & England & LFS \\
\hline 22 & $\begin{array}{l}\text { Long periods on income-related } \\
\text { benefits }\end{array}$ & GB & $\begin{array}{l}\text { Administrative } \\
\text { data (some } \\
\text { sampled) }\end{array}$ \\
\hline 23 & Low income: & & \\
\hline $23 a$ & Relative low income & GB & HBAI/FRS \\
\hline $23 b$ & Absolute low income & GB & HBAI/FRS \\
\hline $23 c$ & Persistent low income & GB & HBAI/FRS/BHPS \\
\hline 24 & Smoking rates: & & \\
\hline $24 a$ & All adults & England & GHS \\
\hline $24 b$ & Manual SEGs & England & GHS \\
\hline 25 & $\begin{array}{l}\text { Death rates from suicide and } \\
\text { undetermined injury }\end{array}$ & England & ONS \\
\hline 26 & Rough sleepers & England & $\begin{array}{l}\text { Local authority } \\
\text { returns, Housing } \\
\text { Investment } \\
\text { Programme } \\
\end{array}$ \\
\hline 27 & Drug use (16- to 24-year-olds) & & \\
\hline $27 a$ & Use of Class A drugs & $\begin{array}{l}\text { England + } \\
\text { Wales }\end{array}$ & $\begin{array}{l}\text { British Crime } \\
\text { Survey }\end{array}$ \\
\hline $27 \mathbf{b}$ & Frequent use of any illicit drug & $\begin{array}{l}\text { England + } \\
\text { Wales }\end{array}$ & $\begin{array}{l}\text { British Crime } \\
\text { Survey }\end{array}$ \\
\hline
\end{tabular}




\begin{tabular}{|c|c|c|c|}
\hline \multicolumn{2}{|c|}{ People aged 50+ and retired people } & \multirow{3}{*}{ Coverage } & \multirow[b]{2}{*}{ Source } \\
\hline \multicolumn{2}{|c|}{ Indicator } & & \\
\hline 28 & Low income: & & \\
\hline 28a & Relative low income & GB & HBAI/FRS \\
\hline $28 b$ & Absolute low income & GB & HBAI/FRS \\
\hline $28 \mathrm{c}$ & Persistent low income & GB & HBAI/FRS/BHPS \\
\hline 29 & $\begin{array}{l}\text { People contributing to a non- } \\
\text { state pension }\end{array}$ & GB & FRS \\
\hline 30 & $\begin{array}{l}\text { People making continuous } \\
\text { contributions to a non-state } \\
\text { pension }\end{array}$ & GB & BHPS \\
\hline 31 & Healthy life expectancy at 65 & England & ONS \\
\hline 32 & $\begin{array}{l}\text { Being helped to live } \\
\text { independently }\end{array}$ & & \\
\hline $32 a$ & Receiving intensive home care & England & $\begin{array}{l}\text { Social Services } \\
\text { Performance } \\
\text { Assessment } \\
\text { Framework } \\
\text { Indicators } \\
\text { AO/C28 }\end{array}$ \\
\hline 32b & $\begin{array}{l}\text { Receiving any community- } \\
\text { based service }\end{array}$ & England & SSPAFI AO/C32 \\
\hline 33 & $\begin{array}{l}\text { Housing that falls below the set } \\
\text { standard of decency }\end{array}$ & England & $\begin{array}{l}\text { English House } \\
\text { Condition Survey }\end{array}$ \\
\hline 34 & Fear of crime & $\begin{array}{l}\text { England + } \\
\text { Wales }\end{array}$ & $\begin{array}{l}\text { British Crime } \\
\text { Survey }\end{array}$ \\
\hline
\end{tabular}

\begin{tabular}{|l|l|l|l|}
\hline Communities & Coverage & Source \\
\hline Indicator & $\begin{array}{l}\text { Employment rates in deprived } \\
\text { areas }\end{array}$ & GB & LFS \\
\hline $\mathbf{3 5}$ & $\begin{array}{l}\text { Crime rates in high-crime } \\
\text { areas }\end{array}$ & $\begin{array}{l}\text { England } \\
\text { Wales }\end{array}$ & $\begin{array}{l}\text { Home Office } \\
\text { Crime/Crime and } \\
\text { Disorder } \\
\text { Statistics }\end{array}$ \\
\hline $\mathbf{3 7}$ & $\begin{array}{l}\text { Housing that falls below the } \\
\text { set standard of decency }\end{array}$ & England & $\begin{array}{l}\text { English House } \\
\text { Condition Survey }\end{array}$ \\
\hline $\mathbf{3 8}$ & Households in fuel poverty & England & $\begin{array}{l}\text { English House } \\
\text { Condition } \\
\text { Survey/ Energy } \\
\text { Follow-up } \\
\text { Survey }\end{array}$ \\
\hline $\mathbf{3 9}$ & Life expectancy at birth & England & ONS \\
\hline $\mathbf{4 0}$ & $\begin{array}{l}\text { Attainment gap at Key Stage } \\
\text { 2 (11-year-olds) }\end{array}$ & England & DfES \\
\hline $\mathbf{4 1}$ & Casualties in deprived areas & England & DfT STATS 19 \\
\hline & \multicolumn{2}{|l}{} \\
\hline
\end{tabular}




\section{Appendix 2: Monitoring Poverty and Social Exclusion 2005 indicators}

\begin{tabular}{|l|l|l|l|}
\hline \multicolumn{2}{|l|}{ Low income } & \multicolumn{2}{l}{} \\
\cline { 1 - 2 } Indicator & Coverage & Source \\
\hline $\mathbf{1}^{* * *}$ & Numbers in low income & GB & HBAI/FES/FRS \\
\hline $\mathbf{1 a}^{* * *}$ & Income inequalities & GB & HBAI/FRS \\
\hline $\mathbf{1 b}^{* * *}$ & Location of low income & GB & HBAI/FRS \\
\hline $\mathbf{2}^{* * *}$ & Low income by age group & GB & HBAI/FRS \\
\hline $\mathbf{3}^{* * *}$ & Low income by family type & GB & HBAI/FRS \\
\hline $\mathbf{3 a}^{* *}$ & Low income and ethnicity & GB & HBAI/FRS \\
\hline $\boldsymbol{3 b}^{* *}$ & Paying Council Tax & $\begin{array}{l}\text { England + } \\
\text { Wales }\end{array}$ & HBAI/FRS \\
\hline $\mathbf{3}^{* *}$ & Persistent low income & GB & BHPS \\
\hline $\mathbf{3 d}^{* *}$ & Material deprivation & GB & BHPS \\
\hline $\mathbf{4}^{* * *}$ & Out-of-work benefit levels & GB & DWP \\
\hline $\mathbf{4 a}^{* * *}$ & Out-of-work benefit recipients & GB & DWP \\
\hline $\mathbf{5}^{* * *}$ & $\begin{array}{l}\text { Long-term working-age } \\
\text { recipients of out-of-work benefit } \\
\text { levels }\end{array}$ & GB & DWP/NOMIS \\
\hline $\mathbf{6}^{* *}$ & In receipt of tax credits & GB & \\
\hline
\end{tabular}

\begin{tabular}{|c|c|c|c|}
\hline \multicolumn{2}{|c|}{ Children } & \multirow{3}{*}{ Coverage } & \multirow{2}{*}{ Source } \\
\hline \multicolumn{2}{|c|}{ Indicator } & & \\
\hline & Economic circumstances & & \\
\hline $7 * * *$ & Numbers in low income & GB & HBAI/FRS \\
\hline $\mathbf{8}^{* * *}$ & $\begin{array}{l}\text { Children in workless } \\
\text { households }\end{array}$ & UK & LFS \\
\hline \multirow[t]{2}{*}{ 9* } & $\begin{array}{l}\text { Concentrations of children } \\
\text { eligible for free school meals }\end{array}$ & England & DfES \\
\hline & Health and well-being & & \\
\hline $10^{*}$ & Low birthweight babies & $\begin{array}{l}\text { England + } \\
\text { Wales }\end{array}$ & ONS DH3 \\
\hline $11 * * *$ & Infant mortality & $\begin{array}{l}\text { England + } \\
\text { Wales }\end{array}$ & ONS \\
\hline $11 a^{* * *}$ & Dental health & GB & $\begin{array}{l}\text { Specialised } \\
\text { dentistry survey }\end{array}$ \\
\hline $11 b^{* *}$ & Accidental deaths & $\begin{array}{l}\text { England + } \\
\text { Wales }\end{array}$ & \\
\hline \multirow[t]{2}{*}{$12 * *$} & Underage conceptions & GB & ONS DH3 \\
\hline & Education & & \\
\hline $13^{* *}$ & $\begin{array}{l}\text { Low attainment at } \\
\text { (maintained) school: } \\
\text { 11-year-olds }\end{array}$ & England & DfES \\
\hline $14 * *$ & $\begin{array}{l}\text { Low attainment at school: } \\
\text { 16-year-olds }\end{array}$ & $\begin{array}{l}\text { England + } \\
\text { Wales }\end{array}$ & $\begin{array}{l}\text { DfES/Welsh } \\
\text { Assembly }\end{array}$ \\
\hline $15 * *$ & $\begin{array}{l}\text { Permanent exclusions from } \\
\text { school }\end{array}$ & GB & $\begin{array}{l}\text { DfES/Welsh } \\
\text { Assembly/Scottish } \\
\text { Executive }\end{array}$ \\
\hline $15 b^{* *}$ & $\begin{array}{l}\text { In young offenders' } \\
\text { institutions }\end{array}$ & $\begin{array}{l}\text { England + } \\
\text { Wales }\end{array}$ & $\begin{array}{l}\text { Youth Justice } \\
\text { Board }\end{array}$ \\
\hline
\end{tabular}




\begin{tabular}{|c|c|c|c|}
\hline \multicolumn{2}{|c|}{ Young adults } & \multirow{3}{*}{ Coverage } & \multirow{3}{*}{ Source } \\
\hline \multicolumn{2}{|c|}{ Indicator } & & \\
\hline & Transitions to adulthood & & \\
\hline $16^{* * *}$ & $\begin{array}{l}\text { Without a basic qualification } \\
\text { (19-year-olds lacking NVQ } \\
\text { Level 2) }\end{array}$ & UK & LFS \\
\hline $16 a^{* * *}$ & Impact of education on work & UK & LFS \\
\hline $17 * * *$ & School leavers & England & Connexions/HEFCE \\
\hline $18^{* *}$ & $\begin{array}{l}\text { 18- to } 20 \text {-year-olds with a } \\
\text { criminal record }\end{array}$ & $\begin{array}{l}\text { England + } \\
\text { Wales }\end{array}$ & $\begin{array}{l}\text { Home Office } \\
\text { Criminal Statistics }\end{array}$ \\
\hline & Economic circumstances & & \\
\hline $19 * * *$ & In low-income households & GB & HBAI/FRS \\
\hline $20 * * *$ & Unemployment & UK & LFS \\
\hline $21 * *$ & Low pay & UK & ONS/LFS/ASHE \\
\hline $21 a^{*}$ & Problem drug users treated & GB & $\mathrm{DH}$ \\
\hline $21 b^{* *}$ & Suicides & GB & ONS \\
\hline
\end{tabular}

\begin{tabular}{|c|c|c|c|}
\hline \multicolumn{2}{|c|}{ Working-age adults aged 25+ } & \multirow{3}{*}{ Coverage } & \multirow{3}{*}{ Source } \\
\hline Indicat & & & \\
\hline & Economic circumstances & & \\
\hline $22 * * *$ & Low income and work & GB & HBAI/FRS \\
\hline \multirow[t]{2}{*}{$23^{* * *}$} & Low income and disability & GB & HBAI/FRS \\
\hline & Exclusion from work & & \\
\hline $24 * * *$ & Wanting paid work & UK & LFS \\
\hline $25 * * *$ & Work and disability & UK & LFS \\
\hline $25 a^{* * *}$ & Work and lone parents & UK & LFS/ONS \\
\hline $25 b^{* *}$ & Work and ethnicity & UK & LFS \\
\hline $26 * * *$ & Workless households & UK & LFS \\
\hline \multirow[t]{2}{*}{$26 a^{* *}$} & Jobs & UK & $\begin{array}{l}\text { Labour Market } \\
\text { Statistics }\end{array}$ \\
\hline & Low pay & & \\
\hline $27 * *$ & Low pay by gender & UK & ONS/LFS/ASHE \\
\hline $28 * *$ & Low pay by industry & UK & LFS \\
\hline $29 * *$ & Low pay and disability & UK & LFS \\
\hline $29 a^{*}$ & Low pay and ethnicity & UK & LFS \\
\hline \multirow[t]{2}{*}{$29 b^{* * *}$} & Pay inequalities & UK & NES/ASHE \\
\hline & Disadvantaged at work & & \\
\hline $30 * * *$ & Insecure at work & UK & JUVOS/LFS \\
\hline $31^{* * *}$ & Support at work & & \\
\hline \multirow[t]{2}{*}{$31 a^{* * *}$} & Adults without qualifications & $\begin{array}{l}\text { UK/ } \\
\text { England + } \\
\text { Wales }\end{array}$ & $\begin{array}{l}\text { LFS/Skills for } \\
\text { Life }\end{array}$ \\
\hline & Health and well-being & & \\
\hline $32 * * *$ & Premature death & GB & ONS \\
\hline $33^{* *}$ & Limiting long-standing illness & GB & GHS \\
\hline $34 * * *$ & Mental health & England & HSE \\
\hline $35 * * *$ & Obesity & England & $\begin{array}{l}\text { Health Survey } \\
\text { for England }\end{array}$ \\
\hline
\end{tabular}




\begin{tabular}{|c|c|c|c|}
\hline \multicolumn{2}{|c|}{ Pensioners } & \multirow{3}{*}{ Coverage } & \multirow{3}{*}{ Source } \\
\hline Indicato & & & \\
\hline & Economic circumstances & & \\
\hline $35 * * *$ & In low-income households & GB & HBAI/FRS \\
\hline $36 * * *$ & No private income & GB & FRS \\
\hline $36 a^{* *}$ & Spending on essentials & UK & EFS \\
\hline \multirow[t]{2}{*}{$37^{* *}$} & Non-take-up of benefits & GB & DWP \\
\hline & Health and well-being & & \\
\hline \multirow[t]{2}{*}{$38 *$} & Excess winter deaths & $\begin{array}{l}\text { England + } \\
\text { Wales }\end{array}$ & ONS \\
\hline & Isolation and support & & \\
\hline $39 * *$ & Limiting long-standing illness & GB & GHS \\
\hline 40a** & Receiving help to live at home & England & DH HHI \\
\hline $41^{* *}$ & $\begin{array}{l}\text { Anxiety: unsafe walking alone after } \\
\text { dark }\end{array}$ & $\begin{array}{l}\text { England + } \\
\text { Wales }\end{array}$ & $\begin{array}{l}\text { British } \\
\text { Crime } \\
\text { Survey }\end{array}$ \\
\hline $41 a^{* * *}$ & Rural access to services & England & $\begin{array}{l}\text { Rural } \\
\text { Services } \\
\text { Survey }\end{array}$ \\
\hline $41 b^{* *}$ & Without a telephone & UK & FES/EFS \\
\hline
\end{tabular}

\begin{tabular}{|c|c|c|c|}
\hline \multicolumn{2}{|c|}{ Community } & \multirow{3}{*}{ Coverage } & \multirow[b]{2}{*}{ Source } \\
\hline Indicate & & & \\
\hline & Polarisation of low income & & \\
\hline $42^{* * *}$ & $\begin{array}{l}\text { Polarisation of low income/ } \\
\text { housing tenure }\end{array}$ & GB/UK & FRS/Census \\
\hline $43 * *$ & Concentration of low income & England & $\begin{array}{l}\text { Index of } \\
\text { Deprivation }\end{array}$ \\
\hline $43 a^{* * *}$ & Dissatisfaction with local area & England & $\begin{array}{l}\text { Survey of } \\
\text { English } \\
\text { Housing }\end{array}$ \\
\hline $44 * * *$ & Victims of crime & $\begin{array}{l}\text { England + } \\
\text { Wales }\end{array}$ & $\begin{array}{l}\text { British Crime } \\
\text { Survey }\end{array}$ \\
\hline \multirow[t]{2}{*}{$44 b^{* *}$} & Non-participation & GB & BHPS \\
\hline & Access to services & & \\
\hline $45 * *$ & $\begin{array}{l}\text { Transport: number of } \\
\text { journeys/car ownership }\end{array}$ & GB & $\begin{array}{l}\text { National } \\
\text { Travel Survey } \\
\end{array}$ \\
\hline $46 * *$ & Without a bank account & GB & FRS \\
\hline \multirow[t]{2}{*}{$47 * *$} & $\begin{array}{l}\text { Without home contents } \\
\text { insurance }\end{array}$ & $\begin{array}{l}\text { England } \\
\text { and Wales }\end{array}$ & EFS \\
\hline & Housing & & \\
\hline $48 * * *$ & Without central heating & GB & FRS \\
\hline $48 a^{* *}$ & Non-decent homes & England & $\begin{array}{l}\text { English House } \\
\text { Condition } \\
\text { Survey }\end{array}$ \\
\hline $48 b^{* *}$ & Energy inefficient home & England & EHCS \\
\hline $48 c * *$ & Fuel poverty & England & EHCS \\
\hline $49 *$ & Homeless households & England & ODPM \\
\hline $49 a^{*}$ & Overcrowding & GB/England & GHS/SEH \\
\hline $50 * * *$ & Serious mortgage arrears & England & $\begin{array}{l}\text { Survey of } \\
\text { English } \\
\text { Housing }\end{array}$ \\
\hline $50 a^{* *}$ & Housing Benefit(non-take-up) & GB/UK & FRS/DWP \\
\hline
\end{tabular}

Notes: indicators in italics are not included in the hard copy report, but are on the NPI website only. 
* Indicator judged by the report's authors to be of limited overall adequacy.

** Indicator judged by the report's authors to be of medium overall adequacy.

*** Indicator judged by the report's authors to be of high overall adequacy.

1. Indicator 9 is described by the report's authors as 'limited' because "while the underlying data is sound, its relationship to other aspects of poverty and social exclusion is not immediately clear" (Palmer et al, 2005 p 42).

2. Indicator 45 is assessed as of medium adequacy in the report. However, "it is not at all clear that the data fully captures the problems of transport in relation to poverty and social exclusion" (p 106). Moreover, the assessment of 'number of journeys' that leads to the claim that "people in households with a car make twice the number of journeys as those without a car" is "calculated as the total number of trips by all methods less the number of walking trips" (p 106). Given the environmental necessity of raising the proportion of journeys made on foot, and the inclusion of this in the government's sustainable development indicators, this seems perverse.

HEFCE: Higher Education Funding Council for England; ASHE: Association for the Study of Higher Education; NES: New earnings Survey; JUVOS: Joint Unemployment and Vacancies Operating System; HHI; SEH: Survey of English Housing. 


\section{Appendix 3: Index of Multiple Deprivation}

\section{Adapted from: ODPM (2004) The English Indices Of Deprivation 2004 - Summary (Revised)}

The Index of Multiple Deprivation (IMD), uses 33 indicators to measure deprivation in each of the 8,415 wards in England. These indicators can be categorised into the seven domains of:

- Income deprivation

- Employment deprivation

- Health deprivation and disability

- Education, skills and training deprivation

- Barriers to housing and services

- Crime

- Living environment deprivation

\section{Income deprivation domain}

The purpose of this domain is to capture the proportion of the population experiencing income deprivation in an area. The indicators are:

- $\quad$ Adults and children in Income Support households (2001).

- $\quad$ Adults and children in Income-based Jobseeker's Allowance households (2001).

- $\quad$ Adults and children in Working Families Tax Credit households whose equivalised income (excluding Housing Benefits) is below 60\% of median before housing costs (2001).

- $\quad$ Adults and children in Disabled Person's Tax Credit households whose equivalised income (excluding Housing Benefits) is below $60 \%$ of median before housing costs (2001).

- National Asylum Support Service supported asylum seekers in England in receipt of subsistence only and accommodation support (2002).

There are separate indices for income deprivation affecting children and income deprivation affecting older people.

\section{Employment deprivation domain}

This domain measures employment deprivation conceptualised as involuntary exclusion of the working-age population from paid work.

- $\quad$ Unemployment claimant count (JUVOS) of women aged 18-59 and men aged 18-64 averaged over four quarters (2001).

- $\quad$ Incapacity Benefit claimants: women aged 18-59 and men aged 18-64 (2001).

- $\quad$ Severe Disablement Allowance claimants: women aged 18-59 and men aged 18-64 (2001).

- $\quad$ Participants in New Deal for the 18-24s who are not included in the claimant count (2001).

- $\quad$ Participants in New Deal for 25+ who are not included in the claimant count (2001).

- $\quad$ Participants in New Deal for Lone Parents aged 18 and over (2001). 


\section{Health deprivation and disability domain}

This domain identifies areas with relatively high rates of people who die prematurely or whose quality of life is impaired by poor health or who are disabled, across the whole population.

- $\quad$ Years of potential life lost (1997-2001).

- $\quad$ Comparative illness and disability ratio (2001).

- $\quad$ Measures of emergency admissions to hospital (1999-2002).

- $\quad$ Adults under 60 suffering from mood or anxiety disorders (1997-2002).

\section{Education, skills and training deprivation domain}

This domain addresses deprivation in terms of education, skills and training in a local area. There are two sub-domains: one relating to children/young and one relating to lack of skills and qualifications among the working-age adult population.

\section{Sub-domain: Children/young people}

- $\quad$ Average points score of children at Key Stage 2 (2002).

- $\quad$ Average points score of children at Key Stage 3 (2002).

- $\quad$ Average points score of children at Key Stage 4 (2002).

- $\quad$ Proportion of young people not staying on in school or school level education above 16 (2001).

- $\quad$ Proportion of those aged under 21 not entering Higher Education (1999-2002).

- $\quad$ Secondary school absence rate (2001-02).

\section{Sub-domain: Skills}

- Proportions of working-age adults (aged 25-54) in the area with no or low qualifications (2001).

\section{Barriers to housing and services domain}

This domain measures barriers to housing and key local services. There are two sub-domains: 'wider barriers' and 'geographical barriers', which additionally include issues relating to access to housing, such as affordability.

\section{Sub-domain: Wider barriers}

- $\quad$ Household overcrowding (2001).

- Local authority level percentage of households for whom a decision on their application for assistance under the homeless provisions of housing legislation has been made, assigned to SOAs (2002).

- Difficulty of access to owner-occupation (2002).

\section{Sub-domain: Geographical barriers}

- $\quad$ Road distance to GP premises (2003).

- $\quad$ Road distance to a supermarket or convenience store (2002).

- Road distance to a primary school (2001-02).

- $\quad$ Road distance to a post office (2003). 


\section{Crime domain}

This domain measures the incidence of recorded crime for four major crime themes, representing the occurrence of personal and material victimisation at a small area level.

- $\quad$ Burglary (four recorded crime offence types, April 2002-March 2003).

- $\quad$ Theft (five recorded crime offence types, April 2002-March 2003, constrained to CDRP [Crime and Disorder Reduction Partnership] level).

- $\quad$ Criminal damage (10 recorded crime offence types, April 2002-March 2003).

- $\quad$ Violence (14 recorded crime offence types, April 2002-March 2003).

\section{Living environment deprivation domain}

This domain focuses on the characteristics of the living environment, using two sub-domains: the 'indoors' living environment, with indicators of housing quality; and the 'outdoors' living environment, which contains indicators of air quality and the level of road traffic accidents.

\section{Sub-domain: The 'indoors' living environment}

- $\quad$ Social and private housing in poor condition (2001).

- $\quad$ Houses without central heating (2001).

\section{Sub-domain: The 'outdoors' living environment}

- $\quad$ Air quality (2001).

- $\quad$ Road traffic accidents involving injury to pedestrians and cyclists (2000-02). 


\section{Appendix 4: Audit Commission quality of life indicators}

The Audit Commission have also developed quality of life indicators for use at the level of local government. Like the sustainable development indicators, these are often at area rather than individual level. Ten domains are identified:

- People and place

- Community cohesion and involvement

- Community safety

- Culture and leisure

- Economic well-being

- Education and lifelong learning

- Environment

- Health and social well-being

- Housing

- Transport and access

- Other indicators

\section{People and place}

- Priorities for improvement in the local area, as defined by local residents.

\section{Community cohesion and involvement}

- The percentage of residents who think that people being attacked because of their skin colour, ethnic origin or religion is a very big or fairly big problem in their local area.

- The percentage of residents who think that for their local area, over the past three years, community activities have got better or stayed the same.

- Election turnout.

\section{Community safety}

- The percentage of residents surveyed who said they feel 'fairly safe' or 'very safe' outside (a) during the day; (b) after dark.

- Domestic burglaries per 1,000 households.

- Violent offences committed per 1,000 of the population.

- Theft of a vehicle per 1,000 of the population.

- Sexual offences per 1,000 of the population.

- The percentage of residents who think that (a) vandalism, graffiti and other deliberate damage to property or vehicles; (b) people using or dealing drugs; and (c) people being rowdy or drunk in public places is a very big or fairly big problem in their local area.

- The number of (a) pedestrian and; (b) cyclist road accident casualties per 100,000 of the population. 


\section{Culture and leisure}

- The percentage of the population within 20 minutes travel time (urban - walking, rural - by car) of different sports facility types.

- The percentage of residents who think that for their local area, over the past three years the following have got better or stayed the same: (a) activities for teenagers; (b) cultural facilities (for example, cinemas, museums); (c) facilities for young children;

(d) sport and leisure facilities; and (e) parks and open spaces.

\section{Economic well-being}

- The percentage of the working-age population that is in employment.

- The number of Jobseeker's Allowance claimants as a percentage of the resident working-age population and; (b) percentage of these who have been out of work for more than a year.

- The total number of VAT registered businesses in the area at the end of the year.

- The percentage change in the number of VAT registered businesses.

- Job density (number of jobs filled to working-age population).

- The proportion of the population living in the most deprived super output areas in the country.

- The percentage of the population of working age that is claiming key benefits.

- The percentage of (a) children; and (b) population over 60 that live in households that are income deprived.

\section{Education and lifelong learning}

- $\quad$ The percentage of half days missed due to total absence in (a) primary; and (b) secondary schools maintained by the local education authority.

- The proportion of young people (16- to 24-year-olds) in full-time education or employment.

- The proportion of working-age population qualified to (a) NVQ Level 2 or equivalent; and (b) NVQ Level 4 or equivalent.

- The percentage of 15-year-old pupils in schools maintained by the local authority achieving five or more GCSEs at grades $\mathrm{A} *$-C or equivalent.

\section{Environment}

- The proportion of developed land that is derelict.

- The proportion of relevant land and highways that is assessed as having combined deposits of litter and detritus.

- Levels of key air pollutants.

- Carbon dioxide emissions by sector and per capita emissions.

- Average annual domestic consumption of gas and electricity (kwh).

- Daily domestic water use (per capita consumption).

- The percentage of river length assessed as (a) good biological quality; and (b) good chemical quality.

- The volume of household waste collected and the proportion recycled.

- The percentage area of land designated as sites of special scientific interest (SSSI) within the local authority area in favourable condition; and (b) the area of land designated as a local nature reserve per 1,000 of the population. 


\section{Health and social well-being}

- Age-standardised mortality rates for (a) all cancers; (b) circulatory diseases; and (c) respiratory diseases.

- Infant mortality.

- Life expectancy at birth (male and female).

- The percentage of households with one or more person with a limiting long-term illness.

- Teenage pregnancy, conceptions under 18 years, per 1,000 females aged 15-17.

\section{Housing}

- The total number of new housing completions.

- Affordable dwellings completed as a percentage of all new housing completions.

- Household accommodation without central heating.

- The percentage of residents who think that people sleeping rough on the streets or in other public places is a very big or fairly big problem in their local area.

- The percentage of all housing that is unfit.

- House price to income ratio.

\section{Transport and access}

- The percentage of the resident population who travel to work (a) by private motor vehicle; (b) by public transport; (c) on foot or cycle.

- The percentage of the resident population travelling over $20 \mathrm{~km}$ to work.

- The percentage of residents who think that for their local area, over the past three years, that (a) public transport has got better or stayed the same; (b) the level of traffic congestion has got better or stayed the same.

- Estimated traffic flows for all vehicle types (million vehicle $\mathrm{km}$ ).

\section{Other indicators}

The indicators below cover important quality of life areas. Unfortunately, there are no guaranteed national data sources at present to provide comparable data for every local authority area. Nevertheless, we have listed them below as we are confident that the indicators themselves are robust and that a national source is likely to become available in the next few years:

- The percentage of people surveyed who feel that their local area is a place where people from different backgrounds get on well together.

- The percentage of people surveyed who feel they can influence decisions affecting their local area.

- Percentage of people surveyed finding it easy to access key local services.

- The number of childcare places. 


\section{Appendix 5: Percentage of the population perceiving adult item or activity as necessary in the 1999 PSE Survey}

\begin{tabular}{|c|c|c|c|}
\hline Adult item and activity & Necessary & Desirable & Don’t know \\
\hline Beds and bedding for everyone & 95 & 4 & \\
\hline Heating to warm living areas & 94 & 5 & \\
\hline Damp free home & 93 & 6 & 1 \\
\hline Visiting friends or family in hospital & 92 & 7 & 1 \\
\hline Two meals a day & 91 & 9 & 1 \\
\hline Medicines prescribed by doctor & 90 & 9 & 1 \\
\hline Refrigerator & 89 & 11 & 1 \\
\hline Fresh fruit and vegetables daily & 86 & 13 & 1 \\
\hline A warm waterproof coat & 85 & 14 & 1 \\
\hline Replace broken electrical goods & 85 & 14 & 2 \\
\hline Visits to friends or family & 84 & 15 & 1 \\
\hline Celebrations on special occasions & 83 & 16 & 2 \\
\hline Money to keep home decorated & 82 & 17 & 1 \\
\hline Visits to school eg sports day & 81 & 17 & 2 \\
\hline Attending weddings, funerals & 80 & 19 & 1 \\
\hline Meat, fish or vegetarian equivalent & 79 & 19 & 1 \\
\hline Insurance of contents of dwelling & 79 & 20 & 1 \\
\hline A hobby or leisure activity & 78 & 20 & 1 \\
\hline A washing machine & 76 & 22 & 1 \\
\hline Collect children from school & 75 & 23 & 3 \\
\hline Telephone & 71 & 28 & 1 \\
\hline Deep freezer/fridge freezer & 68 & 30 & 2 \\
\hline Carpets in living rooms and bedrooms & 67 & 31 & 2 \\
\hline Regular savings for rainy days & 66 & 32 & 2 \\
\hline Two pairs of all weather shoes & 64 & 34 & 2 \\
\hline Friends or family round for a meal & 64 & 34 & 2 \\
\hline Leisure equipment (eg for sports) & 60 & 38 & 2 \\
\hline Money to spend on self weekly & 59 & 39 & 2 \\
\hline A television & 56 & 43 & 2 \\
\hline $\begin{array}{l}\text { A roast joint/vegetarian equivalent } \\
\text { weekly }\end{array}$ & 56 & 41 & 3 \\
\hline Presents for friends/family yearly & 56 & 42 & 2 \\
\hline A holiday away from home & 55 & 43 & 3 \\
\hline Replace worn out furniture & 54 & 43 & 3 \\
\hline A dictionary & 53 & 44 & 3 \\
\hline An outfit for social occasions & 51 & 46 & 3 \\
\hline New, not second-hand, clothes & 48 & 49 & 3 \\
\hline A car & 38 & 59 & 3 \\
\hline $\begin{array}{l}\text { Coach/train fares to visit } \\
\text { friends/family }\end{array}$ & 38 & 58 & 4 \\
\hline A evening out once a fortnight & 37 & 56 & 3 \\
\hline A dressing gown & 34 & 63 & 4 \\
\hline Having a daily newspaper & 30 & 66 & 4 \\
\hline A meal in a restaurant/pub monthly & 26 & 71 & 4 \\
\hline Microwave oven & 23 & 73 & 4 \\
\hline Tumble dryer & 20 & 75 & 4 \\
\hline Going to the pub once a fortnight & 20 & 76 & 4 \\
\hline A video cassette recorder & 19 & 78 & 3 \\
\hline Holidays abroad once a year & 19 & 77 & 4 \\
\hline CD player & 12 & 84 & 4 \\
\hline A home computer & 11 & 85 & 4 \\
\hline A dishwasher & 7 & 88 & 5 \\
\hline
\end{tabular}


Mobile phone

Access to the internet

Satellite television
88

89

90
5

6

5

5

5 


\section{Appendix 6: A survey of surveys}

Title: The Avon Longitudinal Study of Parents and Children (ALSPAC), formerly the Avon Longitudinal Study of Pregnancy and Childhood

Principal Investigator(s):

George Davey Smith, Bristol University

Description: The aims of ALSPAC are to determine which biological, environmental, social, psychological and psychosocial factors are associated with the survival and optimal health and development of the foetus, infant and child, and the ways in which causal relationships might vary with the genetic composition of mother and/or child. The study seeks to identify the complex ways in which environmental features may be associated with the optimal development, health and well-being of the child, and involves an examination of the ways in which genes and the environment interact. A child's ability to meet environmental and social challenges is influenced by genetic variation, but the interactions are complex. ALSPAC was specifically designed to analyse this interplay between genes and environment with respect to important relatively common health outcomes.

ALSPAC has the long-term aim of following the children into adulthood and thus seeks to answer questions related to prenatal and postnatal factors associated, for example, with schizophrenia, delinquency, reproductive failure on the one hand, and realisation of full educational potential, health and happiness on the other.

The study of the ways in which genes and the environment interact to result in morbidity of the parents will provide a very valuable scientific resource to suggest hypotheses and mechanisms for detailed study in the children.

Although the study will not itself make any health service provision it is designed to identify strategies that may improve health and to test them using appropriate research methods.

\section{Coverage:}

Dates of Fieldwork: Questionnaires started in pregnancy and conducted on a rolling basis according to age of children. See: www.alspac.bris.ac.uk/quests/default.shtml for further details. Hands-on assessments of the children carried out on a $10 \%$ subsample every 4 months from birth to age 1 then every 6 months to age 4 and again at age 5. Hands-on assessments were then carried out on the whole cohort annually from age 7 to age 13 and then again at age 15 .

Country: England

Spatial Units: Ward. Matching via postcode/enumeration district is available.

Observation Units: Individuals/Families

\section{Universe Sampled:}

Location of Units of Observation: Avon

Population: Children born in Avon between 1991 and 1992 and their parents. 
Sample Frame: Mothers resident in Avon with an expected date of delivery between 1st April 1991 and 31st December 1992 inclusive. Mothers who were resident in the area but left shortly after enrolment were omitted from further follow-up. However, those who had completed the questionnaire scheduled for the third trimester of pregnancy before leaving the study area have been kept in the study, even if they had not delivered at the time of moving.

Sample Design: All eligible population invited to participate formerly through midwives and informally through local publicity

\section{Methodology:}

Time Dimensions: Continuous panel survey.

Number of Units (year): Initial sample consisted of: 14,541 pregnancies resulting in 14,062 live born children.

Method of Data Collection: Postal questionnaires, hands on assessments, biological samples (e.g. blood), linked to medical and educational records and ONS vital events data.

Weighting: No

\section{Additional Information:}

Use of proxy informants: No

Proxy respondents: N/A

Missing data on proxy informants: N/A

Overall response rate: Some information exists on each of the 14,541 pregnancies. The average response rate to questionnaires sent to mothers as of December 1998 is $80.69 \%$ (255,961 questionnaires returned out of 317,201 sent). The response rates from partners averages $52.04 \%(61,359$ out of 117,898$)$.

Differential response rate: Response rates are lower and decline faster for certain groups e.g. non white ethnic groups, lower socio economic groups, lower education, striving neighbourhoods Imputation of missing information: No

Attrition rates: Response rate at age 4 weeks was 88\%; at 24 months (74\%); at 54 months (69\%); at 77 months (61\%); at 103 months (58\%); at 128 months (54\%); and at 157 months (49\%).

Boosters: No

Period covered by series: September 1990 - present

Common risk factors: Age, sex, gender, ethnicity, tenure, household type, social class Less common risk factors: Religion, involvement in criminal activities, criminal record

Critical life events: Divorce, pregnancy

Local area information: Local MID score, council tax bands, ACORN, plus also individual level data such as end of key stage assessment scores.

\section{Overview:}

Despite the richness of data contained in ALSPAC, secondary analysis has thus far been restricted because the data have not been available for analysis without charge. However, this is likely to change because the cost is reducing to actual cost and plans are in place for some data to be made freely available. 
ALSPAC offers a number of potential advantages to social policy analysts in relation to the study of exclusion, including:

- A longitudinal cohort survey, collecting data at frequent intervals, allowing for investigation of process and causal inference.

- Long time span (since 1991) allowing for the investigation of long-term timedependent processes.

- Rich data source; captures many dimensions of social exclusion in detail, and has a particularly strong emphasis health, quality of home and neighbourhood environment, and also parental and peer relationships.

- Contains bio-medical data on both children and their parents which allow for the examination of gene/environment interaction.

- Is one of the few surveys which includes data obtained directly from children. It also has proxy data obtained from the child's main carer and the school teacher.

- Is linked to a number of administrative data sources e.g. NHS Vital Events data, and contains relevant local information e.g. multiple deprivation, neighbourhood type.

The disadvantages of ALSPAC in relation to the study of multi-dimensional exclusion include:

- Survey coverage of income, material deprivation and political participation is relatively weak.

- Sample is drawn from the Avon region; it is not a nationally representative survey.

- It is not representative of all adults; ALSPAC surveys parents about their circumstances and views.

- As the cohort is clustered geographically, detailed analysis of some subgroups more vulnerable to social exclusion (e.g. minority ethnic children and their parents) cannot be undertaken.

- Increasing problems of non-response and attrition (resulting in sample bias and reduced sample sizes).

For further information about ALSPAC: www.alspac.bris.ac.uk/welcome/index.shtml 
Title: Annual Population Survey, 2005

Principal investigator(s): Office for National Statistics (ONS), Social and Vital Statistics Division

Description: The Annual Population Survey (APS) is a major new survey series. It aims to provide data that can produce reliable estimates at local authority level, across the UK, in key areas including education, employment, health and ethnicity. Until the end of December 2005, the APS comprised key variables from the Labour Force Survey (LFS), all its associated LFS boosts and the APS boost. Thus, the APS combined results from five different sources: the LFS (waves 1 and 5); the English Local Labour Force Survey (LLFS), the Welsh Labour Force Survey (WLFS), the Scottish Labour Force Survey (SLFS) and the APS boost sample. However, from January 2006 onwards the APS contains all the above data apart from the APS boost.

The APS aims to provide enhanced annual data for England, covering a target sample of at least 510 economically active people for each unitary authority/local authority district and at least 450 in each Greater London Borough.

\section{Coverage:}

Dates of fieldwork: January 2005-December 2005

Country: United Kingdom

Spatial units: Government Office for the Regions (GORs)

Observation units: Individuals

Kind of data: Numeric data; individual (micro) level

\section{Universe sampled:}

Location of units of observation: National

Population: People resident in the UK in private households, and young people living away from the parental home in student halls of residence or similar institutions during term time

Sample frame: Postcode address file

Sample design: Multi-stage stratified random sample

\section{Methodology:}

Time dimensions: Repeated cross-sectional study. The survey has a panel element, in that the households at selected addresses are interviewed annually over four waves, in the same way as for the LFS boosts. They then leave the survey and are replaced by other households.

Number of units (year): 495,097 individuals

Method of data collection: Face-to-face interview; telephone interview

Weighting: The APS requires two weighting variables due to the different data sources that make up the final data set. One weight is required when looking at core variables (in the APS boost sample), and one weight when looking at either only noncore variables (in the LLFS/LFS) or a combination (for example, a crosstab) of core and non-core variables.

\section{Additional information:}

Use of proxy informants: Yes (46\% of total interviews: 17\% spouse/partner proxy; $9 \%$ other proxy; and $21 \%$ children under 16 ) 
Proxy respondents: The LFS allows interviewers to take answers to questions by proxy if a respondent is unavailable. This is usually from another related adult who is a member of the same household, although there are exceptions to this rule: (i) a young person, of the same household, may translate for a non-English speaking relative; (ii) a carer, of the elderly or infirm, although not related, may answer for someone in their care if it can be established that they know the respondent well enough; (iii) anyone can respond by proxy with the personal permission of the head of household or spouse. See ONS (2003: 15) for information on variables relating to proxy informants.

Missing data on proxy informants: NA

Overall response rate: The overall response rate for the UK in the LFS is as follows:

\begin{tabular}{|l|c|c|c|c|c|c|}
\hline Quarter & \multicolumn{2}{|c|}{ Wave 1 } & \multicolumn{2}{c|}{ Waves 2-5 } & \multicolumn{2}{c|}{ Income } \\
\hline & & & & & wave 5/1 & waves 1 \& 5 \\
\hline & Percent & Number & Percent & Number & Percent & Percent \\
\hline Winter 00101 & 75 & 11,924 & 93 & 45,529 & $89 / 76$ & 82 \\
\hline Spring 01 & 78 & 12,391 & 88 & 43,240 & $88 / 76$ & 82 \\
\hline Summer 01 & 78 & 12,403 & 89 & 43,402 & $87 / 75$ & 81 \\
\hline Autumn 01 & 79 & 12,611 & 90 & 43,891 & $88 / 75$ & 81 \\
\hline Winter 01/02 & 78 & 12,488 & 90 & 44,087 & $87 / 75$ & 81 \\
\hline Spging 02 & 78 & 12,473 & 94 & 45.882 & $86 / 77$ & 81 \\
\hline
\end{tabular}

Source: ONS (2003: 2)

Differential response rate: A comparison of the census characteristics of responding and all non-responding households was carried out and multivariate analysis confirmed that region, building type, number of cars, number of adults, age of head, marital status of head, sex of head and qualification of head were most strongly independently associated with non-response in the LFS (see ONS, 2003, Section 9) Imputation of missing information: Imputation is used to estimate missing items on a questionnaire so that the potential bias in estimates due to item non-response may be reduced.

Attrition rates: See above

Boosters: Until January 2006, the APS contains the boost sample. When the APS booster is stopped, the sample size of the APS will be reduced by approximately 65,000 .

Period covered by series: 2004-05

Common risk factors: Includes gender, age, ethnicity, marital status, national identity, NS-SEG, tenure and household composition

Less common risk factors: Religion, English as a second language

Critical life events: Detailed questions on health, sickness and accidents

Local area information: None

Overview: The APS aims to plug an important gap in the provision of data at the local level. Until the existence of the APS, the LFS was used to provide estimates for a range of indicators down to the local education authority level. Now the APS is able provide information at the (smaller) local authority district level. It aims to meet a number of changing needs, including: (i) improved inter-censal monitoring of key variables; and (ii) provide statistics to the Neighbourhood Statistics Service (NeSS) in support of the National Strategy for Neighbourhood Renewal (Fido, 2005).

The survey has been used by a number of secondary analysts to explore different aspects of social exclusion, including: migrant workers, labour supply and labour 
market transitions, the social mobility of black people, poverty and debt, minority ethnic groups and work, and time and income poverty.

The APS offers a number of potential advantages to social policy analysts in relation to the study of social exclusion, including:

- extensive and reliable coverage of indicators relating to labour market exclusion and also health;

- reliable data at the local authority district level;

- data at quarterly intervals rather than on annual basis;

- a large sample size allowing for sub-group analyses (for example, life stage, gender, ethnicity, NS-SEC, disability);

- potential for multivariate analyses to explore relationships between labour markets, income poverty and ethnicity, gender, health, for example.

The disadvantages of the APS in relation to the study of multi-dimensional exclusion include:

- no information on a number of themes relating to social exclusion including material and economic resources, services, social resources and social participation, political participation, living environment, crime and criminalisation.

- nearly half of the cases are proxy interviews. Some of the data, particularly on income and hours of work, will not be as reliable as those based on non-proxy interviews.

- early sweeps have been withdrawn because of data errors. ONS decided to withdraw the April 2004-March 2005 datasets from the UK data archive and cancel the release of the July 2004-June 2005 datasets due to an error in the data. 
Title: 1970 British Cohort Study

Principal investigator(s): University of London, Institute of Education, Centre for Longitudinal Studies; City University, Social Statistics Research Unit; University of Bristol, Department of Child Health

Description: The 1970 British Cohort Study (BCS70) is a continuing, multidisciplinary longitudinal study taking as its subjects all those living in Great Britain born between 5th and 11th April 1970. Following the initial 1970 birth survey, there have been several attempts to gather information from the full cohort. With each successive wave, the scope of the study has broadened from a medical focus at birth, to encompass physical and educational development at the age of five, physical, educational and social development at the ages of 10 and 16, and physical, educational, social and economic development at 26 years. In addition, some subsample surveys have been carried out. In 1999/2000, the BCS70 was undertaken jointly with the National Child Development Study (NCDS) to interview cohort members on a wide range of topics at age 29. The main components of the BCS70 are detailed below:

1970: British Births Survey (J. Golding, University of Bristol)

1975: Child Health and Education Study (J. Golding, University of Bristol)

1980: Child Health and Education Study (J.M. Bynner, City University)

1986: Youthscan (J.M. Bynner, City University)

1992: BCS Twenty-One-Year Sample Survey (J.M. Bynner, City University)

1996: BCS Twenty-Six-Year Follow-Up (J.M. Bynner, City University)

2000: NCDS/BCS70 Follow-up (J. Elliott, Institute of Education)

\section{Coverage:}

Dates of fieldwork: 1970; 1972; 1975; 1980; 1986; 1992; 1996; 1999-2000

Country: Great Britain

Spatial units: No spatial units used

Observation units: Individuals; families/households

\section{Universe sampled:}

Location of units of observation: National

Population: All babies born between 5th and 11th April in Britain in 1970

Sample frame: Birth records of births in the UK 5-11 April 1970 maintained by health authorities

Sample design: In 1970, mothers of infants were recruited into the study by midwives. From 1970 through 1986, surviving cohort members were tracked through school records, the National Health Service Central Register (NHSCR), and media appeals. From 1996, cohort members have been traced through mailings, with the assistance of the NHSCR, the Driver and Vehicle Licensing Agency (DVLA), Ministry of Defence (MOD), NI records, telephone directories and the electoral register.

\section{Methodology:}

Time dimensions: Cohort

Number of units (year): 17,198 at birth in 1970 estimated to have included $96 \%$ to 98\% of all births in Britain in the survey week. Subsequent sample sizes: 13,135 (1975); 14,875 (1980); 11,628 (1998); 9,003 (1992); 11,261 (1996); 9,665 (2000) Method of data collection: Face-to-face interview; self-completion questionnaire 
Weighting: No weighting used

\section{Additional information:}

Use of proxy informants: Yes

Proxy respondents: Where an individual cannot be contacted, a proxy interview is conducted with a carer or near relative living in the same household

Missing data on proxy informants: Not known.

Overall response rate: $95.9 \%$ to $55.9 \%$ (See below)

Differential response rate: Various socio-economic factors are associated with differential response and attrition in the BCS70 including: parental social class, parental employment status, parental educational achievement, household benefit receipt, parents' country of origin, and housing tenure. Whilst spatial variations are negligible, many of these socio-economic factors are statistically significant. For further details see Bynner, 1996: 10-13; Goodman \& Butler, 1995: 11-13. Imputation of missing information: NA.

Attrition rates: The 1970 sample was estimated to include $96 \%$ to $98 \%$ of all births in the survey week. Response rates at subsequent age points as follows: $80 \%$ (age 5); 93\% (age 10); 72\% (age 26); 56\% (age 30); 70\% (age 34). For further details see Plewis et al. (2004).

Boosters: Not applicable

Period covered by series: 1970-2000

Common risk factors: Includes gender, age, ethnicity, tenure, household type, SEG, social class.

Less common risk factors: None.

Critical life events: Critical events in youth transitions such as leaving home, labour market entry, changes in marital status

Local area information: NA.

\section{Overview:}

Along with associated cohort datasets such as the Millennium Cohort Study (MCS) and NCDS, the BCS70 has established an international reputation for excellence in the field of cohort and longitudinal studies. As such, the BCS70 is a vital source in the analysis of the changing profile of youth transitions in Britain and has informed several major studies in this area (for example, Bynner et al, 1997; Ferri et al, 2003), as well as more specialised studies focusing on childhood and youth disadvantage and its consequences (for example, Bynner, 2003; Blanden, 2006; Blanden and Gibbons, 2006).

The principal advantages of the BCS70 in the investigation of multiple disadvantage include:

- international reputation for methodological rigour

- large sample sizes that allow for detailed sub-group analyses

- cohort structure allowing for investigation of process and causal inference

- long time span allowing the investigation of long-term time-dependent processes.

The main limitations of the BCS70 (and other British cohort studies) are detailed below (see also Longview Associates, 2006):

- an inability to address short-term poverty dynamics due to the infrequency of observations

- absence of spatial data referencing 
- lack of data on other household members

- increasing problems of non-response and attrition (resulting in sample bias and reduced sample sizes)

- absence of an intermediate study between BCS70 and MCS00 means that timedependent processes across the 1970-2000 period cannot be observed. 
Title: British Crime Survey, 2004-05

Principal investigator(s): Home Office, Research, Development and Statistics Directorate; British Market Research Bureau (BMRB) Social Research

Description: The British Crime Survey is primarily a 'victimisation' survey for England and Wales, in which respondents are asked about the experiences of property crimes of the household (for example, burglary) and personal crimes (for example, assault) that they themselves have experienced in the 12 months prior to interview. Because members of the public are asked directly about their experiences, the British Crime Survey provides a consistent measure of crime that is unaffected by the extent to which crimes are reported to the police, or by changes in the criteria used by the police when recording crime.

The British Crime Survey has also been successful at developing special measures to estimate the extent of domestic violence, stalking and sexual victimisation, which are probably the least reported to the police, but are among the most serious of crimes in their impact on victims. The scope of the British Crime Survey goes well beyond the counting of criminal incidents, although it is for this estimate that it has become established as a definitive source of information. In order to classify incidents, the British Crime Survey collects extensive information about the victims of crime, the circumstances in which incidents occur and the behaviour of offenders in committing crimes. In this way, the survey provides information to inform crime reduction measures and to gauge their effectiveness.

The data set includes information from two sections of the survey, the non-victim form questionnaire and the victim form questionnaire. The non-victim form questionnaire gathers respondent-level data: topics covered include fear of crime, perception of anti-social behaviour, victimisation screener questions, performance of the criminal justice system (CJS), experiences of the police, attitudes to the CJS, crime prevention and security, victims and the CJS and demographic information.

The victim form contains offence-level data. Up to six different incidents are asked about for each respondent - each of these constitutes a separate victim form and can be matched back to the respondent-level data through the variable ROWLABEL. Topics covered include the nature and circumstances of the incident, details of offenders, security measures, costs, emotional reactions, contact with the CJS and outcomes where known.

Self-completion modules were also fielded in the 2004-05 survey, covering drug use, drinking behaviour and interpersonal violence.

\section{Coverage:}

Time period covered: The survey covers experiences of crime in the 12 months prior to interview

Dates of fieldwork: April 2004-March 2005

Country: England and Wales

Spatial units: Government Office for the Regions (GORs); police force areas

Observation units: Individuals

Kind of data: Individual (micro) level 


\section{Universe sampled:}

Location of units of observation: National

Population: Adults aged 16 and over in private households in England and Wales

Sample frame: Postcode address file

Sample design: Multi-stage stratified random sample

\section{Methodology:}

Time dimensions: Repeated cross-sectional study. From the year 2001, the British

Crime Survey moved from a biennial to an annual cycle

Number of units: 45,120 cases (non-victim form); 16,868 cases (victim form)

Method of data collection: Face-to-face interview. Plus computer-assisted

interviewing for sensitive modules. The self-completion modules were only asked of respondents aged less than 60 years of age

Weighting: Weightings for individual and household analysis and for analyses of offences

\section{Additional information:}

Use of proxy informants: No

Proxy respondents: NA

Missing data on proxy informants: NA

Overall response rate: Core sample (75\%); non-white boost sample (54\%); youth boost sample (74\%)

Differential response rate: Weights have been adjusted for differential response in relation to areas (there are differential response rates between inner city areas and non-inner city area). Since 2001 the Home Office has also applied additional calibration weights to counter the effect of differential response rates between age, gender, regional sub-groups.

Imputation of missing information: NA

Attrition rates: NA

Boosters: Minority ethnic booster $(n=3,833)$. Youth boost sample $(n=2,703)$

Period covered by series: 1982-2004/05

Common factors: Includes gender, age, ethnicity, tenure, household type, national identity, SEG and marital status

Less common risk factors: Religion

Critical life events: None

Local area information: ACORN neighbourhoods

Overview: The British Crime Survey is the most authoritative data source on crime in England and Wales because it overcomes the problems of reporting and recording associated with police recorded crime statistics. Yet, compared to other major social surveys there has been relatively limited secondary analysis of the British Crime Survey. Some secondary analysis has, however, examined the relationship between poverty and victimisation and poverty and fear of crime, although not the broader dimensions of social exclusion (see, for example, Pantazis and Gordon, 1998; Pantazis, 2000).

The British Crime Survey offers a number of potential advantages to in relation to the study of exclusion, including:

- reliable data on 'victimisation', 'fear or crime', and 'anti-social behaviour' and other sensitive topics such as drug use, sexual crimes and stalking; 
- since the survey has been in existence for more than 20 years, based on a limited number of core topics, a range of longitudinal analyses can be therefore be undertaken;

- a relatively large sample size (with additional booster samples for minority ethnic groups and young people) allowing for sub-group analyses (for example, life stage, gender, ethnicity, income group) especially as samples may be combined across waves;

- computer-assisted interviewing for sensitive topics such as sexual abuse;

- potential for multivariate analyses (for example, general linear models) to explore the relationship between social exclusion sub-themes (for example, income poverty, paid work, health, and victimisation, fear of crime) and also risk factors associated with social exclusion;

- potential for multi-level modelling analyses to examine individual and area effects on victimisation etc;

- contains some information relating to neighbourhoods, for example, ACORN variable.

The disadvantages of the British Crime Survey in relation to the study of multidimensional exclusion include:

- no information on material and social deprivation at all and little information on economic resources other than income and home ownership;

- no information on service exclusion and social resources;

- only limited information on civic and political participation;

- income data is self-reported using income bands and not as reliable as computed income;

- low response rate for minority ethnic booster sample. 
Title: British Household Panel Survey

Principal investigator(s): University of Essex, Institute for Social and Economic Research

Description: The British Household Panel Survey (BHPS) is conducted by the Economic and Social Research Council (ESRC) UK Longitudinal Studies Centre (UKLSC), together with the Institute for Social and Economic Research (ISER) at the University of Essex. The main objective of the BHPS is to further understanding of socioeconomic change at the individual and household levels in Britain, and to identify, model and forecast such changes and their causes and consequences. The BHPS is used as a research resource for a wide range of social science disciplines and to support interdisciplinary research in many areas.

The BHPS was designed as an annual survey of each adult (aged 16 years and over) within a nationally representative sample of more than 5,000 households, making a total of approximately 10,000 individual interviews. The same individuals are reinterviewed in successive waves and, if they leave their original households, all adult members of their new households are also interviewed. Children are interviewed once they reach the age of 16 and there is also a special survey of household members aged 11-15 from wave 4 onwards. Further information about the BHPS can be found on the ISER/UKLSC BHPS web pages at www.iser.essex.ac.uk/ulsc/.

\section{Coverage:}

Dates of fieldwork: Annually since 1991 in September to May

Country: United Kingdom

Spatial units: Non-metropolitan shire counties; unitary authorities; metropolitan counties; local authority districts

Observation units: Individuals; families/households

\section{Universe sampled:}

Location of units of observation: National

Population: Households and household members living in the UK

Sample frame: Small users postcode address file for Great Britain

Sample design: Two-stage stratified systematic sample

\section{Methodology:}

Time dimensions: Panel

Number of units (year): 5,538 households and 10,264 individuals at wave 1 (all interviews)

Method of data collection: Face-to-face interview; telephone interview; selfcompletion

Weighting: Weighting used to adjust for unequal selection probabilities and nonresponse at individual and household levels

\section{Additional information:}

Use of proxy informants: Yes ( $\mathrm{N}=352$ at Wave 1$)$

Proxy respondents: Where a sample member is too ill or too busy to be interviewed, a proxy interview is conducted with another household member (with preference shown 
for the spouse or adult child). The questionnaire is a much shortened version of the individual questionnaire.

Missing data on proxy informants: See Taylor (2001)

Overall response rate: $69 \%$ (incl. proxies)

Differential response rate: Comparisons with official sources suggest overrepresentation within the BHPS of older and married persons, and the underrepresentation of professionals and the self-employed (Nathan, 1999: 21-22). Previous research based upon a variety of panel studies have shown higher drop-out rates amongst low income households (e.g. Fitzgerald et al., 1998; Lillard \& Panis, 1998; Nathan, 1999; Zabel, 1998; Watson, 2003; Behr et al., 2002). As a result, imputation and weighting are regularly used in the BHPS to address the effects of sample attrition. The overall representativeness of the BHPS is contingent on the development of suitable weights to account for differential attrition. Since this is related to known characteristics at a wave of interview, further re-weighting may be necessary to account for differential attrition amongst 'poor' households since this is frequently not controlled for in weighting procedures to account for differential attrition.

Imputation of missing information: Missing data on a range of income and housing cost variables were imputed in all waves of data of the BHPS using a combination of 'hot deck' and regression imputation (see Lynn et al., 2006).

Attrition rates: $53 \%$ of sample members at Wave 1 completed full interviews at Wave 14. For further details see Taylor (2001).

Boosters: Scottish and Welsh booster samples of approx. 1,200 households each were introduced in Wave 9 (1999) to increase the relatively small Scottish and Welsh sample sizes (around 400-500 households in each country in the initial sample) in order to facilitate between-country comparisons.

Period covered by series: Since 1991 (on-going)

Risk factors: Includes gender, age, ethnicity, tenure, household type, SEG, social class. Less common risk factors: NA

Critical life events: Critical life events include leaving parental home, getting married, child births, unemployment, bereavement, etc.

Local area information: NA

Overview: As Longview Associates (2006) note, the BHPS shares many of the advantages and limitations of other panel and cohort studies. The principal strengths of the BHPS are detailed below:

- the methodological rigour of BHPS survey design, data collection and processing mean that the large body of research generated by the BHPS has been well received in social science and policy circles.

- the short interval between data collection points facilitates close monitoring of household and family dynamics, and - increasingly - more extended transitions as the study progresses.

- availability of information on other household members facilitating investigation of household-level effects in individual behaviour.

Nonetheless, as with other panel and cohort studies there are a number of limitations to the BHPS as a data source in investigating multiple disadvantage. Specifically:

- $\quad$ sub-groups with low prevalence (for example, people with disabilities, lone parents, minority ethnic groups) are too small to yield robust inferences on the 
basis of probability sampling. This is an especial problem in relation to multiple disadvantage where such groups are often at greater risk of disadvantage.

- attrition over the life of the panel has further reduced sample sizes and introduced a major source of sample bias especially with respect to the analysis of multiple disadvantage where, in the UK at least, low-income groups are more likely to refuse participation than other income groups.

- immigrants into the UK since 1992 are excluded (except by joining panel households) and sample re-weighting cannot account for post-1992 migration trends.

- infrequent events need to be aggregated across waves to achieve sufficient sample sizes, in the process restricting analysis options.

- very limited scope for spatial analysis at the small-area level (that is, sub-GOR) due to insufficient sample sizes. 
Title: English Longitudinal Study of Ageing: waves 1-2, 2002-05

Principal investigator(s): M. Marmot, University College London, Department of Epidemiology and Public Health; J. Banks, Institute for Fiscal Studies; R. Blundell, Institute for Fiscal Studies; B. Erens, National Centre for Social Research; C. Lessof, National Centre for Social Research; J. Nazroo, University College London, Department of Epidemiology and Public Health

Description: The English Longitudinal Study of Ageing (ELSA) is a longitudinal study of ageing and quality of life among older people that explores the dynamic relationships between health and functioning, social networks and participation, and economic position as people plan for, move into and progress beyond retirement.

ELSA is a study of people aged 50 and over and their younger partners, living in private households in England. The sample was drawn from households that had previously responded to the Health Survey for England (HSE) in 1998, 1999 or 2001. Every two years they hope to interview the same group of people to measure change in their health, economic and social circumstances. ELSA can complete the picture of what it means to grow older in the new century, and help one understand what accounts for the variety of patterns that are seen.

The survey covers the broad set of topics relevant to a full understanding of the ageing process, these include:

- health, disability, healthy life expectancy;

- the relationship between economic position and both physical and cognitive health;

- the determinants of economic position in older age;

- the timing and circumstances of retirement and post-retirement labour market activity;

- the nature of social networks, support and participation;

- household and family structure and the transfer of resources.

The main objectives of ELSA are to:

- construct three waves of accessible and well-documented panel data;

- provide these data in a convenient and timely fashion to the scientific and policy research community;

- describe health trajectories, disability and healthy life expectancy in a representative sample of the English population aged 50 and over;

- examine the relationship between economic position and health;

- investigate the determinants of economic position in older age;

- describe the timing of retirement and post-retirement labour market activity; understand the relationships between social support, household structure and the transfer of assets.

\section{Coverage:}

Dates of fieldwork: March 2002-March 2003

Country: England

Spatial units: At present the ELSA team are not depositing any variables that will allow analysis by or on spatial units. However, they are developing a system by which 
these data could be provided to researchers who want to use it. Various methods of providing access to these data are currently being considered, including specialised datasets and data enclaves. In order to obtain access to these data, researchers will need to provide details of the analysis they wish to do and sign an agreement stating that they would use the data appropriately.

Observation units: Individuals

Kind of data: Numeric data; individual (micro) level

\section{Universe sampled:}

Location of units of observation: National

Population: The ELSA sample was selected from three survey years of the HSE (1998, 1999 and 2001). Together these three HSE years contained 23,132 responding households. Households were included in ELSA if they contained at least one adult of 50 years or older in the household who had agreed to be re-contacted at some time in the future when participating in HSE.

Sample frame: Postcode address file (HSE)

Sample design: Multi-stage stratified random sample (HSE). Each of the main HSE samples had originally been drawn in two stages. First, postcode sectors were selected from the postcode address file, stratified by health authority and proportion of households in the non-manual SEGs. Addresses were then selected systematically from each sector and a specified number of adults and children in each household were deemed eligible for interview.

\section{Methodology:}

Time dimensions: Longitudinal/panel/cohort. The current deposit includes waves 1 and 2. Wave 3 has been conducted in 2006, and wave 4 is at the planning stage Number of units (year): Wave 1: 12,100 cases. Wave 2: 9,433 cases Method of data collection: Face-to-face interview; self-completion; clinical measurements; physical measurements; performance measurements, such as the timed walk, were conducted, and wave 2 included a nurse visit.

Weighting: Weights were calculated for core sample members only (including proxy and partial interviews), as this is the sample of interest. All other non-sample individuals that were interviewed (that is, core, new and younger partners) have a weight of zero. Weighting for non-response between waves 1 and 2 calculated based on a full range of household and individual level information collected from both HSE and ELSA waves 1 and 2.

\section{Additional information:}

Use of proxy informants: Yes. Wave 1 ( $n=171,1.4 \%)$; wave 2 ( $n=123,1.3 \%)$ Proxy respondents: If an eligible respondent was physically or cognitively impaired, or in hospital or temporary care for the whole of the fieldwork period, a proxy interview was permissible. Interviewers were asked to identify a proxy informant (that is, a person who could answer the interview on behalf of the eligible respondent). The proxy informant was a responsible adult (aged 16 years or over) who knew enough about the respondent's circumstances to be able to provide information about them. Where possible, close family members such as a partner or son or daughter fulfilled this role.

Missing data on proxy informants: NA

Overall response rate: $82 \%$ of those who completed a wave 1 interview and were eligible for a wave 2 interview as an ELSA 'core member' took part in the survey. Of 
these, $88 \%$ also took part in the nurse interview (representing $71 \%$ of those eligible for a wave 2 interview). The response to specific elements of the interview was high. Working on the basis of an estimated 71\% response at wave 0 (HSE), $61 \%$ at wave 1 and $82 \%$ at wave 2, results in a cumulative longitudinal response rate of $35 \%$. Differential response rate: Calculated for gender and age sub-groups, as well as wealth quintiles (wave 1). Imputation of missing information: NA Attrition rates: $47.7 \%$ (wave 0 to wave 1), 22\% (wave 1 to wave 2)

Boosters: The HSE 1999 sample design also included a boost sample that represented minority ethnic groups. Because of funding constraints, it was not possible to follow up the boost sample and it was discarded.

Period covered by series: Wave 1: March 2002-March 2003; wave 2: June 2004-July 2005. Most of the data refer to the time period when the interview took place. Some of the questions however did ask about past events (for example, pension history, respondent's father's employment when respondent was aged 14).

Common risk factors: Gender, age, ethnicity, tenure, household type and NS-SEC Less common risk factors: Religious affiliation

Critical life events: Deaths, marriages and divorce

Local area information: NA

Overview: There are several important advantages of ELSA in carrying out secondary analysis on social exclusion:

- currently the pre-eminent study of people's quality of life as they age beyond 50 and of the factors associated with it.

- first study in the UK to connect the full range of topics necessary to understand the economic, social, psychological and health elements of the ageing process.

- possible to explore the unfolding dynamic relationships between health, functioning, social networks and economic position of older people in England.

- first nationally representative study of English people aged 50 years and older to combine measurements on poverty, social exclusion and quality of life.

- possible to examine how social exclusion changes over the latter part of the life course (for those 50 years of age and older).

- as ELSA incorporates many different dimensions of disadvantage: exclusion from social relations, exclusion from cultural activities, exclusion from civic activities, exclusion from access to basic services, neighbourhood exclusion, exclusion from financial products and exclusion from material goods. Using these different dimensions, it is possible to examine not only the relationship between the different dimensions but also how they relate to quality of life (Barnes et al, 2006).

- can be used to show how longstanding illnesses, social context, and current socioeconomic circumstances predict quality of life (Netuveli et al, 2006).

Despite its many advantages compared with preceding surveys, ELSA has some disadvantages, specifically in terms of its sample and the ability to make population estimates from the survey findings:

- sample only includes residents of England and not the UK as a whole.

- there is no current release of spatial units necessary for spatial/geographic analysis. This is a drawback as previous studies on poverty and social exclusion have shown that they are very much area-based (cf Scarf et al, 2002). 
- non-response at HSE, refusals to be re-interviewed post-HSE and non-response at ELSA wave 1 all have the potential to make the ELSA respondent sample unrepresentative of the population. 
Title: European Community Household Panel

Principal investigator(s): European Commission Statistical Office, Luxembourg

Description: European Community Household Panel (ECHP) data are collected to provide harmonised panel data at a European level in order to facilitate crossEuropean comparative analysis of social and economic change and social policyrelated issues. The ECHP is a harmonised panel data set designed to collect the same information from individuals and households in many different European countries. The study is coordinated in Luxembourg by Eurostat and Eurostat oversees the final data quality checking and the distribution of the data, with national data collection units implementing the study in participating countries. The survey covers household composition, family structure and dynamics, health, income, material and social wellbeing, education, housing, attitudes and economic activity. The data collect detailed income information covering the year prior to the survey, and detailed economic activity information that covers the full calendar year in the year prior to the year in which the interview occurs. (Data for Sweden are cross-sectional only and do not allow for the tracking of individuals across time.)

\section{Coverage:}

Dates of fieldwork: Annually since 1994 in Belgium, Denmark, France, Germany, Greece, Ireland, Italy, Luxembourg, The Netherlands, Portugal, Spain and the UK. Annually since 1995 in Austria. Annually since 1996 in Finland. Annually since 1997 in Sweden.

Country: Belgium, Denmark, France, Germany, Greece, Ireland, Italy, Luxembourg, The Netherlands, Portugal, Spain, the UK, Austria and Finland

Spatial units: NUTS Level 2

Observation units: Individuals; families; households

\section{Universe sampled:}

Location of units of observation: Multinational European dataset comprising 15 countries

Population: Private households in participating countries

Sample frame: Sample frames vary from country to country

Sample design: Multi-stage stratified random sample

\section{Methodology:}

Time dimensions: Panel

Number of units (year): 149,306 individuals; 71,367 households (wave 1)

Method of data collection: Face-to-face interview; telephone interview

Weighting: Weighting used to adjust for non-response and unequal selection

probabilities at individual and household levels. No specially constructed

'longitudinal weights' other than the base weights are included in the ECHP.

\section{Additional information:}

Use of proxy informants: Yes. Wave $1(\mathrm{~N}=171,1.4 \%)$; Wave $2(\mathrm{~N}=123,1.3 \%)$

Proxy respondents: If an eligible respondent was physically or cognitively impaired, or in hospital or temporary care for the whole of the fieldwork period, a proxy interview was permissible. Interviewers were asked to identify a proxy informant (i.e. a person who could answer the interview on behalf of the eligible respondent). The 
proxy informant was a responsible adult (aged 16 years or over) who knew enough about the respondent's circumstances to be able to provide information about them. Where possible, close family members such as a partner or son or daughter fulfilled this role.

Missing data on proxy informants: NA

Overall response rate: $82 \%$ of those who completed a Wave 1 interview and were eligible for a Wave 2 interview as an ELSA 'core member' took part in the survey. Of these, $88 \%$ also took part in the nurse interview (representing $71 \%$ of those eligible for a wave 2 interview). The response to specific elements of the interview was high. Working on the basis of an estimated 71\% response at wave 0 (HSE), 61\% at wave 1 and $82 \%$ at wave 2, results in a cumulative longitudinal response rate of $35 \%$.

Differential response rate: Calculated for gender and age sub-groups, as well as wealth quintiles (Wave 1).

Imputation of missing information: NA

Attrition rates: $47.7 \%$ (Wave 0 to Wave 1), 22\% (Wave 1 to Wave 2).

Boosters: The HSE 1999 sample design also included a boost sample that represented ethnic minorities. Because of funding constraints, it was not possible to follow-up the boost sample and it was discarded.

Period covered by series: Wave 1: March 2002 - March 2003; Wave 2: June 2004 July 2005. Most of the data refer to the time period when the interview took place. Some of the questions however did ask about past events (e.g. pension history, respondent's father's employment when respondent was aged 14).

Common Risk factors: Gender, age, ethnicity, tenure, household type, and social class.

Less common risk factors: Religious affiliation.

Critical life events: Deaths, marriages and divorce.

Local area information: NA

Overview: The ECHP is a major cross-national panel survey that has been widely used to investigate a wide range of social policy-related issues including the comparative analysis of poverty dynamics within Europe. As a result of such work, and the role of the ECHP data within official approaches to the measurement of social cohesion in Europe, the ECHP has gained an international reputation for methodological rigour and reliability in data collection and processing.

The advantages of the ECHP data set in the investigation of multiple disadvantage include:

- the comparative nature of the study allows for the investigation of the effects of different national policy regimes in shaping poverty dynamics and trends.

- large sample sizes make it possible to investigate within-country variations in poverty at the individual and household levels alongside regime-level effects.

- the panel structure allows for causal inference, for example, on the basis of event history and duration modelling approaches.

Nonetheless, the ECHP shares a number of limitations with many other panel studies, specifically:

- the discontinuation of the ECHP in 2001 means that long-term social processes are not amenable to analysis using the ECHP.

- for some countries (including the UK) full deprivation data are not available for all waves. In some cases (including the UK) data from local sources (for example, 
BHPS) have been harmonised with ECHP data although differences remain in definitions and methods.

- $\quad$ sub-groups with low prevalence (for example, people with disabilities, lone parents, minority ethnic groups) are too small to yield robust inferences on the basis of probability sampling. This is an especial problem in relation to multiple disadvantage where such groups are often at greater risk of disadvantage.

- infrequent events need to be aggregated across waves to achieve sufficient sample sizes, in the process restricting analysis options.

- attrition over the life of the panel has further reduced sample sizes and introduced a major source of sample bias especially with respect to multiple disadvantage where attrition rates are known to vary across Europe by poverty status. 
Title: European Union Statistics on Income and Living Conditions, 2003-04

\section{Principal investigator(s): Eurostat}

Description: All members of the European Community are now required to collect some cross-sectional and longitudinal statistical information on income and living conditions. European Union Statistics on Income and Living Conditions (EU-SILC) replaces the European Community Household Panel (ECHP) that ran from 1994 to 2001 (Eurostat, 2005). The UK started data collection for the EU-SILC in April 2005 via the new longitudinal General Household Survey (GHS[L]). Following concerns about the comparability and timeliness of data across the European Community, the European Directors of Social Statistics decided in June 1999 to replace the ECHP after 2002 with EU-SILC.

The EU-SILC is an instrument aimed at collecting timely and comparable crosssectional and longitudinal multi-dimensional micro data on income, poverty, social exclusion and living conditions. This instrument is anchored in the European Statistical System (ESS). The EU-SILC was launched in 2004 in 13 member states (BE, DK, EE, EL, ES, FR, IE, IT, LU, AT, PT, FI and SE) and in NO and IS. This first release of the cross-sectional data mainly refers to income reference year 2003 with a fieldwork carried out in 2004. The EU-SILC will reach its full-scale extension with the 25 member states plus NO, IS in 2005. It will later be completed by TR, RO, $\mathrm{BG}$ and $\mathrm{CH}$.

The main features of EU-SILC are:

- the use of harmonised methods and definitions in order to establish reliable comparisons between member states;

- the provision of both cross-sectional and longitudinal micro-data at the household and person level in order to investigate major issues of social concern; people to be followed up within the UK;

- statistics to be updated annually to reflect changes in income distribution and levels of social exclusion;

- flexibility of data sources. The use of existing national data sources, whether surveys or registers, and national sample designs should be encouraged, and the integration of the new source(s) into established national statistical systems should be promoted;

- cross-sectional and longitudinal micro data sets to be updated on a yearly basis;

- from 2005, ad hoc modules will be added to EU-SILC to investigate particular areas of policy interest in more detail if and when required.

Social exclusion and housing condition information is collected at household level while labour, education and health information is obtained for people aged 16 and over. The core of the instrument, income at very detailed component level, is mainly collected at personal level but a few components are included in the household part of SILC.

\section{Coverage:}

Dates of fieldwork: 2003-04

Country: Austria, Belgium, Cyprus, Czech Republic, Denmark, Estonia, Finland, France, Germany, Greece, Hungary, Iceland, Ireland, Italy, Latvia, Lithuania, 
Luxembourg, Malta, Netherlands, Norway, Poland, Portugal, Slovakia, Slovenia, Spain, Sweden, United Kingdom

Spatial units: National

Observation units: Individuals and households

Kind of data: Numeric data; individual (micro) level; aggregate (macro) level

\section{Universe sampled:}

Location of units of observation: National

Population: Individuals and private households

Sample frame: National registers in some cases, post code and address lists in other cases

Sample design: Depending on the country, micro data could come from: two or more national sources (surveys and/or registers); one or more existing national sources combined or not with a new survey; a new harmonised survey to meet all EU-SILC requirements called the integrated design.

\section{Methodology:}

Time dimensions: Cross-sectional indicators: annual. Longitudinal indicators: typically cover a period of four years (for example, persistent risk of poverty rate; anchored risk of poverty rate).

Number of units (year): 60,500 households were included in the 2003 pre-study wave; aiming for a minimum of 95,200 households were sampled for 2005 (covering 195,200 people aged $16+$ for 2005 )

Method of data collection: Multinational comparative data sets Weighting: Estimates at aggregate level (for example, EU25) are calculated as the population-weighted arithmetic average of individual national figures.

\section{Additional information:}

Use of proxy informants: Varies according to National Samples

Proxy respondents: Varies according to National Samples

Missing data on proxy informants: NA

Overall response rate: Not yet conducted

Differential response rate: NA

Imputation of missing information: NA

Attrition rates: Not yet conducted

Boosters: NA

Period covered by series: 2004-present

Common risk factors: Gender, age, ethnicity, tenure, household type, SEG and NSSEC

Less common risk factors: Religion not currently included

Critical life events: NA

Local area information: NA

Overview: There are many advantages of EU-SILC in relation to measuring social exclusion:

- it provides comparable and timely statistics on income and living conditions for each EU member state.

- the statistical indicators presented in the various collections under the SILC domain cover a range of topics relating to income poverty and social exclusion. 
- the EU-SILC micro data is a unique information source for studying poverty in its relation to socioeconomic variables.

- it will be the primary source of data used by Eurostat for the calculation of many indicators in the field of income, poverty and social exclusion such as the structural indicators of social cohesion; indicators adopted under the Open Method of Coordination such as the Laeken indicators of social inclusion and indicators of pensions adequacy; sustainable development indicators of poverty and of ageing; and many other indicators published on the Eurostat New Cronos database.

- a key tool for policy makers in particular, for monitoring the Lisbon strategy.

Disadvantages:

- the first set of micro data and cross-sectional indicators from EU-SILC that covers all the EU25 member states will not be available until December 2006. 
Title: Expenditure and Food Survey, 2004-05

Principal investigator(s): Office for National Statistics; Department for Environment, Food and Rural Affairs

Description: The Expenditure and Food Survey (EFS) is the result of more than two years' development work to bring together the Family Expenditure Survey (FES) and the National Food Survey (NFS). Both survey series were well established and important sources of information for the government and the wider community, charting changes and patterns in Britain's spending and food consumption since the 1950s. From 2001-02, both series were completely replaced by the EFS. As with the FES and NFS, the EFS continues to be primarily used to provide information for the Retail Prices Index, National Accounts estimates of household expenditure, analysis of the effect of taxes and benefits and trends in nutrition.

The household questionnaire covers both one-time purchases and regular payments, including expenditure on rent, rates, mortgages, insurance, Council Tax, pensions, consumer durables, telephone, electricity and gas, central heating, television and satellite/digital services, vehicles, season tickets, credit cards, loans, hire purchase, club credit, second dwellings, capital improvements and house maintenance, house moves, furniture, carpets, holidays and flights, banking, welfare and free school milk and meals, education, separation/maintenance allowances, employer refunds, items paid from outside the household, money given to household and internet purchasing. Demographic information on household composition, age, gender, benefit units, accommodation and tenure is also collected.

The income questionnaire collects detailed information about the income of each adult member of the household. Topics covered include employment status, job description, pay details, income from self-employment and subsidiary employment, National Insurance contributions, redundancy payments, concessionary bus passes, social security benefits, pensions, allowances, money sent abroad, investments and children's income. Personal information such as age, gender and marital status is also collected.

In addition to the two questionnaires, each individual aged 16 years and over in the household is asked to keep diary records of daily expenditure for two weeks. Children aged 7-15 keep a simplified diary for two weeks.

\section{Coverage:}

Dates of fieldwork: 2004-05

Country: United Kingdom

Spatial units: Government Office for the Regions (GORs)

Observation units: Families/households; a household comprises one person or a group of people who have the accommodation as their only or main residence and (for a group) share the living accommodation (that is, a living or sitting room), or share meals together or have common housekeeping.

Kind of data: Numeric data; individual level

\section{Universe sampled:}

Location of units of observation: National 
Population: Households in the United Kingdom surveyed during 2004-05

Sample frame: Postcode address file

Sample design: Multi-stage stratified random sample. Sample is arranged in strata

defined by GOR (sub-divided into metropolitan and non-metropolitan areas) and two 1991 Census variables - SEG and ownership of cars

\section{Methodology:}

Time dimensions: Repeated cross-sectional study. The 2001-02 survey is the first in the annual EFS series.

Number of units (year): 6,265 cooperating households in Great Britain; 533

households in Northern Ireland

Method of data collection: Face-to-face interview; diaries; only derived variables from the diary are included in the dataset, as the raw diary data are not released to the public for confidentiality reasons

Weighting: Weightings used

\section{Additional information:}

Use of proxy informants: Yes (15\%)

Proxy respondents: While questions about general household affairs are put to all household members or to a main household informant, questions about work and income are put to the individual members of the household. Where a member of the household is not present during the household interview, another member of the household (for example, spouse) may be able to provide information about the absent person. The individual's interview is then identified as a proxy interview.

Missing data on proxy informants: NA

Overall response rate: 57\% (Great Britain); 52\% (Northern Ireland)

Differential response rate: Data are re-weighted to compensate for the main nonresponse biases. A comparison with the 1991 Census revealed that non-response was higher in Greater London, metropolitan areas, and tended to increase with age, up to 65 years. Households containing three or more adults, or where the head was born outside the UK or was classified to a minority ethnic group, or where the head of household had no post-school qualification, was self-employed, or was in a manual social class group, were also more likely than others to be non-responding (see Foster, 1996).

Imputation of missing information: Although the EFS is generally based on complete households responding, there are areas in the survey for which missing information is imputed. This falls into two broad categories: (i) Specific items of information missing from a response. These missing values are imputed on a case-by-case basis using other information collected in the interview. The procedure is used, for example, for Council Tax payments and for interest received on savings. (ii) Imputation of a complete diary case. Where a response is missing a diary from a household member, this information is imputed using information from respondents with similar characteristics.

Attrition rates: NA

Boosters: None

Period covered by series: 2001/02-2004/05

Common risk factors: Includes gender, age, ethnicity, national identity, tenure, marital status, household type, and SEG

Common factors: Includes gender, age, ethnicity, tenure, household type, national identity, NS-SEC and marital status 
Less common risk factors: Free school milk. Religion not included

Critical life events: Pregnancy

Local area information: Urban and rural indicator, local authority areas, ACORN, Council Tax band, Mosaic code

Overview: The EFS is the result of a merger of two surveys. This brings benefits to the secondary analyst because a single survey removes the difficulties of reconciling data from two sources. However, to date there has been limited use of the EFS by secondary analysts. Nevertheless some topics related to social exclusion that have been investigated using the EFS include: time and income poverty, low-cost home ownership, trends in and transitions to unpaid care giving, financial exclusion among social housing tenants, poverty and debt and pensioner expenditure patterns.

The EFS offers a number of potential advantages to social policy analysts in relation to the study of exclusion, including:

- detailed and reliable income data

- extensive and reliable coverage of expenditure patterns on goods and services

- the survey has been in existence since 1957, which allows for the investigation of trends

- $\quad$ one of the few large surveys that involves children (7-15 years).

The disadvantages of the EFS in relation to the study of multi-dimensional exclusion include:

- no information on the quality of life domain.

- limited information on some themes relating to the domains of resources and participation. For example, there are no variables relating to the themes of social resources and political participation.

- lower than average response rate. Under the EFS rules, a refusal by just one person to respond to the section in the questionnaire on income invalidates the response of the whole household. Additionally, a refusal by the household's main shopper to complete the two-week diary results in an invalid response.

- relatively small sample size that limits analysis of vulnerable sub-groups. 
Title: Families and Children Study (formerly known as the Survey of Low Income Families, SOLIF)

Principal investigator(s): National Centre for Social Research (NatCen); Department for Work and Pensions

Description: The Families and Children Study (FACS) originally provided a new baseline survey of lone-parent families and low-income couples with dependent children in Britain. The FACS study has become a true panel study since 1999 respondents have been re-interviewed in subsequent annual waves in from 2000 to 2004, and new families added in each of these years, to allow for representative crosssectional as well as longitudinal comparisons. Starting with wave 3 (2001), the survey was extended to provide a complete sample of all British families (that is, including higher-income families). From wave 4 (2002) onwards, longitudinal comparisons for all British families can be made.

The main objectives of the survey are to:

- evaluate the effectiveness of government social policies for low-income families

- compare the living standards and outcomes for children and families across the income distribution.

Topics covered in the main interview include household characteristics, health and well-being, children's schooling, behaviour and childcare provision, use of local services, education and training, employment, family income and finances, in-work support through the use of Tax Credits, benefit receipt, child maintenance, housing, and material deprivation. The children's self-completion questionnaire covers leisure activities, ICT access, social participation, use of local amenities and attitudes to neighbourhood, substance misuse, self-esteem, health, attitudes to school, relationship with parents and income.

\section{Coverage:}

Dates of fieldwork: July-September 1999 (wave 1); June-October 2000 (wave 2); then September-January (waves 3-6)

Country: Great Britain

Spatial units: Not recorded

Observation units: Individuals; families; households

\section{Universe sampled:}

Location of units of observation: National

Population: Low-income families with dependent children in Great Britain (waves 1 and 2); all families with dependent children in Great Britain (waves 3 to 6)

Sample frame: Child Benefit records (wave 1)

Sample design: Multi-stage stratified random sample

\section{Methodology:}

Time dimensions: Panel

Number of units (year): 5,397 (wave 1); 5,250 (wave 2); 8,541 (wave 3); 7,352 (wave 4) ; 7,746 (wave 5) ; 7,471 (wave 6)

Method of data collection: Face-to-face interview; self-completion interview 
Weighting: Weighting and imputation used. The wave 1 sample is self-weighting (based on proportionate selection probabilities). Subsequent waves are adjusted for sample non-response attrition. Imputation is used to address item non-response. See Lyon et al (2006) for further details.

\section{Additional information:}

Use of proxy informants: Yes $(\mathrm{N}=1,867$ in Wave 6)

Proxy respondents: In couple families, partner interviews were conducted. In cases where partner data was not collected proxy interviews were conducted with the main respondent for key topic areas only (34\% of couple families).

Missing data on proxy informants: Not known

Overall response rate: Cross-sectional response rates vary between $80 \%$ and $85 \%$ Differential attrition rate: Families more likely to drop out of the study include minority ethnic families, those receiving state benefits, non-working and non-home owning families Imputation of missing information: Yes. For key variables imputation is currently based on (weighted) median imputation (see Lyon et al., 2006).

Attrition rates: 86\%, Waves 5 to 6; 50\%, Waves 1 to 6

Boosters: Boost sample for in-migration into Postcode Sampling Units (PSU), $\mathrm{N}=1,363$ (Wave 6)

Period covered by series: 1999-2004

Risk factors: Includes gender, age, ethnicity, tenure, household type, SEG, social class, and some critical events.

Less common risk factors: Divorce, separation and relationship breakdown.

Critical life events: Some critical life events including change in personal relationship status, child births, unemployment, etc.

Local area information: Local Authority, travel to work area, rural indicator, Government Office Region, postcode sector, 2000 indices of deprivation (deciles)

Overview: The FACS has been used extensive in the analysis of multidimensional exclusion amongst families with children, resulting in an extensive series of 'inhouse' analyses by DWP and further research reports. In several key respects may serve as a template for further methodological development in relation to the operationalisation of social exclusion-related survey items in other large scale official surveys (e.g. Willitts, 2006; McKay \& Collard, 2004). This is so specifically with reference to the:

- broad topic coverage of FACS - especially with regard to the measurement of social and material necessities, and its focus upon housing and the built environment, and access to services

- focus upon interviewing of children and young persons themselves. FACS is one of very few large-scale surveys which elicit information from children themselves specifically in relation to neighbourhood and access to services, social participation, and health and well being

- relatively high cross-sectional response rates for a survey of this type

- emphasis upon children's services and policy interventions encourages evaluation of policy effectiveness and outcomes 
Title: Family Resources Survey, 2004-05

Principal investigator(s): Department for Work and Pensions; Office for National Statistics, Social Survey Division; National Centre for Social Research

Description: The Family Resources Survey (FRS) collects information on the incomes and circumstances of private households in the United Kingdom (or Great Britain before 2002-03). It aims to: support the monitoring of the social security programme; support the costing and modelling of changes to National Insurance contributions and social security benefits; and provide better information for the forecasting of benefit expenditure. Households interviewed in the survey are asked a wide range of questions about their circumstances including receipt of social security benefits, housing costs, assets and savings. Although some of the information collected is available elsewhere, the FRS provides new or much more detailed information in a number of areas and brings some topics together on one survey for the first time.

\section{Coverage:}

Dates of fieldwork: April 2004-March 2005

Country: Great Britain; Northern Ireland Spatial units: Government Office for the Regions (GORs)

Observation units: Families/households

\section{Universe sampled:}

Location of units of observation: National

Population: Private households in the UK. Information about all people in the household is requested and all non-dependent adults aged 16 or over are interviewed. Sample frame: Postcode address file Sample design: Multi-stage stratified random sample. The stratification factors for the 2004/05 FRS, which were based on 1991 Census data, were as follows: a regional stratifier based on GOR; the proportion of household heads in SEGs 1-5 and 13; the proportion of economically active adults aged 16-74; the proportion of economically active men who are unemployed aged 16-74; the proportion of men who are unemployed.

\section{Methodology:}

Time dimensions: Repeated cross-sectional study annual - analysed on a financial year basis

Number of units: 28,041 (obtained)

Method of data collection: Face-to-face interview; computer-assisted personal interviewing (CAPI)

Weighting: Weighting used

\section{Additional information:}

Use of proxy informants: Yes (15\% of adults in fully cooperating households) Proxy respondents: NA

Missing data on proxy informants: NA

Overall response rate: $62 \%$ for the UK (63\% for Great Britain) (60\% for Northern Ireland) 
Differential response rate: Weights attempt to correct for differential non-response taking into account demographic variables such as age and sex, together with region and tenure.

Imputation of missing information: Variables that are components of key derived variables, such as total household income and housing costs, and benefit receipt are imputed where the information is missing because it has been refused or the respondent does not know the answer to the question.

Attrition rates: NA

Boosters: None

Period covered by series: 1994/95-2004/05

Common risk factors: Includes gender, age, ethnicity, national identity, tenure, household type and SEG

Less common risk factors: Religion included

Critical life events: None

Local area information: ACORN neighbourhood

Overview: The FRS is used by the DWP to produce information on the size and characteristics of low-income households and families. The main uses of the FRS data relate to three key publications (i) Households Below Average Income (HBAI), which uses household disposable incomes, adjusted for household size and composition, as a proxy for material living standards; (ii) Individual Income Series, which provides estimates of the total net and disposable incomes of individual men and women; and (iii) Estimates of Take-Up of Income Related Benefits, which combines FRS data with administrative data to estimate the numbers of people who are not claiming benefits to which they appear to be entitled. In 2003 the DWP made the decision to move beyond indirect income measures of child poverty, and include questions on children's material deprivation - measures originally derived from the 1999 Millennium Survey of Poverty and Social Exclusion (see further below for more detail on the PSE Survey). Beyond government needs, the survey has served secondary researchers interested in investigating poverty and social exclusion. Topics that have been investigated include: child poverty in London, time and income poverty, financial exclusion among social housing tenants, means testing and retirement, poverty and debt, fuel poverty, and Working Families Tax Credit.

The FRS offers a number of potential advantages to social policy analysts in relation to the study of exclusion, including:

- detailed and reliable income data;

- contains a sub-set of questions on direct measures of poverty in relation to adults and children taken from the PSE Survey (see Willitts, 2006);

- the relatively large sample size allows more confidence in the analyses of smaller sub-groups, including, for example, regional breakdowns and recipients of certain benefits;

- potential for multivariate analyses (for example, general linear models) across some themes relating to multiple exclusion (for example, disability, economic participation and resources).

However, the disadvantages of the FRS in relation to the study of multi-dimensional exclusion include: 
- there is no information whatsoever on service exclusion, civic and political participation, housing quality, crime and criminalisation, and culture, education and skills;

- there is no information on intra-household poverty/exclusion;

- has a relatively low response rate. 
Title: General Household Survey, 2004-05

Principal investigator(s): Office for National Statistics, Social and Vital Statistics Division

Description: The General Household Survey (GHS) is a continuous national survey of people living in private households conducted on an annual basis. The main aim of the survey is to collect data on a range of core topics, covering household, family and individual information. This information is used by government departments and other organisations for planning, policy and monitoring purposes, and to present a picture of households, family and people in Great Britain.

The GHS consists of a household questionnaire, completed by the Household Reference Person, and an individual questionnaire, completed by all adults aged 16 and over resident in the household. A number of different trailers each year covering extra topics are included in later (post-review) surveys in the series, from the 2000-01 survey onwards. The household questionnaire covers the following topics: demographic information about household members, household and family information, household accommodation, housing tenure, consumer durables including vehicle ownership, and migration. The individual questionnaire includes sections on employment, pensions, education, health and use of health services, smoking, drinking in the last seven days, family information including marriage, cohabitation and fertility history, and income.

\section{Coverage:}

Dates of fieldwork: 01 April 2004-31 March 2005

Country: Great Britain

Spatial units: Standard Regions; countries

Observation units: Individuals; families/households

\section{Universe sampled:}

Location of units of observation: National

Population: Private households and individuals aged 16 and over resident in the household

Sample frame: Postcode address file

Sample design: Stratified by region, proportion of households with no car, proportion of households in SEG 1-5, or SEG 13, proportion of people who were pensioners

\section{Methodology:}

Time dimensions: Repeated cross-sectional study

Number of units (year): 8,700 households (20,421 individual interviews)

Method of data collection: Face-to-face interview

Weighting: Individual and household weights

\section{Additional information:}

Use of proxy informants: Yes ( $n=944,4.6 \%)$

Proxy respondents: Where an individual cannot be contacted, a proxy interview is conducted with a near relative who is living in the same household 
Missing data on proxy informants: Smoking and drinking behaviour, qualifications, health questions, family information and income, educational qualifications and income and opinion-type questions are omitted

Overall response rate: $71 \%$ (2002)

Differential response rate: Adjusted for non-response in relation to region, age group and sex (see Barton, 2001)

Imputation of missing information: NA

Attrition rates: NA

Boosters: None

Period covered by series: 1971 to present (except 1997/98 and 1999/2000)

Common risk factors: Includes gender, age, ethnicity, tenure, household type, SEG and NS-SEC

Less common risk factors: Religion not included.

Critical life events: Deaths, marriages, divorce, children and pregnancy

Local area information: None

Overview: The GHS has been widely used for secondary analysis of UK social policy issues since the 1970s. It has also been used to examine social inequalities in income and earnings, healthcare and illness, pension provision, and housing tenure. So far, use of the GHS to explore poverty and social exclusion has been limited. This reflects the limited range of direct (deprivation) measures available in the GHS, and the superiority of other survey sources with income data (for example, the Family Resources Survey [FRS]).

Nonetheless, the GHS offers a number of potential advantages to social policy analysts in relation to the study of exclusion, including:

- $\quad$ since the survey has been in existence for more than 30 years, based on a limited number of core topics, a range of longitudinal analyses can be therefore be undertaken (for example, pooled cross-sectional analysis, trend analysis).

- a relatively large sample size allowing for sub-group analyses (for example, life stage, gender, ethnicity, social class, disability) especially as samples may be combined across waves.

- extensive and reliable coverage of a number of themes related to social exclusion including economic resources, social relations, cultural education and skills, political and civic participation; health and well-being, and environmental deprivation.

- potential for multivariate analyses (for example, general linear models) across a range of themes relating to multiple exclusion (for example, health and well-being, economic participation and resources).

The disadvantages of the GHS in relation to the study of multi-dimensional exclusion include:

- limited information on social deprivation

- no information on service exclusion and limited information on economic participation, crime and criminalisation, and culture, education and skills. 
Title: General Household Surveys - Elderly Individuals (People Aged 65 and Over) Supplement, 2001-02

Principal investigator(s): Office for National Statistics (ONS), Social Survey Division

Description: The General Household Survey (GHS) is a continuous national survey of people living in private households conducted on an annual basis, by the Social Survey Division of the ONS. The GHS has been widely used for secondary analysis of UK social policy issues since the 1970s. It has also been used to examine social inequalities in income and earnings, healthcare and illness, pension provision, and housing tenure. The main aim of the survey is to collect data on a range of core topics, covering household, family and individual information. This information is used by government departments and other organisations for planning, policy and monitoring purposes, and to present a picture of households, family and people in Great Britain. Since 1980, the GHS has periodically $(1980,1985,1991,1994,1998,2001)$ included a set of questions for people aged 65 and over. These covered a range of topics including: health, their ability to perform a range of domestic and self-care activities and the help they receive, social networks, and the use they make of health and social services. In addition older people were asked questions on a wide range of topics covered more generally on the GHS, including: basic demographics, housing, consumer durables and health. In 2001, the GHS collected information from 3,356 people aged 65 and over living in private households. People aged 65 and over living in communal establishments such as local authority homes, nursing homes and hospitals, were therefore excluded from the study.

\section{Coverage:}

Dates of fieldwork: 1 April 2001-31 March 2002

Country: Great Britain

Spatial units: (A) Standard regions; (B) countries

Observation units: Individuals; families/households

Kind of data: Numeric; individual (micro) level

\section{Universe sampled:}

Location of units of observation: National

Population: Private households in Great Britain. The People Aged 65 and Over Supplement sought interviews on all older people aged 65 years or age and older. Sample frame: Postcode address file Sample design: The GHS samples around 13,000 addresses each year and aims to interview all adults aged 16 or over at every household at the sampled address. It uses a probability, stratified two-stage sample design. The primary sampling units are postcode sectors, which are similar in size to wards and the secondary sampling units are addresses within those sectors.

\section{Methodology:}

Time dimensions: Repeated cross-sectional study Number of units (year): 1980: 4,516. 1985: 3,691. 1991/92: 3,785. 1994/95: 3,501. 1998: 3,082. 2001: 3,356

Method of data collection: Face-to-face interview 
Weighting: A major methodological change introduced for the new survey in 2000 was the introduction of weighting and grossing. A full description of this can be found in the 2000 report with additional technical papers on the website. A dual weighting scheme was introduced. First, weighting to compensate for non-response in the sample based on known under-coverage in the Census-linked study of non-response (Foster, 1994). Second, the (weighted) sample has been weighted (grossed) up to match known population distributions (as used in the Labour Force Survey [LFS]).

\section{Additional information:}

Use of proxy informants: 1980, 1985, 1991, 1998, 2001 ( $n=125,3.7 \%)$ : yes. 1994: no Proxy respondents: Interviewers were permitted to conduct a proxy interview with a close household member

Missing data on proxy informants: Opinion-type questions and questions on smoking and drinking behaviour, qualifications, health, family information and income were omitted

Overall response rate: $71 \%$ (2001)

Differential response rate: NA

Imputation of missing information: NA

Attrition rates: NA

Boosters: None

Period covered by series: 1980, 1985, 1991, 1994, 1998, 2001

Common risk factors: Gender, age, ethnicity, tenure, household type, SEG and NSSEC

Less common risk factors: Religion/religious affiliation not asked

Critical life events: NA

Local area information: NA

Overview: There are some advantages in using the GHS older people trailers in analysing social exclusion:

- the information collected has enabled the GHS to present regular snapshots of older people's lives and to examine how they have changed over the years.

- the module of questions asks people aged 65 and over about their living circumstances, their health, their ability to perform a range of domestic and other tasks, and the use they make of health and social services.

- nationally representative sample of older people 65 plus living at home.

- proxy data is collected.

- ability to link 'trailer' data to main GHS survey data.

Disadvantages:

- not specifically designed to measure poverty and social exclusion, so secondary analysis limited to use of health and social services and ADL limitations.

- reflects the limited range of direct (deprivation) measures available in the GHS, and the superiority of other survey sources with income data (for example, the Family Resources Survey [FRS]).

- since the GHS covers private households only, analyses undertaken not representative of all people aged 65 and over, due to the fact that a significant proportion of them (roughly 5\%) live in communal establishments such as residential homes, nursing homes and long-stay hospitals. 
Title: Health Survey for England, 2004

Principal investigator(s): National Centre for Social Research; University College London, Department of Epidemiology and Public Health

Description: The Health Survey for England (HSE) is part of a wider programme of surveys commissioned by the Department of Health (DH), and is designed to monitor trends in the nation's health. The HSE was first proposed in 1990 to improve information of morbidity by the (then) newly created Central Health Monitoring Unit within the DH. This information is used to underpin and improve targeting of nationwide health policies. It comprises a series of annual surveys beginning in 1991 . All surveys have covered the adult population aged 16 and over living in private households in England. Children were included in every year since 1995. Each year the HSE focuses on a different demographic group and looks at such health indicators as cardio-vascular disease, physical activity, eating habits, oral health, accidents and asthma. Since 1994 onwards the survey has been carried out by the Joint Survey Unit of the National Centre of Social Research and the Department of Epidemiology and Public Health at University College London.

The aims of the HSE series are to:

- provide annual data about the nation's health

- estimate the proportion with specified health conditions

- estimate the prevalence of risk factors associated with these conditions

- examine differences between population sub-groups

- assess the frequency with which combinations of risk factors occur

- monitor progress towards selected health targets

- measure (since 1995) the height of children (aged two and over) at different ages, replacing the National Study of Health and Growth.

The survey focuses on different health issues each year, although a number of core questions are included every year. Topics are revisited at appropriate intervals in order to monitor change:

- in 1991, 1992, 1993, 1994, 1998 and 2003, the survey focused on cardiovascular disease and associated risk factors;

- $\quad$ in 1995 and 1996, the major focus of the survey was atopic disease (including asthma and eczema), accidents and disability;

- in 1997 the survey report focused on the health of young people aged 2-24 years, and combined data (in report format only) from the 1995-97 surveys;

- in 1999 and again in 2004, the focus was on the health of minority ethnic groups. The boost sample was designed solely to yield additional interviews with members of the most populous minority ethnic groups: Black Caribbean, Black African (covered in 2004 only), Indian, Pakistani, Bangladeshi, Chinese and Irish;

- in 2000, the survey focused on the health and social exclusion of older people and included a sample of care home residents;

- the 2001 survey included for the first time questions on fruit and vegetable consumption;

- the 2002 survey focused on children, young people and maternal health, and included a boost sample of young people aged 0-24 and mothers of infants aged under one year. 


\section{Coverage:}

Dates of fieldwork: January 2005-June 2005

Country: England

Spatial units: Health authorities (England)

Observation units: Individuals

Kind of data: Numeric data; individual (micro) level

\section{Universe sampled:}

Location of units of observation: National

Population: Adults (aged 16 and over) and children (aged 0-15 years) in the general population and minority ethnic groups, living in private households in England

Sample frame: Postcode address file

Sample design: Multi-stage stratified random sample

\section{Methodology:}

Time dimensions: Repeated cross-sectional study. The survey is conducted annually Number of units (year): 10,114 (general population and minority ethnic boost samples); 8,354 (general population sample); 21,157 (all individuals in cooperating households)

Method of data collection: Face-to-face interview; self-completion; clinical measurements; physical measurements; computer-assisted personal interviewing (CAPI)

Weighting: Non-response, child, household, interview and nurse weights used

\section{Additional information:}

Use of proxy informants: Yes ( $n=2759,27.3 \%)$

Proxy respondents: Proxy interviews were carried out for infants aged 0-2 and children 2-12. Information about children under 13 was obtained from a parent with the child present. If a person was unable to complete the interview in person then the appropriate code was used (for example, language difficulties, physically or mentally incapable).

Missing data on proxy informants: NA

Overall response rate: $80.8 \%$

Differential response rate: NA

Imputation of missing information: NA

Attrition rates: NA

Boosters: 483 ethnic boost sample points covering Black Caribbean, Black African, Indian, Pakistani, Bangladeshi, Chinese and Irish. Additionally, in order to increase further the number of Chinese informants in 2004, the sample was supplemented with a extra sample consisting of people with 'Chinese sounding' surnames obtained from the Electoral Register (for further information see HSE 2004 report, Vol 2,

Methodology and documentation).

Period covered by series: 1991 to present

Common risk factors: Gender, age, ethnicity, tenure, household type, SEG and NS-

SEC

Less common risk factors: Religion

Critical life events: NA

Local area information: NA 
Overview: The HSE offers several advantages in relation to studying social exclusion:

- $\quad$ the Social Capital and Social Exclusion module for the Health Survey (2000) captured key elements of social capital (new to the survey) and aspects of social exclusion not covered by the existing suite of questions on socioeconomic status asked every year in the HSE.

- module covered a number of domains directly related to social exclusion: neighbourhood, access to services, perceived trust, social support and social networks, and social/civic participation (Bajekal and Purdon, 2002).

- running alongside the general population sample (HSE 2000) was a care homes sample, selected from the Laing \& Buisson database. This allows comparisons on the various dimensions of social exclusion according to living situation (that is, residential versus non-residential) to be determined.

- permits analysis on the relationship between general health, disability, psychosocial health and specific dimensions of social capital and social exclusion (see, for example, Bajekal, 2002; Boreham et al, 2002; Falaschetti et al, 2002).

- possible to examine 'deep exclusion', particularly in relation to care home residents in poor physical and mental health who neither participate in the available activities nor have contact with their family and friend networks.

There are also some disadvantages as regards the measurement of social exclusion:

- the scope, content and breadth of the dimensions in relation to social exclusion are limited. To explain, the HSE 2000 is quite strong in terms of perceived social support, social networks, social and civic activities, neighbourhood satisfaction and trust, but there is little in the way of the reasons why these dimensions are lacking, that is, what leads to - or explains - social exclusion.

- unlikely that the sample of care home residents is representative of all older people living in a non-residential setting, which leads to a sample selection bias as those residents most able to complete the survey were chosen to participate in the study. 
Title: Home Office Citizenship Survey

Principal investigator(s): Office for National Statistics, Home Office Communities Group

Description: The Home Office Citizenship Survey (HOCS) is a biennial social survey delivering essential data on topics relating to community cohesion, 'race' and faith, volunteering, civic participation and views on neighbourhood. The 2003 HOCS questionnaire comprised four modules:

- Family and household composition, including interaction with non-resident children, family networks and sources of parenting advice and information.

- Active communities and social capital, including neighbourliness, civic participation, volunteering, and receipt of voluntary help.

- Racial equality and prejudice, including perceptions of 'race' equality and prejudice, identity, religion and language.

- Rights and responsibilities, including: self-defined rights and responsibilities, and balancing rights and responsibilities.

Separate questionnaires were developed for children's and young people's booster samples. The children's questionnaire comprised three modules:

- Neighbourhood and school, including feelings of safety and enjoyment.

- Active communities and social capital, including help given within family networks and social participation.

- Right and wrong, including perceptions of these concepts.

The young people's questionnaire was more detailed, covering in addition perceptions of 'race', 'race' equality, prejudice and religion. Children's (aged 8-10) and young people’s (11-15) boost samples were also included in the 2003 survey.

\section{Coverage:}

Dates of fieldwork: February-September 2003

Country: England and Wales

Spatial units: Government Office for the Regions (GORs)

Observation units: Individuals

\section{Universe sampled:}

Location of units of observation: National

Population: Nationally representative sample of adults in England and Wales aged 16+; boost sample of minority ethnic adults aged 16+; children's (aged 8-10) and young people's (11-15) boost samples (2003 only)

Sample frame: Small user postal address file for England and Wales

Sample design: Multi-stage stratified random sample

\section{Methodology:}

Time dimensions: Repeated cross-sectional study (biennial)

Number of units (year): Main sample: target 10,000, achieved 9,486. Minority ethnic boost sample: target 5,022, achieved 4,571. Young people's boost sample: target 1,500 , achieved 1,666. Children's boost sample: target 1,200, achieved 1,032 (2003) Method of data collection: Face-to-face interview 
Weighting: Weighting used to adjust for non-response based on ACORN

classification and GOR separately for the main sample and combined samples. Unlike 2003, the 2005 survey samples households based on equal selection probabilities.

\section{Additional information:}

Use of proxy informants: Yes ( $\mathrm{N}=881$ in 2003, 5.7\% of valid cases)

Proxy respondents: Where a sample member is too ill or too busy to be interviewed, or has limited English language skills, a proxy interview is conducted with a close relative or another household member Missing data on proxy informants: NA

Overall response rate: 64\% (2003); 63\% (2005)

Differential response rate: Response rates lower in London than other areas.

Response rates were lower in the minority ethnic booster sample in 2005 (54\%)

Imputation of missing information: NA

Attrition rates: NA.

Boosters: Minority ethnic booster sample (2001, 2003); children's (aged 8-10) and young people's (11-15) booster samples (2003)

Period covered by series: Ongoing since 2001

Risk factors: Includes gender, age, ethnicity, tenure, household type, SEG, social class. Less common risk factors: Religion, discrimination, religious prejudice.

Critical life events: None.

Local area information: Rural indicator and population density, Government Office Region, Index of Multiple Deprivation (deciles)

Overview: The HOCS is a recent addition to the array of UK official surveys designed to address a perceived lacuna of data relating to social cohesion, social capital and social and civic participation. As such, the HOCS series is an important source of data on multi-dimensional exclusion, not least in relation to the social position of minority ethnic groups in the UK.

The advantages of the HOCS as a survey resource in the study multiple disadvantage include:

- good spatial referencing of observations (for example, ACORN, IMD, ONS area classification), which allow for the estimation of both area and individual-level effects;

- relatively large sample sizes mean that it is possible to analyse specific population sub-groups where data are pooled across waves;

- minority ethnic booster sample allows for detailed analysis of non-white ethnic groups within and across waves.

Nonetheless, and in addition to the generic limitations of cross-sectional surveys the potential of the HOCS series as a survey resource in the study multiple disadvantage is constrained by:

- the short time span of the HOCS series that makes it impossible at present to discern long-term trends in social and civic participation;

- limited information on household incomes (self-reported banded data only) and an absence of direct measures of deprivation;

- limited information on other household members. 
Title: Longitudinal Study of Young People in England

Principal investigator(s): Department for Education and Skills (DfES); University of London, Institute of Education, Centre for Longitudinal Studies; National Centre for Social Research (NatCen)

Description: The Longitudinal Study of Young People in England (LSYPE) - also known as Next Steps - is one of the largest and most challenging studies of young people undertaken in Britain. The development of the LSYPE reflects wider changes in the socioeconomic context of youth transitions, as well as changes in government policy and information needs. The LSYPE seeks to chart the progress of a cohort of young people who had been exposed to recent government policies directed at young people (for example, Connexions, Educational Maintenance Allowances). One important objective of the study is to augment the existing evidence base in order to support the development of policies to meet the changing educational and training needs of young people and their parents. Wave 1 questionnaire content includes:

- attitudes to school/education

- school subject preferences, choices and performance

- access to and use of ICT

- homework polices and practice

- study support

- aspirations/expectations for 16 and beyond

- 'at-risk' markers.

The initial sample comprises 21,000 young people aged 13 and 14 sampled from Year 9 attainment records at schools throughout England (both state and independent). Both young people and their parents are interviewed at home about a range of experiences and views. The survey is conducted annually until age 25 with additional interviews with parents at waves 1 and 2.

\section{Coverage:}

Dates of fieldwork: April-May 2004 (wave 1)

Country: England

Spatial units: Not known

Observation units: Individuals; households; schools

\section{Universe sampled:}

Location of units of observation: National

Population: Young people aged 13-14 attending state or independent schools in England in 2004 (wave 1)

Sample frame: Year 9 pupil-level attainment records

Sample design: Two stage sampling using schools (c 670). Separate designs for state and independent sectors

\section{Methodology:}

Time dimensions: Cohort

Number of units (year): Approximately 20,000 (wave 1)

Method of data collection: Face-to-face interview. Self-completion questionnaire

Weighting: Not known 


\section{Additional information:}

Use of proxy informants: Yes.

Proxy respondents: Proxy responses are used in parent interviews where second parent in unavailable or has language difficulties.

Missing data on proxy informants: Not known

Overall response rate: $75 \%$ (Wave 1).

Differential response rate: Not known.

Imputation of missing information: Not known

Attrition rates: NA.

Boosters: The sample contains boost elements for pupils from an ethnic minority background $(\mathrm{N}=1,000)$ and those attending schools with high deprivation scores (more than $20 \%$ of pupils eligible for free school meals).

Period covered by series: Ongoing since 2004

Risk factors: Includes gender, age, tenure, household type, SEG, social class.

Less common risk factors: Not known.

Critical life events: Not known.

Local area information: Not known.

Overview: The main strengths of the LSYPE derive from its focus on informing the policy process through the development of a robust evidence base on youth transitions, education, training and employment. The LSYPE has a specific emphasis on exclusion and disadvantage amongst young adults. The advantages of the LSYPE in investigating youth multi-dimensional exclusion include:

- emphasis on policy interventions in youth transitions encourages evaluation of policy effectiveness and outcomes;

- relatively narrow time intervals allows for analysis of short-run time-dependent effects in youth transitions;

- large sample size in comparison with alternative panel data (for example, British Household Panel Survey [BHPS]);

- focuses on specific policy problems based on sub-samples of key policy interest (for example, minority ethnic groups, area deprivation);

- extensive topic detail, for example, about parents and family circumstances;

- single agency funding secures long-term cohesion of study. 
Title: Millennium Cohort Study

Principal investigator(s): University of London, Institute of Education, Centre for Longitudinal Studies

Description: The Millennium Cohort Study (MCS) seeks to chart the social, economic and health advantages and disadvantages facing children born at the start of the 21st century, and to provide a basis for comparisons with preceding cohorts (for example, National Child Development Study [NCDS], 1970 British Cohort Study [BCS70]). The MCS also collect information on previously neglected topics, such as fathers' involvement in children's care, parents' own childhood experiences, and the wider 'social ecology' of the family (social networks, community engagement, access to services). Both mothers and fathers of infants included in the sample were interviewed (where resident) when the babies were nine months old, and again when the children were three years of age.

The mother or main carer interviews covered ethnicity and language, the baby's father, lone parenthood, pregnancy, labour and delivery, the baby's health and development, childcare, grandparents, friends and social support, parental health, education and training, employment and earnings, housing, community and local services, time with and without the baby and other interests. The interview also included a selfcompletion element covering the baby's temperament and behaviour, relationship with partner, previous relationships, domestic tasks, previous pregnancies, mental health, attitudes to relationships, parenting, work, etc.

The father or main carer's partner interviews covered ethnicity and language, father's involvement with the baby, lone parenthood, baby's mother (if not resident), grandparents and friends, parental health, education and training, employment and earnings, time with and without the baby and other interests. The self-completion element of the father/carer's partner interview covered baby's temperament and behaviour, relationship with partner, previous partners, previous children, mental health and attitudes to marriage, parenting and work. Either parent or carer could answer the household module questions, which covered household composition and relationships, children, employment status, caring responsibilities for the baby born in 2000 and language spoken at home.

\section{Coverage:}

Dates of fieldwork: June 2001-September 2002 (England and Wales); September 2001-January 2003 (Northern Ireland, Scotland)

Country: United Kingdom

Spatial units: Countries; Government Office for the Regions (GORs)

Observation units: Individuals; families/households

\section{Universe sampled:}

Location of units of observation: National

Population: Parents of living babies born September 2000-August 2001 (England and Wales); November 2000-January 2002 (Northern Ireland, Scotland)

Sample frame: Not known

Sample design: Stratified random sample 


\section{Methodology:}

Time dimensions: Cohort

Number of units (year): 20,646 (target); 18,819 (obtained) (18,533 families)

Method of data collection: Face-to-face interview; self-completion

Weighting: Weighting used

\section{Additional information:}

Use of proxy informants: Yes.

Proxy respondents: Conducting main interviews by proxy was not permitted though some information could be collected by proxy if a respondent was away from home or incapacitated (see Shaw and Calderwood, 2004).

Missing data on proxy informants: Not known.

Overall response rate: Overall field response for the birth cohort survey was estimated to be $81 \%$.

Differential response rate: Response rates were lower in 'disadvantaged' wards and those containing high minority ethnic concentrations (see Shaw and Calderwood, 2004).

Imputation of missing information: Not known.

Attrition rates: Around 15,000 of the 18,533 original study families were reinterviewed in Wave 2.

Boosters: Booster samples were used to ensure adequate representation of all four UK countries, deprived wards and wards with high concentrations of black and Asian families.

Period covered by series: 2001, 2003, 2006 (on-going).

Risk factors: Includes gender, age, ethnicity, tenure, household type, SEG, social class. Less common risk factors: None.

Critical life events: None yet available.

Local area information: Not known.

Overview: The main limitations of the MCS are shared with the other British cohort studies (for example, NCDS, BCS70), namely (see Longview Associates, 2006):

- an inability to address short-term poverty dynamics due to the infrequency of observations;

- absence of spatial data referencing;

- lack of data on other household members;

- increasing problems of non-response and attrition (resulting in sample bias and reduced sample sizes);

- absence of an intermediate study between BCS70 and MCS00 means that timedependent processes across the 1970-2000 period cannot be observed. 
Title: Millennium Survey of Poverty and Social Exclusion, 1999

Principal investigator(s): D. Gordon, University of Bristol, School for Policy Studies; S. Middleton, Loughborough University, Centre for Research in Social Policy; J.R. Bradshaw, University of York, Social Policy Research Unit

Description: The Millennium Survey of Poverty and Social Exclusion (PSE Survey) was designed to update the Breadline Britain Surveys that were conducted by MORI in 1983 and 1990. Firstly, a representative sample of the population of Great Britain was asked for their views on what constitutes the necessities of life in present-day Britain. This was done in June 1999 using the Office for National Statistics (ONS) Omnibus Survey. Second, a specially selected sample was drawn from respondents to the 1998/99 General Household Survey [GHS], and interviewed in detail about their circumstances and their views on a range of issues associated with poverty and social exclusion. This data set is associated with the second aspect of the survey; the followup to the GHS, referred to as PSE. The main topics covered included social and material deprivation, housing, health, time poverty, social networks and support, finance and debts, intra-household poverty, poverty over time, absolute and overall poverty, area deprivation, local private and public services, crime and harm, child's school, perceptions of poverty, activism as well as some demographics and information on income.

\section{Coverage:}

Dates of fieldwork: 1 September 1999-15 October 1999

Country: Great Britain

Spatial units: Countries; standard regions

Observation units: Individuals

Kind of data: Numeric data

\section{Universe sampled:}

\section{Location of units of observation: National}

Population: Adults aged 16 or over from a sample of private households using a Kish grid

Sample frame: Sample from the 1998/99 GHS drawn from the postal address file Sample design: Sampled households were in the lower income groups using a measure of household income, which takes account of household size and composition. It also over-sampled in Scotland.

\section{Methodology}

Time dimensions: Cross-sectional (one-time) study

Number of units: 1,534

Method of data collection: Face-to-face interview; compilation or synthesis of existing material. The face-to-face interviewing was done using computer-assisted personal interviewing (CAPI) and the interview included a card-sorting exercise. A computer-assisted self-interviewing (CASI) module was used to collect answers to sensitive questions, such as those on crime. Where the respondent was reluctant or unable to complete the self-completion section on the laptop the interviewer asked the respondent's permission to ask these questions. Some data were also obtained for this study from the GHS.

Data sources: Data derived in part from the GHS 
Weighting: Individual and household weights

\section{Additional information:}

Use of proxy informants: No

Proxy respondents: NA

Missing data on proxy informants: NA

Overall response rate: $63 \%$

Differential response rate: Weighting used for non-response

Imputation of missing information: None

Attrition rates: NA

Boosters: None

Period covered by series: 1999

Common risk factors: Includes gender, age, ethnicity, housing tenure, household type, SEG and NS-SEC

Less common risk factors: Religion was not included

Critical life events: A number including accidents, deaths, divorce, and losing one's job

Local area information: Population density

Overview: To date, the PSE is the only survey designed specifically to examine the extent and nature of poverty and social exclusion. The original analysis of the PSE is contained in Gordon et al (2000) but most extensive secondary analysis of the survey is in Pantazis et al (2006).

The PSE offers a number of potential advantages to social policy analysts in relation to the study of exclusion, including:

- offers an extensive coverage of social exclusion using four dimensions: (i) impoverishment; (ii) labour market exclusion; (iii) service exclusion; and (iv) exclusion from social relations.

- contains direct measures of poverty for both adults and children.

- trend analysis is possible, using the previous Breadline Britain Surveys, on indicators relating to the perception of necessities, material and social deprivation and subjective poverty (see Mack and Lansley, 1985;Gordon and Pantazis, 1997).

- potential for multivariate analyses across a range of themes relating to multiple exclusion (for example, health and well-being, crime and social harm, economic participation and social and economic resources).

- the PSE over-sampled households in low-income groups.

- contains self-reported element for sensitive topics.

The disadvantages of the PSE in relation to the study of multi-dimensional exclusion include:

- sample size is relatively small, which limits the analysis of social exclusion for vulnerable sub-groups, for example, minority ethnic respondents, lone mothers.

- response rate is lower than most surveys. This was most probably the result of the length of the questionnaire (Gordon et al, 2000).

- the 1999 PSE Survey is now relatively dated and there are no plans to repeat the survey. 
Title: National Child Development Study

Principal investigator(s): City University, Social Statistics Research Unit

Description: The National Child Development Study (NCDS) is a continuing longitudinal study that follows the lives of all those living in Britain who were born between 3rd and 9th March 1958. The aim of the study is to improve understanding of the factors affecting human development over the whole lifespan. It has its origins in the Perinatal Mortality Survey, which examined the social and obstetric factors associated with stillbirth and death in early infancy among the 17,000 children born in Britain in that week. To date there have been six attempts to trace all members of the original birth cohort in order to monitor their physical, educational and social development.

In the first three NCDS surveys, information was obtained from parents, teachers, schools health services and subjects. The birth cohort was augmented by including immigrants born in the relevant week for the first three follow-ups based on school registers. Since 1974 no attempt has been made to include new immigrants in the survey. Information was obtained directly from subjects in the 1981 and 1991 surveys as well as from the spouses and children of cohort members. The fifth NCDS followup (1991) obtained information from the cohort member and other family members for 1 in 3 cohort families. The sixth wave (1999-2000) was combined with the 1970 British Cohort Study [BCS70]. The topic coverage for each wave of the NCDS is shown below:

Perinatal Mortality Survey (1958): biometric, obstetric and social background data; pregnancy histories.

Sweep 1 (age 7): educational progress; early life environment; medical history and biometric data.

Sweep 2 (age 11): access to local amenities; chronic illness in the family, medical history; educational aspirations; out-of-school activities; educational progress; living conditions and socioeconomic data.

Sweep 3 (age 16): medical history and tests; educational background; home environment; living conditions and socioeconomic data; familial relationships; behavioural difficulties; educational and career aspirations; employment; leisure activities; social attitudes; sex education; cigarette and alcohol consumption; public exam results (1978).

Sweep 4 (age 23): labour force participation; training and skills; family and household composition; family income, savings and investment; health status; voluntary activity; census area data.

Sweep 5 (age 33): education and training; employment history; housing history; partnership and family formation; income and wealth; health -elated behaviour; citizenship and participation; parenting; psychosocial development of cohorts' children; social attitudes.

\section{Coverage:}

Dates of fieldwork: 1958; 1965-66; 1969; 1974/78; 1982; 1991; 1999-2000

Country: Great Britain

Spatial units: Standard regions

Observation units: Individuals; families/households 


\section{Universe sampled:}

Location of units of observation: National

Population: All children in England, Scotland and Wales born in the week 3-9 March 1958

Sample frame: Birth records of those born in the reference week

Sample design: NA

\section{Methodology:}

Time dimensions: Cohort

Number of units (year): 17,419 (1958); 15,496 (1965-66); 18,285 (1969); 14,761

(1974); 12,538 (1982); 11,363 (1991)

Method of data collection: Face-to-face interview; postal survey; self-completion; psychological and educational measurements; observation; clinical measurements Weighting: No weighting used

\section{Additional information:}

Use of proxy informants: Yes.

Proxy respondents: Yes. Where an individual cannot be contacted, a proxy interview is conducted with a near relative living in the same household.

Missing data on proxy informants: NA.

Overall response rate: Cross-sectional (estimated): 99\% (Sweep 0); 93\% (Sweep 1); 92\% (Sweep 2); 87\% (Sweep 3); 78\% (Sweep 4); 72\% (Sweep 5); 72\% (Sweep 6). Differential response rate: Item non-response is high in relation to 'attitudes' and 'health' domains. Longitudinal response rates decline with age of cohort member from $99 \%$ (age 0) to $72 \%$ (age 42). In general, attrition due to non-response is low in the non-adult sweeps and increases in adulthood - possibly stabilising at age 42 - with 39\% of respondents being observed at Sweeps 1 to 5 (Plewis et al., 2004). for further details. Higher rates of longitudinal non-response in the NCDS is associated with low parental social class (Davie et al., 1972), social disadvantage (Goldstein, 1976;

Shepherd, 1993), minority ethnic background (Iyer, 1984; Shepherd, 1993), disability, poor housing, and educational under-achievement (Iyer, 1984).

Imputation of missing information: Imputation is not routinely undertaken

Attrition rates: Longitudinal sample, sweeps 1-6: 88\% (target); 73\% (estimated

response rate). See Plewis et al. (2004) for further details.

Boosters: None

Period covered by series: Ongoing since 1958.

Risk factors: Includes gender, age, ethnicity, tenure, household type, SEG, social class. Less common risk factors: Measures of social adjustment, psycho-social development. Critical life events: Critical life events include leaving parental home, getting married, child births, unemployment.

Local area information: Extensive local area information derived from UK Census and other sources.

Overview: The main limitations of the NCDS (and other British cohort studies) are detailed below (see Longview Associates, 2006):

- an inability to address short-term poverty dynamics due to the infrequency of observations.

- absence of spatial data referencing. 
- lack of data on other household members.

- increasing problems of non-response and attrition (resulting in sample bias and reduced sample sizes).

- absence of an intermediate study between BCS70 and the Millennium Cohort Study 2000 [MCS00] means that time-dependent processes across the 1970-2000 period cannot be observed. 
Title: Offending, Crime and Justice Survey, 2005

Principal investigator(s): Home Office; National Centre for Social Research and BMRB

Description: The Offending, Crime and Justice Survey (OCJS) is the national longitudinal, self-report offending survey for England and Wales.

The main aim of the survey is to examine the extent of offending, anti-social behaviour and drug use among the household population, particularly among young people aged from 10-25. The survey covers offences against households, individuals and businesses. In addition to 'mainstream' offences such as burglary, shoplifting and assault, it also covers fraud and technology offences.

The survey will also collect longitudinal data to allow researchers to examine the pathways into and out of delinquency and the impact various risk and protective factors have on these pathways.

The survey gathers evidence to support the effective targeting of resources for reducing levels of crime and illegal drug use. It provides: (i) measures of self-reported offending; (ii) indicators of repeat offending; (iii) trends in the prevalence of offending; (iv) trends in the prevalence and frequency of drug and alcohol use; (v) evidence on the links between offending and drug/alcohol use; (vi) evidence on the risk factors related to offending and drug use; and (vii) information on the nature of offences committed, such as the role of co-offenders and the relationship between perpetrators and victims.

\section{Coverage:}

Dates of fieldwork: January to October 2005

Country: England and Wales

Spatial units: Government Office for the Regions (GORs), standard region

Observation units: Individuals

Kind of data: Numeric data; individual (micro) level

\section{Universe sampled:}

Location of units of observation: National

Population: People living in private households. The first sweep of the OCJS in 2003 covered around 12,000 people aged from 10-65 living in private households in England and Wales. Subsequent annual sweeps between 2004 and 2006 focus on young people aged from 10-25. In each of these subsequent sweeps young people who have previously been interviewed and have agreed to further contact are followed up for re-interview. In addition to these 'panel' respondents, 'fresh sample' respondents aged from 10-25 are also introduced to ensure the total sample is around 5,000 young people each year.

Sample frame: Postcode address file

Sample design: Multi-stage random sample

\section{Methodology:}

Time dimensions: Refreshed panel 
Number of units (year): The initial 2003 survey set out to conduct 10,000 interviews with a 'core' sample of respondents aged 10-65. Of these core interviews, 5,000 were to be with respondents aged 10-25. An additional 2,000 interviews were to be completed with a boosted sample of non-white respondents aged 10-65. The final numbers achieved were 10,079 core sample respondents, of whom 4,576 were aged 10-25, and 1,886 additional interviews were achieved with respondents from minority ethnic groups. In both 2004 and 2005, the intention was to achieve an overall sample of 5,000 young people. In 2004, 3,449 interviews were carried out with young people aged $10-25$ at the time of the first interview in 2003. This does not include 40 partial interviews that were not included in the final dataset. An additional 1,843 interviews were carried out with young people who were contacted and interviewed for the first time in 2004 from our 'fresh' sample. This meant that a total of 5,292 interviews were conducted in 2004. In 2005 the 'panel' sample included everyone who had been interviewed previously and agreed to be re-contacted. In addition to this, panel cases from 2003, which were not interviewed in 2004, due to being 'non-contacts' or 'soft refusals' were also included. The total panel sample consisted of 5,324 respondents, from this, 4,421 interviews were achieved. As in 2004, 'fresh' sample was used to boost the figures in order to achieve a target of 5,000 interviews. Following the panel response, a total of 579 'fresh' interviews were needed to achieve the overall target; however, this was exceeded and a total of 817 'fresh' interviews were achieved.

Overall a total of 5,238 interviews were conducted in 2005.

Method of data collection: Computer-assisted interviews using computer-assisted personal interviewing (CAPI), computer-assisted self-interviewing (CASI) and audiocomputer-assisted self-interviewing (A-CASI). CAPI questions are administered by the interviewer, who reads the questions from a laptop and enters answers directly into the laptop. For CASI, the respondent reads the questions themselves on the laptop and enters their own answer, unaided by the interviewer. A-CASI is like CASI but the respondent can also listen to the question through headphones. The main benefit of using A-CASI is that it allows respondents who have reading difficulties to answer questions without interviewer involvement. CASI and A-CASI are being used for the most sensitive modules.

Weighting: Weightings are used to adjust for: unequal selection probabilities; nonresponse bias; analysis of the offending data to reflect the number of times an offence has been committed in the past 12 months; and longitudinal analyses that include responses from previous sweeps.

\section{Additional information:}

Use of proxy informants: Yes

Proxy respondents: Proxy answers from parents or guardians were accepted in the case of 10- to 15-year-olds for some household grid questions, for example, child's ethnicity and religious group

Missing data on proxy informants: NA

Overall response rate: The response rate in 2003 was $74 \%$; $69 \%$ for the fresh sample in 2004 sweep; and 70\% for the fresh sample in the 2005 sweep

Differential response rate: Not stated but weightings adjust for the possibility of nonresponse bias

Imputation of missing information: NA

Attrition rates: The response rate for the 2004 panel sample was 84\%; and 83\% for the 2005 panel sample

Boosters: Minority ethnic booster in the 2003 survey (see above Number of units) 
Period covered by series: 2003-06

Common risk factors: Gender, age, tenure, ethnicity, nationality, marital status and SEG

Less common risk factors: Religion, free school meals, no contact with either mother or father, truancy, gang membership, stayed away from home without parental permission

Critical life events: Looked after by foster parents or in care

Local area information: ACORN, ONS classification of local authorities, ONS classification of health authorities, Indices of Deprivation, rural and urban area classification

Overview: The survey offers a number of potential advantages to social policy analysts in relation to the study of exclusion, including:

- extensive and detailed data on offending, victimisation and criminalisation;

- extensive and detailed data on alcohol and drug use that allows for relationships to be examined with offending behaviour;

- includes an extensive range of variables from all themes relating to social exclusion;

- includes a range of risk factors related to social exclusion;

- $\quad$ one of the few surveys to include young people;

- 2003 survey included a booster minority ethnic respondents;

- uses sensitive computer-assisted interview techniques that should improve the reliability of the data;

- relatively, high response rate among fresh and panel samples.

The disadvantages of the OCJS in relation to the study of multi-dimensional exclusion include:

- coverage of variables relating to material and economic resources is not very extensive.

- the survey, by interviewing only those in private households, excludes those groups in the population (for example, prisoners, the homeless, also perhaps also those in care) that are most likely to be at risk of offending and victimisation and also substance misuse.

- the survey uses a narrow definition of crime and victimisation and also drug use. For example, crimes committed against young people by corporations, public and state institutions are not captured by the survey.

- $\quad$ self-report studies involving young people may exaggerate offending patterns.

- the survey has a limited lifespan (2003-06). 
Title: Office for National Statistics Longitudinal Study - England and Wales, 19712001

Principal investigator(s): Demography and Health Division, Office for National Statistics (ONS); with Centre for Longitudinal Study Information and Support (CeLSIUS), London; London School of Hygiene and Tropical Medicine, University of London

Description: The ONS Longitudinal Study $(L S)$ is a complete set of individual-level census records, linked between successive censuses, together with data for various events, relating to a sample of the population of England and Wales. The sample is comprised of people born on one of four selected dates of birth and therefore makes up about $1 \%$ of the total population. The sample was initiated at the time of the 1971 Census, and the four dates were used to update the sample at the 1981, 1991 and 2001 Censuses and in routine event registrations. New LS members enter the study through birth and immigration and existing members leave through death and emigration. Thus, the LS represents a continuous sample of the population of England and Wales, rather than a sample taken at one time point only. It now includes records for over 900,000 study members.

The LS is useful for longitudinal and cross-sectional studies of census and event data. It contains data on:

- all information from census returns since 1971, including data on occupation, economic activity, housing, ethnicity, age, sex, marital status and education;

- event data on births and deaths, fertility, mortality, morbidity, migration and cancer registrations;

- geographic data.

In addition to the census records, the individual LS records contain data for events such as deaths, births to sample mothers, emigrations and cancer registrations. Census information is also included for all people living in the same household as the LS member. However, it is important to emphasise that the LS does not follow up household members, in the same way, from census to census.

\section{Coverage:}

Dates of fieldwork: Four selected dates of birth in 1971, 1981, 1991 and 2001

Country: England and Wales

Spatial units: County district/ward, Government Office for the Regions (GORs), standard region, various health authority classifications (Area Health Authorities, District Health Authorities, Regional Health Authorities, Strategic Health Authorities for various Census years), and enumeration postcode Observation units: Individuals and households

Kind of data: Numeric data; individual (micro) level

\section{Universe sampled:}

Location of units of observation: National (England and Wales)

Population: 1\% sample of the total population of England and Wales clustered by date of birth (four individual dates of birth)

Sample frame: Random, 1\% sample of the population of England and Wales clustered by date of birth 
Sample design: Multi-cohort continuous design. LS members enter the study either at census or birth/immigration when their records are identified as having one of the four LS birthdates. New births and immigrants enter the study on a continuous basis. Resampling is effectively done at each census.

\section{Methodology:}

Time dimensions: Panel, record linkage study (National Health Service Central Register [NHSCR])

Number of units (year): 1971: 529,764 achieved records. 1981: 535,859 achieved records. 1991: 543,884 achieved records, 927,000 records as of 2001

Method of data collection: Census questionnaire and event registration. Information from the 1971, 1981, 1991 and 2001 Censuses has been linked across censuses as well as information on events such as births, deaths and cancer registrations.

Weighting: The data are not weighted

\section{Additional information:}

Use of proxy informants: Yes

Proxy respondents: Infants, new births

Missing data on proxy informants: NA

Overall response rate: 1971 - 529,764 (achieved). 1981 - 557,724 (planned) 535,859 (achieved). 1991 - 559,985 (planned) 543,884 (achieved). 2001 - not yet available. While a response rate per se is not applicable, there are questions about dimensions of the population which may be left out of the Census data. See 'How sample members identified', in Hattersley \& Creeser (1995) and Census quality reports on underenumeration.

Differential response rate: NA Imputation of missing information: NA

Attrition rates: People cannot refuse to participate, so the conventional notion of a response rate is not relevant. Nevertheless, there are complications for tracing sample members. In some cases, people's date of birth may be incorrectly recorded, resulting in a small section of the sample that is included being ineligible, and also in a small number of cases that should have been sampled being excluded. Challenges arise from continuing to identify sample members over time, as in some cases, records are not available about people's ultimate fate. $99.3 \%$ of new sample members identified in the 2001 Census have been traced in other records. 96.6\% of sample members identified in 2001 have been linked to a previous record in the study. 74.3\% of sample members identified in 1971 who have not been registered as having died in the UK and who did not report leaving England and Wales to a doctors surgery have been traced through 2001.

Boosters: NA

Period covered by series: 1971, 1981, 1991, 2001

Common Risk factors: Gender, age, ethnicity, tenure, household type, socio-economic group (SEG), social class (NS-SEC).

Less common risk factors: Ethnicity and religion available in certain Censuses only. Critical life events: Deaths, births to sample mothers, emigrations and cancer registrations.

Local area information: Able to link with ONS area-based statistics 
Overview: There are many in using the ONS LS for studying dimensions of social exclusion:

- one of the major strengths of the ONS LS sample is its size. It represents $1 \%$ of the population of England and Wales, about 500,000 people.

- the combination of large sample size and long follow-up time makes it unique.

- for studies in certain areas, such as ethnicity, the LS is the only longitudinal study large enough to give statistically useful sample sizes.

- data set includes information on co-residents of LS members as well as the members themselves, and information on people in communal establishments, who are excluded from most national surveys.

- census coverage rates and the linkage and trace rates obtained in the LS compare very favourably with response rates achieved in surveys.

- can be used to carry out a wide range of cross-sectional and longitudinal analyses relating to the type of family in which an LS member lives, the overall composition of their household and the relationships that exist between family and household members.

- extended possibilities for life course analyses of, for example, social mobility and housing deprivation (Brassett-Grundy, 2003, p 25).

- availability of census and event data spanning 30 years for those included in the original sample presents new opportunities for analysing links between childhood circumstances and adult circumstances, for example, health and long-term illness.

- inclusion of the question on ethnic origin presents new opportunities for examining changes in the reporting of ethnicity between 1992 and 2001 and for examining changes in the characteristics and locations of members of minority ethnic groups, for example, the extent to which they may be geographically excluded from services.

- enhancements to the individual and household level data in the LS through addition of geographic variables also present new opportunities and are likely to be of particular appeal to geographers and others concerned with differences by type of area (cf Gleave et al, 1998, 2000).

- finally, computation of variables such as educational, employment, housing, health and disability, and housing deprivation in the 2001 Census will allow various precursors and antecedents of 'social exclusion' to be determined and 'deep exclusion' to be calculated and estimated at the population level.

- it is possible to link information on the characteristics of areas that LS members live in (for example, Index of Multiple Deprivation score of the ward of residence).

The disadvantages of the ONS LS are as follows:

- it is not specifically designed to measure the various dimensions of social exclusion.

- its main limitation is the relatively restricted range of variables available, for example, there is no information on smoking or on income.

- follow-up of samples is difficult, for example, to go to the sample and gather information on extra variables, as is sometimes the case when dealing with surveys.

- the LS is also currently restricted to England and Wales, although a Scottish LS is being developed. 
Title: Office for National Statistics Omnibus Survey, June 2004

Principal investigator(s): Social Survey Division, Office for National Statistics (ONS)

Description: The Omnibus is a regular, multi-purpose survey, which in recent years has gone into the field in eight months of the year. It started operating commercially in 1990. It was set up originally to meet the needs of government departments for a survey that used short and simple sets of questions, had greater statistical reliability than private sector omnibus surveys and a properly designed random sample. Now, however, an increasing number of academics are finding it a valuable research tool.

The ONS Omnibus is used for a number of purposes, for example: to provide quick answers to questions of immediate interest; to provide information on topics that do not require a full survey; to develop and pilot questions for other surveys; and to sift for sub-groups that can be followed-up in another survey.

Each month's questionnaire consists of two elements: core questions, covering demographic information, are asked each month together with non-core questions that vary from month to month. Over 300 question modules have been included to date covering a very wide range including contraception, unused medicines, tobacco consumption, changes to family income, internet access, arts participation, transport, fire safety and time use.

The non-core questions for this month (that is, June 2004) were:

Tobacco consumption (Module 210): this module was asked on behalf of the Department of Customs and Excise to help them estimate the amount of tobacco consumed as cigarettes.

Relationships (Module 350): this module was asked on behalf of the ONS and questions relate to the changing patterns of relationships. This has implications, for instance, on housing needs, and will inform policy and planning decisions.

Attitudes to domestic violence (Module 355): this module was asked on behalf of the Home Office and questions relate to attitudes towards domestic violence. Many of the questions in this survey have been asked by previous (non-Omnibus) surveys and show if and how attitudes are changing.

Social significance of birthdays (Module 356): this module was asked on behalf of researchers at the Open University and questions relate to whether people are aware of the impact of changes in their age. The module records changes in status directly related to age.

\section{Coverage:}

Dates of fieldwork: June 2004

Country: Great Britain

Spatial units: Government Office for the Regions (GORs); standard regions

Observation units: Individuals; families/households 


\section{Universe sampled:}

Location of units of observation: National

Population: Adults, aged 16 or over, living in private households

Sample frame: Postal address file

Sample design: Multi-stage stratified random sample. Stratified by: region; the proportion of households with no car; the proportion of households where the household reference person is in the NS-SEC categories 1-3; and the proportion of people who are aged over 65 years.

\section{Methodology:}

Time dimensions: Repeated cross-sectional study. Monthly (up to year 2000), eight cycles per year thereafter

Number of units (year): 1,841 (obtained)

Method of data collection: Computer-aided personal interviewing (CAPI)

Weighting: Weighting factors are applied to Omnibus data to correct for unequal probability of selection caused by interviewing only one adult per household, or restricting the eligibility of the module to certain types of respondent. In April 2005, a new weighting system was introduced on the Omnibus that supplies weights to correct for non-response bias. Applying these weights will gross up the data by age and sex and by region to the population control totals used on the Labour Force Survey [LFS]. As well as accounting for the unequal probability of selection, these weights will correct for certain types of non-response bias and should improve precision for most variables. Weights will be supplied at person level in each survey month and if required will be available at a household level and on a quarterly or annual basis (for further information see National Statistics, 2004).

\section{Additional information:}

Use of proxy informants: No

Proxy respondents: NA

Missing data on proxy informants: NA

Overall response rate: 67\% (June 2004)

Differential response rate: Weighting is applied to correct for differential response rates (see Weightings section above)

Imputation of missing information: None

Attrition rates: NA

Boosters: No

Period covered by series: 1990-2004

Common risk factors: Gender, age, tenure, marital status, national identity, ethnicity, NS-SEC and household type

Less common risk factors: None included in core questions

Critical life events: None included in core questions

Local area information: None

Overview: Since its inception the ONS Omnibus Survey has included a range of diverse topics including those related to social exclusion. For example, in 1999 the Survey included questions on the necessities of life for adults and children (see Pantazis et al, 2006), while in 2002 the Survey included a module on the population's access to key services (National Statistics, 2002). 
The survey offers a number of potential advantages to social policy analysts in relation to the study of exclusion, including:

- a quick and flexible means to ask questions on some aspects of social exclusion

- core questions include common risk factors.

The disadvantages of the ONS Omnibus Survey in relation to the study of multidimensional exclusion include:

- non-core modules are designed to be relatively short and would therefore not generally allow for an extended analysis of social exclusion;

- core questions do not include less common risk factors or critical life events;

- relatively small sample, which does not allow for the analysis of sub-groups. 
Title: OPCS/Office for National Statistics Surveys of Psychiatric Morbidity in Great Britain and the Mental Health of Children and Young People in Britain, 2004

Principal investigator(s): Office for National Statistics (ONS), Social and Vital Statistics Division; ONS Health and Care Division; T. Ford, University of London, Institute of Psychiatry, Department of Child and Adolescent Psychiatry; R. Goodman, University of London, Institute of Psychiatry, Department of Child and Adolescent Psychiatry

Description: The OPCS/ONS Surveys of Psychiatric Morbidity in Great Britain (OPCS/ONS SPM) aim to provide up-to-date information about the prevalence of psychiatric problems among people in Great Britain, as well as their associated social disabilities and use of services.

The series started in 1993, and so far consists of the following surveys:

- OPCS SPM: Private Household Survey, 1993 - this covered 10,000 adults aged 16-64 years living in private households;

- a supplementary sample of 350 people aged 16-64 years with psychosis, living in private households, which was conducted in 1993-94 and then repeated in 2000;

- OPCS SPM: Institutions sample, 1994 - this covered 1,200 people aged 16-64 years living in institutions specifically catering for people with mental illness;

- OPCS SPM among Homeless People, 1994 - this covered 1,100 homeless people aged 16-64 living in hostels for the homeless or other such institutions. The sample also included people sleeping 'rough';

- ONS SPM among Prisoners in England and Wales, 1997;

- Mental Health of Children and Adolescents in Great Britain, 1999;

- Psychiatric Morbidity among Adults living in Private Households, 2000 - this Survey was a repeat of the 1993 Private Households Survey;

- Mental Health of Young People Looked After by Local Authorities in Great Britain, 2001-2002;

- Mental Health of Children and Young People in Great Britain, 2004 - this was a repeat of the 1999 survey.

The main aims of the Mental Health of Children and Young People (MHCYP) in Great Britain, 2004 survey were:

- to examine whether there were any changes between 1999 and 2004 in the prevalence of the three main categories of mental disorder: conduct disorders, emotional disorders and hyperkinetic disorders;

- to describe the characteristics and behaviour patterns of children in each main disorder category and sub-groups within those categories;

- to look in more detail at children with autistic spectrum disorder;

- to examine the relationship between mental disorder and aspects of children's lives not covered in the previous survey, for example, medication, absence from school, empathy and social capital;

- to collect baseline information to enable identification of the protective and risk factors associated with the main categories of disorder and the precursors of personality disorder through future follow-up surveys.

The data file contains: 
- a subset of information collected in the previous 1999 survey on 10,438 children aged 5-15; these variables included those that were repeated in comparable form in 2004. The full 1999 dataset has also been deposited at United Kingdom Data Archive;

- the full data collected in the 2004 survey on 7,977 children aged 5-16;

- any potentially 'disclosive’ variables have been removed.

Information was provided for the survey from up to three sources: the primary care giver, the child/young person (aged 11-15/16) and the child/young person's teacher (nominated by child/parent).

\section{Coverage:}

Dates of fieldwork: March 2004-June 2004

Country: Great Britain

Spatial units: Government Office for the Regions (GORs)

Observation units: Individuals

Kind of data: Numeric data; individual (micro) level

\section{Universe sampled:}

Location of units of observation: National

Population: Children and young persons aged 11-15/16, living in Great Britain during 2004, and their parents and teachers

Sample frame: Postcode address file. The frame was stratified by GOR and within that by SEG. The sample was then selected from Child Benefit records.

Sample design: Multi-stage stratified random sample. The sample design consisted of a sample of postal sectors and, within these, a sample of addresses. The sampling design for the survey involved a two-stage process: the selection of 426 postal sectors and then 29 children within each sector. The postal sectors were selected by the Office for National Statistics. In order to preserve the confidentiality of the respondents, the Department for Work and Pensions' Child Benefit Centre selected the addresses following ONS instructions and then dispatched a letter on behalf of ONS to each selected household explaining the purpose of the survey and giving parents an opportunity to opt-out.

\section{Methodology:}

Time dimensions: Repeated cross-sectional study

Number of units (year): Parents and children (families) target: 12,294 (2004), obtained: 7,977 (2004). Teachers: 7,521, contacted (2004), completed and returned: 6,243 (2004)

Method of data collection: Face-to-face interview; postal survey; self-completion; parents/carers were interviewed face-to-face, children/young people completed the self-completion questionnaire, and teachers were surveyed by post.

Weighting: Weighting used. Weighting was carried out in two stages. First, weights were applied to correct for the unequal sampling probabilities of the children that arose because of the delay between selecting the area and children samples.

Respondents were then weighted to represent the age/sex/region structure of the total population of children and young people aged 5-16 in Great Britain, using ONS population figures for April-June 2004. The weights were calculated separately for boys and girls aged 5-9, 10-15 and 16. The former allow the data to be grossed to 
population figures. The latter scale the weights so that the number of respondents in each age/sex group matches the total number of interviews carried out in that group.

\section{Additional information:}

Use of proxy informants: No

Proxy respondents: NA

Missing data on proxy informants: NA

Overall response rate: Parents and children: 65\% (2004). Teachers: 83\% (2004)

Differential response rate: Adjusted for teacher non-response (17\%) in relation to

clinically assessed type of mental disorder

Imputation of missing information: NA

Attrition rates: NA

Boosters: NA

Period covered by series: 1993-2004

Common risk factors: Gender, age, ethnicity, tenure, household type, SEG and NS-

SEC

Less common risk factors: Religion not recorded

Critical life events: NA

Local area information: NA

Overview: There are several advantages in using OPCS/ONS SPM for analysing social exclusion:

- large and representative purposive samples.

- a wide variety of topics covered in the 2004 survey, including: housing, general health, strengths and difficulties, friendship, development, separation anxiety, social and specific phobias, panic attacks and agoraphobia, post-traumatic stress disorder, compulsions and obsessions, generalised anxiety, depression, self-harm, attention and activity, awkward and troublesome behaviours, eating disorders, tics, personality issues, stress and life events, school exclusions.

- information provided by a variety of sources, that is, the primary care giver, the child/young person (aged 11-15/16) and the child/young person's teacher (nominated by child/parent).

- ability to carry out pseudo-panel studies, for example, combining data from the 1999 and 2004 surveys should allow researchers to explore the prevalence and incidence of mental health disorders and social behavioural problems over a short period of time and the extent to which this impacts on social exclusion.

- $\quad$ protective and contextual factors were included for the first time in the 2004 survey relating to current governmental concerns on social inclusion and mental health improvement. These included questions measuring the child's resilience (for example, the extent of their social support networks), their ability to empathise with others and possible precursors of personality disorder.

Some of the disadvantages of these surveys include:

- not specifically designed to measure the various dimensions of social exclusion, including quality of life.

- infrequent collection periods for the various population samples interviewed, which affects the ability to determine prevalence and incidence of the various dimensions of social exclusion. 
Title: Quarterly Labour Force Survey, April 2006-June 2006

Principal investigator(s): Office for National Statistics (ONS), Social and Vital Statistics Division; Northern Ireland Statistics and Research Agency, Central Survey Unit

Description: The Labour Force Survey (LFS) survey seeks information on respondents' personal circumstances and their labour market status during a specific reference period, normally a period of one week or four weeks (depending on the topic) immediately prior to the interview. The LFS is carried out under a European Union Directive and uses international definitions of employment and unemployment and economic inactivity, together with a wide range of related topics such as occupation, training, hours of work and personal characteristics of household members aged 16 years and over. It is the source of the internationally comparable (International Labour Organization) measure known as 'ILO unemployment'.

The LFS was carried out biennially from 1973 to 1983, and was increasingly used during this time by British government departments to obtain information that would assist in the framing of social and economic policy. By 1983, the LFS was being used by the Employment Department to obtain information that was not available from other sources or was only available for census years. Between 1984 and 1991 the survey was carried out annually and consisted of two elements:

1. A quarterly survey conducted in Great Britain throughout the year, in which each sampled address was called on five times at quarterly intervals, and which yields about 15,000 responding households in every quarter.

2. A 'boost' survey in the spring quarter (March to May), which produced interviews at over 44,000 households in Great Britain and over 4,000 households in Northern Ireland.

During 1991, the LFS was further developed, so that from March 1992, quarterly data were made available, with a quarterly sample size approximately equivalent to that of the previous annual data. Thus, the survey became known as the Quarterly Labour Force Survey (QLFS). Between March 1992 and November 1994, interviewing in Northern Ireland was only conducted in the spring, with no quarterly element. However, from December 1994 (for the December 1994-February 1995 quarter), data gathering for Northern Ireland moved to the full quarterly cycle to match the rest of the country. From that date, the QLFS covered the whole of the UK.

The QLFS questionnaire comprises a 'core' of questions that are included in every survey, together with some 'non-core' questions that vary from quarter to quarter.

The questionnaire can be split into two main parts. The first part contains questions on the respondent's household, family structure, basic housing information and demographic details of household members. The second part contains questions covering economic activity, education and health, and also may include a few questions asked on behalf of other government departments (for example, the Department for Work and Pensions and the Home Office). Until the spring 1997 quarter, the questions on health covered mainly problems that affected the respondent's work. From that quarter onwards, the questions cover all health problems. Detailed questions on income have also been included in each quarter since 
winter 1992-93. The basic questionnaire is revised each spring, and a new version published, along with a transitional version that details changes from the previous year's questionnaire.

\section{Coverage:}

Dates of fieldwork: April 2006-June 2006

Country: United Kingdom

Spatial units: Government Office for the Regions (GORs); unitary authorities (England); unitary authorities (Wales); standard regions; NUTS Level 2 areas Observation units: Individuals; families/households

\section{Universe sampled:}

Location of units of observation: National

Population: All people normally resident in private households in Great Britain and Northern Ireland. When the LFS moved to a quarterly cycle, two new groups of people were included in the survey to improve the coverage of young people: residents in National Health Service (NHS) hospital accommodation (formerly called nurses' homes), and students living in halls of residence or boarding schools. Northern Ireland is not included in the local area data files before 1997.

Sample frame: Four sampling frames are used. For Great Britain, south of the Caledonian Canal, the postal address file is used, while north of the Caledonian Canal, a random sample is drawn from the published telephone directory. The sample of residents in NHS accommodation is also drawn, unclustered, for the whole of Great Britain using a specially prepared frame. In Northern Ireland, the source of the sample is the valuation list used for rating purposes, excluding commercial units and known institutions.

Sample design: Simple random sample

\section{Methodology:}

Time dimensions: Repeated cross-sectional study. Data are collected quarterly. In accordance with EU regulations, the LFS moved from seasonal (spring, summer, autumn, winter) quarters to calendar quarters (January-March, April-June, JulySeptember, October-December) in 2006. The last seasonal quarter dataset issued was the QLFS, December 2005-February 2006 and the first calendar quarter dataset was the QLFS, January-March 2006. For further details see Madouros (2006).

Number of units (year): The sample design currently (2003) consists of about 55,000 responding households in Great Britain every quarter, representing about $0.2 \%$ of the British population. A sample of approximately 2,000 responding households in Northern Ireland is added to this, representing $0.3 \%$ of the Northern Irish population, allowing UK analyses to be made.

Method of data collection: Face-to-face interview; telephone interview; the first interview is conducted face-to-face, and subsequent interviews by telephone where possible. Each quarter's LFS sample is made up of 5 'waves'. Each wave is interviewed in five successive quarters, such that in any one quarter, one wave will be receiving their first interview, one wave their second, and so on, with one wave receiving their fifth and final interview. As a result, there is an $80 \%$ overlap in the samples for successive quarters.

Weighting: Population weighting in the LFS serves two purposes. First it enables tables showing population estimates to be produced. Second, it compensates for different response among sub-groups in the population (see Differential response rate 
section, below). There is also an earnings weight, which is restricted to employees' earnings: other income data are not (yet) weighted (See Section 10, Labour Force Survey User guide).

\section{Additional information:}

Use of proxy informants: Yes (approximately 32\% in 2003)

Proxy respondents: The LFS allows interviewers to take answers to questions by proxy if a respondent is unavailable. This is usually from another related adult who is a member of the same household, although there are exceptions to this rule: (i) a young person, of the same household, may translate for a non-English speaking relative; (ii) a carer, of the elderly or infirm, although not related, may answer for someone in their care if it can be established that they know the respondent well enough; and (iii) anyone can respond by proxy with the personal permission of the head of household or spouse.

Missing data on proxy informants: None

Overall response rate: For Spring 2002, 79\% (wave 1)

Differential response rate: A multi-stage population weighting procedure is used. Each stage corrects for a different cause of non-response: stage 1 corrects for nonresponse at a local area level, stage 2 corrects for non-response among young people by age and sex; and stage 3 corrects for non-response by region, age (banded) and sex.

Imputation of missing information: Imputation is used to estimate missing items on a questionnaire so that the potential bias in estimates due to item non-response may be reduced.

Attrition rates: For spring 2002: wave 1 (79\%); wave 2 (70\%); wave 3 (695); wave 4 (66\%); wave 5 (66\%)

Boosters: The sample was initially boosted in England from 2000 and in Wales from 2001, providing significantly more robust results at the local level. This was due to the increased amount of data provided in England thorough the English Local Labour Force Survey (ELLFS), and in Wales thorough the Welsh Local Labour Force Survey (WLLFS). In March 2003, a boost was introduced in Scotland for the first time. As a result, more robust results are now available for Scotland due to the increased amount of data provided through the Scottish Local Labour Force Survey (SLFS). More information on the methodology behind the ELLFS is available in the May 2000 issue of Labour Market Trends, pp 195-9 and the January 2002 issue of Labour Market Trends, pp 33-41. See also LFS User guide - Volume 6.

Period covered by series: 1979 (Biennial - but not using ILO definition of unemployment); 1984 (annual); 1992 (seasonal quarters); 2006 (calendar quarters) Common risk factors: Gender, age, ethnicity, national identity, tenure, marital status, household type, SEG and industrial occupation

Less common risk factors: Religion, English as a second language Critical life events: Detailed questions on transitions to retirement Local area information: None

Overview: The LFS has been extensively re-analysed by researchers, with relevant topics including: job insecurity, polarisation in mother's employment and labour force participation of older people. The survey offers a number of potential advantages to social policy analysts in relation to the study of exclusion.

- it contains very detailed information on labour market involvement - a key concern of government policy. 
- it uses internationally agreed definitions of employment, which allows for comparative European analysis.

- as a long-standing survey, it means that time-trend analyses can be undertaken (but see note below on discontinuities).

- it contains reliable information at the local level on an annual basis (local area information may also be obtained from the quarterly LFS, however this is less robust due to its smaller sample size). See LFS User guide - Volume 6.

- averaging LFS estimates over four or more quarters ensures reliable analyses of minority ethnic groups and sub-groups in the population. See LFS User guideVolume 1 (Section 20).

The disadvantages of the LFS in relation to the study of multi-dimensional exclusion include:

- there are a number of discontinuities in LFS data caused by changes in the way the survey has been conducted and changes in the definitions of certain variables. For example, since survey became quarterly, the major change to the survey was the introduction of a section of earnings questions from winter 1992/93 onwards. Discontinuities are described in the LFS User Guide (Section 14).

- proxy interviews in the LFS form approximately one third of all interviews. A study looking at the quality of the information provided by proxy informants found that although the agreement levels between information given by proxy informants and the same information given by the subjects themselves were found for many key variables to be above $80 \%$, those variables requiring less straightforward information (such as training in the last week and highest qualification obtained) and those requiring very detailed numerical information (such as hours worked and income) showed a less satisfactory match between proxy and subject responses, which means higher gross error rates. A big problem for such variables is also the high level of 'don't knows'. If the data is used in a banded form, or to calculate averages the match of proxy and subject data is greatly increased. (For further information see, Dawe and Knight, 1997.)

- the use of proxy information affects the reliability of the data for the core purpose of estimating unemployment levels, since the ILO definition is having done no paid work in the last week, being available to start work in the next fortnight or waiting to start a new job, and having looked for work in the past four weeks. The accuracy of this is likely to be less in relation to non-standard employment. The reasons given for not working - believing there are no jobs available or looking after home and family - are heavily gendered but his may reflect social desirability factors rather than activity. Thus this data needs to be treated with enormous caution if used to estimate other forms of social participation.

- the survey contains limited information on material resources and no information on social resources and access to private and local services (although there are details questions on transport at a barrier to employment and some questions on childcare facilities). There are no questions on political and civic participation, living environment nor crime, harm and criminalisation.

- LFS is affected by falling response rates - a problem associated with all panel surveys. 
Title: Survey of English Housing, 2002-03

Principal investigator(s): National Centre for Social Research; Department for Transport, Local Government and the Regions

Description: The Survey of English Housing (SEH) is a continuous annual survey series, which began in 1993. The survey provides key housing data on tenure, owneroccupation and the social rented sector, and regular information about the private rented sector. The SEH comprises a main core of factual questions that remain largely unchanged from year to year, and cover tenure, housing costs and difficulties with mortgage/rent payments, housing history, moving intentions and the type of home desired. The survey also carries a set of attitudinal questions that are revised/rotated each year.

In 2002-03, topics covered included attitudes towards crime, racial harassment, parking provision, noise and neighbours in respondents' local area, and what aspects of their area respondents would like to see improved. The survey includes a separate module for all private tenants. This module includes detailed questions about tenancy type, rent paid and Housing Benefit as well as some attitudinal questions.

The main aims of the SEH are to provide:

- regular information about the main features of people's housing and their views about their circumstances;

- information about the private rented sector (which is not covered by routine administrative statistics like the owner-occupied and social rented sectors).

\section{Coverage:}

Dates of fieldwork: April 2002-March 2003

Country: England

Spatial units: Government Office for the Regions (GORs); counties; local authority areas; standard statistical regions

Observation units: Families/households; tenancy groups

Kind of data: Numeric data; individual (micro) level

\section{Universe sampled:}

Location of units of observation: National

Population: Private households and privately renting tenancy groups in England Sample frame: Postcode address file

Sample design: Two-stage sample design used with postcode sectors, which are similar in size to wards, as the primary sampling units. The design involves both stratification and clustering. The first stratifier used was GOR. Within each region, postcode sectors were further stratified according to selected housing and economic indicators from the 1991 Census.

\section{Methodology:}

Time dimensions: Repeated cross-sectional study, conducted annually from 1993

Number of units (year): 29,400 (target 2002-03); 19,640 (obtained 2002-03)

households

Method of data collection: Face-to-face interview; computer-assisted personal interviewing (CAPI) 
Weighting: Household and tenancy group weightings

\section{Additional information:}

Use of proxy informants: Yes ( $n=369,1.9 \%)$

Proxy respondents: Proxy interviews were carried out: (a) When the Household Reference Person (HRP)/partner is senile, has learning disabilities or is totally deaf; (b) when the HRP/partner is ill and is not well enough to see you before the end of the field period; (c) when no contact can be made with the HRP/partner during the field period, for example, when the HRP/partner is away or in hospital for the whole of the remaining field period; and (d) when the HRP or partner is 'too busy' or 'not interested in this sort of thing', provided they give permission for the proxy to take place.

Missing data on proxy informants: NA

Overall response rate: $72 \%$ among eligible households. At the cooperating households, 1,997 privately renting tenancy groups were identified. A private renter's interview was carried out with 1,951 tenancy groups (98\% of those eligible) Differential response rate: NA Imputation of missing information: NA

Attrition rates: NA

Boosters: NA

Period covered by series: 1993 to present

Common risk factors: Gender, age, ethnicity, tenure, household type NS-SEC. SEG not asked

Less common risk factors: Religion not asked

Critical life events: NA

Local area information: NA

Overview: The advantages of the SEH in terms of measuring social exclusion include:

- the inclusion of questions on: access to local amenities, satisfaction with local area, problems in area, improvements to area, frequent movers and length of tenure, disability and wheelchair usage, and general attitudes to housing.

- in 2003/04 the SEH included questions about wheelchair use for the first time. As the findings reveal, many wheelchair users did not live in suitable accommodation (DCLG, 2006).

- having background information on family type, tenure, employment status, gender, etc allows us to see which families/households these various domains of social exclusion affect most.

The disadvantages of the SEH are the following:

- the main drawback of the SEH - like many of the other 'purposive' surveys reviewed here - is that it was not specifically designed to measure the various aspects of social exclusion.

- limited scope on the measurement dimensions. For example, in terms of access to local amenities, only five (5) are included. Similar problem with respect to problems in the area - again, only five (5) problems are surveyed.

- in relation to satisfaction with local area, we cannot determine which aspect(s) respondents are most satisfied with.

- another drawback of the survey is that it only partially collects information on frequent movers, that is, the reasons why they moved so frequently. 
- in terms of general attitudes to housing, it is not clear whether respondents would prefer a different housing-tenure arrangement than the one they are currently in.

- lastly, one of the great drawbacks of the survey is that it does not ask specific questions on overall well-being or quality of life as it relates to housing. 
Title: Survey of Quality of Life in Old Age, 2000-01

Principal investigator(s): T. Scharf, Keele University, School of Social Relations, Centre for Social Gerontology; C. Phillipson, Keele University, School of Social Relations, Centre for Social Gerontology; P. Kingston, University of Wolverhampton

Description: The Survey of Quality of Life in Older Age (SQOL OA) was part of the Growing Older: Extending Quality of Life research programme funded by the Economic and Social Research Council (ESRC). The research for this study sought to generate new insights into the experience of inequality in later life. It examined aspects relating to the quality of life of older people living in areas of intense social deprivation, and developed understanding of factors contributing to social inclusion and exclusion in later life.

The aims and objectives of the survey were to:

- contribute to knowledge about the circumstances of older people living in areas of concentrated poverty, examining the specific characteristics of social exclusion as it affects different groups within the older population;

- explore ways in which older people manage their daily lives in deprived urban environments. The research addressed how individuals handle the multiple risks associated with living in such localities, along with the survival strategies and support networks that develop;

- develop research methods relevant to studying quality of life issues for older people living in areas of concentrated poverty;

- the research sought to contribute to the development of research techniques designed to measure poverty, social deprivation and social exclusion;

- identify forms of deprivation that have yet to be addressed fully in gerontological and social policy research;

- examine the dynamics of social exclusion at a neighbourhood-level, and the implications of this for social policy.

\section{Coverage:}

Dates of fieldwork: October 2000-March 2001

Country: England

Spatial units: (A) Wards; (B) postcode districts

Observation units: Individuals

Kind of data: Numeric data; alpha/numeric data; individual (micro) level

\section{Universe sampled:}

Location of units of observation: Sub-national

Population: Data were collected on individuals aged 60 and over living in noninstitutional households in the three most deprived electoral wards in each of the three most deprived local authorities of England (based on 1999 Index of Local Deprivation). The following study areas were chosen: Liverpool - Clubmoor, Granby and Pirrie; Manchester - Cheetham, Longsight and Moss Side; Newham - Park, Plashet and St Stephens.

Sample frame: 501 individuals were recruited from electoral registers using CACI Ltd's MONICA classification (www.caci.co.uk/); 99 individuals belonging to the largest minority ethnic groups in each electoral ward were recruited as a booster sample. 
Sample design: Simple random sample; purposive selection (minority ethnic groups) and case studies

\section{Methodology:}

Time dimensions: Cross-sectional

Number of units (year): 600 (target) 600 (obtained)

Method of data collection: Face-to-face interview

Weighting: The data are not weighted

\section{Additional information:}

Use of proxy informants: No

Proxy respondents: NA

Missing data on proxy informants: NA

Overall response rate: $100 \%$

Differential response rate: NA

Imputation of missing information: NA

Attrition rates: NA

Boosters: Yes. 99 individuals belonging to the largest minority ethnic groups in each electoral ward

Period covered by series: 2000-01

Common risk factors: Gender, age, ethnicity, tenure, household type, SEG and NS-

SEC

Less common risk factors: Religion not recorded

Critical life events: NA

Local area information: NA

Overview: The main advantages of this survey:

- specifically designed to measure several dimensions of poverty and social exclusion, including overall quality of life.

- purposive sampling to collect in-depth information on older people living in deprived neighbourhoods.

- breadth and quality of socio-demographic data collected on the circumstances of older people living in deprived areas and information relating to themes of social exclusion and quality of life, including: characteristics of poverty and its impact on daily life; networks (including support networks) of older people; patterns of support within the older population and with other social groups; quality of life of older people (using standardised measures of psychological well-being); characteristics of social participation within deprived localities; experiences of the urban environment in relation to services, crime, transportation and related issues (Scharf et al, 2002).

- built on previous research (Evandrou, 2000) to develop an 'index of multiple deprivation' comprising seven items considered especially important to older people (for example, central heating, use of a telephone, access to a car).

- research followed the 'consensual poverty' model approach initially developed by Mack and Lansley (1985) and was built largely on the Millennium Survey of Poverty and Social Exclusion(PSE Survey) carried out by Gordon et al (2000) in terms of identifying as poor those respondents who said they were unable to afford what the majority of British people view as basic necessities.

- built on the work of Burchardt et al (1999) and Gordon et al (2000), Scharf et al (2002) and conceptualised social exclusion as encompassing five dimensions: 
exclusion from material resources; exclusion from social relations; exclusion from civic activities; exclusion from basic services; and neighbourhood exclusion.

- the innovative part of Scharf et al's work was to explore interactions between social exclusion and quality of life, which hitherto had been done in piecemeal fashion. Specifically, they investigated the link between living in deprived areas and the effect this has on the quality of life of older people (Scharf et al, 2002).

The main drawbacks of the survey were:

- purposive sampling method

- small sample sizes

- no proxy informants, which could lead to a sample bias

- not nationally representative. 
Title: Youth Cohort Study

Principal investigator(s): R. Fitzgerald and S. Finch, National Centre for Social Research

Description: The Youth Cohort Study (YCS) is a major longitudinal study that monitors the labour market transitions of distinct cohorts of young people aged 16+, specifically with regard to educational attainment, training opportunities and experiences at school. The YCS currently covers 10 cohorts and over 20 surveys beginning in 1985. For cohorts 1-6 cohort members were contacted annually by post when they were 16-17, 17-18 and 18-19. For cohorts 7 and 8 the sweeps were carried out at bi-annual intervals instead of annual. Cohort 9 surveys were carried out annually for sweeps 1 and 2 in 1998 and 1999 respectively, and sweeps 3 and 4 were both conducted in the same year, 2000. Cohort 10 sweeps 1 and 2 were also both conducted in 2000, and sweep 3 in 2002.

Sweep 1: The questionnaire for sweep 1 included: GCSE attainment in Year 11; participation in education, training and employment; school experiences of and leaving education; contact with Careers Service; work experience; and truancy. Sweep 2: Sweep 2, conducted later in the same year, includes the following information: education, training and labour market history update; qualifications gained; and qualifications currently sought.

- All cohort members who had not achieved Level 2 qualifications by the end of Year 11 received the 'options and choices' module, covering: expected activities in 12 months' time/at age of 21; qualifications/job experience needed to attain expected activity; worries with continuing education; current prospects and training; finding work; advice and guidance; and parents and families.

- All cohort members who had achieved Level 2 qualifications by the end of Year 11 received the 'Higher Education' (HE) module, covering: HE applications; gap years; decisions about HE; and advice about HE.

Sweep 3: Sweep 3, conducted in 2002, included a postal questionnaire covering the following topics: views about work and education; current activities and qualifications obtained (since January 2001); educational participation; qualifications being studied for now; jobs and training; work, earnings and looking for work; on-the-job and offthe job training; and household details.

- All cohort members who had achieved Level 2 qualifications by the end of Year 11 and who responded to the HE module at sweep 2 were asked the additional HE module covering: entry routes; current experiences/difficulties; student finances; career plans and current activities; gap years; and attitudes towards HE.

\section{Coverage:}

Dates of fieldwork: Cohort 10: February-July 2000 (sweep 1); November 2000February 2001 (sweep 2); March-June 2002 (sweep 3)

Country: England and Wales

Spatial units: Training and Enterprise Council/Local Enterprise Company areas Observation units: Individuals

\section{Universe sampled:}

Location of units of observation: National 
Population: Young people who reached minimum school leaving age in the 1998/99 school year

Sample frame:

Sample Design: Simple random sample; multi-stage stratified random sample. Multistage stratified random sampling was used for cohorts 1-5. The YCS sample has been a single-stage simple random sample since cohort 6

\section{Methodology:}

Time dimensions: Cohort

Number of units (year): 13,698 (obtained) sweeps 1, 2 and 3 combined

Method of data collection: Postal survey; telephone interview

Weighting: Data weighted for non-response by sex, school type, region and

educational attainment

\section{Additional information:}

Use of proxy informants: Not reported.

Proxy respondents: NA.

Missing data on proxy informants: NA.

Overall response rate: 55\% (total productive interviews). Response rates vary

between 69\% (Cohort 1) and 55\% (Cohort 10) (see Russell \& Phelps, 2001).

Differential response rate: Previous YCS cohorts have been characterised by lower response rates amongst the following groups: men; less academically qualified respondents; respondents in comprehensive schools, and; by region (unspecified). (See Russell \& Phelps, 2001: 24-5).

Imputation of missing information: Not known.

Attrition rates: Not reported.

Boosters: None.

Period covered by series: 1985-2005 (on-going).

Risk factors: Classificatory variables include gender, socio-economic grade of parents, household composition, region, ethnicity and disability.

Less common risk factors: None.

Critical life events: No.

Local area information: Spatially referenced to LEAs.

Overview: The advantages of the YCS in the study of youth disadvantage include the relatively large sample sizes associated with the survey - among the largest samples of young people covered by any sample survey. Because the survey focuses on a relatively narrow age range of school leavers it is well suited to detailed analysis of population sub-groups and the analysis of their school-to-work transitions.

However, despite the longitudinal nature of the survey, the study does not by its nature lend itself to analysis of longer-term youth transitions, nor to detailed investigation of domestic and housing transitions, nor to a holistic understanding of these processes with respect to social networks, support, and relationships, nor to the detailed investigation of health behaviours, etc. The study is ideally suited to analysis of labour market insertion policies and educational participation - and hence to the analysis of the 'NEET' group, those young people not in education, training and employment. 


\section{Appendix 8: Statistical analyses of social exclusion indicators}

Social indicators, of which social exclusion measures are an example, are of surprisingly recent origin. They were defined 40 years ago as "statistics, statistical series, and all other forms of evidence that enable us to assess where we stand and are going with respect to our values and goals" (Bauer, 1966). Social indicator systems are still heavily influenced by the 1975 UN System of Social and Demographic Statistics and the OECD Programme of Work on Social Indicators (OECD, 1982). The UN System was conceptualised by UK economist Richard Stone, who also jointly developed the system of national accounts, for which he won the Nobel Prize for Economics. In Europe the 1971 Delores report, Les indicateurs sociaux, has also influenced later work on social planning in all EU member states.

The nature of social indicators has evolved such that they can now be considered to be statistical time series "used to monitor the social system, helping to identify changes and to guide intervention to alter the course of social change" (Ferriss, 1988). However, the problem remains that the term 'social indicators' encompasses at least four different concepts:

- Social statistics: statistical time series that provide information on social goals, such as indicators, measures and indices.

- Social accounts, which assume the existence of a holistic interrelated social system in which the relationship between social goals is understood.

- Sub-system variables in which social indicators are output and input measures that can be used to judge 'progress' towards social goals (for example, progress in health, education, inclusion, etc). A causal model is implicitly assumed to exist.

- Quality of life: objective and subjective indicators of an individual's (and sometimes society's) sense of well-being.

The best methods of statistical analyses to use with social exclusion measures to provide evidence for policy makers crucially depends on which of these concepts is applicable, but also on other factors All statistical analyses depend on both the 
theoretical framework and the objective of the analysis. Without these, the question of the 'best' method is meaningless. The purpose of this report is to identify potential data on social exclusion within a sub-system variable framework. A causal model is implicitly assumed to exist such that exclusionary processes are assumed to result in individuals and groups of people becoming excluded. It is therefore necessary to consider what kinds of data and statistical analyses are needed to measure causality.

\section{Measuring causality with statistical data}

Social scientists agree that measuring causality is very difficult, but it is not impossible. Most attempts by social scientists in the UK to establish causal relationships with statistical data draw either implicitly or explicitly on epidemiological practice. The statistical research of Richard Doll and Austin Bradford-Hill, which established an unexpected causal relationship between smoking and lung cancer, has been highly influential.

Bradford Hill (1965) outlined nine viewpoint/guidelines that could be used to establish causality (rather than just association) with statistical data:

1. Strength: the statistical association between the cause and effect should be strong (highly significant).

2. Consistency: the same or similar results have been repeatedly found by different people, in different places, circumstances and times, in a range of studies.

3. Specificity: ideally one cause should lead to one effect.

4. Temporality: the cause should precede the effect.

5. Biological gradient: there should be a dose-response relationship between the cause and the effect, that is, the 'stronger' the cause the 'stronger' the effect.

6. Plausibility: it is helpful if the causation appears to be plausible given 'current' knowledge. (It should be noted that Bradford Hill had mixed feelings about this criteria since 'current' knowledge may be incorrect.)

7. Coherence: the cause-and-effect interpretation of the data should not seriously conflict with the generally known facts.

8. Experiment: It is helpful if there is some experimental or semi-experimental evidence for the cause and effect either from 'deliberate' or 'natural' 
experiments, which for example show that preventative interventions do indeed prevent the effect.

9. Analogy: that there is evidence that similar causes have similar effects.

There has been extensive debate on the relative merits of Bradford Hill's nine viewpoints over the past 40 years (Cox, 1992; Goldthorpe, 2001; Thygesen et al, 2005). Although it is possible to reject all these nine viewpoints as 'just' inductive criteria, they have proved useful in many pragmatic studies into causality. All of the nine viewpoints can be criticised, and examples/“special cases' found where they do not work; however, some remain more controversial than others. In particular, specificity has been criticised since it is rare in social science for a single cause to have a single effect: with social phenomena effects may be due to multiple causes and causes may have multiple effects.

Similarly, there is nothing in the philosophy of logic or science that requires a cause to occur before an effect - cause and effect can occur simultaneously and in modern physics an effect may even occur before the cause ${ }^{2}$. Nevertheless, in social science temporality is often seen as a useful criterion and longitudinal panel data can be used in measuring this phenomenon. However, it should also be noted that the only major advantage longitudinal panel data have over repeated cross-sectional survey data is their ability to provide evidence on temporality (that cause occurs before effect); the other eight of Bradford Hill's criteria can often be better measured using other types of statistical data. It is not, therefore, the case that longitudinal data sets are preferable, especially if the range and quality of data in relation to the questions asked is limited.

The key point from the Bradford Hill viewpoints for this review is that in order to establish causal relationships in social exclusion studies, many data sets/surveys will be needed - causality is very unlikely to be established from the analysis of just one 'perfect' longitudinal panel survey or randomised control trial. Although, studies of social exclusion should be commissioned using the 'best' data sources, it is also important to check the results from these analyses using the 'second best' data sources. This is particularly important if the analysis of the 'best' survey data suffer from model selection bias. 


\section{The problem of model selection bias}

Statistical theory assumes that models are known and have been clearly specified before the analysis. However, in reality models are almost never known in advance and the same data set is often used to both formulate the models (select the most 'important' variables) and then to undertake the analyses (fit the models). Almost all studies in social science undertake some analyses on the data prior to fitting a statistical model (for example, running a regression analysis) in order to select the best sub-set of variables to use in the modelling. In fact, many studies make use of step-wise procedures, where a lot of variables are entered into the model and the 'computer' removes the variables that are not statistically significant. Thus the explanatory variables in a model have usually been selected from a much larger initial set of variables. This is known as 'data mining' and suites of analysis software have been developed solely for this purpose.

Unfortunately, it is not possible to make inferences as if a model is known to be true when it has, in fact, been selected from the same data to be used for estimation purposes (Zhang, 1992). If this is done then the $p$ values and other model parameters will be incorrect.

Chatfield (1995) argues that there are typically three main sources of uncertainty in any problem:

a) uncertainty about the structure of the model;

b) uncertainty about estimates of the model parameters, assuming that we know the structure of the model;

c) unexplained random variation in observed variables even when we know the structure of the model and the values of the model parameters.

Uncertainty about model structure can arise in different ways such as:

i) model misspecification (for example, omitting/including a variable by mistake); 
ii) specifying a general class of models of which the true model is a special, but unknown, case; or

iii) choosing between two or more models of quite different structures.

Statistical theory has much to say about (b) and (c) and about the mechanics of the choice in (ii) (for example, F-tests in analysis of variance [ANOVA]), but it has little to say about (iii) and even less about (i), and largely ignores the effects of (a) in ensuing inferences. This is very strange given that errors arising from (a) are likely to be far worse than those arising from other sources (Chatfield, 1995, p 421).

The only real solution to this largely unacknowledged problem (it is entirely ignored by most textbooks on statistics) is to develop models on one dataset (that is, select the statistically important variable) and then fit the models on a completely different dataset. This has important implications for analyses on social exclusion using the BHPS that is currently the only available longitudinal panel survey for the UK. It would be far better to develop models (find the 'best' variables) of social exclusion using different survey data and only then attempt to fit these models using the BHPS. To date this has not been done in any study of social exclusion in the UK.

\section{Univariate methods}

Many analyses of social exclusion indicators venture little beyond the production of contingency tables. However, most people are not good at extracting any useful information from numerical tables and most published results do not follow the simple rules that can be used to improve the 'readability' of tables (see Tufte, 1983; Cleveland, 1993).

Statisticians have repeatedly argued that much of the data and statistical analyses presented as tables would be better presented graphically. Over 30 years ago, Anscombe (1973) argued that graphs are essential to good statistical analysis. He illustrated this point effectively by presenting four scatter plots showing very different relationships between variables $\mathrm{y}$ and $\mathrm{x}$. All four data sets had similar statistical properties but in three of the four cases the statistical analysis would mislead a researcher who failed to graphically display the data (Franke, 1997). 
Figure 6.1: Anscombe's illustration of the need to visualise data

(1)

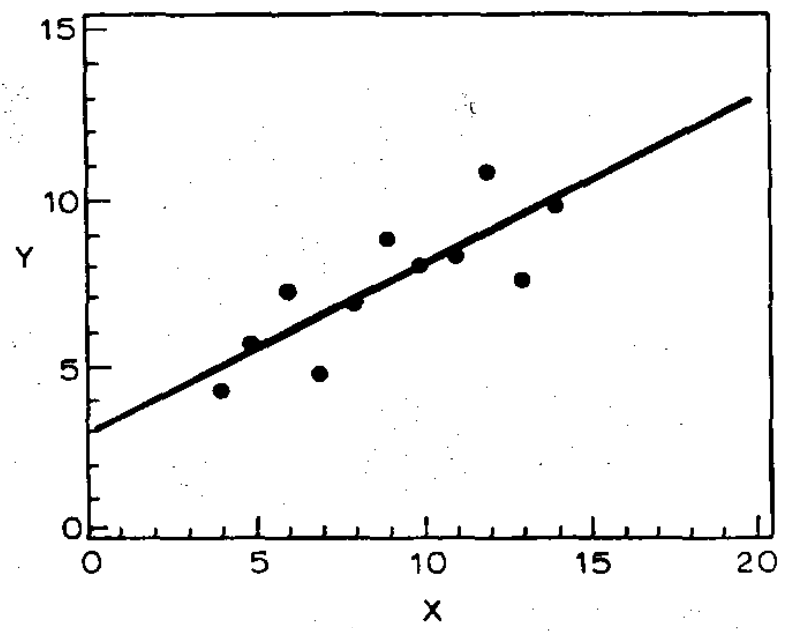

(3)

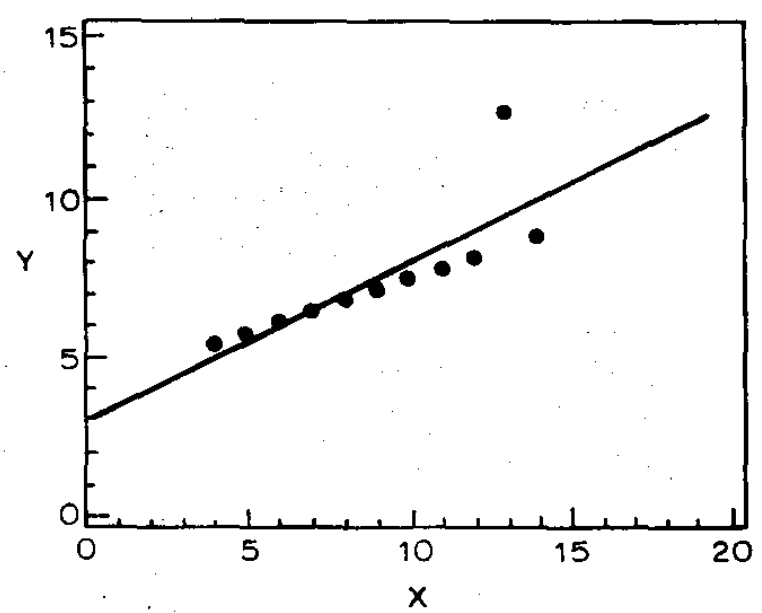

(2)

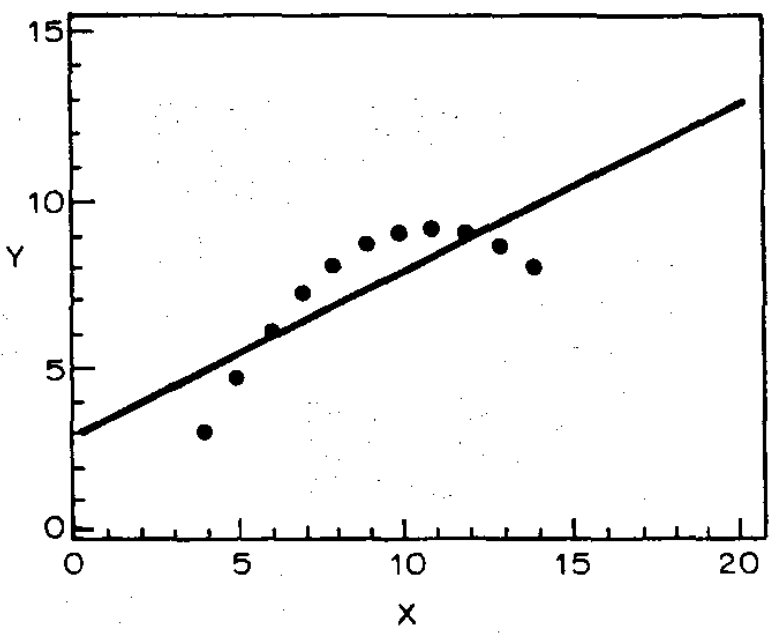

(4)

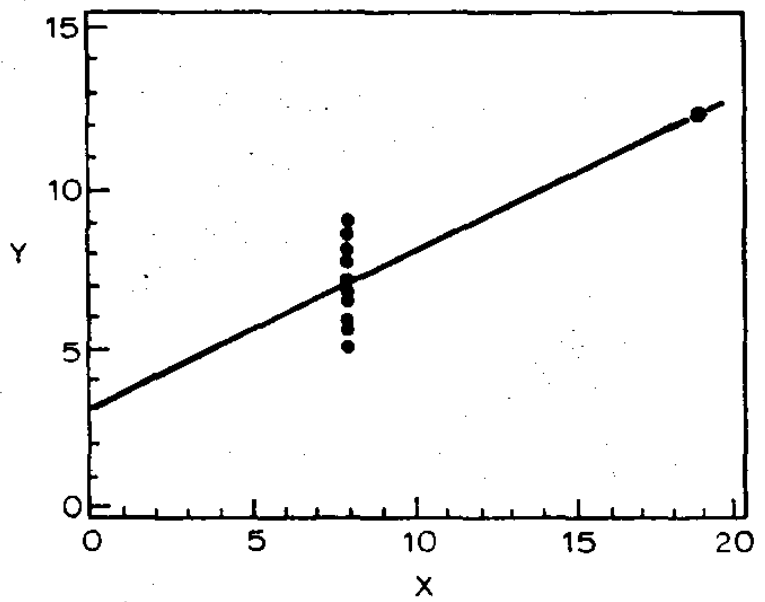

Source: Anscombe, F. J. (1973) Graphs in Statistical Analysis. The American Statistician, 27, 17-21

Reprinted with permission from The American Statistician. Copyright 1973 by the American Statistical Association. All rights reserved.

In Figure 6.1 the first plot shows the stereotypical scatter of points around the fitted regression line, the second shows a parabolic relationship between the variables, the third shows a linear relationship between $\mathrm{y}$ and $\mathrm{x}$ for all but one data point, and the fourth shows that the fitted regression line is completely determined by a single outlying observation. Yet the basic regression results for all four data sets are identical. They have the same regression coefficient and intercept, same $\mathrm{R}^{2}$, and same significance level. Unfortunately, even statisticians often fail to practice what they preach and frequently resort to publishing results as tables when graphical methods would be preferable (Gelman et al, 2002). 
The 'best' statistical methods to use for the analyses of social exclusion indicators will often be graphical methods, particularly where changes over time and dynamic processes are being measured using multiple indicators/multivariate data. There are a wide range of statistical software packages that have been designed to help with the visualisation and exploration of these kinds of data, for example BMDP/SPSS Diamond (Franke, 1997) However, these often expensive commercial software packages may be superseded in the near future by free software such as Gapminder (see www.gapminder.org/) and similar developments. It should be noted that when analysing data using visual methods Mark et al (2002) found "that people who worked in groups were more correct in their answers for objective questions, based on searching a large dataset" and that "groups were more accurate in their results for a free data discovery task...". We suggest that given the right visualisation system, groups do better than individuals in finding more accurate results.

\section{Multivariate methods}

Most multivariate analyses of social exclusion data are undertaken using General Linear Model (GLM) techniques. Regression analysis (including logistic regression), analysis of variance, discriminant function analysis and canonical correlation are all versions of the GLM. Regression analysis was first developed by Legendre (1805) and Gauss (1809) to fit data on the orbits of astronomical objects. At the end of the 19th century it was used by Yule (1899) to investigate the causes of changes in pauperism in England. This was one of the first studies to use multivariate statistical techniques to try to establish causal relationships in the social sciences - to study the 'social physics' of poverty (Freedman, 2002).

Yule's analysis of census data used only four variables (pauperism $=$ out relief ratio + proportion of the old + population) and 'showed' that providing 'out relief' caused pauperism. With the benefit of 20:20 hindsight and modern knowledge it is obvious that Yule's model was hopelessly mis-specified - it omitted many important variables that should have been included, for example, the availability of work. This illustrates the problems of model selection and model bias discussed previously, and is a reminder that in a hundred years time our causal models of social exclusion may also seem equally over-simplistic. The usual GLM methods make a number of 
assumptions about social exclusion data that are rarely correct (for example, data are continuous, normally distributed, etc).

Social exclusion indicators are often designed to measure the lower tail of a normally distributed variable that measures the degree to which people are excluded from obtaining goods and services. Thus, social exclusion indicators give special attention to the 'worst off' section of the population. The statistical problem is that most of the population is not excluded, so there will be a large proportion of zero scores. Common regression techniques that require variables with a normal distribution, like OLS (ordinary least squares), will most likely produce biased and unreliable estimates with these kinds of data (Breen, 1996). However, social exclusion measures can be looked on as censored variables that represent an underlying unobserved normally distributed variable.

If this is the case, they can therefore be analysed as metric variables using a Tobit Regression Model. The Tobit Model assumes a relationship between the latent (unobserved) normally distributed variable $y^{*}$ and the actually observed outcome measure $y$. The latent dimension $y^{*}$ is equal to the observed dependent variable $y$ if $y$ exceeds the cut-off point for censoring, which in this case is zero. If $y^{*}$ is below the cut-off point, $y$ is equal to the cut-off value, that is, zero. The model assumes a linear relationship between the independent variables and the latent dimension $\mathrm{y}^{*}$ based on a likelihood function that estimates a linear model for the metric data and a probability model for the censored data. The estimated Tobit regression coefficients are linear and additive in relation to the latent response continuum, not in relation to the observed measures.

\section{Multiple causation}

An additional problem with the multivariate analyses of social exclusion data is that a multiple causation framework implicitly underlies these analyses. In other words, there is assumed to be a complex 'web of causation', with numerous interconnected risks and protective factors, which results in social exclusion. A similar multi-causal framework is also commonly found in many other subjects, for example, epidemiology (Krieger, 1994). However, there is little theoretical evidence to believe that a causal web is the correct framework explaining social exclusion - there is 
currently no detailed theory that would lead to this belief. Instead there is detailed multivariate statistical method and an implicit assumption in the existence of a causal web.

The primary problem with this situation is that both the multivariate methods and the nature of available survey data tend to focus analyses at the individual and household level. However, the causes of social exclusion of population groups may be more than the sum of the causes of social exclusion at the individual or household level. For example, it may not be possible to explain the social exclusion of refugees or travellers from the multivariate analyses of the characteristics and circumstances of individuals. There may well be structural and hierarchal effects and the primary causes of the social exclusion of population groups and of individuals may be different.

\section{Spatial data analysis}

There is increasing evidence that a 'one size fits all' set of policies to tackling the problem of social exclusion can be both ineffective and inefficient. Exclusion is not a result of a single set of processes that effect all groups equally wherever they may live. There may be considerable and significant variations in the causes of exclusion depending on who you are and where you live and in order to be effective and efficient polices need to be tailored to address local needs.

One of the most confusing issues with measuring social exclusion is to identify the correct level of analysis. In particular, should the analysis be carried out at the individual, household/family, population group or area level? A considerable amount of research has been carried out at both the household and area level. Unfortunately, some researchers have not realised that analysis at these different levels requires the use of different statistical techniques and therefore much of the area-level research has been of relatively poor quality.

Area-level data tend to violate two basic assumptions of most statistical techniques: 
1. All observations are independent: the answer one person gives to a question should not affect or influence the answer another person gives to the same question.

2. Measurement errors are normally distribute: it is impossible to measure anything perfectly. There will always be some error of measurement. What matters is there is no systematic bias in the measurement error.

Area-level data often violate these assumptions due to the following.

\section{Spatial autocorrelation}

Areas next to each other are likely to be more similar than areas further away. Spatial autocorrelation can be defined as the clustering pattern in the spatial distribution of a variable that is due to the very fact that the occurrences are physically close together, that is, that they are in geographical proximity. They are not independent of each other, but are linked. The data are spatially dependent.

Spatial autocorrelation is widespread: rich people move to areas where other rich people live; disease can spread from one neighbour to another, etc. If the values in a poverty or health 'cluster' are more alike than would be due to random processes, there exists a positive autocorrelation; if they are less alike than would occur through random processes, there exists a negative autocorrelation.

\section{Modifiable area effect}

All area boundaries are artificial social constructs that are usually a result of 'political' or 'religious' influences, for example, electoral divisions, parishes, etc. If the areas change so will the strength of the association between any two variables such as poverty and health.

This change in association between variables with the selection of different areal units can call into question the reliability of results. The effect of the selection of areal units on analysis is termed the modifiable areal unit problem (MAUP). It is formally defined as: 
... a problem arising from the imposition of artificial units of spatial reporting on continuous geographical phenomenon resulting in the generation of artificial spatial patterns. (Heywood et al, 1998).

The MAUP had been most prominent in the analysis of socioeconomic data. Such areal data cannot be measured at a single point, but must be contained within a boundary to be meaningful. For example, it is not possible to measure the percentage of infant deaths or low-income households at a single point; this percentage must be calculated within a defined area. It is the selection of these artificial boundaries and their use in analysis that produces the MAUP.

The effects of the MAUP can be divided into two components: the scale effect and the aggregation or zonation effect. The scale effect is the variation in numerical results that occurs due to the number of zones used in an analysis. The aggregation or zonation effect is the variation in numerical results arising from the grouping of small areas into larger units. The use of small areal units has a tendency to provide unreliable rates because the population used to calculate the rate is smaller. On the other hand, using larger areal units will provide more stable rates but may mask meaningful geographic variation evident with smaller areal units.

\section{Other area problems}

There is a long list of other potential statistical problems in analysing area-level data, including the ecological fallacy that can occur where assumptions about individuals are made from the analysis of area-level data (see Robinson, 1950). For example, in many countries 'poor' areas suffer from high crime rates and this often leads people to assume that 'poor' people suffer high levels of crime. However, in many countries it is the 'richer' people living in 'poorer' areas that are often the victim of many crimes.

\section{Statistical solutions}

A number of different statistical solutions have been developed that to varying degrees can overcome these area-level analysis problems. Among them are Poisson regression, multi-level modelling, generalized regression (GREG), synthetic estimators, composite estimators (along with modifications for logistic regression and 'ecological effect'). However, the 'best' statistical method currently available for 
analysing spatial data is probably geographical weighted regression (GWR). GWR is a relatively new modelling technique for spatial analysis that allows local, as opposed to global, spatial models to be calculated and interesting variations in relationships to be measured and mapped. GWR is based on the logical idea that relationships between variables measured at different locations might not be constant over space, for example, lack of available public transport might be a more important cause of exclusion in rural areas than in inner-city areas. However, almost all statistical techniques assume that relationships between variables are constant and do not change from one area to another. If relationships do vary significantly over space, then serious questions are raised about the reliability of traditional, global-level analyses.

GWR is not restricted to simple global analyses in which interesting local variations in relationships are 'averaged away' and unobservable; GWR allows these local relationships to be measured and mapped. This modelling approach challenges many of the global statements of spatial relationships that have been made in the academic and policy literature.

Fotheringham et al (2002) explain how GWR differs from the 'usual' OLS 'global' regression model as follows. A global regression model is given by:

$\mathrm{y}_{\mathrm{i}}=\mathrm{a}_{0}+\Sigma_{\mathrm{k}} \mathrm{a}_{\mathrm{k}} \mathrm{x}_{\mathrm{ik}}+\varepsilon_{\mathrm{i}}$

In the calculation of this model, one parameter is estimated for the relationship between each independent variable and the dependent variable and this relationship is assumed to be constant across all geographic areas in the study region. The estimator for the parameters in this model is:

$a=\left(X^{t} X\right)^{-1} X^{t} y$

where a represents the vector of global parameters to be estimated, $\mathrm{X}$ is a matrix of independent variables with the elements of the first column set to 1 , and y represents a vector of observations on the dependent variable. GWR is a relatively simple 
technique that extends the traditional regression framework by allowing local rather than global parameters to be estimated so that the model is rewritten as:

$\mathrm{y}_{\mathrm{i}}=\mathrm{a}_{0}\left(\mathrm{u}_{\mathrm{i}}, \mathrm{v}_{\mathrm{i}}\right)+\Sigma_{\mathrm{k}} \mathrm{a}_{\mathrm{k}}\left(\mathrm{u}_{\mathrm{i}}, \mathrm{v}_{\mathrm{i}}\right) \mathrm{x}_{\mathrm{ik}}+\varepsilon_{\mathrm{i}}$

where $\left(\mathrm{u}_{\mathrm{i}}, \mathrm{v}_{\mathrm{i}}\right)$ denotes the coordinates of the ith point in space and $\mathrm{a}_{\mathrm{k}}\left(\mathrm{u}_{\mathrm{i}}, \mathrm{v}_{\mathrm{i}}\right)$ is a realisation of the continuous function $\mathrm{a}_{\mathrm{k}}(\mathrm{u}, \mathrm{v})$ at point $\mathrm{i}$ (Brunsdon et al, 1996). That is, we allow there to be a continuous surface of parameter values and measurements of this surface are taken at certain points to denote the spatial variability of the surface. Note that the global model is a special case of the GWR model in which the parameter surface is assumed to be constant over space.

In the calibration of the GWR model it is assumed that observed data near to point $\mathrm{i}$ have more of an influence in the estimation of the $a_{k}\left(u_{i}, v_{i}\right)$ 's than do data located farther from i. In essence, the equation measures the relationships inherent in the model around each point $i$.

\section{Conclusions}

This review is about the multi-dimensional analyses of social exclusion. The underlying statistical framework is a sub-system variables approach in which social indicators are identified as output and input measures which can be used to judge 'progress' towards the social goal of inclusion. A causal model is implicit in this work that will facilitate the identification of policy interventions that will reduce exclusion. The 'best' type of statistical analysis to use depends on both the nature of the survey data available and the purpose of the analysis. In many circumstances when trying to analyse dynamic data, visualisation of the data may be more successful than formal statistical modelling. When undertaking causal modelling it is important to analyse multiple data sets rather than just a single survey, particularly when the 'correct' model is unknown.

\section{Notes}

${ }^{1}$ Crockett (2006, p 6) notes that prior to version 12, SPSS (Statistical Package for the Social Sciences) was incapable of correct weighted data analysis resulting in spurious statistical significance. Although SPSS now produces correctly weighted analysis for 
descriptive measures (using the complex samples module) this is still not the case for type multivariate approaches.

${ }^{2}$ If you are not a physicist it is inadvisable to dwell on this point for too long. 


\section{Bibliography}

Aassve, A., Iacovou, M. and Mencarini, L. (2005) Youth poverty in Europe: What do we know?, ISER Working Paper 2005-2, Colchester: University of Essex, Institute for Social and Economic Research.

Adelman, L., Middleton, S. and Ashworth, K. (2003) Britain's poorest children: Severe and persistent poverty and social exclusion, London: Save the Children.

Aldridge, S. (2001) Social mobility: A discussion paper, London: Performance and Innovation Unit.

Aldridge, S. (2004) Life chances and social mobility: An overview of the evidence, London: Prime Minister's Strategy Unit.

Anscombe, F.J. (1973) 'Graphs in statistical analysis', The American Statistician, vol 27, pp 17-21.

Apospori, E. and Millar, J. (2003) The dynamics of social exclusion in Europe, Cheltenham: Edward Elgar.

Arts Council of England (1999) Social exclusion: A framework for action, London: Arts Council.

Ashworth, K. Middleton, S., Walker, R., Kellard, K., Peaker, A. and Thomas, M. (1994a) 'Keeping up appearances: peer pressures and children's clothes', in S. Middleton, K. Ashworth and R. Walker (eds) Family fortunes: Pressures on parents and children in the 1990s, London: Child Poverty Action Group, pp 51-9.

Ashworth, K., Middleton, S., Walker, R., Kellard, K., Peaker, A. and Thomas, M. (1994b) 'There's nothing to do 'round here: things children do', in S. Middleton, K. Ashworth and R. Walker (eds) Family fortunes: Pressures on parents and children in the 1990s, London: Child Poverty Action Group, pp 34-50.

Atkinson, T., Cantillon, B., Marlier, E. and Nolan, B. (2002) Social indicators: The EU and social inclusion, Oxford: Oxford University Press.

Audit Commission (2005) Local quality of life indicators: Supporting local communities to become sustainable, London: Audit Commission.

Bailey (2006) Does work pay? Employment, poverty and exclusion from social relations, in C. Pantazis, D, Gordon, and R, Levitas (eds.) Poverty and social exclusion in Britain, Bristol: Policy Press

Bajekal, M. (2002) Health Survey for England 2000: Care homes and their residents, London: The Stationery Office.

Bajekal, M. and Purdon, S. (2002) Social capital and social exclusion: Development of a condensed module for the Health Survey for England, London: The Stationery Office.

Ballard, M. (2006) 'Gov spins data sharing', The Register (www.theregister.co.uk/2006/09/14).

Banks, J., Breeze, E., Lessof, C. and Nazroo, J. (eds) (2006) Retirement, health and relationships of the older population in England: The 2004 English Longitudinal Study of Ageing (Wave 2), London: Institute for Fiscal Studies, July.

Barnes, M. (2005) Social exclusion in Great Britain: An empirical investigation and comparison with the EU, Aldershot: Ashgate.

Barnes, M., Blom, A., Cox, K., Lessof, C. and Walker, A. (2006) The social exclusion of older people: Evidence from the first wave of the English Longitudinal Study of Ageing (ELSA), Final report, London: SEU/OPDM, January.

Barnes, M., Heady, C., Middleton, S., Millar, J., Papadopoulos, F., Room, G. and Tsakloglou, P. (2002) Poverty and social exclusion in Europe, Cheltenham: Edward Elgar. 
Barry, B. (2002) 'Social exclusion, social isolation, and the distribution of income', in J. Hills, J. Le Grand and D. Piachaud (eds) Understanding social exclusion, Oxford: Oxford University Press, pp 13-29.

Barton, J. (2001) 'Developing a weighting and grossing system for the GHS', Survey Methodology Bulletin 49

Bates, B. et al (2001) Housing in England 1999/00, London: The Stationery Office.

Bates, B. et al (2002) Housing in England 2000/01, London: The Stationery Office.

Bauer, R. (ed) (1966) Social indicators, Cambridge, MA: MIT Press.

Bauman, Z. (1998) Work, consumerism and the new poor, Buckingham: Open University Press.

Behr, A., Bellgardt, E. and Rendtel, U. (2002) Extent and determinants of panel attrition in the European Community Household Panel, CHINTEX Working Paper No 7, November.

Beresford, B. and Oldman, C. (2002) Housing matters: National evidence relating to disabled children and their housing, Bristol: The Policy Press.

Bernard, B. (2005) EU-SILC user database description, Luxembourg: Eurostat (http://epunet.essex.ac.uk/EU-SILC_UDB.pdf)

Better Regulation Task Force (2004) The regulation of child employment, London: Cabinet Office.

Bhalla, A.S and Lapeyre, F. (1997) 'Social exclusion: towards an analytical and operational framework', Development and Change, vol 28, pp 413-33.

Bhalla, A.S. and Lapeyre, F. (1999, 2004) Poverty and exclusion in a global world, Basingstoke: Macmillan.

Blackwell, L., Lynch, K., Smith, J. and Goldblatt, P. (2003) Longitudinal Study 1971-2001: Completeness of census linkage, Series LS No 10, London: ONS.

Blanden, J. (2006) 'Bucking the trend': What enables those who are disadvantaged in childhood to succeed later in life?, DWP Working Paper 31, London: The Stationery Office.

Blanden, J. and Gibbons, S. (2006) The persistence of poverty across generations: A view from two British cohorts, Bristol: The Policy Press.

Boreham, R., Stafford, M. and Taylor, R. (2002) Health Survey for England 2000: Social capital and health, London: The Stationery Office.

Bourdieu, P. (1984) Distinction: A social critique of the judgement of taste, London: Routledge.

Bourdieu, P. (1997) 'The forms of capital', in A H. Halsey, H. Lauder, P. Brown and A.S. Wells (eds) Education: Culture, economy, society, Oxford: Oxford University Press.

Bowring, F. (2000) 'Social exclusion: limitations of the debate', Critical Social Policy, vol 20(3), no 64, August, pp 307-30.

Bradford Hill A. (1965) 'The environment and disease: association or causation?', Proc $R$ Soc Med, vol 58, pp 295-300.

Bradshaw, J., Kemp, P., Baldwin, S. and Rowe, A. (2004) The drivers of social exclusion: A review of the literature for the Social Exclusion Unit in the Breaking the Cycle series, London: SEU/ODPM.

Bradshaw, J., Finch, N., Mayhew, E., Ritakallio, V.-M.R. and Skinner, C. (2006) Child poverty in large families, Bristol: The Policy Press in association with the Joseph Rowntree Foundation.

Brassett-Grundy, A. (2003) Researching households and families using the ONS Longitudinal Study, LS User Guide 20, London: ONS.

Breen, R. (1996) Regression models: Censored, sample selected or truncated data, London: Sage Publications. 
British Crime Survey (2004-05) Final questionnaire (www.dataarchive.ac.uk/doc/5347/mrdoc/pdf/5347userguide2.pdf).

BMA (British Medical Association) (2006) Child and adolescent mental health: A guide for healthcare professionals, London: BMA.

Brown, P. and Crompton, R. (1994) A new Europe: Economic restructuring and social exclusion, London: UCL Press.

Brunsdon, C., Fotheringham, A.S. and Charlton. M.E. (1996) 'Geographically weighted regression: a method for exploring spatial non-stationarity’, Geographical Analysis, vol 28, no 4, pp 281-98.

Buck, N. (2002) National Strategy for Longitudinal Studies, Report to ESRC Research Resources Board, Essex: Institute for Social and Economic Research.

Burchardt, T. (2000) 'Social exclusion: concepts and evidence', in D. Gordon and P. Townsend (eds) Breadline Europe: The measurement of poverty, Bristol: The Policy Press.

Burchardt, T., Le Grand, J. and Piachaud, D. (1999) 'Social exclusion in Britain 1991-1995', Social Policy and Administration, vol 33, no 3, pp 227-44.

Burchardt, T., Le Grand, J. and Piachaud, D. (2002) 'Degrees of exclusion: developing a dynamic multidimensional measure', in J. Hills, J. Le Grand and D. Piachaud (eds) Understanding social exclusion, Oxford: Oxford University Press, pp 30-43.

Burrows, R. (2003) Poverty and home ownership in contemporary Britain, Bristol: The Policy Press.

Bynner, J. (2003) Young people's changing routes to independence, York: Joseph Rowntree Foundation.

Bynner, J. with Despoditou, S. and Sheppard, P. (1996) 1970 British Cohort Study: Twenty six-year follow-up: Guide to data available at the ESRC data archive, London: Institute of Education.

Bynner, J., Ferri, E. and Sheppard, P. (1997) Twenty-something in the 1990s: Getting on, getting by, getting nowhere, Aldershot: Ashgate.

Bynner, J., Londra, M. and Jones, G. (2004) The impact of government policy on social exclusion among young people, London: The Stationery Office.

Bynner, J, Londra, M., Plewis, I., Emler, N, Maung, M., Finch, S., Barnham, L., Collins, D. and Breman, N. (2000) Scoping study and development work for a new cohort study of young people (14 To 25), London: DfES.

Byrne, D. (1999, 2005) Social exclusion, Milton Keynes: Open University Press.

Cabinet Office (2006) 'Tackling deep-seated social exclusion: Hilary Armstrong announces next steps and new arrangements in government', Press Release CAB/035/06 13 June.

Calandrino, M. (2003) Low income and deprivation in British families: An exploratory analysis of the 'consistent poverty' approach to poverty measurement using data for Great Britain drawn from the families and children study, DWP Working Paper 10, London: DWP.

Calderwood, L., Cheshire, H., Conway, L., Lee, M., Taylor, R. and Lessof, C. (2005) Health, wealth and lifestyles of the older population in England: The 2002 English Longitudinal Study of Ageing: Technical report, London: National Centre for Social Research

Carey, S. (1995) Private renting in England, 1993/94, London: HMSO.

Carpenter, J., and Kenward, M. (2006) 'A comparison of multiple imputation and inverse probability weighting for analyses with missing data', Journal of the Royal Statistical Society, Series A, vol 169, no 3, pp 571-84.

Chamberlayne, P., Rustin, M. and Wengraf, T. (2002) Biography and social exclusion in Europe: Experiences and life journeys, Bristol: The Policy Press. 
Chatfield, C. (1995) 'Model uncertainty, data mining and statistical inference', Journal of the Royal Statistical Society. Series A (Statistics in Society), vol 158, pp 419-66.

Cleveland, W.S. (1993) Visualizing data, Summit, NJ: Hobart Press.

Coleman, C. and Moynihan, J. (1996) Understanding crime data: Haunted by the dark figure, Milton Keynes: Open University Press

Courtenay, G. \& Mekkeholt, P. (1996) The Youth Cohort Study Handbook: The first ten years. DfEE Research Series 22. London: The Stationery Office.

Cox, D. (1992) 'Causality: some statistical aspects', Journal of the Royal Statistical Society; Series A (Statistics in Society), vol 155, pp 291-301.

Crockett, A. (2006) Weighting the social surveys, London: Economic and Social Data Service.

Cross, M. (2006) 'It's not always good to share', The Guardian, 24 August.

Cross, M. and Travis, A. (2006) 'Ministers plan to overturn key data protection principle', The Guardian, 24 August.

Cultural Trends (2004) no 50, Special Issue on Cultural Capital and Social Exclusion.

Cultural Trends (2006) vol 15 (2/3), no 58/9, June/September, Special Issue on Cultural Capital and Social Exclusion.

Dale, A. (2006) 'Quality issues with survey research', International Journal of Social Research Methodology, vol 9, no 2, pp 143-58.

Davie, R., Butler, N. and Goldstein, H. (1972) From birth to seven, London: Longman.

Davis, J. and Ridge, T. (1997) Same scenery, different life style: Rural children in a low income, London: The Children's Society.

Davis, J., Watson, N., Corker, M. and Shakespeare, T. (2003) 'Reconstructing disability, childhood and social policy in the UK', in C. Hallett and A. Prout (eds) Hearing the voices of children, London: RoutledgeFalmer, pp 192-21

Dawe, F. and Knight, I. (1997) 'A study of proxy response in the Labour Force Survey', Survey Methodology Bulletin, No 40, January.

DCA (Department for Constitutional Affairs) (2006) Information sharing vision statement, London: DCA.

DCLG (Department for Communities and Local Government) (May 2006) Housing in England 2003/04: A report principally from the 2003/04 Survey of English Housing, London: ONS.

DCMS (Department of Culture, Media and Sport) (2001) Building on PAT10: Progress report on social inclusion, London: DCMS.

DCMS (2003a) Annual report 2003, London: The Stationery Office.

DCMS (2003b) Press release, 15 July ( www.culture.gov.uk/Reference_library/press_notices)

Dean, M. (2003) Growing older in the 21st century, Swindon: ESRC (www.esrc.ac.uk/ESRCInfoCentre/Images/GO_in_the_21st_Century_tcm6-5504.pdf)

Demos (1997) The wealth and poverty of networks: Tackling social exclusion, London: Demos.

DfES (2005) Youth Matters, Cm 6629, July, London: The Stationery Office.

DfES (Department for Education and Skills) (2006) Youth Matters: Next steps, London: The Stationery Office.

DfES (2006a) Every Child Matters: Integrated working to improve outcomes for children and young people (www.everychildmatters.gov.uk/deliveringservices/integratedworking/).

DfES (2006b) Outcomes framework: Every Child Matters (www.everychildmatters.gov.uk/_content/documents/Outcomes\%20Framework.pdf).

DfT (Department for Transport) (nd) Social exclusion and the provision of public transport.

DH (Department of Health) (1999) Caring About carers: A national strategy for carers, London: The Stationery Office. 
DSS (Department of Social Security) (1999) Opportunity for All: Tackling poverty and social exclusion, Cm 4445, London: The Stationery Office.

DWP (2005a) Work and Pensions Longitudinal Study: Ethics Committee Report to 31 December

(www.dwp.gov.uk/asd/longitudinal_study/annual_ethic_rep_2005.pdf).

DWP (2005b) Work and Pensions Longitudinal Study: List of uses (www.dwp.gov.uk/asd/longitudinal_study/WPLS_Uses.pdf).

DWP (2005c) Work and Pensions Longitudinal Study: Safeguards (www.dwp.gov.uk/asd/longitudinal_study/WPLS_Safeguards.pdf

DWP (2006) Opportunity For All: Seventh Annual Report, CM6673, Leeds: CDS

DWP/ONS (Office for National Statistics) (2006) Family Resources Survey: United Kingdom 2004-2005, London: DWP.

Donovan, N. and Halpern, D. with Sargeant, R. (2002) Life satisfaction: The state of knowledge and the implications for government, London: UK Government Strategy Unit.

Duffy, K. (2005) Social exclusion and human dignity in Europe, Council of Europe.

English, V., Romano-Critchley, G., Sheather, J. and Sommerville, A. (2002) 'Ethics briefing', Journal of Medical Ethics, vol 28, pp 327-8.

Erens, B. and Primatesta, P. (eds) (1999) Health Survey for England 1998, Vol 2: Methodology and documentation, London: The Stationery Office.

Erens, B., Primatesta, P. and Prior, G. (eds) (2001) Health Survey for England. The health of minority ethnic groups 1999, Vol 2: Methodology and documentation, London: The Stationery Office.

ESRC (Economic and Social Research Council) (2004) www.esrc.ac.uk (retrieved August).

Estivill, J. (2003) Concepts and strategies for combating social exclusion, Geneva: International Labour Office.

Eurostat (2005) The continuity of indicators during the transition between ECHP and EUSILC, Working Papers and Studies, 2005 edn, Luxembourg: Office for Official Publications of the European Communities (http://epp.eurostat.cec.eu.int/cache/ITY_OFFPUB/KS-CC-05-006/EN/KS-CC-05006-EN.PDF).

Evandrou, M. (2000) 'Social inequalities in later life: the socio-economic position of older people from ethnic minority groups in Britain’, Population Trends, Autumn, pp 1118.

Expenditure and Food Survey 2004-2005, Questionnaire documentation (www.dataarchive.ac.uk/doc/5375/mrdoc/pdf/5375userguide1.pdf).

Fabian Society, The (2006) Narrowing the gap: The Fabian Commission on Life Chances and Child Poverty, London: The Fabian Society.

Fahmy, E. (2006a) 'Youth, poverty and social exclusion', in C. Pantazis, D. Gordon and R. Levitas (eds) Poverty and social exclusion in Britain: The Millennium Survey, Bristol: The Policy Press, pp 347-74.

Fahmy, E. (2006b) 'Social capital and civic action: a study of youth in the UK', Young: Nordic Journal of Youth Research, vol 2, no 14, pp 101-18.

Falaschetti, E., Malbut, K. and Primatesta, P. (2002) Health Survey for England 2000: The general health of older people and their use of health services, London: The Stationery Office.

Feinstein, L. and Sabates, R. (2006) Predicting adult life outcomes from earlier signals: identifying those at risk, Report for the Prime Minister's Strategy Unit, Institute of Education, University of London. 
Ferri, E., Bynner, J. and Wadsworth, M. (2003) Changing Britain, changing lives: Three generations at the turn of the century, London: Institute of Education.

Ferriss, A.L. (1988) 'The uses of social indicators', Social Forces, vol 66, pp 601-7.

Fido, M. (2005) An update on the Annual Population Survey (APS), Labour Force Survey User Group, Tuesday 6 December, Royal Statistical Society www.ccsr.ac.uk/esds/events/2005-12-06/fido.ppt

Fisher, T. and Bramley, G. (2006) 'Social exclusion and local services', in C. Pantazis, D. Gordon and R. Levitas (eds) Poverty and social exclusion in Britain: The Millennium Survey, Bristol: The Policy Press, pp. 217-48.

Fitzgerald, J., Gottschalk, P. and Moffitt, R. (1998) 'An analysis of the impact of sample attrition on the second generation of respondents in the Michigan Panel Study of Income Dynamics', Journal of Human Resources, vol 33, no 2, pp 300-44.

Ford, T., Goodman, R. and Meltzer, H. (2003) 'The British Child and Adolescent Mental Health Survey 1999: the prevalence of DSM-IV disorder', Journal of the American Academy of Child and Adolescent Psychiatry, vol 42, pp 1203-10.

Foster, K. (1996) 'A comparison of the characteristics of respondents and non-respondents to the 1991 Census’, ONS Survey Methodology Bulletin No 38, January.

Fotheringham, A.S., Brunsdon, C. and Charlton, M.E. (2002) Geographically weighted regression: The analysis of spatially varying relationships, Chichester: Wiley.

Franke, G. (1997) 'SPSS Diamond for Windows', Journal of Marketing Research, vol 34, no 4, pp 544-6.

Fraser, N., Honneth, A., Golb, J. and Wilke, C. (2003) Redistribution or recognition?: A political-philosophical exchange, London: Verso.

Freedman, D. (2002) From association to causation: Some remarks on the history of statistics, Statistics Department Technical Report No 521, Berkeley, CA: University of California.

Gauss, C.F. (1809) Theoria Motus Corporum Coelestium, Hamburg: Perthes et Besser (reprinted in 1963 by Dover, New York).

Gelman, A., Pasarica, C. and Dodhia, R. (2002) 'Let's practice what we preach: turning tables into graphs', American Statistician, vol 56, pp 121-30.

General Household Survey, 2004-2005, General guidelines for using the data (www.dataarchive.ac.uk/doc/5346/mrdoc/pdf/5346userguide.pdf).

Gleave, S., Bartley M. \& Wiggins, R.D. (1998), Limiting long term illness: A question of where you live or who you are? A multi-level analysis of the 1971-1991 ONS Longitudinal Study. Working Paper no. 79. London: Centre for Longitudinal Studies.

Gleave, S., Wiggins, R.D., Joshi, H. and Lynch, K. (2000) Identifying area effects: A comparison of single and multi-level models, Working Paper No 79, London: Centre for Longitudinal Studies.

Goldstein, H. (1976) 'A study of response rates of sixteen-year-olds in the NCDS', in K. Fogelman (ed) Britain’s sixteen-year-olds, London: National Children’s Bureau.

Goldthorpe, J.H. (2001) 'Causation, statistics and sociology’, European Sociological Review, vol 17, pp 1-20.

Goodman, A. and Myck, M. (2005) Parental income and child outcomes: What can we learn from material deprivation?, London: Institute for Fiscal Studies.

Gordon, D. and Pantazis, C. (eds) (1997) Breadline Britain in the 1990s, Aldershot: Ashgate.

Gordon, D., Adelman, L., Ashworth, K., Bradshaw, J., Levitas, R., Middleton, S., Pantazis, C., Patsios, D., Payne, S., Townsend, P. and Williams, J. (2000) Poverty and social exclusion in Britain, York: Joseph Rowntree Foundation. 
Gordon, D. (2006), 'The concept and measurement of poverty', in C. Pantazis, D. Gordon and R. Levitas (eds) Poverty and social exclusion in Britain: The Millennium Survey, Bristol: The Policy Press, pp 29-70.

Grant, C., Harvey, A., Bolling, K. and Clemens, S. (2006) 2004-2005 British Crime Survey (England and Wales) Technical report, Vol 1 (www.dataarchive.ac.uk/doc/5347/mrdoc/pdf/5347userguide1.pdf).

Green, H. and Farmer, C. (2004) 2003 Home Office Citizenship Survey: People, families and communities: Technical report, London: ONS.

Green, H. and Hansbro, J. (1995) Housing in England 1993/94, London: HMSO.

Green, H., Connolly, H. and Farmer, C. (2004) 2003 Home Office Citizenship Survey: People, families and communities, Home Office Research Study 289, London: ONS.

Green, H., Deacon, K. and Down, D. (1998) Housing in England 1996/97, London: The Stationery Office.

Green, H. et al (1996) Housing in England 1994/95, London: The Stationery Office.

Green, H et al (1997) Housing in England 1995/96, London: The Stationery Office.

Green, H. et al (1999) Housing in England 1997/98, London: The Stationery Office.

Green, H., McGinnity, Á., Meltzer, H., Ford, T. and Goodman, R. (2005) Mental health of children and young people in Great Britain, 2004, London: The Stationery Office.

Grundy, E. (1992) 'Sociodemographic variations in rates of movement into institutions among elderly people in England and Wales: an analysis of linked Census and mortality data 1971-1985', Population Studies: A Journal of Demography, vol 46, no 1 , pp 65-84.

Grundy, E. and Harrop, A. (1992) 'Co-residence between adult children and their elderly parents in England and Wales', Journal of Social Policy, vol 21, pp 325-48.

GSS (Government Statistical Service) (1998) Evaluating non-response on household surveys, by K. Foster, National Statistics Methodology Series 8, London: GSS.

GSS (1999) A review of sample attrition and representativeness in three longitudinal surveys, by G. Nathan, National Statistics Methodology Series 13, London: ONS.

GSS (1999a) Measuring and improving data quality, by V. Ruddock, National Statistics Methodology Series 14, London: GSS.

GSS (1999c) Methodological issues in the production and analysis of longitudinal data from the Labour Force Survey, by P.S. Clarke and P.F. Tate, National Statistics Methodology Series 17, London: GSS.

GSS (2000) Longitudinal data for policy analysis, by M. White, J. Payne and J. Lakey, National Statistics Methodology Series 22, London: GSS.

GSS (2001) Methods for automatic record matching and linkage and their use in national statistics, by L. Gill, National Statistics Methodological Series 25, London: GSS.

Guio, A.C. (2005a) Income poverty and social exclusion in the EU25, Statistics in Focus Series, Issue number 13/2005, Luxembourg: Eurostat

(http://epp.eurostat.cec.eu.int/cache/ITY_OFFPUB/KS-NK-05-013/EN/KS-NK-05013-EN.PDF)

Guio, A.C. (2005b) Material deprivation in the EU, Statistics in Focus Series, Issue number 21/2005, Luxembourg: Eurostat.

(http://epp.eurostat.cec.eu.int/cache/ITY_OFFPUB/KS-NK-05-021/EN/KS-NK-05021-EN.PDF)

Hattersly, L. and Creeser, R. (1995) Longitudinal study 1971-1991: History, organisation and quality of data, London: HMSO (www.celsius.lshtm.ac.uk/documents/lswrk77.pdf; www.celsius.lshtm.ac.uk/documents/lswrk79.pdf; www.statistics.gov.uk/downloads/theme_compendia/Tracking_v8.pdf). 
Heywood, I., Cornelius, S. and Carver, S. (1998) An introduction to Geographical Information Systems, New York, NY: Addison Wesley Longman.

Higginson, S., Sommer, F. and Terry, A. (2003) Making indicators count: Using quality of life indicators in local governance, London: NEF and University of the West of England.

Hills, J., Le Grand, J. and Piachaud, D. (eds) (2002) Understanding social exclusion, Oxford: Oxford University Press.

Hirani, V. and Malbut, K. (2002) Health Survey for England 2000: Disability among older people, London: The Stationery Office.

HM Treasury (2003) Every Child Matters, Cm 5860, London: The Stationery Office.

HM Treasury (2004) Supporting young people to achieve: Towards a New Deal for skills, London: The Stationery Office.

HM Treasury (2006) Written Ministerial Statement by Mr. Ed Balls: Children and Young People's Review, 5 July.

Hobbs, S., Lindsay, S. and McKechnie, J. (1996) 'The extent of child employment in Britain', British Journal of Education and Work, vol 9, no 1, pp 5-18.

Honneth, A. and Anderson, J. (1996) The struggle for recognition: Moral grammar of social conflicts, Cambridge: Polity Press.

Howarth, C. and Street, C. (2000) Sidelined: Young adults' access to services, London: NPI.

Howarth, C., Kenway, P. and Palmer, G. (2001) Responsibility for All: A national strategy for social inclusion, London: NPI/The Fabian Society.

Howarth, C., Kenway, P., Palmer, G. and Street, C. (1998) Monitoring poverty and social exclusion: Labour's inheritance, York: NPI/Joseph Rowntree Foundation.

Hutton, W. (1996) The state we're in, London: Vintage.

Iyer, R. (1984) Analysis of response, NCDS Working Paper 25, London: National Children’s Bureau.

Jermyn, H. (2001) The arts and social exclusion: A review prepared for the Arts Council of England, London: Arts Council.

Jones, P. and Elias, P. (2006) Administrative data as a research resource: A selected audit, London: National Data Strategy.

Kablenet (2006) 'Data proposal prompts legal warning', The Register (www.theregister.co.uk/2006/08/25).

Kahneman, D., Krueger, A.B., Schkade, D.A., Schwarz, N. and Stone, A.A. (2004) 'A survey method for characterizing daily life experience: the Day Reconstruction Method (DRM)', Science, 3 December, vol 306, pp 1776-80.

Kelly, G. and Lissauer, R. (2000) Assets for all, London: IPPR.

Kempson, E. and Whyley, C. (1999) Kept out or opted out? Understanding financial exclusion, Bristol: The Policy Press.

Kempson, E., McKay, S. and Willitts, M. (2004) Characteristics of families in debt and the nature of indebtedness, DWP Research Report No 211, Leeds: Corporate Document Services.

Krieger, N. (1994) 'Epidemiology and the web of causation : has anyone seen the spider?', Social Science \& Medicine, vol 39, pp 887-903.

Labour Force Survey (2003) User guide - Volume 1, Background and methodology (www.data-archive.ac.uk/doc/5395/mrdoc/pdf/background.pdf).

Labour Force Survey (2004) User guide - Volume 6, Local area data (www.dataarchive.ac.uk/doc/5467/mrdoc/pdf/localarea.pdf).

Layard, R. (2005) Happiness: Lessons from a new science, London: Allen Lane.

Legendre, A.M. (1805) Nouvelles méthodes pour la détermination des orbites des cométes, Paris: Courcier (reprinted in 1959 by Dover, New York). 
Levitas, R. (1998) The inclusive society and New Labour (1st edn), Basingstoke: Macmillan.

Levitas, R. (2004) 'Let's hear it for Humpty: social exclusion, the third way and cultural capital', Cultural Trends 50, vol 13, no 2, pp 41-50.

Levitas, R. (2005) The inclusive society and New Labour (2nd edn), Basingstoke: Palgrave Macmillan.

Levitas, R. (2006) 'The concept and measurement of social exclusion', in C. Pantazis, D. Gordon and R. Levitas (eds) Poverty and social exclusion in Britain: The Millennium Survey, Bristol: The Policy Press, pp 123-60.

Lillard, L.A. and Panis, C. (1998) 'An analysis of panel attrition in the Panel Study of Income Dynamics: income, marital status and mortality’, Journal of Human Resources, vol 33, no 2, pp 437-57.

Lister, R. (2004) Poverty, Cambridge: Polity Press.

Lloyd, E. (2006) 'Children, poverty and social exclusion', in C. Pantazis, D. Gordon and R. Levitas (eds) Poverty and social exclusion in Britain: The Millennium Survey, Bristol: The Policy Press, pp 315-345.

Longview Associates (2006) Strategic review of panel and cohort studies, Report to the Research Resources Board of the ESRC.

Lynn, P. (undated) Methodological issues in the development of a survey to measure the prevalence of offending, Report prepared for the Home Office, Crime and Criminal Justice Unit, London: National Centre for Social Research.

Lynn, P., Buck, N., Burton, J., Jäckle, A., and Laurie, H. (2005) A review of methodological research pertinent to longitudinal survey design and data collection, ISER Working Paper 2005-29, Colchester: University of Essex.

Lyon, N., Barnes, M. and Sweiry, D. (2006) Families with children in Britain: Findings from the 2004 Families and Children Study (FACS), DWP Research Report 350, London: DWP.

Lyon, N., Tait, C. and Scholes, S. (2006) Families and Children Study (FACS) 2004, Wave 6: Technical report, London: National Centre for Social Research.

McConaghy, M. et al (2000) Housing in England 1998/99, London: The Stationery Office.

McKay, S. (2003) Families and Children Study: A review of FACS 1999, Bristol: University of Bristol.

McKay, S. (2004) 'Poverty or preference: what do "consensual deprivation indicators" really measure?’, Fiscal Studies, vol 25, no 2, pp 201-23.

McKay, S. and Collard, S. (2004) Developing deprivation questions for the Family Resources Survey, DWP Working Paper No 13, London: DWP.

McKay, S. and Collard, S. (2006) 'Debt and financial exclusion', in C. Pantazis, D. Gordon and R. Levitas (eds) Poverty and social exclusion in Britain: The Millennium Survey, Bristol: The Policy Press, pp 191-215.

Mack, J. and Lansley, S. (1985) Poor Britain, London: Allen and Unwin.

Madouros, V. (2006) Impact of the LFS switch from seasonal to calendar quarters: An overview of the switch of the LFS to calendar quarters and the potential effects of this change on users. London: ONS

www.statistics.gov.uk/articles/labour_market_trends/CQ_article.pdf

Magadi, M. and Middleton, S. (2005) Britain's poorest children revisited: Evidence from the BHPS (1994-2002), London: Save the Children.

Mark, G., Kobsa, A. and Gonzalez, V. (2002) 'Do four eyes see better than two? Collaborative versus individual discovery in data visualization systems', Proceedings. Sixth International Conference on Information Visualisation, pp 24955. 
Marks, N., Shah, H. and Westall, A. (2004) The power and potential of well-being indicators: Measuring young people's well-being in Nottingham, London: New Economics Foundation.

Marmot, M., Banks, J., Blundell, R., Lessof, C. and Nazroo, J. (eds) (2003) Health, wealth and lifestyles of the older population in England: The 2002 English Longitudinal Study of Ageing, London: Institute for Fiscal Studies.

Marsh, A., Gordon, D., Pantazis, C. and Heslop, P. (1999) Home Sweet Home? The impact of poor housing on health, Bristol: The Policy Press.

Martin, J., Bynner, J., Kalton, G., Boyle, P., Goldstein, H., Gayle, V., Parsons, S. and Piesse, A. (2006) Strategic review of panel and cohort studies: Report to the Research Resources Board of the Economic And Social Research Council, Swindon: ESRC.

Maughan, B. (2004) 'Mental health', The health of children and young people, ch 12 (www.statistics.gov.uk/Children/downloads/mental_health.pdf).

Meltzer, H., Gatward, R., Goodman, R. and Ford, T. (2000) Mental health of children and adolescents in Great Britain, London: The Stationery Office.

Middleton, S. and Loumidis, J. (2001) 'Young people, poverty and part-time work', in P. Mizen, C. Pole and A. Bolton (eds) Hidden hands - International perspectives on children's work and labour, London: Routledge/Falmer.

Middleton, S., Ashworth, K. and Walker, R. (1994) Family fortunes, York: Joseph Rowntree Foundation.

Middleton, S., Ashworth, K. and Braithwaite, R. (1997) Small fortunes: Spending on children, childhood poverty and parental sacrifice. York: Joseph Rowntree Foundation.

Migration Resource Centre (2006) Seeking asylum: A report on the living conditions of asylum seekers in London, London: Migration Resource Centre.

Miliband, D. (2006) Social exclusion: The next steps forward, London: ODPM.

MORI (2002) Trusting the Politicians. www.mori.co.uk/mrr/2002/c020927.shtml

MORI (2003) Privacy and Data-Sharing: Survey of Public Awareness and Perceptions: Research Study Conducted for the Department of Constitutional Affairs, London: MORI

Morris, M., Nelson, J., Stoney, S. with Benefield, P. (1999) Disadvantaged youth: A critical review of the literature on scope, strategies and solutions, DfES Research Brief No 169, London: DfES.

Nathan, G. (1999) A review of sample attrition and representativeness in three longitudinal surveys, GSS Methodology Series No 13, London: ONS.

National Centre for Social Research/National Statistics (2005) Family Resources Survey: Annual technical report: 2004/05, London: National Statistics.

National Statistics (2002) Difficulty in accessing key services, National Statistics (www.statistics.gov.uk/pdfdir/dak0202.pdf).

National Statistics (2004) National Statistics Omnibus Survey: Technical report June 2004 (www.data-archive.ac.uk/doc/5381/mrdoc/pdf/5381userguide.pdf).

National Statistics (2005) Expenditure and Food Survey, Volume 1, User guide, London: The Stationery Office (www.data-archive.ac.uk/doc/5375/mrdoc/pdf/5375userguide1.pdf).

NDS (National Data Strategy) (2005a) Developing administrative data as a research resource, UKDF/05/15 (www2.warwick.ac.uk/fac/soc/nds).

NDS (2005 b) The national strategy for data resources in the social sciences, UKDF/05/09 (www2.warwick.ac.uk/fac/soc/nds).

NDS (2006) The national strategy for data resources for research in the social sciences, UKDF/06/17 (www2.warwick.ac.uk/fac/soc/nds).

NEF (2004) Chasing progress: Beyond measuring economic growth, London: NEF. 
Netuveli, G., Wiggins, R.D., Hildon, Z., Montogmery, S.M. and Blane, D. (2006) 'Quality of life at older ages: evidence from the English Longitudinal Study of Aging (wave 1)', Journal of Epidemiology and Community Health, vol 60, pp 357-63.

Nicholas, S., Povey, D., Walker, A. and Kershaw, C. (2005) Crime in England and Wales 2004/2005, Home Office Statistical Bulletin 11/05, London: Home Office (www.homeoffice.gov.uk/rds/pdf05/hosb1105chap123.pdf).

NPI (New Policy Institute) (2006) www.npi.org.uk?projects.htm, retrieved 27 April.

Nussbaum, M. and Sen, A. (eds) (1993) The quality of life: A study prepared for the World Institute for Development Economics Research (WIDER) of the United Nations University, Oxford: Clarendon Press.

OECD (Organisation for Economic Co-operation and Development) (1982) The OECD list of social indicators, OECD Social Indicator Development Programme, Paris: OECD.

ONS (Office for National Statistics) (1989) Disability Survey GB Report No 6, London: Palgrave.

ONS (1991) National Prison Survey 1991, London: ONS.

ONS (1999a) Mental health of children and adolescents in Great Britain, London: The Stationery Office.

ONS (1999b) Tracking people: A guide to longitudinal social sources, London: ONS.

ONS (2003) Labour Force Survey User Guide - Volume 1, Background and Methodology, www.data-archive.ac.uk/doc/5395/mrdoc/pdf/background.pdf

ONS (2005) Mental health of children and young people in Great Britain, 2004, London: The Stationery Office.

ONS (2004a) Harmonised concepts and questions for social data sources, London: ONS.

ONS (2004b) Living in Britain: Results from the 2003 General Household Survey, London: ONS.

ONS (2005) GHS 2004: Sample design and response. Appendix B, London: ONS.

ONS (2006) Family spending: A report on the 2004-2005 Expenditure and Food Survey, London: ONS.

ONS, Social Survey Division (1996) Living in Britain: Results from the 1994 General Household Survey, London: The Stationery Office.

ONS, Social Survey Division (2000) People aged 65 and over: Results of an independent study carried out on behalf of the Department of Health as part of the 1998 General Household Survey, London: The Stationery Office.

ONS, Social Survey Division (2002) Living in Britain: Results from the 2001 General Household Survey, London: The Stationery Office.

OPCS, Social Survey Division (1972-95) General Household Survey, London: HMSO.

OPCS (1994) OPCS Survey of Psychiatric Morbidity among Homeless People, London: OPCS.

Oppenheim, C. (1998) An inclusive society: Strategies for tackling poverty, London: IPPR.

Palmer, G., Carr, J. and Kenway, P. (2005) Monitoring poverty and social exclusion 2005, York: Joseph Rowntree Foundation and NPI.

Pantazis, C. (2000) 'Fear of crime, vulnerability, and poverty', British Journal of Criminology, vol 40, no 3, pp 414-36.

Pantazis, C. and Gordon, D. (1998) 'Do poor people experience more crime and greater fear of crime?', in D. Dorling and L. Simpson (eds) Statistics in society, London: Arnold Publishers, pp 198-212.

Pantazis, C., Gordon, D. and Levitas, R. (eds) (2006) Poverty and social exclusion in Britain: The Millennium Survey, Bristol: The Policy Press. 
Parsons, S. and Bynner, J. (2002) Basic skills and social exclusion, London: Basic Skills Agency.

Patsios, D. (2006) 'Pensioners, poverty and social exclusion', in C. Pantazis, D. Gordon and R. Levitas (ed) Poverty and social exclusion in Britain: The Millennium Survey, Bristol: The Policy Press, pp 431-58.

Percy-Smith, J. (2000) Policy responses to social exclusion: Towards inclusion?, Oxford: Oxford University Press.

Phelps, A., Maxwell, C., Anderson, T., Pickering, K. and Tait, C. (2006) Offending, Crime and Justice Survey (England and Wales): Technical report, Volume 1, London: National Centre for Social Research/BMRB Social Research.

Pleace, N. and Bretherton, J. (2006) Sharing and matching local and national data on adults of working age facing multiple barriers to employment: Administrative datasets for measuring impacts on disadvantage, DWP research Report no. 387, Leeds: CDS.

Plewis, I. (2004a) Weighting for non-response: Illustrative examples (www.ccsr.ac.uk/esds/events/2004-03-12/documents/plewisexampleshandout.doc).

Plewis, I. (2004b) Millennium Cohort Study First Survey: Technical report on sampling, London: Institute of Education.

Plewis, I., Calderwood, L., Hawkes, D. and Nathan, G. (2004) National Child Development Study and 1970 British Cohort Study Technical report, London: Institute of Education.

Prior, G., Deverill, C., Malbut, K. and Primatesta, P. (eds) (2003) Health Survey for England 2001, Vol 2: Methodology and documentation, London: The Stationery Office.

Prior, G., Teers, R., Brookes, M. and Primatesta, P. (2002) Health Survey for England 2000: Methodology and documentation, London: The Stationery Office.

Putnam, R. (2001) Bowling alone, London: Simon and Schuster.

Ridge, T. (2002) Childhood poverty and social exclusion: From a child's perspective, Bristol: The Policy Press.

Robinson, W.S. (1950) 'Ecological correlations and the behavior of individuals', American Sociological Review, vol 15, pp 351-7.

Robinson C. et al (2004) Housing in England 2002/3: A report of the Survey of English Housing, London: The Stationery Office.

Roker, D. (1998) Worth more than this: Young people growing up in family poverty, London: The Children's Society.

Room, G. (ed) (1995) Beyond the threshold: The measurement and analysis of social exclusion, Bristol: The Policy Press.

Room, G. (1998) 'Social exclusion, solidarity and the challenge of globalization', International Journal of Social Welfare, Vol. 8, No. 3, pp 166-74.

Room, G. (2000) 'Trajectories of social exclusion' in Gordon, D. and Townsend, P. (eds) Breadline Europe, Bristol: The Policy Press.

Rowntree (1995) Joseph Rowntree Foundation Inquiry into Income and Wealth, 2 vols, York: Joseph Rowntree Foundation.

Royal Commission on Long-term Care (1999) With respect to old age: Long term care rights and responsibilities, Report by the Royal Commission on Long-term Care, London: The Stationery Office, March.

Russell, N. and Phelps, A. (2001) Youth Cohort Study, Cohort 10, Sweep 1: Technical report, Report prepared for DfES, London: Taylor Nelson Sofres.

Sayer, A. (2005) The moral significance of class, Cambridge: Cambridge University Press.

Scharf, T., Phillipson, C., Smith, A.E. and Kingston, P. (2002) Growing older in socially deprived areas: Social exclusion in later life, London: Help the Aged. 
Scott, J. (1990) A matter of record: Documentary sources in social research, Cambridge: Polity Press.

Scottish Executive (nd) The role of transport in social exclusion in urban Scotland, Edinburgh: Central Research Unit.

Sefton, T. (2002) Recent changes in the distribution of the social wage, CASEPaper 62, London: LSE

(http://sticerd.lse.ac.uk/dps/case/cp/CASEpaper62.pdf\#search=\%22the\%20\%22social \%20wage\%22\%20britain\%22).

Seligman, M. (2003) Authentic happiness: Using the new positive psychology to realise your potential for lasting fulfilment, London: Nicholas Brealey.

Sen, A. (1995) Inequality re-examined, Oxford: Oxford University Press.

Sen, A. (2001) Development as freedom, Oxford: Oxford University Press.

Sennett, R. (1998) The corrosion of character: The personal consequences of work in the new capitalism, London: Norton \& Co.

Sennett, R. (2004) Respect: The formation of character in an age of inequality, Harmondsworth: Penguin.

SEU (Social Exclusion Unit) (1997) Social Exclusion Unit: Purpose, work priorities and working methods, London: SEU.

SEU (1998) Rough sleeping, London: SEU.

SEU (1999a) Bridging the gap: New opportunities for 16-18 year olds not in education, employment or training, London: The Stationery Office.

SEU (1999b) Teenage pregnancy, Cm 4342, London: The Stationery Office.

SEU (2000) Policy Action Team Report 12: Young people, London: The Stationery Office.

SEU (2002a) Young runaways, London: SEU.

SEU (2002b) Reducing re-offending by ex-prisoners, London: SEU.

SEU (2003a) A better education for children in care, London: SEU.

SEU (2003b) Making the connections: Transport and social exclusion, London: SEU.

SEU (2004) Action on debt: Why it matters and what you can do, London: SEU.

SEU (2005) Transitions: Young adults with complex needs, London: The Stationery Office.

SEU (2006) A Sure Start to later life: Ending inequalities for older people, London: ODPM.

Shah, H. and Marks, N. (2004) A well-being manifesto for a flourishing society, London: New Economics Foundation.

Sheppard, B. (2006) Work And Pensions Longitudinal Study: Towards A Merged Dataset For Policy And Evaluation: Note By Disadvantaged Groups Team

Sheppard, P. (1993) 'Analysis of response bias', in E. Ferri (ed) Life at 33: The fifth followup of the National Child Development Study, London: National Children's Bureau.

Shropshire, J. and Middleton, S. (1999) Small expectations: Learning to be poor?, York: Joseph Rowntree Foundation.

Silver, H. (1994) 'Social exclusion and social solidarity: three paradigms', International Labour Review, vol 133, nos 5-6, pp 531-578.

Social Exclusion Task Force (2006) Reaching out: An action plan on social exclusion, London: Cabinet Office.

Social Protection Committee (2001) Social Protection Committee: Report on indicators in the field of poverty and social exclusion, European Commission.

Sproston, K. and Mindell, J. (eds) (2006a) Health Survey for England 2004. Volume 1: The health of minority ethnic groups, London: National Centre for Social Research.

Sproston, K. and Mindell, J. (eds) (2006b) Health Survey for England 2004. Volume 2: Methodology and documentation, London: National Centre for Social Research.

Tait, C. and Fuller, E. (2002) Health Survey for England 2000: Psychosocial well-being among older people, London: The Stationery Office. 
Taylor, M. (2005) Multiple disadvantage in Britain: Analysis of the British Household Panel Survey (1997-2003), Essex: ISER.

Taylor, M. with Brice, J., Buck, N. and Prentice-Lane, E. (2001) British Household Panel Survey User manual Volume A: Introduction, technical report and appendices, Colchester: University of Essex.

Taylor, M., Berthoud, R. and Jenkins, S. (2004) Low income and multiple disadvantage 1991-2001. Analysis of the British Household Panel Survey, London: SEU/ODPM.

Thygesen, L.C., Andersen, G.S. and Andersen, H. (2005) 'A philosophical analysis of the Hill criteria', Journal of Epidemiology and Community Health, vol 59, pp 512-16.

Townsend, P. (1979) Poverty in the United Kingdom, London: Allen Lane and Penguin.

Tufte, E. (1983) The visual display of quantitative information, Cheshire, CT: Graphics Press.

UK National Plan on Social Inclusion 2001-03

UK National Plan on Social Inclusion 2003-05

UN (United Nations) (1995) The Copenhagen Declaration and Programme of Action: World Summit for Social Development, 6-12 March 1995, UN Department of Publications.

Walker, A. and Walker, C. (eds) (1997) Britain divided: The growth of social exclusion in the 1980s and 1990s, London: CPAG.

Walker, D. (2003) 'Whitehall database will track 50 million lives', The Guardian, 22 December.

Watson, D. (2003) 'Sample attrition between waves 1 and 5 in the European Community Household Panel', European Sociological Review, vol 19, no 4, pp 361-78.

White, S. (2001) 'Asset-based egalitarianism: forms, strengths, and limitations', in S. Regan (ed) Assets and progressive welfare, London: IPPR.

White, S., Paxton, W. and Maxwell, D. (eds) (2006) The citizen's stake: Exploring the future of universal asset policies, Bristol: The Policy Press.

Wilkinson, R. (1996) Unhealthy Societies: the afflictions of inequality London: Routledge

Wilkinson, R. (2006) The impact of inequality: How to make sick societies healthier, The New Press

Williams, M. and Dale, A. (1992) Measuring housing deprivation using the OPCS Longitudinal Study, London: Centre for Longitudinal Studies.

Willitts, M. (2006)Measuring child poverty using material deprivation: Possible approaches, DWP Working Paper No 28, Leeds: Corporate Document Services.

Woodard, S. and Collins, D. (2001) Families and Children Study (FACS) 1999, Wave 1: Technical report, London: National Centre for Social Research.

Yule, G.U. (1899) 'An investigation into the causes of changes in pauperism in England', Journal of the Royal Statistical Society, vol 62, pp 249-95.

Zabel, J. (1998) 'An analysis of panel attrition in the Panel Study of Income Dynamics', Journal of Human Resources, vol 33, no 2, pp 479-506.

Zhang, P. (1992) 'Inference after variable selection in linear regression models', Biometrika, vol 79, pp 741-6. 